\title{
Development of fluorescent cholesterol derivatives for the exogenous introduction of proteins to the plasma membrane
}

PhD thesis

Balázs Schäfer

Supervisor:

Dr. Csaba Tömböly

Laboratory of Chemical Biology, Institute of Biochemistry Biological Research Center of the Hungarian Academy of Sciences

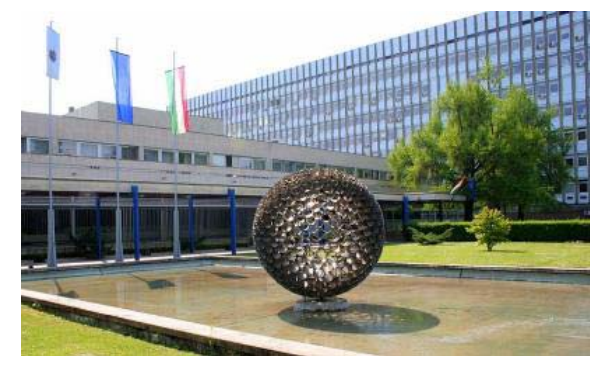

Szeged, Hungary

2015 


\section{List of Publications}

I. Schäfer B., Orbán E., Borics A., Huszár K., Nyeste A., Welker E. and Tömböly C. (2013) Preparation of Semisynthetic Lipoproteins with Fluorescent Cholesterol Anchor and Their Introduction to the Cell Membrane with Minimal Disruption of the Membrane. Bioconjugate Chemistry 24, 1684-1697.

II. Schäfer B., Orbán E., Kele Z., Tömböly Cs. (2015): Tritium labeling of a cholesterol amphiphile designed for cell membrane anchoring of proteins. Journal of Labelled Compounds and Radiopharmaceuticals 58, 7-13.

III. Schäfer B., Orbán E., Fiser G. and Tömböly C. (2015) Semisynthesis of membraneanchored cholesteryl lipoproteins on live cell surface by azide - alkyne click reaction. (submitted) 


\section{Table of contents}

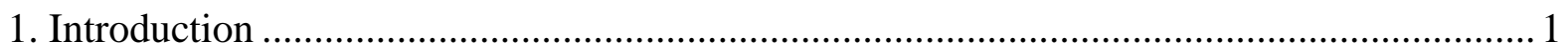

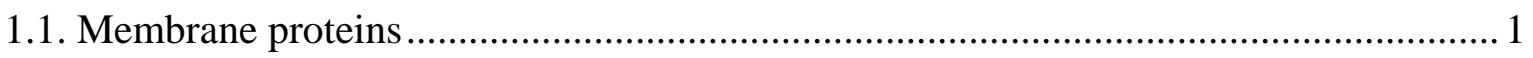

1.2. Glycosylphosphatidylinositol-anchored proteins ..................................................... 2

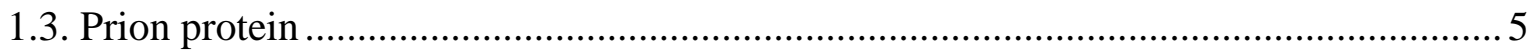

1.4. Synthetic glycosylphosphatidylinositol analogues................................................. 7

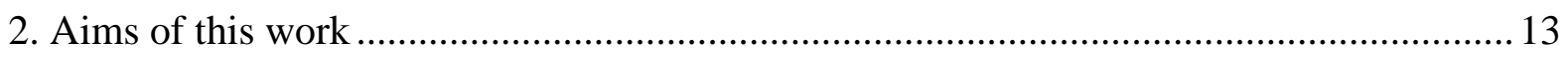

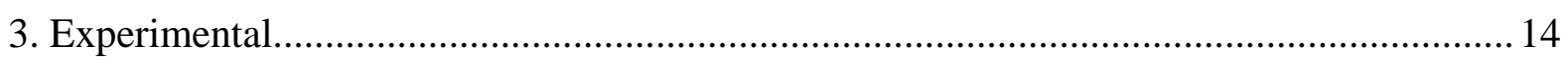

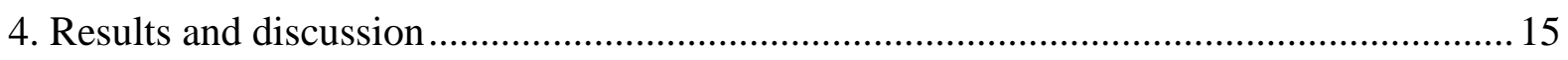

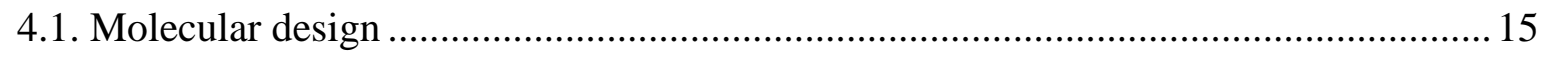

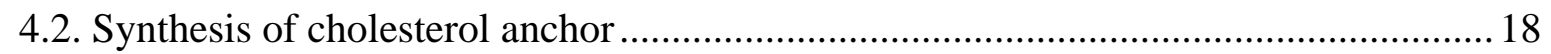

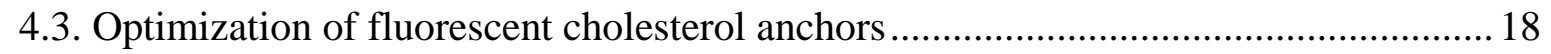

4.4. Investigation of the hydrolytic stability of the cholesterol anchor ............................... 23

4.5. Optimization of the Michael addition of the cholesterol anchors ............................... 24

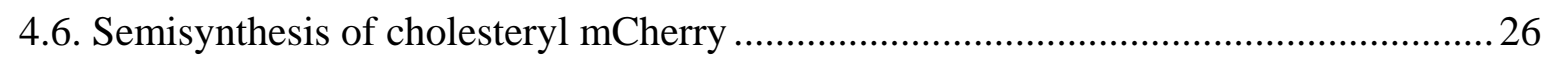

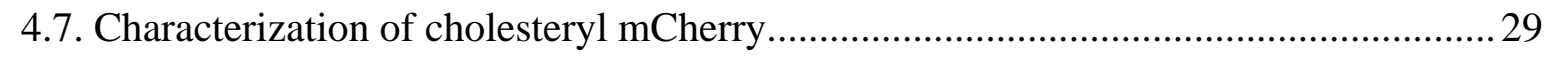

4.8. Cell membrane association of cholesteryl mCherry ................................................. 31

4.9. Conjugation of the full length prion protein with cholesterol anchors......................... 32

4.10. Quantitation of the cell membrane delivery of cholesterol anchors........................... 35

4.11. Protein anchoring to the plasma membrane with cell surface click reaction .............40

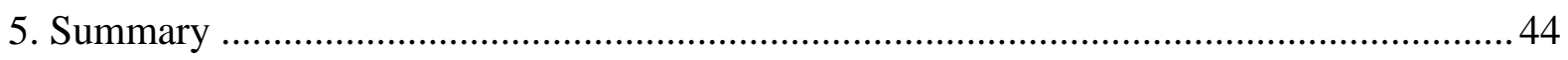

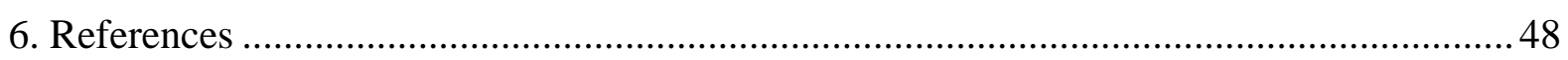

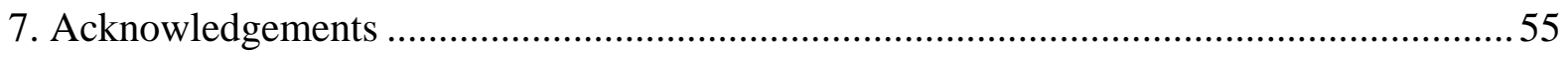

8. Appendices: Off-prints of thesis related publications ........................................................ 56 


\section{List of abbreviations}

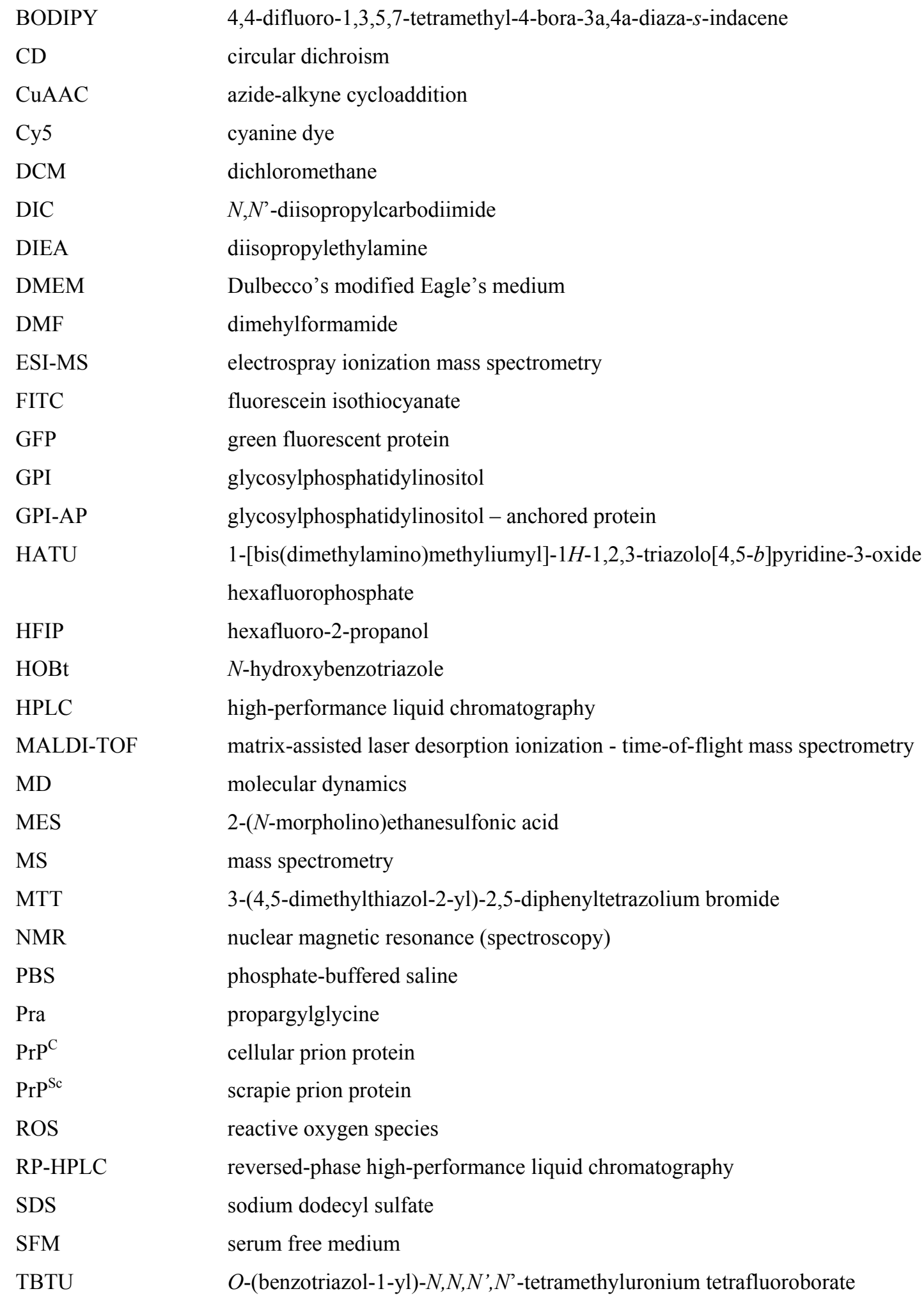


$t \mathrm{BuOH}$

TCEP

THF

THPTA

TLC

TSE tert-buthyl alcohol

tris(2-carboxyethyl)phosphine

tetrahydrofuran

tris(3-hydroxypropyltriazolylmethyl)amine

thin layer chromatography

transmissible spongiform encephalopathy 


\section{Introduction}

\subsection{Membrane proteins}

In living systems the membrane-associated proteins play essential roles in the maintenance of the normal life functions. Membrane proteins have various functions as there are membrane receptors, transport proteins, enzymes and cell adhesion molecules among them. ${ }^{1-8}$ Typically $50 \%$ of the membrane mass is protein, but this ratio varies between $25 \%$ and $75 \%$ depending on the type of the membrane. The importance of membrane proteins is also indicated by the fact that $20-30 \%$ of the genes in most organisms encodes membrane proteins. ${ }^{9}$

Membrane proteins are associated with lipid bilayers in different ways, and they can be classified as integral, peripheral and lipid-anchored proteins. ${ }^{10-12}$ Integral membrane proteins are persistently bound to cell membrane and transmembrane proteins spanned across the membrane at least once. ${ }^{13}$ This type of proteins occurs as $\alpha$-helix bundle proteins in all cell membrane and $\beta$-barrel proteins which occur in the membrane bilayer of bacteria, mitochondria and chloroplasts. Peripheral membrane proteins can temporarily associate with the cell membrane (Figure 1) or with integral membrane proteins via non-covalent hydrophobic-hydrophobic interactions. ${ }^{14}$ Furthermore, membrane anchoring via a lipid moiety that is covalently linked to the protein is also frequent. ${ }^{12}$ The membrane anchors of these lipoproteins are added to the prematured protein in co- or posttranslational lipidation processes, and these lipid modifications modulate the membrane affinity, localization and trafficking of the protein. ${ }^{15}$

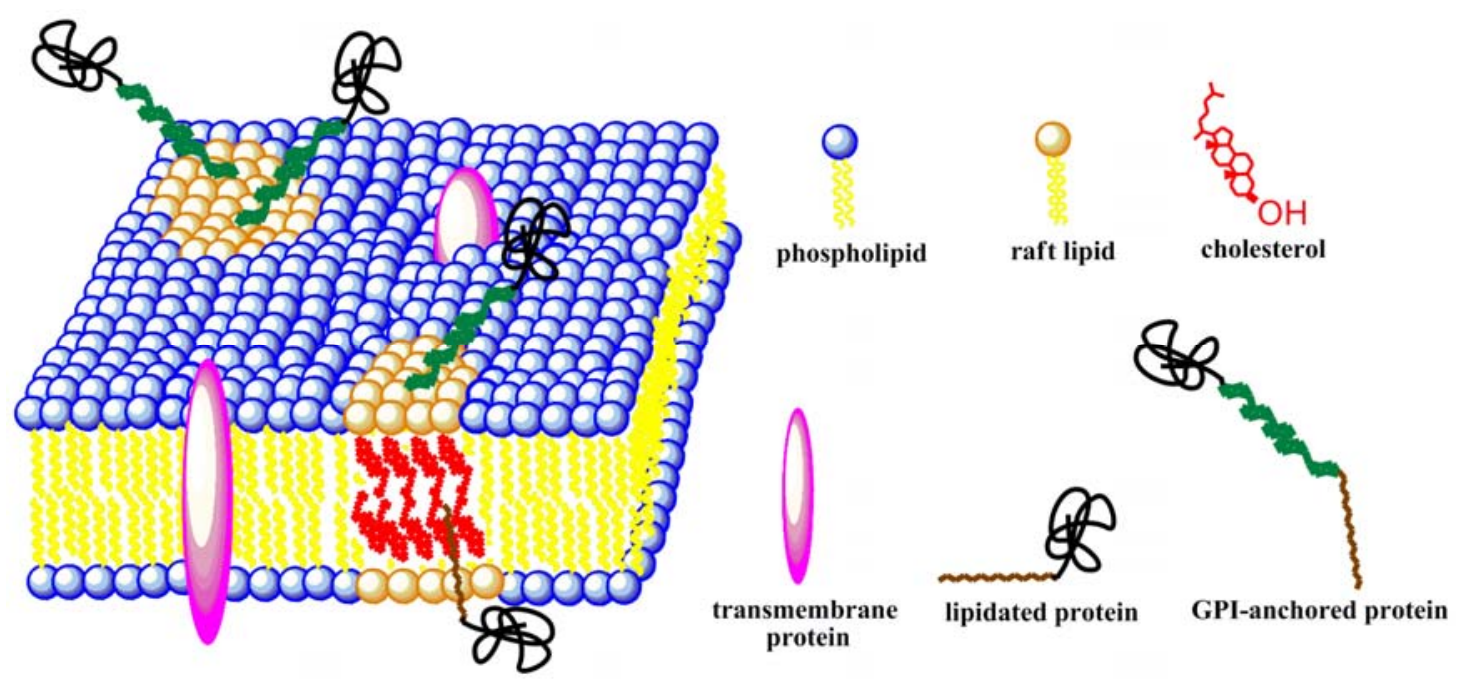

Figure 1. Representative section of the plasma membrane. 


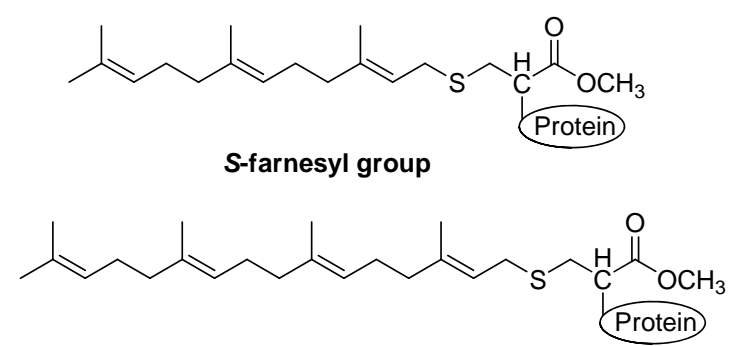

S-geranylgeranyl group

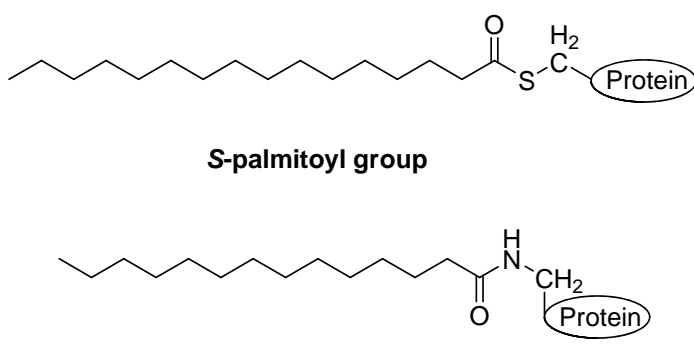

$N$-myristoyl group

Figure 2. Typical lipidated proteins.

The most frequent lipid modifications include $S$-prenylation and $S$-palmitoylation of Cys residues, $N$-myristoylation of $N$-terminal Gly residues (Figure 2) and $C$-terminal amidation with glycosylphosphatidylinositol (GPI) glycolipids (Figure 3). ${ }^{3,16-20}$ The GPI anchor molecule is a glycosylated phosphatidylinositol where the glycan core consists of a glucosamine and three mannoses, and also contains a terminal ethanolamine phosphate.

The different topology results in functional differences between integral and anchored membrane proteins. The integral membrane proteins have hydrophobic polypeptide region(s) which can span the lipid bilayer, and in general the major part of these proteins is located in the membrane bilayer. Consequently, these proteins connect the extra- and intracellular space, and thus, they can transmit environmental information or stimuli across the plasma membrane. In contrast, the polypeptide chain of the membrane anchored proteins is located outside the lipid bilayer and only a tiny portion of the sequence can be found in the lipid bilayer.

\subsection{Glycosylphosphatidylinositol-anchored proteins}

The amidation of a protein $C$-terminus with a GPI glycolipid results in proteins that are tethered to the extracellular leaflet of the cell membrane. ${ }^{21-23}$ The GPI anchor is widespread throughout eukaryotes and GPI-anchored proteins (GPI-APs) are presented in all major cell types and tissues. More than 150 human proteins with various functions contain a GPI anchor: enzymes, receptors, complement regulation proteins, antigens or adhesion molecules. ${ }^{24,25}$ The size of these proteins varies between the 12 amino acid glycopeptide CD52 and the $175 \mathrm{kDa}$ protein CDw109. ${ }^{26}$ Beyond the normal physiological functions, GPI-APs are associated with a range of diseases including paroxysmal nocturnal hemoglobinuria, prion diseases, carcinogenesis and sleeping sickness and the pathobiology of trypanosomal parasites. ${ }^{24,27-29}$ 
The important functional role of the GPI-APs is further evidenced by the embryonic lethality of the GPI-deficient mice. ${ }^{30}$

The GPI glycolipids have the conserved $\operatorname{Man}(\alpha 1-2) \operatorname{Man}(\alpha 1-6) \operatorname{Man}(\alpha 1-4) \operatorname{GlcN}(\alpha 1-$ 6)myoIno glycan core and variations arise in the substitution pattern and in the number and type of the lipid moiety (Figure 3). ${ }^{31,32}$ The glycan can be substituted with phosphoethanolamine, sialic acid or other carbohydrates. ${ }^{33-43}$ The most frequent modification on the Man I residue is another mannose, while a phosphoethanolamine can be linked to Man II or Man III. In GPI-APs the phosphoethanolamine attached to Man III is $N$-acylated with the $C$-terminal carboxyl group of the protein. Furthermore, $\mathrm{N}$-acetylgalactoseamine-containing oligosaccharides can also be attached to Man III. $^{23}$ The identified lipids include diacylglycerols, alkylacylglycerols or ceramides with different length of alkyl chains between 14 and 28 carbons. $^{43}$ There are species of GPI anchors where the 2-hydroxyl group of the inositol ring is $O$-acylated with an additional fatty acid, such as palmitic acid. ${ }^{43}$ This feature makes these GPI anchors resistant to phosphatidylinositol phospholipase C (PI-PLC)catalysed hydrolysis. $^{21,44}$ This cleavage mechanism is involved in GPI-AP-mediated cellular communications or signal transduction. ${ }^{44}$
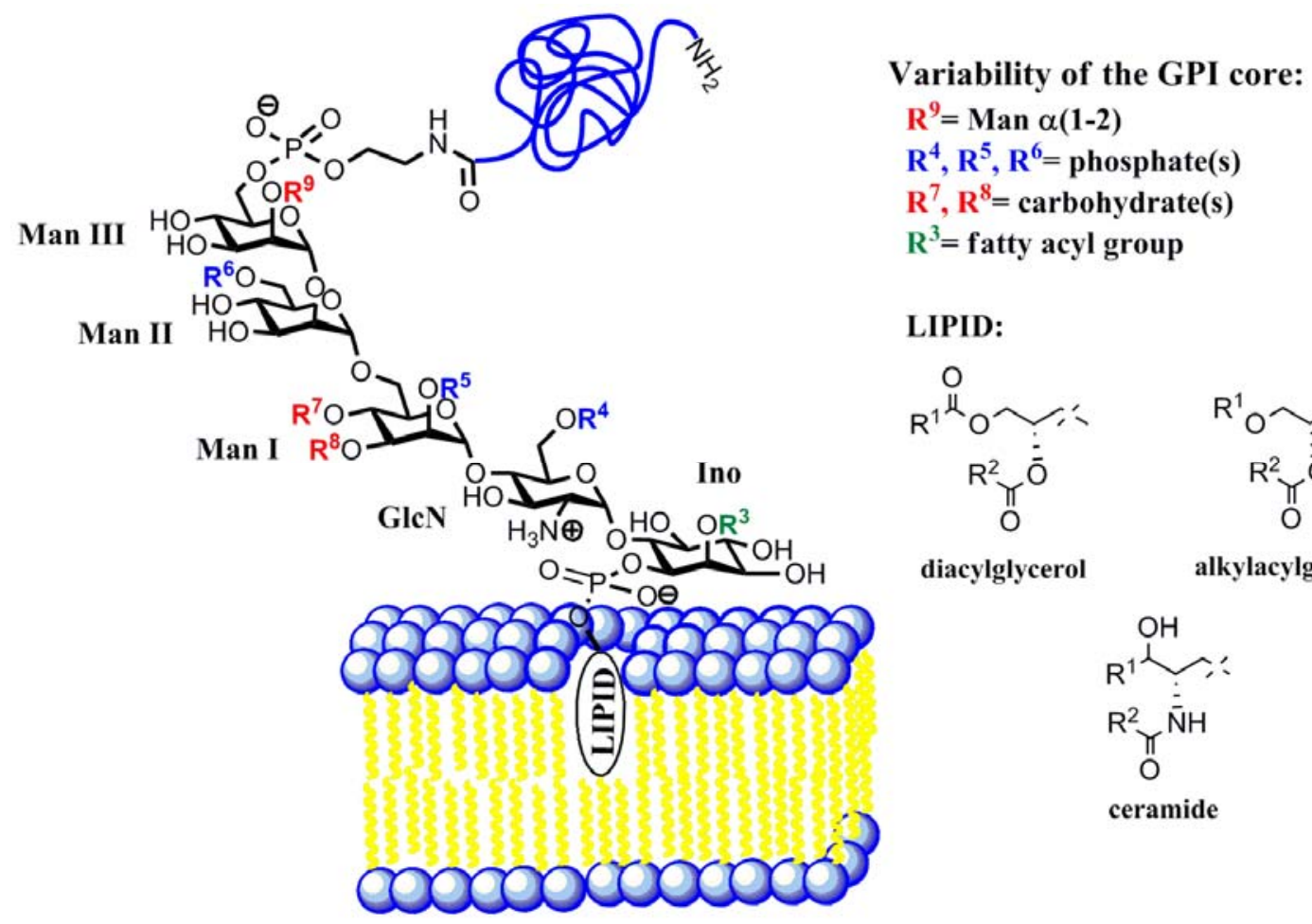<smiles>[R]OC(=O)CC(CC)OC([R])OC</smiles>

diacylglycerol

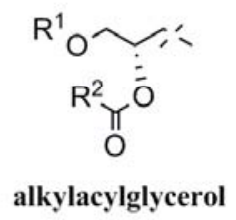<smiles>[R]C(=O)NC(C)C([R])O</smiles>

ceramide

Figure 3. General structure of the GPI anchors. 
The lipid part of the mammalian GPIs is phosphatidylinositol with stearyl chains, therefore the GPI-APs are able to temporarily associate with sphingolipid- and cholesterol-rich membrane microdomains, i.e. lipid rafts. ${ }^{21,32,44-48}$ Cholesterol is an essential component of the lipid rafts evidenced by the observation that the depletion of cholesterol causes disruption of the rafts. ${ }^{49}$ Furthermore, the lipid raft association of the GPI-APs could be abrogated by cholesterol depletion of the cell membrane and by replacing the GPI moiety with a transmembrane anchor. ${ }^{50}$ The accumulation of the GPI-APs in the less fluidic lipid rafts may serve as platforms for diverse cellular functions (e.g. signal transduction) via optimizing protein-protein interactions. ${ }^{51,52}$ However, the enrichment of GPI-APs in rafts is a matter of debate, because this process might depend on both the GPI anchor species and the attached protein. ${ }^{49,53,50}$ There are evidences for the presence of GPI-APs in Triton X-100 insoluble membrane fractions that is lipid rafts. ${ }^{49,53}$ It was also reported that cell surface GPI-APs were present as monomers and $20-40 \%$ of GPI-APs were present in cholesterol-sensitive lipid clusters containing up to four GPI-APs. ${ }^{50}$

The only established role of the protein attached GPI anchors is to accomplish the membrane association of the protein. However, the complex structure and the energetically expensive biosynthesis of GPIs suggest further functions. ${ }^{21,44}$ The GPI anchor might change the structure of the attached protein and this way it might transfer external signals through the lipid bilayer. ${ }^{23}$ The anchored proteins are positioned about 10-14 $\AA$ away from the membrane surface, and this distance and the flexibility of the glycan core allow the interaction of the proteins with the membrane. ${ }^{54}$ However, the details of such possible interactions between the protein and the cell membrane are unknown. A GPI molecule can keep connection between the extracellular environment and internal signaling molecules. If an antibody is cross-linked with GPI anchored proteins, cellular activation or inhibition signals will be started through $\mathrm{Ca}^{2+}$ fluxes, protein tyrosine phosphorylation or cytokine secretion. These effects are not observed when the GPI anchor is replaced with a transmembrane domain. ${ }^{55,56}$ In other GPIAP-related signal transduction the GPI-APs are associated with transmembrane signal transduction partners, such as protein tyrosine kinases, integrins and heterotrimeric GTPbinding proteins. ${ }^{52,55,56}$ But these biological functions of the GPIs are rather unknown in details, partly because the structural complexity of the GPIs restricts the preparation of GPIAP derivatives for systematic studies. ${ }^{23}$ The influence of GPIs has also been supposed in 
either endocytosis or in the distribution between the apical and basolateral cell surface. ${ }^{57,58}$ The best characterized endocytosis is the clathrin-dependent endocytosis which requires a cytoplasmic tail of the transmembrane protein. This tail is recognized by endocytic adaptor proteins which serve as a bridge between transmembrane protein and clathrin. GPI-APs are targeted for clathrin dependent endocytosis probably with their interactions with transmembrane proteins because their cytoplasmic tail is lacking. ${ }^{59,60}$

The absence of their association with transmembrane proteins supposed another endocytic mechanism which depends on the GPI anchor itself. The raft regions cannot undergo clathrinmediated endocytosis because the highly ordered nature of saturated lipids in rafts will not permit the tight curvature of the membrane required for the formation of clathrin-coated pits. ${ }^{61}$

In the context of targeted protein delivery, a unique feature of the GPI-APs is that after isolation they spontaneously reintegrate into lipid membranes of enveloped viruses or live cells with the retention of the biological function. ${ }^{62-76}$ Since exogenously added GPI-APs retained the characteristics and functions of the expressed GPI-APs, this method can be exploited for structural and functional studies of GPI-APs and for delivery of pharmacologically active proteins. Furthermore, GPI-APs could be presented with this process by cells that cannot synthesize their own GPI-APs under normal conditions.

\subsection{Prion protein}

The prion protein (PrP) is a cell surface GPI-anchored glycoprotein ${ }^{77}$, expressed by a variety of cell types, but particularly abundant in neurons. The PrP is associated with transmissible spongiform encephalopathies (TSEs), also known as prion diseases, a group of neurodegenerative disorders. These encephalopathies include scrapie in sheep, bovine spongiform encephalopathy or "mad cow disease" in cattle, chronic wasting disease in deer and elk, as well as Creutzfeldt-Jakob disease in humans. ${ }^{61,78}$ These diseases are similar to amyloidosis and Alzheimer's syndrome where a host-derived protein is misfolded and persists in an aggregated form that may damage nearby cells. ${ }^{79}$ Besides the similarity, there are important differences between them. In amyloidosis the amyloid deposits are directly pathogenic, in Alzheimer's diseases pre-amyloid forms may be the major neuropathogenic form. ${ }^{80-82}$ In prion diseases the host protein is involved in misfolding and amyloid formation, and $\operatorname{PrP}$ is necessary for replication and infectivity of the disease. ${ }^{83,84}$ The fundamental molecular event behind the serious damage of the central nervous system is the 


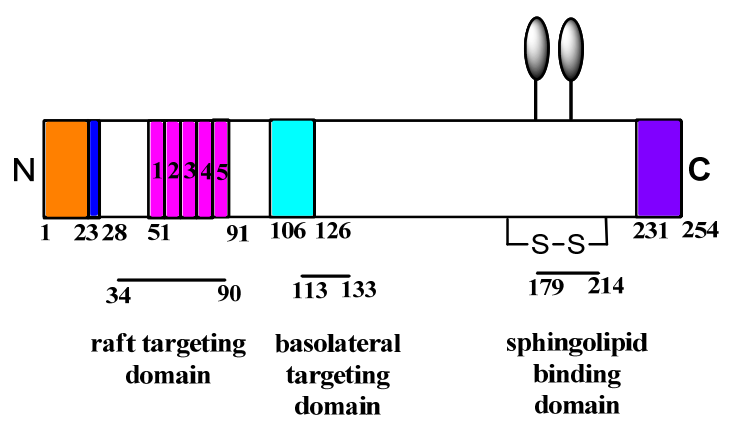

Figure 4. Structure of the prematured murine $\operatorname{PrP}^{\mathrm{C}}$. (23-28) polybasic region, (51-91) copper binding octapetide region, (106-126) hydrophobic neurotoxic domain. This figure is a reproduction of the work of Taylor and Hooper. ${ }^{61}$

conformational conversion of the metastable cellular normal protease-sensitive prion protein $\left(\mathrm{PrP}^{\mathrm{C}}\right)$ into the infectious, protease-resistant pathogenic isoform $\left(\mathrm{PrP}^{\mathrm{Sc}}\right){ }^{61}$ If this proteaseresistant GPI anchored $\mathrm{PrP}^{\mathrm{Sc}}$ is formed and propagated, it will result in insoluble protein plaques on neurons. The formation of these plaques might interfere with the normal $\operatorname{PrP}$ signaling function, leading to neuronal death. PrP is expressed as a GPI-anchored cell surface glycoprotein. ${ }^{77}$ The human PrnP gene encodes a precursor protein with 253 amino acids, and the $N$-terminal 22-mer signal sequence directs the protein to the rough endoplasmic reticulum, then the $C$-terminal 23-mer peptide is removed and the new $C$-terminus $\left(\mathrm{Ser}^{230}\right)$ is amidated with a GPI followed by the cleavage of the $N$-terminal signal sequence (Figure 4). ${ }^{77}$ These maturation events yield a GPI-anchored $\mathrm{PrP}^{\mathrm{C}}$ of 208 amino acids, which is transferred to the extracellular space and it remains attached to the exterior leaflet of the cell membrane. $\operatorname{PrP}^{\mathrm{C}}$ has a folded $C$-terminal domain with three $\alpha$-helices and an unstructured $N$-terminal domain. ${ }^{85}$ Although the exact 3D structure of $\operatorname{PrP}^{\mathrm{Sc}}$ is not known, there is an increased $\beta$-sheet content replacing the normal $\alpha$-helical areas of $\operatorname{PrP}^{\mathrm{C}} .86$

Both isoforms possess a disulfide bond between Cys ${ }^{179}$ and $\mathrm{Cys}^{214}$ linking the $\alpha$-helices 2 and $3,{ }^{87}$ and they can be di-, mono- or nonglycosylated at $\mathrm{Asn}^{180}$ and $\mathrm{Asn}^{196}$ with more than 50 different carbohydrate species. The $C$-terminal GPI anchor plays a crucial role in the prion diseases, because the anchorless PrP does not lead to pathological conditions. It was proved by the combined expression of the anchorless and the wild-type $\operatorname{PrP}$, when accelerated clinical scrapie was produced. ${ }^{79,88}$ Furthermore, replacing the $C$-terminal GPI addition sequence of PrP to a transmembrane or a cytosolic domain of non-raft proteins also prevented the formation of $\mathrm{PrP}^{\mathrm{Sc}} \cdot{ }^{89},{ }^{90}$ Additionally, in vitro experiments with raft preparations from PrP- 


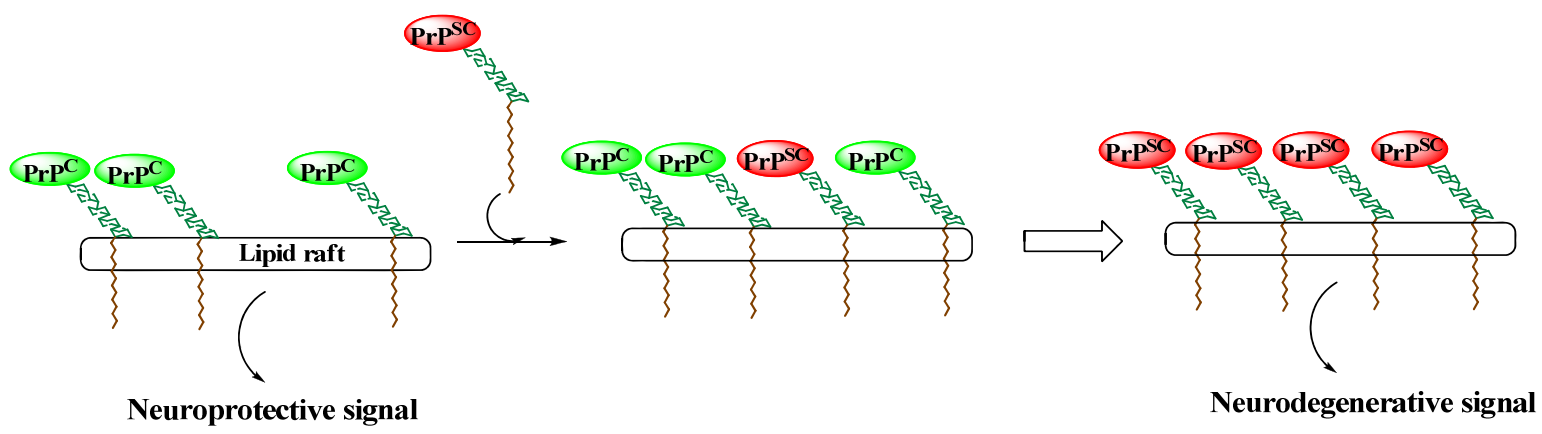

Figure 5. A possible mechanism of $\operatorname{PrP}^{\mathrm{Sc}}$ propagated conformational conversion of $\operatorname{PrP}^{\mathrm{C}}$ that results in neurotoxicity. ${ }^{61}$

infected and non-infected cells point to the fact that co-localization of $\operatorname{PrP}^{\mathrm{C}}$ and $\operatorname{PrP}^{\mathrm{Sc}}$ is a prerequisite for the conversion of $\mathrm{PrP}^{\mathrm{C}}$ to $\mathrm{PrP}^{\mathrm{Sc}} \cdot{ }^{91-94}$ The importance of lipid raft association in the conformational changes of $\operatorname{PrP}^{\mathrm{C}}$ to $\mathrm{PrP}^{\mathrm{Sc}}$ is further indicated by the finding that the depletion of cellular cholesterol diminished the formation of $\operatorname{PrP}^{\mathrm{Sc}} \cdot 89,95,96$ The GPI anchor also plays an important role in prion pathogenesis via the plaque formation of $\operatorname{PrP}^{\mathrm{Sc}}$ which might interfere with the normal prion signaling and can cause neuronal death. ${ }^{79,88}$

In contrast, Priola and coworkers evidenced that the GPI anchor is not essential for the formation of $\operatorname{PrP}^{\mathrm{Sc}}$, but it is important in the amplification and spread of prion infectivity. ${ }^{97}$ Even though the membrane attachment seems to be crucial for the pathogenesis, previous studies have only been performed with recombinant, soluble PrP lacking any membrane anchor $^{98,99}$ or with PrP having anchor mimics structurally not related to the native GPI anchor. $93,94,100,101$ The structural consequences of the membrane association of these $\operatorname{PrP}$ derivatives have not been investigated on cellular or model membranes.

According to these observations the following mechanism was hypothesized for the prion pathogenesis. The GPI anchored $\operatorname{PrP}^{\mathrm{C}}$ is clustered in lipid rafts and transduces neuroprotective signals into the cell. ${ }^{88}$ Infectious $\mathrm{PrP}^{\mathrm{Sc}}$ is inserted into the target cell membrane alongside the $\operatorname{PrP}^{\mathrm{C}}$ in the rafts. ${ }^{88}$ Conversion of the $\operatorname{PrP}^{\mathrm{C}}$ to $\operatorname{PrP}^{\mathrm{Sc}}$ may affect signaling events involving $\operatorname{PrP}^{\mathrm{C}}$, leading to neurotoxicity and cell death (Figure 5). ${ }^{88}$

\subsection{Synthetic glycosylphosphatidylinositol analogues}

The investigation of the functions of GPIs is challenging, partly because multimilligram quantities of native GPI anchors are hardly available. ${ }^{23}$ Furthermore, the biosynthetic enzymes are not well characterized, and specific inhibitors are not available for the ca. 20 enzymes 
responsible for the GPI synthesis. The extraction of GPI-APs from cell membrane has inherent difficulties because they exist in heterogeneous mixtures with variation in their glycan core and lipid moiety. ${ }^{26,35,37,102}$ A possible solution is the chemical synthesis of representative diacylglycerophosphoinositolglycan species, but currently these methods are complicated and not well applicable for protein anchoring. ${ }^{103,104}$ An example of this problem is to set up appropriate experiments for answering how important the GPI-anchoring is in the basic $\mathrm{PrP}^{\mathrm{Sc}}$ replication process. The demand for membrane associated PrP analogues inspired huge efforts to prepare semisynthetic lipo-PrP derivatives (Figure 6). Because the full length PrP is highly aggregation prone, sometimes the C-terminal folded fragment or even shorter sequences were used to conjugate with the lipophilic anchors. ${ }^{100,101,105,106}$ Beyond, the fluorescent protein GFP was also used to demonstrate the membrane anchoring properties of such synthetic lipids. ${ }^{93,94,100,101,103,105-109}$ It was found that the removal of the carbohydrate moiety or its truncation can retain the anchoring function of the GPIs. ${ }^{110}$ Most of these synthetic anchors act solely as membrane anchoring devices without any carbohydrate unit, but there are analogues where the GPI mimetics contain one or two mannoses or an oligo(ethylene glycol) linker with a length similar to the glycan core of native GPIs. The membrane association features could be successfully investigated with these simple synthetic GPI anchor analogues. The GFP - GPI mimic conjugates were incorporated into model lipid bilayers or cell membranes and it was found that the lipo-GFP derivatives trafficked to

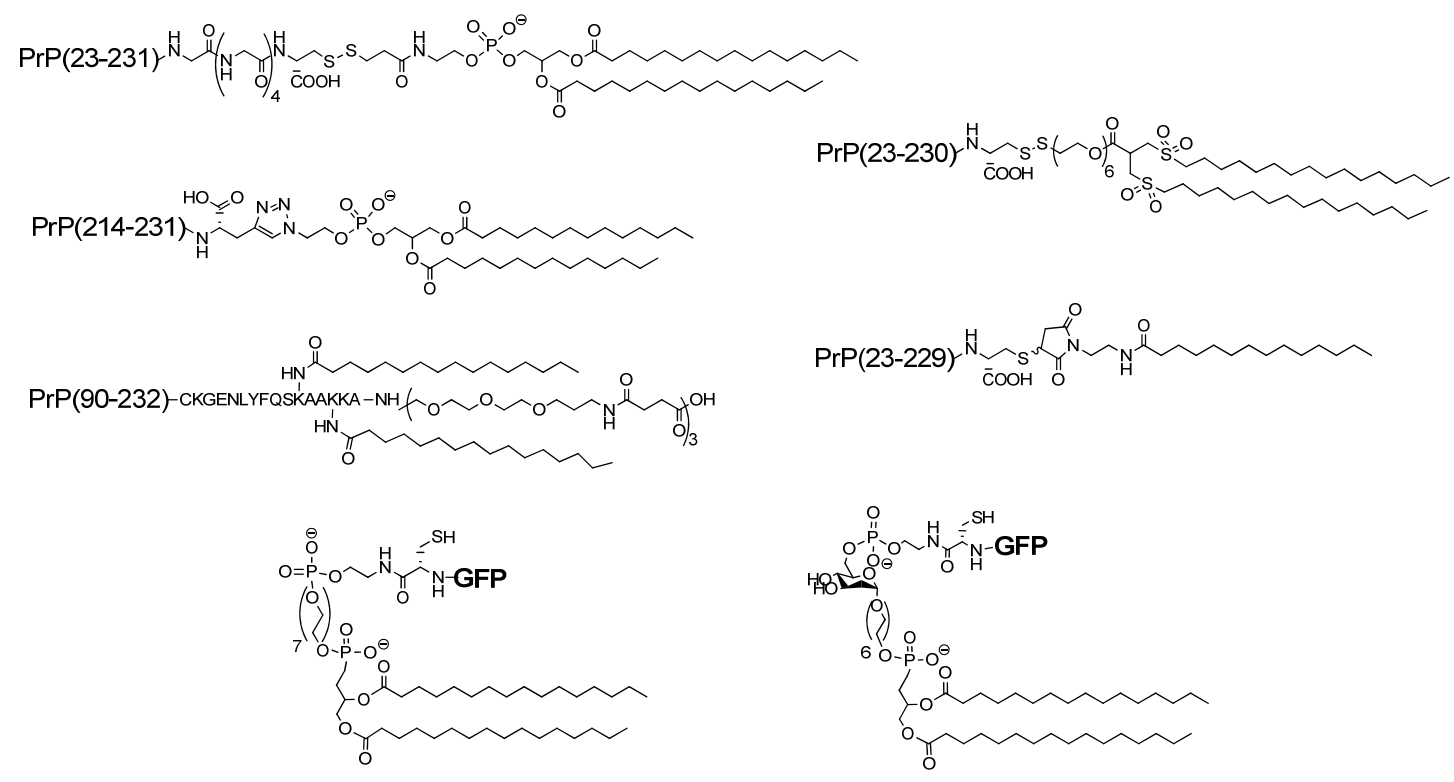

Figure 6. Semisynthetic GPI anchor mimetics attached to PrP or GFP..$^{93,94,100,101,105-107}$ 
recycling endosomes similarly to GFP bearing a native GPI anchor. ${ }^{110}$ However, the deletion of the glycan core significantly altered the lateral diffusion kinetics of these lipoproteins in the plasma membrane. ${ }^{110}$

Lipidation of proteins with GPI surrogates and the purification of the resulting lipoproteins are crucial steps in the semisynthesis of membrane-anchored proteins, because the proteins might lose their native structure and biological function. ${ }^{111}$ In this thesis a new series of protein membrane anchors applicable in aqueous solutions without denaturing the protein were designed, prepared and investigated in vitro. Fluorescent labelling of the GPI mimics was applied to achieve the microscopic monitoring of the cellular traffic of the anchors and their protein derivatives.

Investigation of GPI mimics in the form of GFP conjugates can be used to evaluate that the membrane anchor is appropriate for anchoring attached proteins to the cell membrane. ${ }^{110}$ However, these lipo-GFPs cannot represent the specific protein-membrane interactions of the investigated protein, e.g. PrP. When the fluorescent reporter protein is fused to the lipidated target protein, the reporter protein with a size comparable to that of the target protein might perturb the biophysical and biochemical characteristics of the investigated membraneanchored protein. In order to avoid these drawbacks, our concept is based on the application of a small molecule fluorophore in the lipid headgroup for the imaging of the membrane anchored protein. This way it does not interfere with the lipid chains of the cell membrane, and it has presumably minimal effect on protein - protein and protein - membrane interactions on the cell surface. The capturing of proteins to the synthetic anchors was a crucial point of previous studies to preserve the native protein fold. So it is very important to demonstrate a fast and chemoselective reaction between the designed anchors and proteins. This protein capturing functional group must be located on the upper part of the synthetic anchor for modeling the native GPI.

In analogy with the spontaneous membrane integration property of GPI-APs, semisynthetic lipoproteins containing GPI anchor mimetic lipids can also be exogenously introduced into the cell membrane presumably with the retention of the protein structure and function. Since cholesterol prefers the interaction with sphingolipids in the cell membrane, it has the potential to target an attached protein to lipid rafts. ${ }^{47,48}$ This lipid anchor is found in the matured $\mathrm{Hh}$ and Shh proteins of the hedgehog family as a $C$-terminal cholesteryl ester. ${ }^{112-}$ 
${ }^{115}$ Furthermore, in the case of a semisynthetic peptidyl cholesterol - Ras protein conjugate, cholesterol was reported to anchor the attached protein to the cell membrane. ${ }^{116}$ Other cholesterol derivatives, such as $3 \beta$-cholesterylamine and $3 \beta$-cholesterylcarbamate were also reported as membrane anchors of artificial membrane receptors. ${ }^{117-123}$ Further rationale behind the cholesterol-based anchoring of proteins is the fact that cholesterol depletion decreases the amount of GPI-APs on the cell surface, and abrogates the association of GPI-APs with lipid rafts $^{50}$. The cholesterol "leg" and the fluorescent "headgroup" are linked by a flexible, hydrophilic oligo(ethylene glycol) linker that allows the protein to interact with the lipid bilayer, other cell surface proteins and with extracellular components. Furthermore, it is possible to examine the influence of membrane surface - protein distance and to optimize the hydrophobic/hydrophilic character of the anchor with the variation of linker length.

\subsection{Cell surface bioconjugation}

Sharples and Meldal have independently developed a $\mathrm{Cu}(\mathrm{I})$ catalyzed form of the Husigen's 1,3-dipolar cycloaddition (CuAAC) $)^{124,125}$ that became applicable as a chemical ligation method in biological systems. This chemical transformation is characterized by high chemoselectivity and broad tolerance to diverse reaction condition and functional groups. 23, 24, 126-129 In addition, as neither azide nor alkyne is generally present in biomolecules, they are bioorthogonal functional groups. ${ }^{129}$ In the early CuAAC reactions 1 $\mathrm{mM}$ copper was applied that limited the biological applications because it resulted in considerable cell death. ${ }^{130} \mathrm{Cu}(\mathrm{I})$ concentration below $500 \mu \mathrm{M}$, however, is tolerated by mammalian cells for 1 hour, ${ }^{83}$ and the effective $\mathrm{Cu}^{+}$concentration is maintained by the in situ reduction of $\mathrm{CuSO}_{4}$ with sodium ascorbate $(\mathrm{NaAsc}) .{ }^{131}$ This way the $\mathrm{CuAAC}$ reaction can be widely used for capturing small molecules to proteins or living cells. ${ }^{83}$ There are some examples where the bioactivity of the resulting modified protein decreased after the CuAAC reaction. ${ }^{132-134}$ During the reaction the generated dehydroascorbate and other by-products can react with the amino and guanidino groups of Lys and Arg, respectively, that may causes protein aggregation. ${ }^{135,136} \mathrm{The} \mathrm{Cu}(\mathrm{II}) / \mathrm{NaAsc}$ system generates reactive oxygen species (ROS) in the presence of $\mathrm{O}_{2}$ (Figure 7), which provides oxidative stress for biomolecules. ${ }^{135,137-139}$ In order to facilitate this $\mathrm{CuAAC}$ reaction for biomolecules chelating ligands were developed to stabilize the $\mathrm{Cu}(\mathrm{I})$-ion (Figure 8). ${ }^{127-129,140-147}$ The application of these $\mathrm{Cu}(\mathrm{I})$-ligands decreased the effective concentration of reducing agent and copper-salts, and also accelerated 

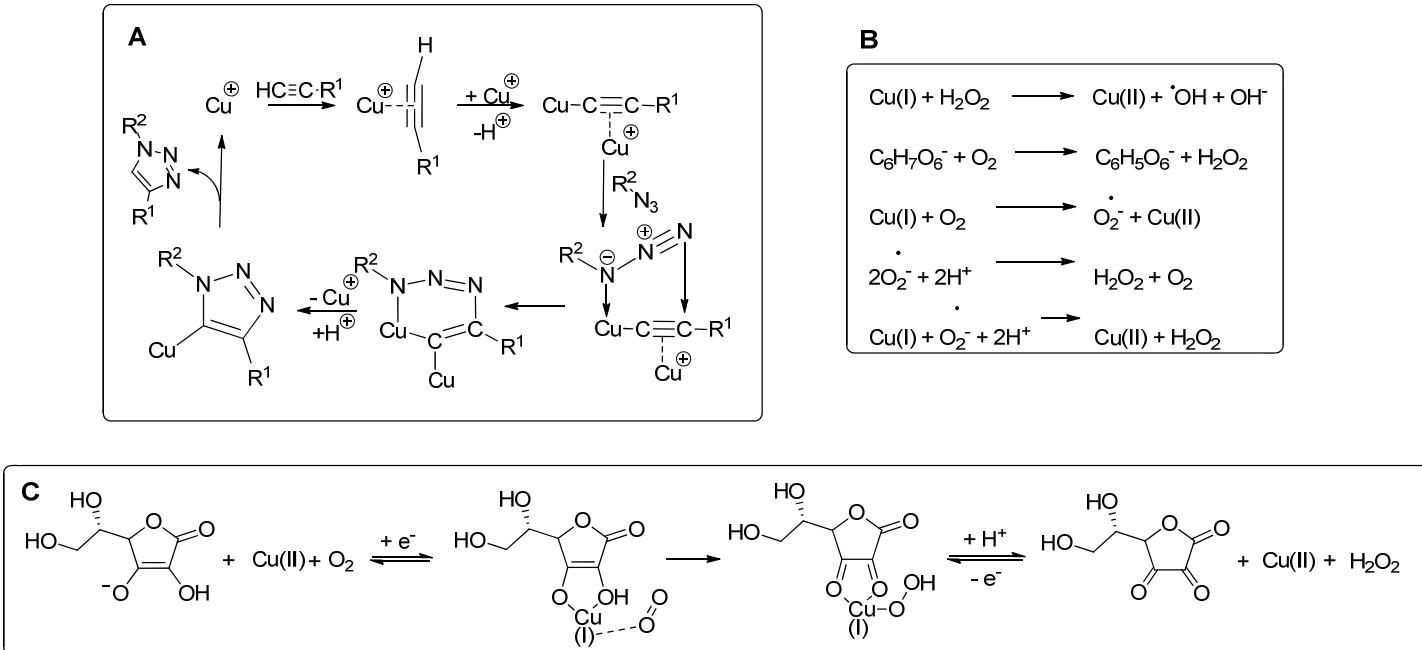

Figure 7. Mechanism of CuAAC (A), reactive oxygen species production (B) and $\mathrm{Cu}(\mathrm{I})$ formation (C) by the NaAsc mediated $\mathrm{CuSO}_{4}$ reduction.

the bioconjugation reaction and protected the biomolecules from the oxidation by ROS. ${ }^{127,129,148-150}$ Aminoguanidine, a carbonyl-capturing reagent is frequently used because it stabilizes proteins during CuAAC by avoiding the adverse effects of ascorbate and its byproducts. ${ }^{23}$ For bioorganic chemistry applications water-soluble accelerator ligands (e.g. tris(triazolylmethyl)amines) were developed. ${ }^{146,}{ }^{151-153}$ When these ligand accelerated CuAAC reactions were used in vitro, live cells showed normal functions after the treatment evidencing their applicability in living systems. ${ }^{146,151-153}$ The reaction time of CuAAC reaction with these accelerator ligands was optimized for 5-10 min, because in longer reaction time significant cell death was observed. ${ }^{146,147,151,154}$ In Kennedy's work L-histidine (His) was used as accelerator ligand that resulted in a two- to threefold slower reaction as compared to other ligands (e.g. BTTAA, BTTP), but the cytotoxicity was lower that makes the application of longer reaction time possible. ${ }^{154}$ It was also reported that cells tolerated the treatment with

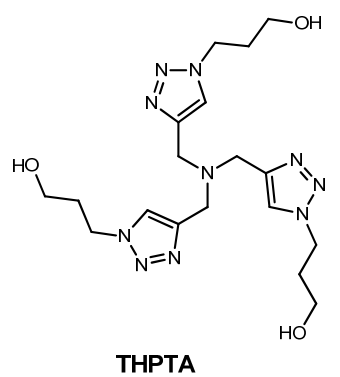

THPTA

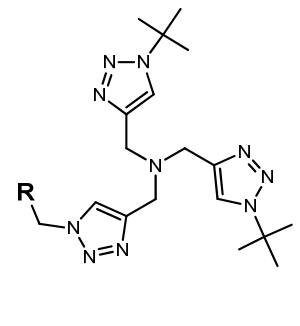

R: $-\mathrm{CH}_{2}-\mathrm{SO}_{3} \mathrm{Na}=\mathrm{BTTES}$ $-\mathrm{COOH}=\mathrm{BTTA}$ $-\mathrm{CH}_{2}-\mathrm{CH}_{2}-\mathrm{OH}=$ BTTP
$-\mathrm{CH}_{2}-\mathrm{CH}_{2}-\mathrm{SO}_{3} \mathrm{Na}=$ BTTPS

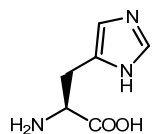

L-histidine (His)

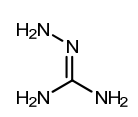

aminogunaidine carbonyl-capturing reagent

Figure 8. $\mathrm{CuAAC}$ reaction accelerator ligands. 


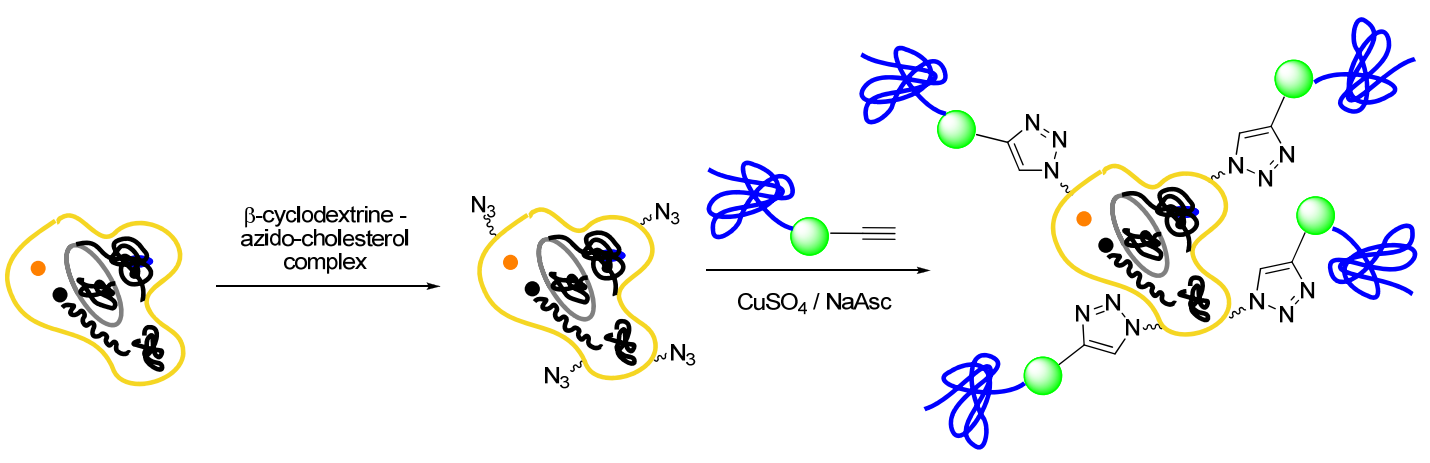

Figure 9. Cell surface CuAAC of a protein alkyne and a membrane incorporated azido-cholesterol.

$\mathrm{Cu}(\mathrm{I})$ - His complex in the presence of sodium ascorbate for $24 \mathrm{~h}^{154}$ The cytotoxicity under these conditions was comparable with that under copper-free conditions. ${ }^{146,147,151,154}$ This latter, the so-called copper-free strain-promoted azide-alkyne cycloaddition (SPAAC) was developed by the Bertozzi group for live cell application. ${ }^{128,132,152,155-165}$ It excludes the application of the cytotoxic copper salts, but the rate of the SPAAC is lower than that of the CuAAC. ${ }^{152,155}$ Even the most reactive strained alkyne biarylazacyclooctynone reacted significantly slower with azides than alkynes in the ligand-accelerated CuAAC reaction. ${ }^{128}$ Furthermore, the nonspecific conjugation of cyclooctynes to the thiols of Cys containing proteins can be significant. ${ }^{152,155-164,166-169}$ The inverse electron-demand Diels-Alder reaction between a strained alkene like norbornene or trans-cyclooctyne and a tetrazine is also an alternative for bioconjugations. ${ }^{126,166}$ The tetrazine dienophile of these cycloadditions is also Michael acceptor, therefore the chemoselectivity is limited by the competing Michael addition of biological nucleophiles. ${ }^{167-169}$ Furthermore, the complicated synthesis of tetrazine and trans-cyclooctyne reagents inhibits their widespread application in bioconjugations. ${ }^{160,161,170}$

Since cholesterol can be applied as a protein membrane delivery vector, it suggests another application for introducing a bioorthogonal function to the plasma membrane of live cells. This way biomolecules containing a complementary function can be directly conjugated to the cholesterol moiety pre-incorporated into the outer leaflet of the plasma membrane (Figure 9). In this method the amphiphilic cholesterol-azide is delivered to the plasma membrane and then a protein equipped with a fluorescent alkyne linker is conjugated via a CuAAC reaction. 


\section{Aims of this work}

1. Synthesis of fluorescent cholesterol derivatives for protein membrane delivery and for mimicking GPI anchors.

2. Optimization of the protein conjugation of the water soluble cholesterol anchors.

3. Investigation of the cell membrane delivery of fluorescent cholesterol anchors and that of their protein conjugates.

4. Anchoring the full length prion protein to the cell membrane with a fluorescent cholesterol anchor.

5. Quantitation of the membrane delivered cholesterol anchor by using a tritium labelled analogue.

6. Application of the cholesterol anchor in cell-surface protein conjugations. 


\section{Experimental}

The purity of all reagents and solvents were analytical or the highest commercially available grade. Amino acids and fluorescein derivatives were purchased from Bachem Feinchemicalen AG (Bubendorf, Switzerland), coupling reagents (DIC, HOBt, TBTU, HATU) were obtained from Calbiochem-Novabiochem AG (Läufelfingen, Switzerland), CLEAR amide resin was from Peptides International (Louisville, USA), other chemicals were from Sigma-Aldrich Ltd. (Budapest, Hungary).

Analytical thin layer chromatography (TLC) was performed on $5 \times 10 \mathrm{~cm}$ glass plates precoated with silica gel $60 \mathrm{~F}_{254}$ (Merck, Darmstadt, Germany), spots were visualized with UV light, ninhydrin or phosphomolybdic acid.

Flash chromatography was carried out on silica gel 60 (Sigma-Aldrich Ltd., Budapest, Hungary) using the indicated solvents.

Analytical HPLC separations and semipreparative HPLC purifications were performed with a Merck-Hitachi LaChrom system under the indicated conditions.

Specific optical rotation was determined with an Optical Activity AA-5 automatic polarimeter at $589.4 \mathrm{~nm}$.

The structure of the compounds was determined by measuring $1 \mathrm{D}\left({ }^{1} \mathrm{H},{ }^{13} \mathrm{C}\right)$ and $2 \mathrm{D}$ (HSQC, HMBC) NMR spectra which were recorded on a Bruker Spectra DRX $500 \mathrm{MHz}$ spectrometer. Proton and carbon assignment of the cholesterol moiety was based on literature $\operatorname{data}^{171}$.

Molecular weight of the compounds was determined by ESI-MS analysis on a Finnigan TSQ 7000 or on a Bruker reflex III MALDI-TOF spectrometer.

FT-IR spectra were recorded with a Bio-Rad Digilab Division FTS-65A/896 FT-IR spectrometer in the $4000-400 \mathrm{~cm}^{-1}$ interval at $4 \mathrm{~cm}^{-1}$ optical resolution using a diamond ATR probe or in $\mathrm{KBr}$ pellets.

Fluorescence excitation and emission spectra were recorded on an Agilent Cary Eclipse fluorescence spectrophotometer.

ECD spectra were recorded on a Jasco (Tokyo, Japan) J815 spectropolarimeter, equipped with a Peltier temperature controller, at $25^{\circ} \mathrm{C}$ and $100 \mathrm{~nm} / \mathrm{s}$ scan speed using a $1 \mathrm{~mm}$ path length quartz cuvette. Protein concentration of the samples was in the $2.5-6.5 \mu \mathrm{M}$ range as it 
was measured by the Bradford method. ${ }^{172}$ Spectra presented here are accumulations of 10 scans and the corresponding solvent spectra recorded under the same conditions were subtracted. The contribution of each secondary structural element of the proteins was determined by deconvolution of the spectra using the CDSSTR method. ${ }^{173}$

For in vitro biological studies, SH-SY5Y (ATCC: CRL-2266) human neuroblastoma cells were cultured in DMEM (Sigma Ltd., St. Louis, MO, USA) medium containing 10\% FCS, Lglutamine $(2 \mathrm{mM})$, gentamycin $(160 \mu \mathrm{g} / \mathrm{mL}), 1 \mathrm{mM}$ pyruvate and non-essential amino acids (Sigma Ltd., St. Louis, MO, USA). The cells were maintained at $37^{\circ} \mathrm{C}$ in a humidified atmosphere with $5 \% \mathrm{CO}_{2}$.

Cells treated with the fluorescent anchors or protein conjugates were visualized with an Olympus IX81 confocal laser scanning microscope and FluoView 500 software. For fluorescent membrane staining 20000 cells per well were plated on 8-well Lab-Tek II Chambered coverglass. After $48 \mathrm{~h}$ incubation at $37^{\circ} \mathrm{C}$, cells were treated with the anchors dissolved in serum-free medium for $30 \mathrm{~min}$. The concentration of probe 29, anchors 19, 20, 22, 23 and 25 was $1 \mu \mathrm{M}$, and the concentration of $\mathbf{2 1}$ and $\mathbf{2 4}$ was $10 \mathrm{nM}$. The mCherry-20 and PrP-20, PrP-21 conjugates were applied at $10 \mu \mathrm{M}$, while mCherry-4 at $60 \mu \mathrm{M}$. Cells treated with serum-free medium for $30 \mathrm{~min}$ were used as negative control. After treatment and incubation, cells were washed with serum-free medium and the nucleus of the cells was stained for 5 min using the nuclear dye DRAQ5.

\section{Results and discussion}

The major goal of these studies was the synthesis of fluorescent cholesterol derivatives as protein delivery vectors to introduce proteins to the plasma membrane of live cells. Furthermore, the semisynthesis of homogenous cholesteryl lipoproteins was also intended, especially a PrP derivative, to achieve potential lipid raft targeting. Crucial points were to retain the native fold of the protein and to attempt fluorescent lipoprotein preparations free of both surplus lipids and detergents.

\subsection{Molecular design}

At the design of the synthetic anchors one of the main aspects was the fast and chemoselective coupling between the anchor molecule and the protein with its conserved structure. For this 
purpose the Michael addition was chosen that requires the separate incorporation of a Michael acceptor like an $\alpha, \beta$-unsaturated carbonyl group and a nucleophilic Michael donor like a thiol into the membrane anchor and the protein. In our semisynthetic concept the anchor molecule contains the Michael acceptor maleimido or vinylsulfone function in the headgroup, while the $C$-terminal thiol was introduced into the proteins by $C$-terminal Cys extension. Thiol functionalization of peptides and proteins is frequently used for protein bioconjugations, and its application is increasing since the native chemical ligation was developed. ${ }^{174}$ The synthetic anchor has to contain a fluorescent reporter as well, which serves for imaging the cell membrane anchoring of the attached protein. Finally, the physicochemical properties of the anchor molecule are also important, because live cell applications are performed in polar cell culture media where the hydrophobicity of the lipid moiety must be compensated to avoid precipitation. Accordingly, an additional key function of the molecule is an oligo(ethylene glycol) chain, which increases the polarity of the anchor, exposes the headgroup to the extracellular space and keeps a distance between the protein and the membrane surface similarly to the native GPI anchor. The distance of the protein $C$-terminal $\alpha$-carbon atom from the glycerol oxygen atom in a GPI corresponds to 29 bonds, while the distance of the protein $C$-terminal $\alpha$-carbon atom from the cholesterol $3 \beta$-oxygen atom corresponds to 30 bonds. Thus, the cholesterol anchor can expose the attached protein to the extracellular space with a

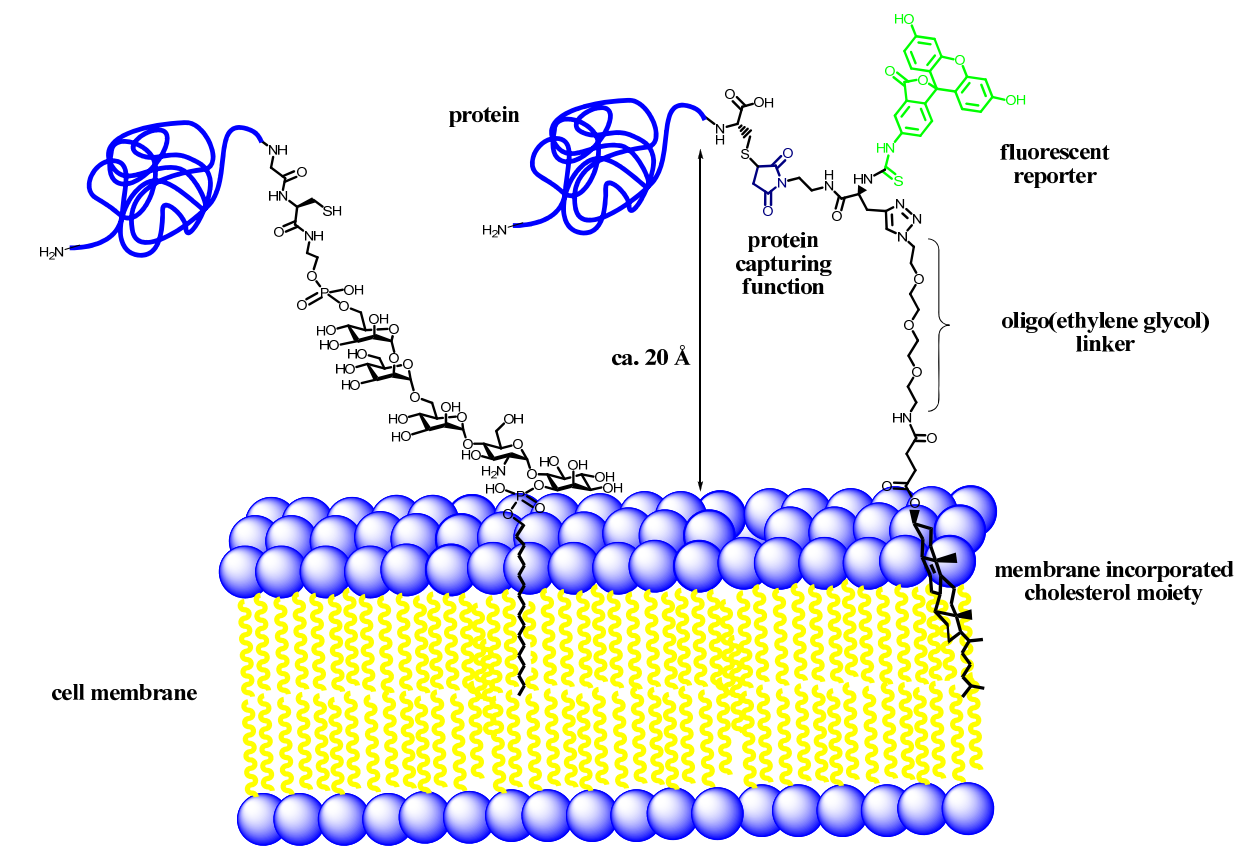

Figure 10. Comparison of the GPI anchor with a designed semisynthetic analogue. 

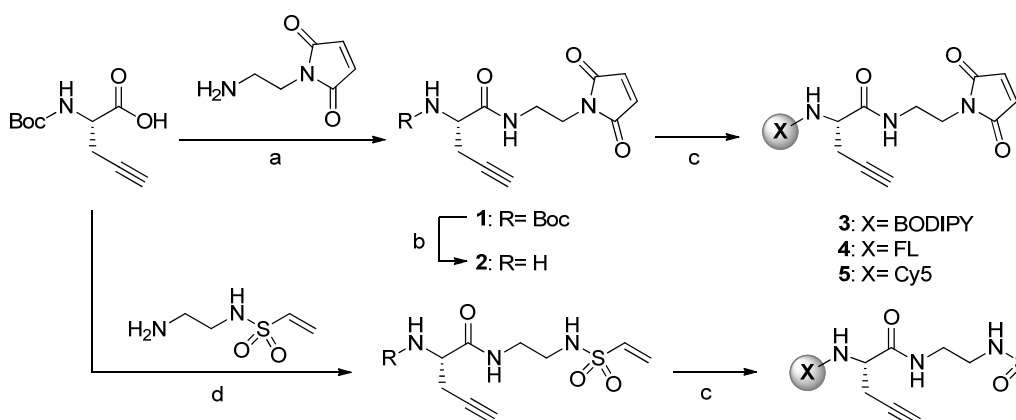

3: $X=$ BODIPY

4: $X=F L$

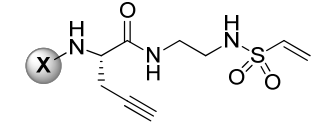

$\mathrm{b}\left[\begin{array}{l}6: \mathrm{R}=\mathrm{BO} \\ \rightarrow 7: \mathrm{R}=\mathrm{H}\end{array}\right.$

8: $X=$ BODIPY 9: $X=F L$
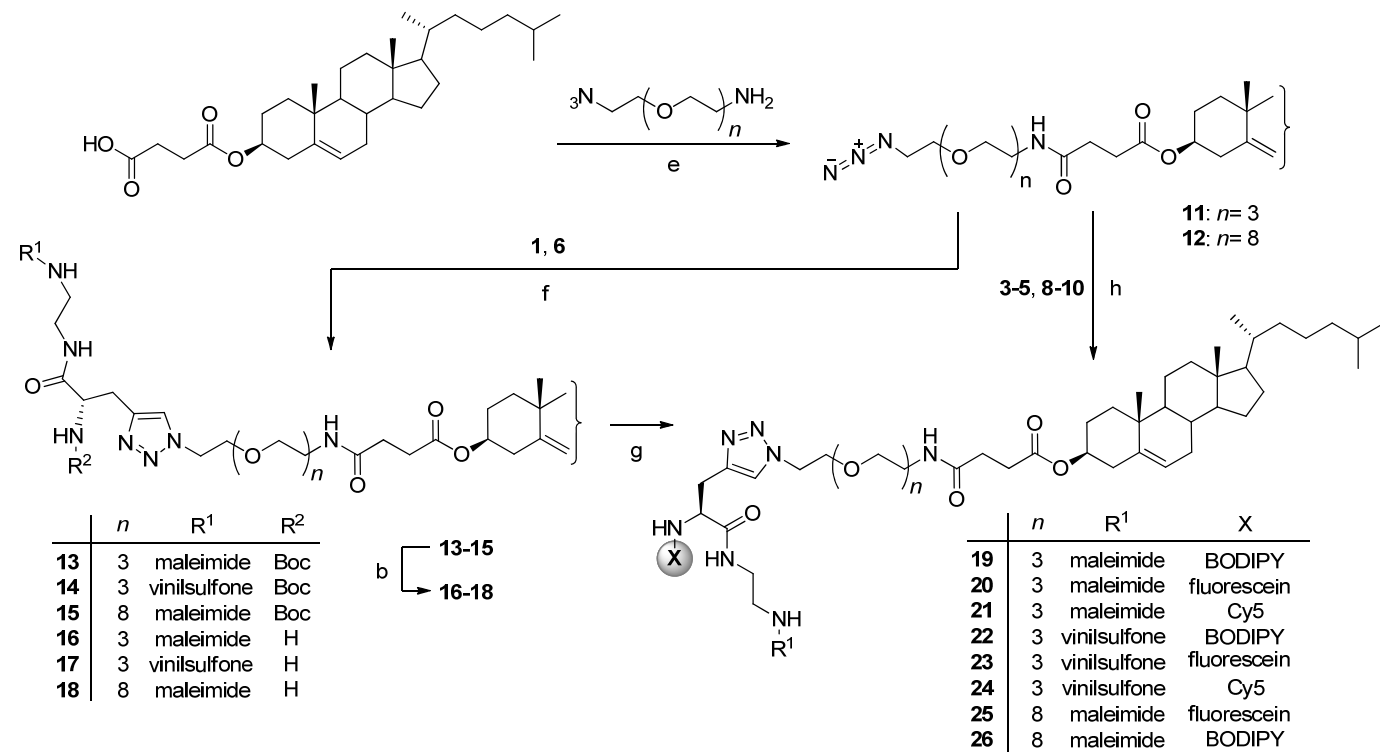

Scheme 1. Preparation of fluorescent cholesterol anchors. a) HOBt, DIC, THF, RT, $8 \mathrm{~h}, 90 \%$; b) TFA $/ \mathrm{CH}_{2} \mathrm{Cl}_{2}$ (1:1), RT, 0.5h, 96\%; c) X= BODIPY: carboxypropyl-BODIPY, TBTU, DIEA, $\mathrm{CH}_{2} \mathrm{Cl}_{2}$, RT, on., $70 \%$ (3), $63 \%$ (8), X= FL: FITC, DIEA, THF, RT, 8h, 69\% (4), 72\% (9), X= Cy5: carboxypentyl-Cy5, HATU, DIEA, DMF, RT, on., 56\% (5), 60\% (10); d) TBTU, DIEA, $\mathrm{CHCl}_{3} / \mathrm{CH}_{2} \mathrm{Cl}_{2} / \mathrm{DMF}$ 8:2:1, RT, on., 70\%; e) TBTU, DIEA, $\mathrm{CHCl}_{3} / \mathrm{CH}_{2} \mathrm{Cl}_{2}$ (4:1), RT, $8 \mathrm{~h}, 90 \%(n=3), 85 \%$ ( $\left.n=8\right)$; f) NaAsc, $\mathrm{CuSO}_{4} .5 \mathrm{H}_{2} \mathrm{O}, \mathrm{CH}_{2} \mathrm{Cl}_{2} / \mathrm{H}_{2} \mathrm{O}(1: 1), \mathrm{RT}, 8 \mathrm{~h}, 87 \%$ (13), 79\% (14), 75\% (15); g) X= BODIPY: carboxypropyl-BODIPY, TBTU, DIEA, $\mathrm{CH}_{2} \mathrm{Cl}_{2}$, RT, on., 50\% (19), 48\% (22), 45\% (25); X= FL: FITC, DIEA, DMF, RT, 6h, 74\% (20), 68\% (23), 64\% (26); X= Cy5: carboxypentyl-Cy5, HATU, DIEA, DMF, RT, on., 57\% (21), 55\% (24); h) X= BODIPY: NaAsc, $\mathrm{CuSO}_{4} .5 \mathrm{H}_{2} \mathrm{O}$, $\mathrm{CH}_{2} \mathrm{Cl}_{2} / \mathrm{H}_{2} \mathrm{O}$ (1:1), RT, 18h, 38\% (19), 32\% (22), 37\% (25), $\mathrm{X}=\mathrm{FL}$ : NaAsc, $\mathrm{CuSO}_{4} \cdot 5 \mathrm{H}_{2} \mathrm{O}, t \mathrm{BuOH} / \mathrm{H}_{2} \mathrm{O}(1: 1)$, RT, on., $57 \%$ (20), $51 \%$ (23), 52\% (26), $\mathrm{X}=\mathrm{Cy} 5$ : NaAsc, $\mathrm{CuSO}_{4} \cdot 5 \mathrm{H}_{2} \mathrm{O}, t \mathrm{BuOH} / \mathrm{H}_{2} \mathrm{O}$ (1:1), RT, 48h, $42 \%$ (21), $50 \%(24)$.

distance of ca. $20 \AA$ from the surface of the membrane bilayer. The lipid anchor cholesterol is attached to the oligo(ethylene glycol) chain, which can target the whole protein-anchor conjugate to the cell membrane (Figure 10). The structures of the designed anchors $19-26$ are shown on Scheme 1. 


\subsection{Synthesis of cholesterol anchor}

The cholesterol anchors were synthesized in convergent way from the trifunctional amino acid propargylglycin (Pra). Its amino and carboxyl functions were used for coupling the fluorescent reporter and the Michael acceptor, and the alkyne function was used for coupling to an azido cholesterol derivative by CuAAC. $N^{\alpha}$-Boc Pra was coupled to the Michael acceptors amino-maleimide 1 or the amino-vinylsulfone 6 (Scheme 1). These two Michael acceptors have different $\mathrm{pH}$ dependent reactivity with nucleophiles like thiols or amines. After the acidolytic removal of the $N^{\alpha}$-Boc protecting group of $\mathbf{1}$ and $\mathbf{6}$, the ammonium salts of the desired compounds 2 and 7 were formed. The fluorescent Pra derivatives 3, 4, 5 and 8, 9, 10 were prepared from the amines liberated in situ from the ammonium salts of 2 and 7. The azido lipids 11 and 12 were prepared from cholesteryl hemisuccinate and the high hydrophobicity of the cholesterol residue was compensated with oligo(ethylene glycols) of different length. Accordingly, $\mathrm{N}$-acylation of 1-amino-11-azido-3,6,9-trioxaundecane or $O$-(2aminoethyl)-O'-(2-azidoethyl)hepta-ethylene glycol with cholesteryl hemisuccinate was achieved in the presence of TBTU and DIEA. The cholesterol anchors 25 and 26 with an octaethoxy linker were also prepared, because the increased polarity of the anchor might be required for the extracellular exposure of the attached protein. In the final step, the functionalized fluorescent Pra derivatives 3, 4, 5 and 8, 9, 10 (Table 1.) were linked to the azido-cholesterol derivative 11, furthermore 3 and 4 were coupled to 12 by CuAAC. Beyond this strategy, another synthetic route was also investigated. It was found that the introduction of the fluorophores is more cost-effective in the last step therefore the amines 16, 17 and 18 were prepared. The purification of their $N^{\alpha}$-Boc protected precursors 13, 14 and 15 was found to be more efficient than that of the anchors from the cycloaddition reaction mixture.

\subsection{Optimization of fluorescent cholesterol anchors}

First the BODIPY labelled cholesterol anchors were prepared, because this dye contains only a carboxyl group that minimizes the possible side-reactions during the $N$-acylation of $\mathbf{2}$ and 7. Furthermore, its high brightness facilitates the sensitive detection of the corresponding anchors. After the preparation of $\mathbf{3}$ and $\mathbf{8}$, azido-cholesterol $\mathbf{1 1}$ was captured to these BODIPY labelled-linkers that resulted in the cholesterol anchors 19 and 22. But it turned out that both the headgroup components $\mathbf{3}$ and $\mathbf{8}$, and the BODIPY-labelled anchors $\mathbf{1 9}$ and 22 
Table 1. Spectral properties of the fluorescent linkers.

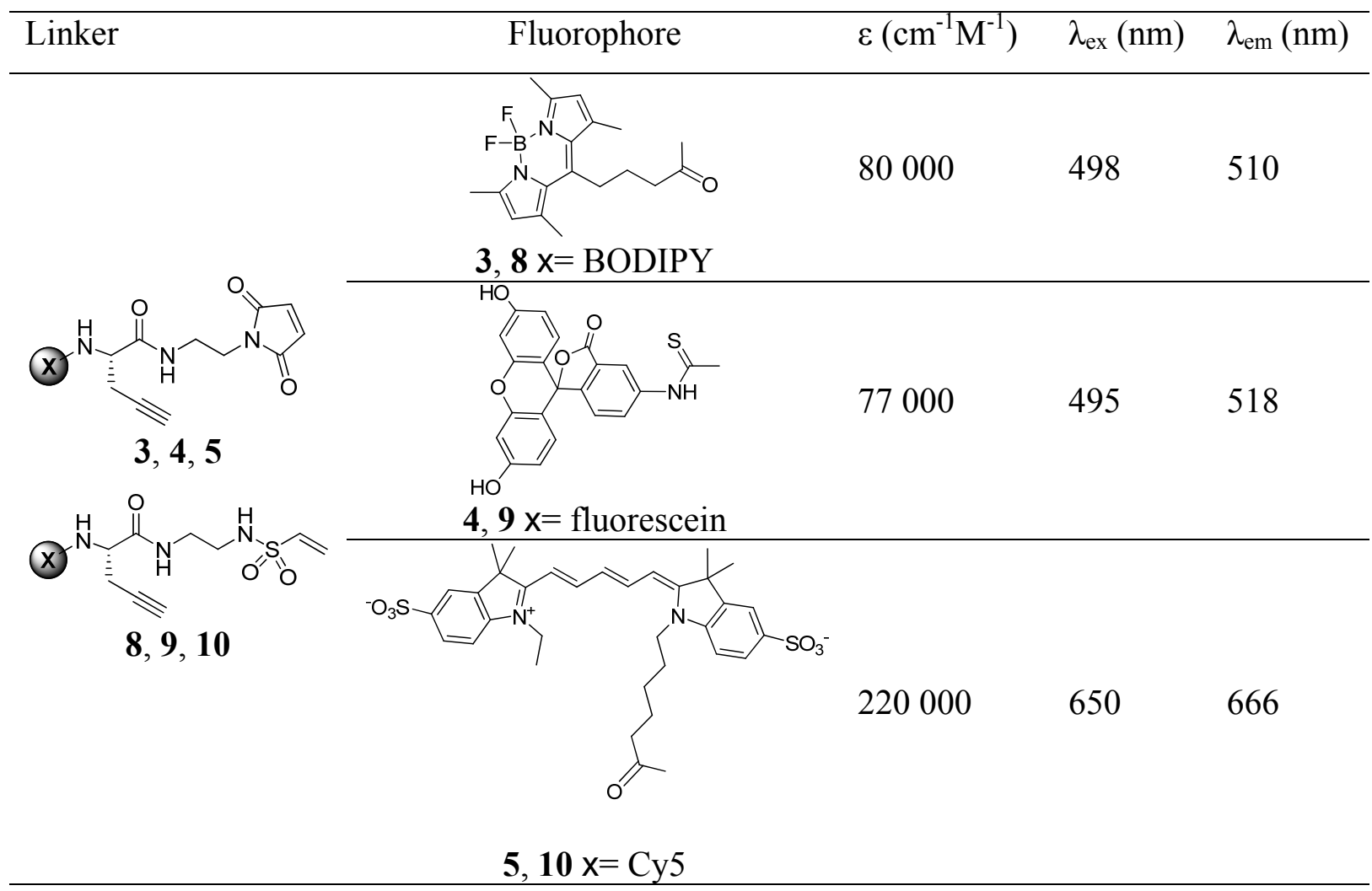

were hardly soluble in polar solvent like the serum-free media (DMEM). Significant precipitation was observed during the confocal microscopy experiments when cells were treated with these compounds (Figure 11). When lower concentration of these anchors was applied, there was no detectable membrane staining, while increasing the concentration resulted in more precipitate. In order to decrease the hydrophobicity of the BODIPY-labelled anchors, the triethoxy linker of $\mathbf{1 9}$ was replaced with a more hydrophilic octaethoxy linker. The cholesterol azide 12 was conjugated with BODIPY-labelled linker 3 that resulted in the anchor 25. During the treatment of SH-SY5Y cells with 25, it was found that this extension of the oligoethoxy linker was not sufficient to achieve reasonable solubility in the serum free medium, and accordingly the precipitation-free cell membrane staining was not achieved.

In order to increase the water solubility of the BODIPY-labelled anchors, the $\beta$ cyclodextrin inculsion complex was investigated. $\beta$-cyclodextrin is a cyclic oligosaccharide with an apolar cavity that has a capacity to form water-soluble inclusion complexes with various compounds including cholesterol. ${ }^{175-178}$ At low $\beta$-cyclodextrin concentration, cholesterol can be incorporated into the cell membrane within a few minutes, ${ }^{176}$ because the 

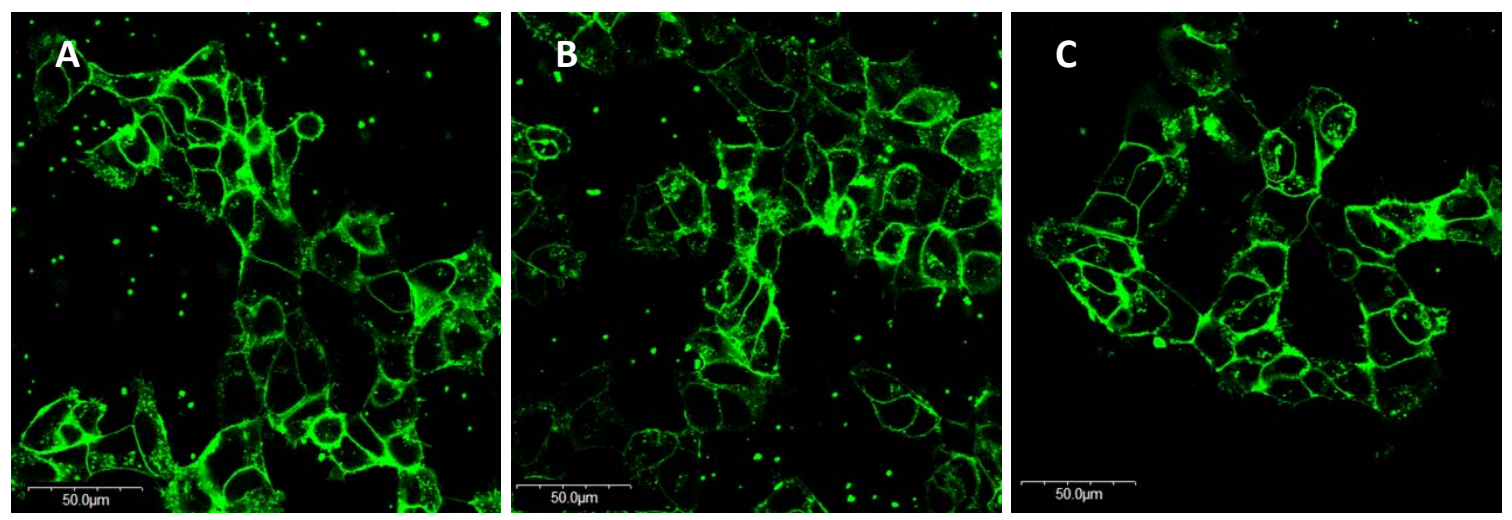

Figure 11. Association of $10 \mu \mathrm{M}$ A) 19, B) 22 and C) 25 with SH-SY5Y cells.
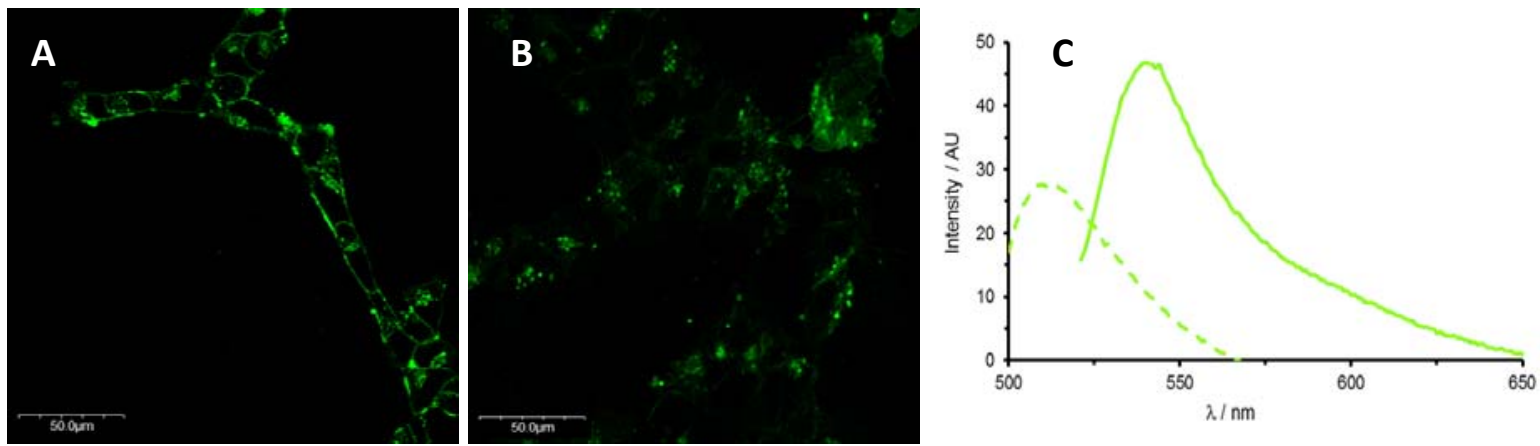

Figure 12. Association of $1 \mu \mathrm{M}$ A) 19- $\beta$-cyclodextrin inclusion complex and B) 19 with SH-SY5Y cell membranes. C) (-) Emission spectra of $100 \mu \mathrm{M} 19$ in PBS without $\beta$-cyclodextrin, and (---) emission spectra of $1 \mu \mathrm{M} 19-\beta$-cyclodextrin inclusion complex in $\mathrm{PBS}$ at $25^{\circ} \mathrm{C} ; \lambda_{\mathrm{ex}}=488 \mathrm{~nm}$.

exchange rate of cholesterol between $\beta$-cyclodextrin and membranes is high. At $\mu \mathrm{M}$ concentrations, $\beta$-cyclodextrin does not extract cholesterol from the cell membrane, it requires $\beta$-cyclodextrin in $\mathrm{mM}$ concentration range. ${ }^{179}$ Furthermore, $\beta$ - cyclodextrin does not accelerate the extraction of phospholipids from the cell membrane when the concentration of $\beta$-cyclodextrin is below $20 \mathrm{mM} .{ }^{180}$ In the form of this inclusion complex, BODIPY-labelled anchors 19 and 22 exhibited intense membrane staining at $1 \mu \mathrm{M}$ concentration without significant precipitation. In contrast, the presence of $1 \mu \mathrm{M} 19$ without $\beta$-cyclodextrin in the medium did not result in membrane staining (Figure 12). The fluorescent spectra of 19 and 19- $\beta$-cyclodextrin inclusion complex represent the differences in the solubility of these species. According to this finding, it was concluded that these synthetic anchors could be applicable for protein conjugation and subsequent imaging. 

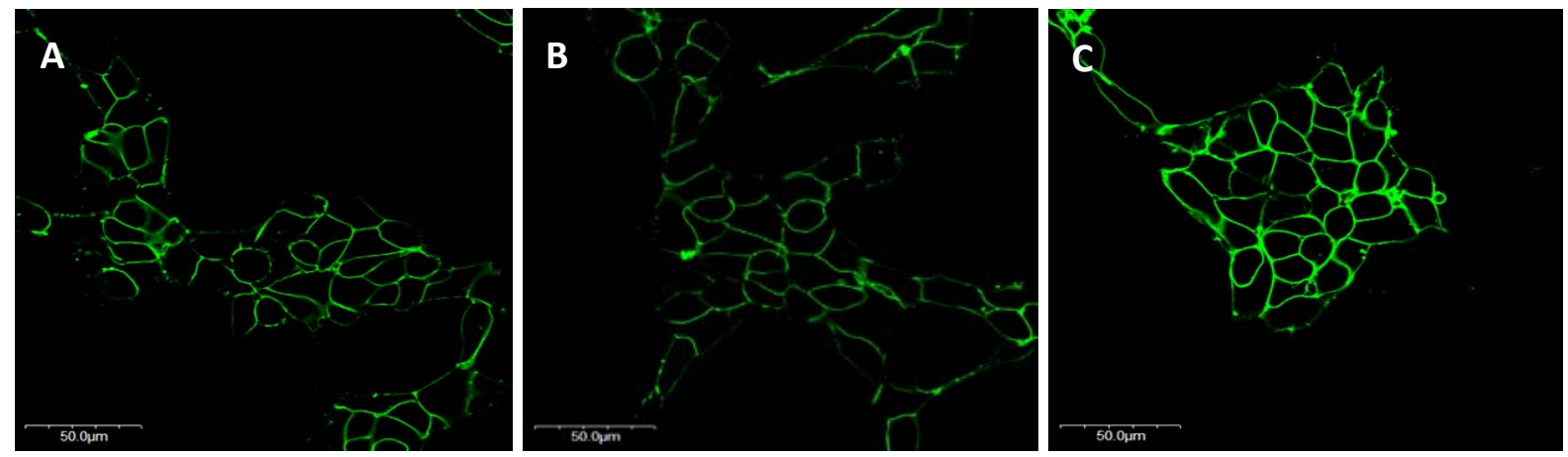

Figure 13. Association of $1 \mu \mathrm{M}$ A) 20, B) 23 and C) 26 with SH-SY5Y cells.

In order to optimize the headgroup of the anchor, the incorporation of polar fluorescent reporters that could exclude the application of $\beta$-cyclodextrin was investigated. For this approach fluorescein isothiocyanate was used. Its phenolic hydroxyl group gives a possibility for salt formation with amines. Thus, the fluorescein-labelled cholesterol anchors 20, 23 and 26 were synthesized and the corresponding triethylammonium and diisopropylethylammonium salts were prepared. It was found, that the solubility of these ammonium salts $(\mathbf{2 0}, \mathbf{2 3}$ and 26) was higher in serum free medium than that of the BODIPY analogues 19, 22, 25. When SH-SY5Y cells were treated with these fluorescent cholesterol derivatives, no fluorescent precipitates were observed that indicated the appropriate physicochemical properties of these anchors (Figure 13). Furthermore, no significant difference was detected between the cell membrane association of 19 and 25 suggesting that incorporation of a polar fluorophore into the headgroup produces more significant effect on the water solubility than the slight extension of the oligoethoxy linker. When these amphiphilic compounds are dissolved in aqueous buffers, they form highly stable micellar associates with an approximate critical micellar concentration of $10-100 \mathrm{nM}^{122}$ The hydrophobic cholesterol moieties form the core of the micelle and the hydrophilic headgroups are situated at the hydrated surface of the micelle. Importantly, in these micelles the protein conjugation Michael acceptor group is accessible by nucleophilic groups during protein conjugation.

The application of fluorescein was found to be advantageous to obtain soluble cholesterol anchors, but the $\mathrm{pH}$-dependent fluorescence ${ }^{181}$ and the low photostability of fluorescein inspired us to substitute fluorescein with a sulfonated pentacyanine (Cy5) dye. This Cy5 derivative is highly water soluble and the fluorescence properties (high brightness, photostability) are advantageous for sensitive detection of low amount of anchors and also for 

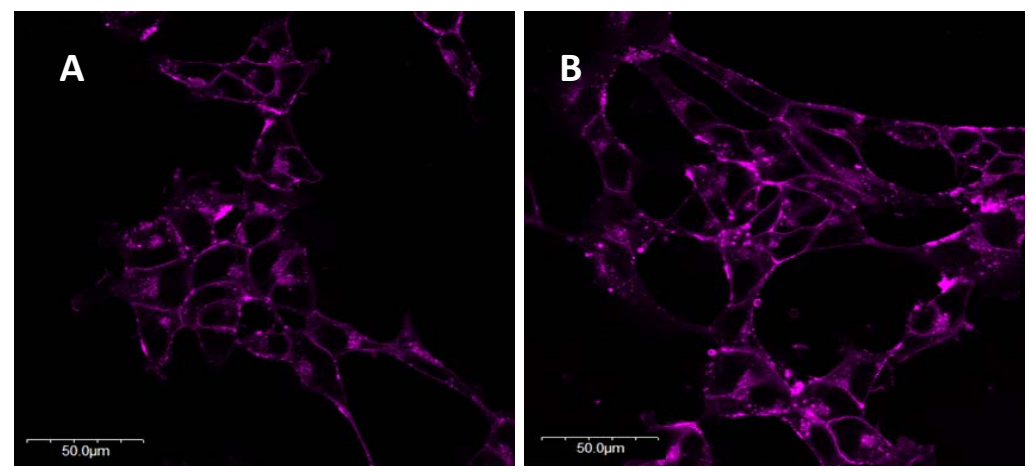

Figure 14. Association of $10 \mathrm{nM} \mathrm{A)} 21$ and B) 24 with SH-SY5Y cell membranes.

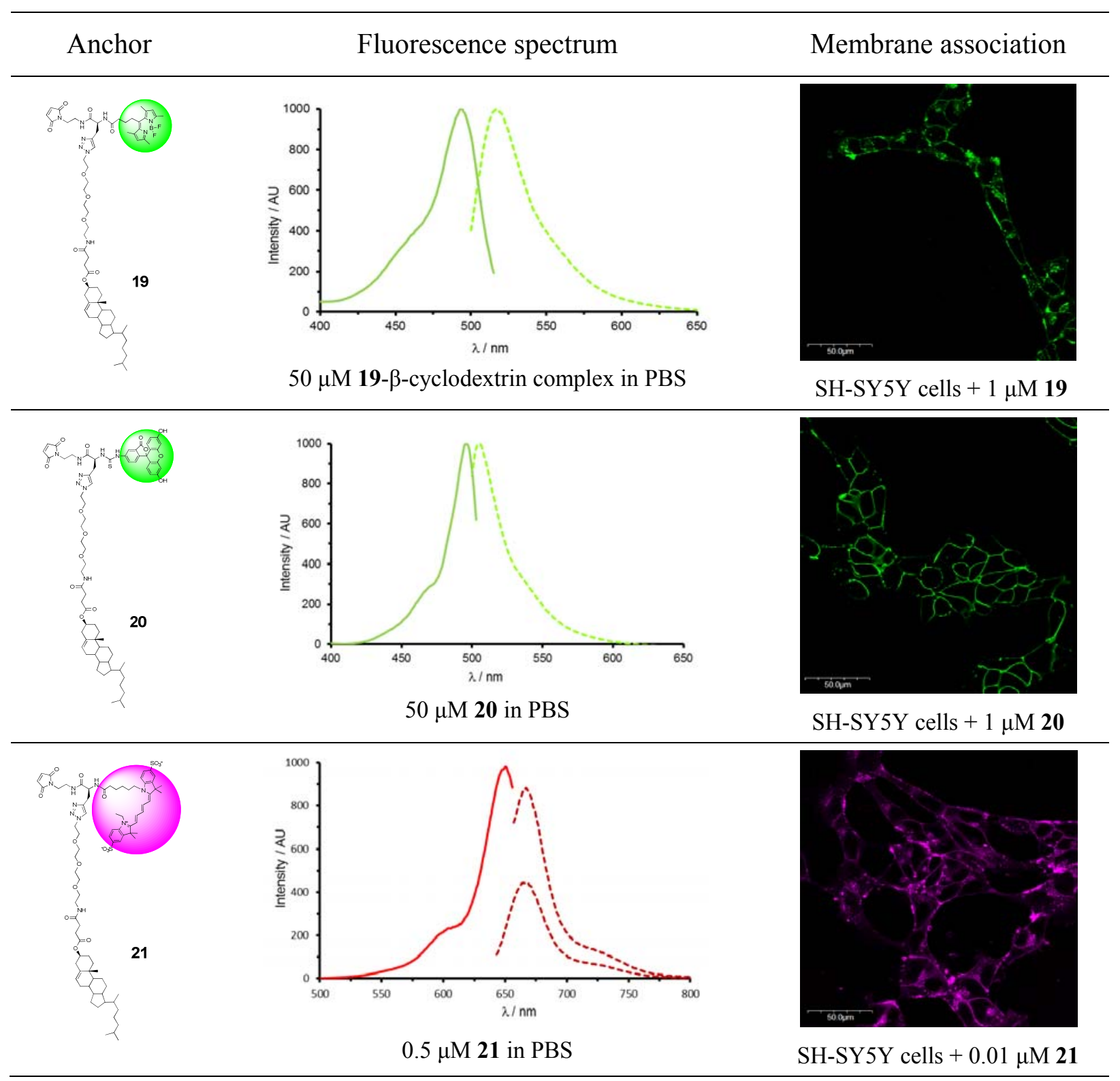

Figure 15. Comparison of the synthetic anchors 19-21. 
multiple imaging. ${ }^{83}$ The maleimido and the vinylsulfone derivatives of Cy5-labelled anchor 21 and 24 were prepared, but the analogue with an octaethoxy linker was not necessary. In fluorescence microscopic studies intensive membrane staining was observed when SH-SY5Y cells were incubated at $10 \mathrm{nM}$ with 21 or 24 (Figure 14). For comparison, similar membrane fluorescence required the presence of $1 \mu \mathrm{M}$ fluorescein-labelled analogues in the cell culture medium.

The fluorescence spectra of fluorescent anchors 19-21 were recorded, and the concentration of BODIPY-labelled 19 in cyclodextrine inclusion complex and the fluoresceinlabelled 20 was $50 \mu \mathrm{M}$, while that of the Cy5-labelled 21 was $0.5 \mu \mathrm{M}$ (Figure 15). The equal fluorescence intensity on the spectra indicated the differences in the effective concentration for cell treatment.

\subsection{Investigation of the hydrolytic stability of the cholesterol anchor}

Before protein conjugation to the cholesterol anchors and cell membrane delivery of the attached protein, the hydrolytic stability of the cholesteryl ester that is the connection between the headgroup and the cholesterol moiety was investigated. For that purpose, the fluoresceinlabelled model compound $\mathbf{2 9}$ was synthesized and subjected to preliminary studies. In order to avoid side-reactions with nucleophiles of biomolecules, this compound does not contain Michael acceptor. The cholesterol probe $\mathbf{2 9}$ was prepared from cholesteryl hemisuccinate. It was activated with TBTU in the presence of DIEA, and used for the $N$-acylation of the monotrityl protected 1,13-diamino-4,7,10-trioxa-tridecane (Scheme 2). The trityl group was chosen

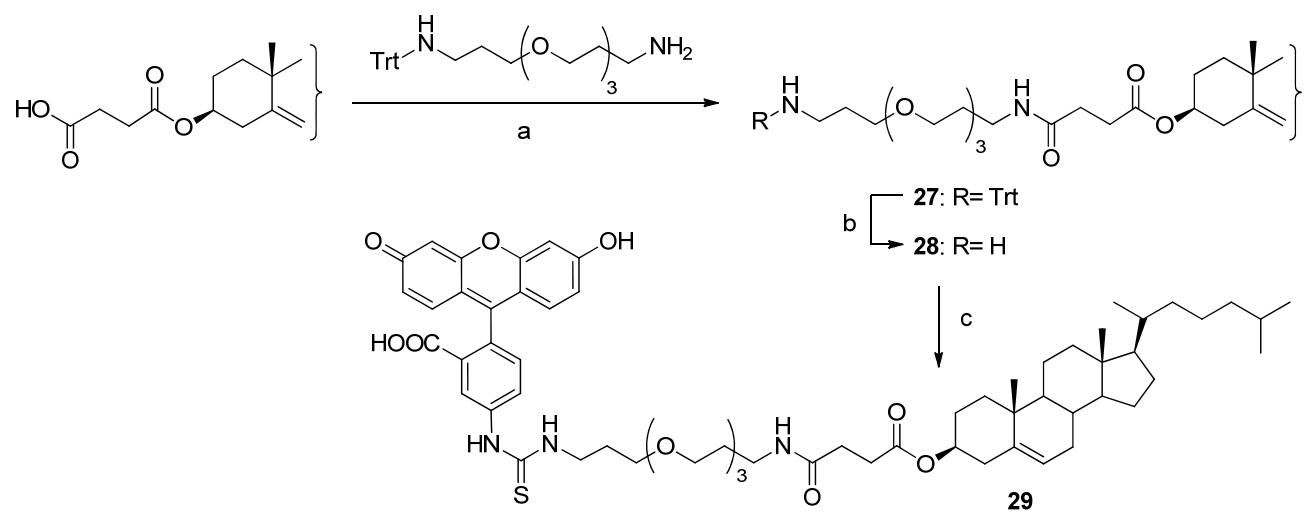

Scheme 2. Synthesis of the fluorescent cholesterol probe: a) TBTU, DIEA, $\mathrm{CHCl}_{3} / \mathrm{CH}_{2} \mathrm{Cl}_{2}$ (4:1), RT, $8 \mathrm{~h}, 95 \%$; b) TFA, TIS, $\mathrm{CH}_{2} \mathrm{Cl}_{2}$, RT, $5 \times 10$ min, 94\%; c) FITC, DIEA, DMF, RT, 6h, 47\%. 


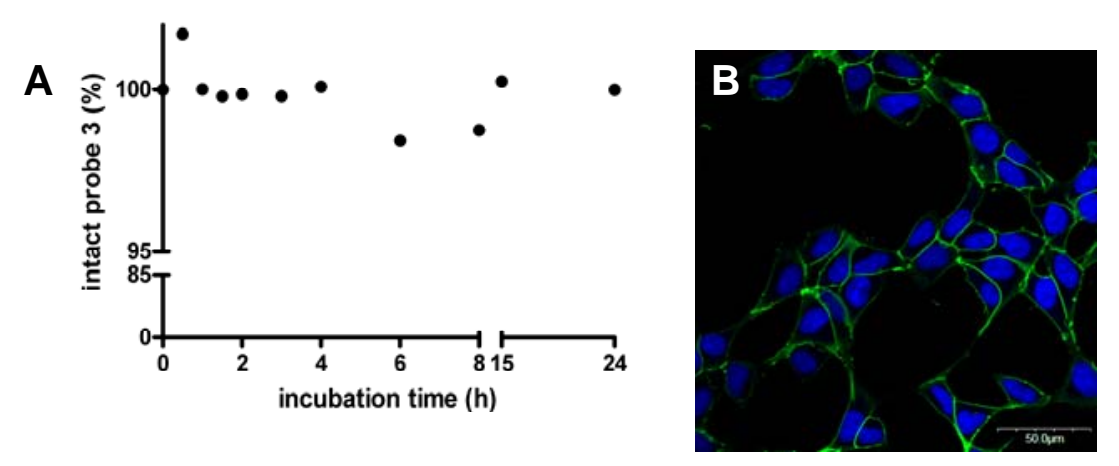

Figure 16. (A) Hydrolytic stability of the fluorescent cholesteryl probe 29. The peak area of 29 in the incubated sample is indicated as a fraction of the peak area of $\mathbf{2 9}$ in the starting solution. (B) SH-SY5Y cells were treated with $1 \mu \mathrm{M} 29$ for $30 \mathrm{~min}$, and nuclear staining was carried out with DRAQ5 for $5 \mathrm{~min}$. The fluorescein is green, and the nuclei are blue in the image.

for protecting the terminal amine, because it is cleaved by mild acids under a condition where the cholesteryl ester is stable. The acidolytic removal of the trityl group of $\mathbf{2 7}$ was performed in the presence of triethylsilane that prevented the realkylation of the amine $\mathbf{2 8}$ during the deprotection. Finally, the addition of the amine $\mathbf{2 8}$ to fluorescein isothiocyanate resulted in the cholesterol probe 29. The hydrolytic stability of the cholesteryl ester in $\mathbf{2 9}$ was explored by incubating the probe in PBS at ambient temperature and HPLC analyses were performed at regular time points. It was found that the HPLC peak area of the probe remained constant over a period of $24 \mathrm{~h}$ (Figure 16), indicating that the cholesteryl ester was not hydrolyzed. In a subsequent experiment SH-SY5Y cells were treated with $1 \mu \mathrm{M}$ of $\mathbf{2 9}$, and an intensive membrane staining was observed (Figure 16).

These experiments suggested that the cholesteryl ester of the anchors was stable under physiological conditions, and the hydrophilic headgroup did not prohibit the fast membrane insertion of the cholesterol amphiphile.

\subsection{Optimization of the Michael addition of the cholesterol anchors}

The Michael addition of the maleimido and the vinylsulfone derivatives of fluoresceinlabelled anchors 20 and $\mathbf{2 3}$ was optimized using a model peptide H-Cys-Lys(biotin)-Asp-GluGly-Asp-Gly- $\mathrm{NH}_{2}$ containing an $\mathrm{N}$-terminal Cys residue. The peptide was added to the solutions of 20 or $23(0.6 \mathrm{mM})$ at different $\mathrm{pH}$, and after $10 \mathrm{~min}$ incubation time the samples 

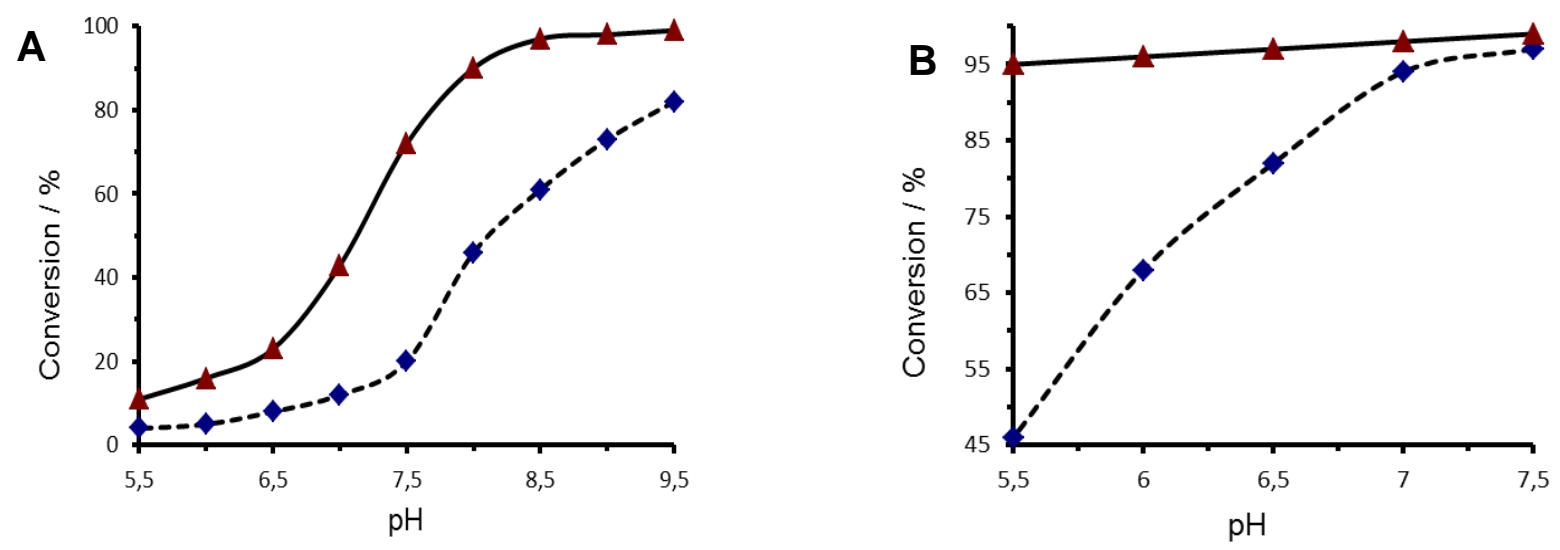

Figure 17. $\mathrm{pH}$ dependence of the Michael addition of 20 and 23. 1 equ (--) or 0.5 equ (-) of H-CysLys(biotin)-Asp-Glu-Gly-Asp-Gly- $\mathrm{NH}_{2}$ was added to the solution of $0.6 \mathrm{mM} 20$ (A) or 23 (B) in $20 \mathrm{mM}$ MES, $10 \mathrm{mM}$ TCEP pH5.5 - 6.5 or in $20 \mathrm{mM}$ Tris, $10 \mathrm{mM}$ TCEP pH7.0 - 9.5. After 10 min incubation time HFIP was added to the solution and it was analysed by HPLC.

of the mixtures were analysed by HPLC. The conversion of the peptide was calculated from the peak areas of the unreacted peptide. In case of the Michael acceptor and donor were present in equimolar ratio, the maleimide was found to be more reactive than the vinylsulfone between $\mathrm{pH} 5.5$ and 7.5. When the cholesterol anchors $\mathbf{2 0}$ and $\mathbf{2 3}$ were applied in two-fold molar excess over the peptide, quantitative anchor - peptide conjugation was observed in the investigated $\mathrm{pH}$ range with the maleimido anchor $\mathbf{2 0}$, and above $\mathrm{pH} 8$ with vinylsulfone anchor 23 (Figure 17).

Maleimides are more reactive than vinylsulfones with thiols, because maleimides are more electrophilic, but under basic conditions, above $\mathrm{pH} 7.5$, maleimides can react with amines also which decreases the chemoselectivity of the Michael addition-based bioconjugation. ${ }^{83}$ In contrast, the weaker electrophile vinylsulfone is less reactive toward nucleophiles, but its thiol addition is significantly faster than the amine addition that results in higher chemoselectivity between $\mathrm{pH} 7.5$ and 9.0. ${ }^{182,183}$ Furthermore, maleimides can hydrolyze under mild basic conditions to maleic acid that is disadvantageous when a longer reaction time is required for capturing of the cholesterol anchor to a protein with a sterically hindered $C$-terminus. When a prolonged reaction time is necessary, the vinylsulfone containing anchor is to be the choice because it was found to be stable for days at $\mathrm{pH} 9$. 


\subsection{Semisynthesis of cholesteryl mCherry}

The red fluorescent protein mCherry lacking any native Cys residues was chosen to optimize the protein - cholesteryl anchor conjugation, and to demonstrate that the designed fluorescent cholesterol derivatives can anchor proteins to the cell membrane. The protein has a sensitive fluorophore within a $\beta$-barrel structure. If it is denatured, the red fluorescence of the protein is lost, and thus, the existence of the protein red fluorescence is an indicator of preserving the native protein structure after cholesterol anchor conjugation. If a green fluorophore containing anchor is used for the mCherry conjugation, then a dual fluorescent cholesteryl lipoprotein is obtained. After introducing this conjugate to the cell membrane, both the cholesterol anchor and the protein can be directly visualized by fluorescence microscopy. Further advantage of this two-color fluorescent lipoprotein conjugate is that the equimolarity of the protein and the anchor can easily be assessed by SDS-PAGE and by measuring the intensity of the fluorescence emissions.

The $C$-terminal Cys extension of mCherry resulted in a protein that possessed a single Michael donor thiol group assuring the chemoselective addition of anchors to the protein $C$ terminus. mCherry-Cys was overexpressed in $E$. coli with a $\mathrm{His}_{6}$ tag preceding the $C$-terminal Cys residue, and was purified from the soluble fraction of the E. coli lysate by Ni-affinity chromatography. The conjugation of the BODIPY-labelled cholesterol anchor 19 to the Cys extended mCherry was performed in $20 \mathrm{mM}$ Tris, $10 \mathrm{mM}$ TCEP at $\mathrm{pH}$ 7.5. Under these conditions the $\beta$-barrel structure of the protein remains intact.

The hydrophobic anchor 19 was applied in $\beta$-cyclodextrin complex and the maleimide was presumed to support a fast reaction under these conditions. But the Michael addition went slowly between 19 and mCherry-Cys and the formation of precipitate was also observed. The SDS-PAGE and MALDI analyses of the precipitate revealed the presence of the unreacted cholesterol anchor and the mCherry-19 conjugate.

In order to avoid the precipitation of the cholesterol anchor - protein conjugate, the mCherry-fluorescein-labelled anchor $\mathbf{2 0}$ conjugate was prepared under similar conditions as described above. It was found that the total conversion of mCherry-Cys required 25-fold molar excess of $\mathbf{2 0}$ in $1 \mathrm{~h}$ (Figure 18). This ratio suggests that the micelles of $\mathbf{2 0}$ is composed of ca. 25 cholesterol amphiphils, and also that a micelle reacts with a single protein molecule because of the sterical hindrance of protein. On preparative scale a protein to anchor ratio of 

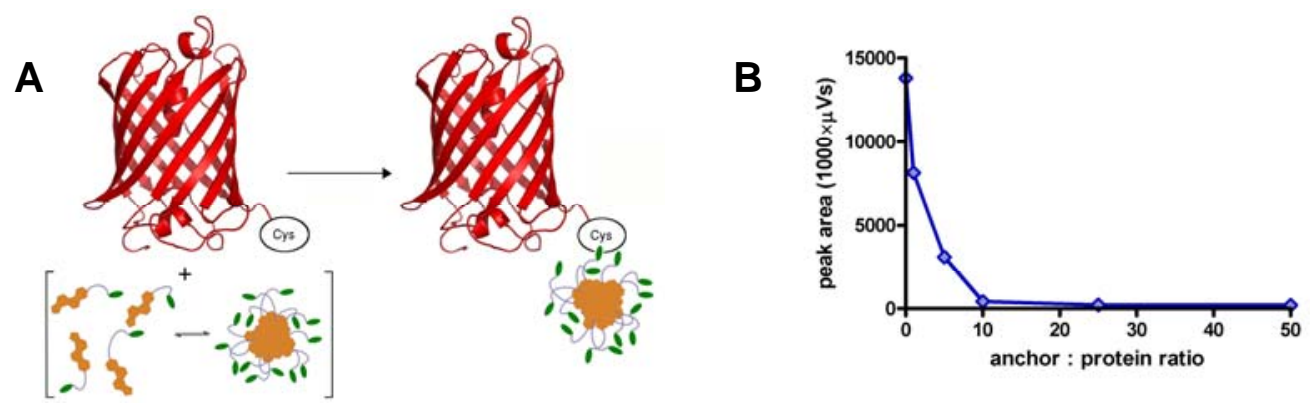

Figure 18. A) Conjugation of fluorescein-labelled cholesterol anchor 20 with mCherry-Cys. The schematic green heads represent the green fluorophore of the cholesterol anchor 20. B) The conversion of mCherry-Cys after $1 \mathrm{~h}$ in the presence of different anchor excess.

1:10 was applied, and the total amount of $\mathbf{2 0}$ was added in 10 portions over $5 \mathrm{~h}$. After the Michael addition, the mixed micelles of the cholesteryl mCherry conjugate and the anchor $\mathbf{2 0}$ amphiphils were separated from both the unreacted protein and from the anchor $\mathbf{2 0}$ micelles by gel chromatography (Figure 19). According to the elution time, the micellar associates of this cholesteryl mCherry preparation exhibited a virtual molecular weight significantly higher than that of the mCherry. The gel chromatographic fraction containing the mCherry-anchor 20 conjugate was subjected to SDS-PAGE, and an intensive fluorescence was detected in the dye front indicating the presence of mixed micelles (Figure 20). These mixed micellar associates keep the cholesteryl lipoprotein dissolved in an aqueous medium. However, it is essential to remove the surplus fluorescent cholesterol, otherwise the plasma membrane or the cholesterol homeostasis ${ }^{184}$ could be perturbed during live cell imaging applications. Furthermore, if the mixed micelles of the conjugate are used for the introduction of the lipoprotein into the cell membrane, the unambiguous imaging of the membrane anchored protein will be impossible via the fluorescence of the cholesterol anchor.

In order to prepare biologically relevant cholesteryl lipoproteins different methods were investigated for the separation of the cholesteryl lipoprotein from the surplus fluorescent cholesterol anchor with an emphasis on the retention of the protein structure. If it is achieved, the fluorescence of the cholesterol anchor can be assigned to the attached protein, and thus, the protein can be unambiguously visualized after cell membrane delivery of the semisynthetic construct. It is important e.g. when the cellular traffic of the exogenously introduced cholesteryl lipoprotein is to be imaged. 

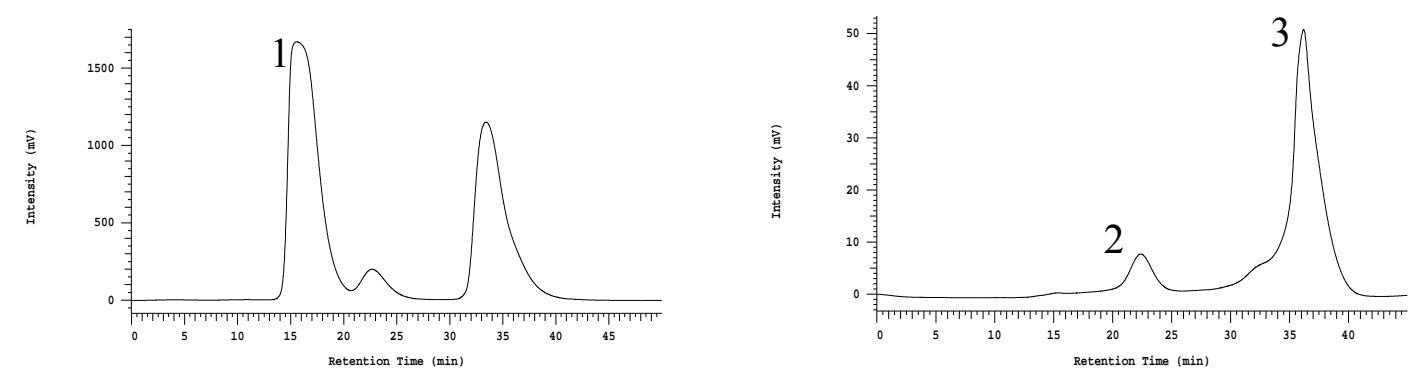

Figure 19. Purification of the mixed micelles of the mCherry-anchor 20 conjugate (fraction 1) followed by the separation of the $\beta$-cyclodextrin inclusion complex of mCherry-20 (fraction 2) and that of the $\mathbf{2 0}$ excess (fraction 3) on Superdex 75 with $50 \mathrm{mM} \mathrm{Na}_{2} \mathrm{HPO}_{4}, 150 \mathrm{mM} \mathrm{NaCl}$, pH7.0, flow rate $0.6 \mathrm{~mL} / \mathrm{min}, \lambda=216 \mathrm{~nm}$.

Dialysis is commonly used to remove small molecules or lipid excess from protein samples, however, the stability of the mixed micelles of fluorescein-labelled anchor $\mathbf{2 0}$ and cholesteryl mCherry limits the performance of this technique. Extraction of the surplus cholesterol anchor with apolar solvents is another option, but the application of chloroform denatured the protein. Refolding of such a denatured cholesteryl lipoprotein was not feasible, because the cholesterol residue permanently participates in hydrophobic interactions, and thus, restricts the protein folding. On the other hand, the application of detergents results in mixed detergent micelles of the cholesteryl lipoprotein which are free of surplus fluorescent cholesterol anchors. The introduction of the cholesteryl lipoprotein into the cell membrane is possible via such detergent micelles, but the detergent molecules have a membrane perturbing effect that is to be avoided in biological applications. When the mixed micelles of mCherry-anchor 20 were purified by reversed phase HPLC, the mixed micelles were disrupted at an acetonitrile concentration of $50 \%$ and the cholesteryl mCherry was eluted as a pure semisynthetic product.

However, the resulting lipoprotein lost the red fluorescent properties indicating the distortion of the $\beta$-barrel structure of mCherry. Afterwards, the refolding of this denatured cholesteryl mCherry failed similarly to that of the chloroform extracted cholesteryl mCherry. The application of an anchor capture resin was also intended for the separation of the lipoprotein and the anchor excess by filtering off the resin bound anchor. A cysteinyl CLEARamide resin was prepared for that purpose, because it has beneficial water swelling properties. The heterogeneous Michael addition, however, was found to be very slow, and the mixed micelles remained intact. All efforts that were made for the separation of the cholesteryl lipoprotein from any interacting partners of the hydrophobic cholesterol residue failed. 
A

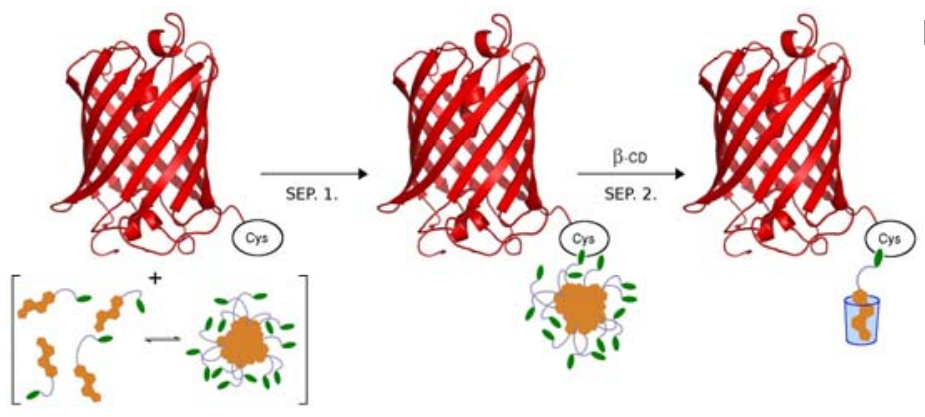

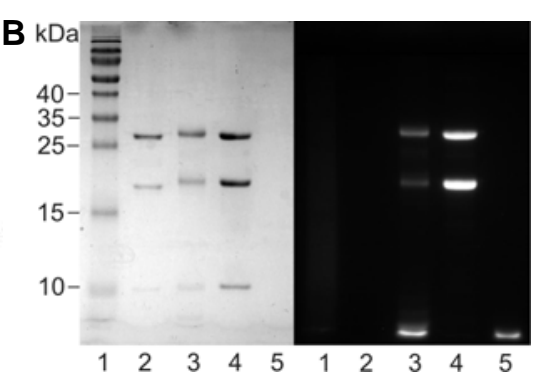

Figure 20. (A) Preparation of the lipid excess-free cholesteryl mCherry. The schematic green heads represent the green fluorophore of the cholesterol anchor 20, $\beta$-cyclodextrin is symbolized with a blue truncated cone, SEP.1. and SEP.2. indicate gel chromatographic separations. (B) Coomassie-stained (left) and fluorescence detected (right) $15 \%$ SDS-PAGE gel: lane 1, molecular weight marker; lane 2, mCherry (under denaturing conditions, the acylimine group of the mCherry fluorophore matured from the $\mathrm{Met}^{71}-\mathrm{Tyr}^{-\mathrm{Gly}^{73}}$ sequence is hydrolyzed ${ }^{185,186}$ that results in the appearance of additional bands with a $\mathrm{M}_{\mathrm{w}}$ of 7.8 and $19.8 \mathrm{kDa}$ ); lane 3, mixed micelles of cholesteryl mCherry (the cholesteryl derivatives of the full length mCherry and that of the C-terminal mCherry fragment, and surplus 20 are fluorescent); lane $4, \beta$-cyclodextrin inclusion complex of cholesteryl mCherry (in order to emphasize the lack of surplus anchor 20, a larger amount of lipoprotein was introduced than in lane 3); lane 5, cholesterol anchor 20.

Therefore, another approach was tried, where the cholesterol moiety of the protein-anchor conjugate was sequestered by a reversible complexation with $\beta$-cyclodextrin, which was suitable for increasing the water solubility of 19. When the mixed micelles composed of the cholesteryl mCherry and anchor $\mathbf{2 0}$ were incubated with 10 eq $\beta$-cyclodextrin, the micellar associates were disrupted without denaturing the protein. The hydrophobic cavity of the $\beta$ cyclodextrin binds the cholesterol moiety of the conjugate and that of the surplus anchor molecules forming host-guest complexes. The molecular weight of the inclusion complex of the protein-anchor $\mathbf{2 0}$ conjugate is significantly higher than that of the cholesterol anchor, and thus, their separation was achieved by size-exclusion chromatography. The purified inclusion complex of the lipoprotein was subjected to SDS-PAGE, and the fluorescence detection revealed that the mCherry-anchor $\mathbf{2 0}$ preparation was free of surplus fluorescent anchor (Figure 20).

\subsection{Characterization of cholesteryl mCherry}

The fluorescence spectra of the pure mCherry-20 lipoprotein exhibited the characteristics of both fluorophores with shoulders on the emission spectrum of fluorescein and on the 

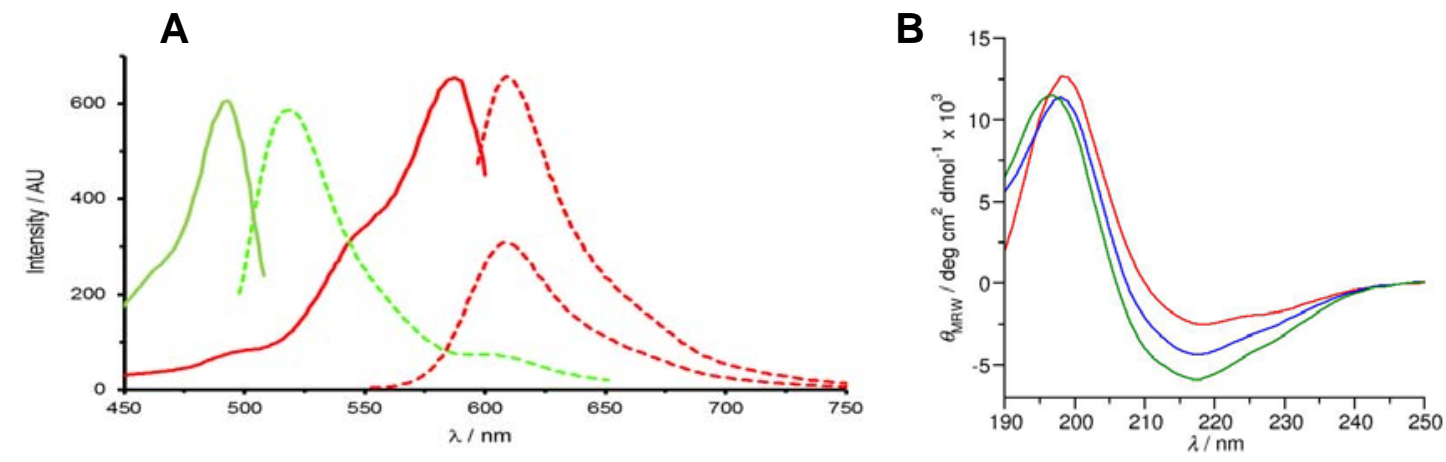

Figure 21. (A) Excitation $\left(-\lambda_{\mathrm{em}}=518 \mathrm{~nm} ;-\lambda_{\mathrm{em}}=610 \mathrm{~nm}\right)$ and emission (--- $\lambda_{\mathrm{ex}}=488 \mathrm{~nm} ;---\lambda_{\mathrm{ex}}=543 \mathrm{~nm}$ and $587 \mathrm{~nm})$ spectra of mCherry-anchor $20\left(20 \mu \mathrm{M}\right.$ in $\left.\mathrm{H}_{2} \mathrm{O}\right)$ at $25^{\circ} \mathrm{C}$. (B) ECD spectra of mCherry-Cys (red), mixed micelles of cholesteryl mCherry (blue) and the $\beta$-cyclodextrin inclusion complex of cholesteryl mCherry (green).

excitation spectrum of mCherry (Figure 21). The emission spectrum of the red fluorophore was also recorded at an excitation wavelength of $543 \mathrm{~nm}$, because it was applied during the confocal laser scanning microscopic experiments. The red fluorescence of the $\beta$-cyclodextrin inclusion complex of cholesteryl mCherry was indicative about the retention of the native protein fold, but it was further evidenced by ECD spectroscopy. ECD spectra of the Cys extended mCherry and that of the mCherry-anchor $\mathbf{2 0}$ conjugate indicated that the attachment of the cholesterol anchor does not cause significant change in the protein structure and that the $\beta$-barrel fold of mCherry is intact both in the mixed micellar form and in the $\beta$-cyclodextrin inclusion complex. The fractions of the secondary structural elements of the lipoprotein were calculated by deconvoluting the ECD spectra (Table 2), and they were compared with that of

Table 2. Fractions of secondary structure elements in mCherry

\begin{tabular}{|c|c|c|c|c|}
\hline Protein & Helix & $\beta$-Sheet & Turns & Random \\
\hline mCherry $^{\mathrm{a}}$ & 0.06 & 0.57 & 0.16 & 0.14 \\
\hline mCherry ${ }^{\mathrm{b}}$ & 0.05 & 0.58 & 0.27 & 0.11 \\
\hline Cys extended mCherry ${ }^{\mathrm{c}}$ & 0.09 & 0.40 & 0.24 & 0.27 \\
\hline mCherry-anchor $\mathbf{2 0}$ conjugate $^{\mathrm{c}}$ & 0.05 & 0.43 & 0.24 & 0.28 \\
\hline mCherry-anchor 20 conjugate with $\beta-\mathrm{CD}^{\mathrm{c}}$ & 0.07 & 0.41 & 0.25 & 0.26 \\
\hline
\end{tabular}

${ }^{a}$ Results obtained from PDB 2H5Q by DSSP algorithm. ${ }^{b}$ Results obtained from PDB 2H5Q by STRIDE algorithm. ${ }^{c}$ Results obtained from experimental ECD spectra by deconvolution. 
the parent mCherry. The distribution of the secondary structural elements was also calculated from the X-ray diffraction structure of mCherry (PDB 2H5Q) for comparison. The crystal structure was analyzed with both the $\mathrm{DSSP}^{187}$ and $\mathrm{STRIDE}^{188}$ secondary structure recognition algorithms, which yielded very similar results. In the solution structures of mCherry-Cys and mCherry-20, slightly higher fractions of random structures and lower fractions of $\beta$-strands were found.

\subsection{Cell membrane association of cholesteryl mCherry}

It was evidenced that our approach offers an effective way to prepare fluorescent cholesteryl lipoproteins without denaturing the protein structure. The resulting semisynthetic lipoproteins do not contain surplus lipids that were achieved without the use of detergents. As a consequence, the fluorescence signal of the anchor molecule can be unambiguously assigned to the attached protein, and the membrane perturbation by external lipid excess or detergents can be excluded in live cell imaging applications. Confocal laser scanning microscopy images of SH-SY5Y cells incubated with the $\beta$-cyclodextrin inclusion complex of the semisynthetic mCherry-anchor $\mathbf{2 0}$ conjugate showed green and red fluorescence on the cell membrane (Figure 22). It suggests that the protein was successfully anchored to the cell membrane after exogenous addition, and also that the protein structure was not affected by the membrane association. Red fluorescence was not observed when cells were treated with the Cys extended mCherry, confirming that the cholesteryl lipoprotein firmly associated to the cell membrane via the cholesteryl anchor. It is important to note, that the fluorescent reporter is situated extracellularly, as it was clarified by MD simulations on the anchor 20, and only the cholesterol residue is immersed into the outer leaflet of the membrane bilayer. This spatial arrangement of the conjugate helps to maintain lipid-lipid interactions specific for cholesterol, and proposes lateral diffusion properties similar to that of the cholesterol. These membrane biophysical properties would be altered if the sterane skeleton was modified with a fluorescent molecule. ${ }^{189}$ The colocalization of the fluorophores also evidenced that the cholesteryl ester and consequently the whole conjugate was stable under the circumstances of the live cell imaging. It is also visible on the differential interference contrast picture that the conjugate is not toxic for the SH-SY5Y cells. This finding is in agreement with the results of the MTT assays, where the mCherry-20 conjugate was found to be non-toxic at the concentration of 10 $\mu \mathrm{M}$. The membrane association of the conjugate results in the liberation of $\beta$-cyclodextrin 

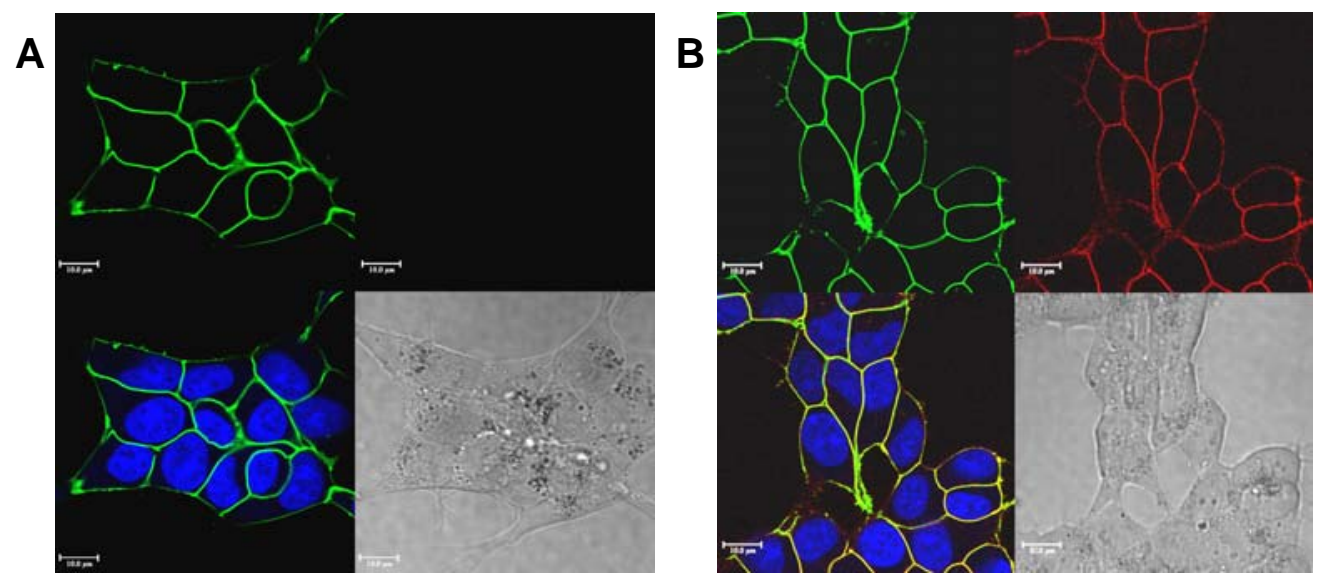

Figure 22. Confocal laser scanning and differential interference contrast (right bottom) microscopy of SHSY5Y cells after 30 min incubation (A) with $1 \mu \mathrm{M}$ fluorescein-labelled cholesterol anchor 20, and (B) with $\beta$ cyclodextrin inclusion complex of $1 \mu \mathrm{M}$ cholesteryl mCherry at $37^{\circ} \mathrm{C}$. On the images fluorescein is green, mCherry is red and nuclei are blue. On the overlayed image (A and B, left bottom) yellow represents the colocalization of the fluorescein and mCherry signals.

from the inclusion complex. However, the presence of $10-20 \mu \mathrm{M} \beta$-cyclodextrin in the cell culture medium has no effect on the normal cellular cholesterol level, because the cholesterol extraction from the cell membrane requires higher $\beta$-cyclodextrin concentration in the $\mathrm{mM}$ range. $^{179}$

\subsection{Conjugation of the full length prion protein with cholesterol anchors}

Due to easier availability of the mouse $\operatorname{PrP}(\mathrm{mPrP})$, human $\operatorname{PrP}$ was replaced by the murine homologue in experiments described in this thesis. The mouse PRNP gene encodes a precursor protein with 254 amino acids which has a sequence homology of $>90 \%$ to the human PrP. The maturation is analogous to the human PrP described in section $\mathbf{1 . 3}$ that yields a GPI-anchored $\mathrm{PrP}^{\mathrm{C}}$ of 208 amino acids, which is transferred to the exterior leaflet of the cell membrane.

In contrast to the mCherry, the Cys extended full length $\mathrm{mPrP}$ has three Cys residues, but the chemoselective addition of an anchor molecule to the $C$-terminal thiol can be achieved. The native $\mathrm{Cys}^{178}$ and $\mathrm{Cys}^{213}$ forms an intramolecular disulfide bond that is buried between $\alpha$ helices of the folded $\mathrm{mPrP}$ excluding them from both thiol-disulfide exchange reactions and subsequent Michael addition. The native disulfide was formed during the folding on Ni-NTA agarose in the presence of the redox system of reduced and oxidized glutathione, and only the properly folded $\mathrm{S} 231 \mathrm{C} \mathrm{mPrP}[23-231]$ protein was eluted from the affinity matrix. Then the 

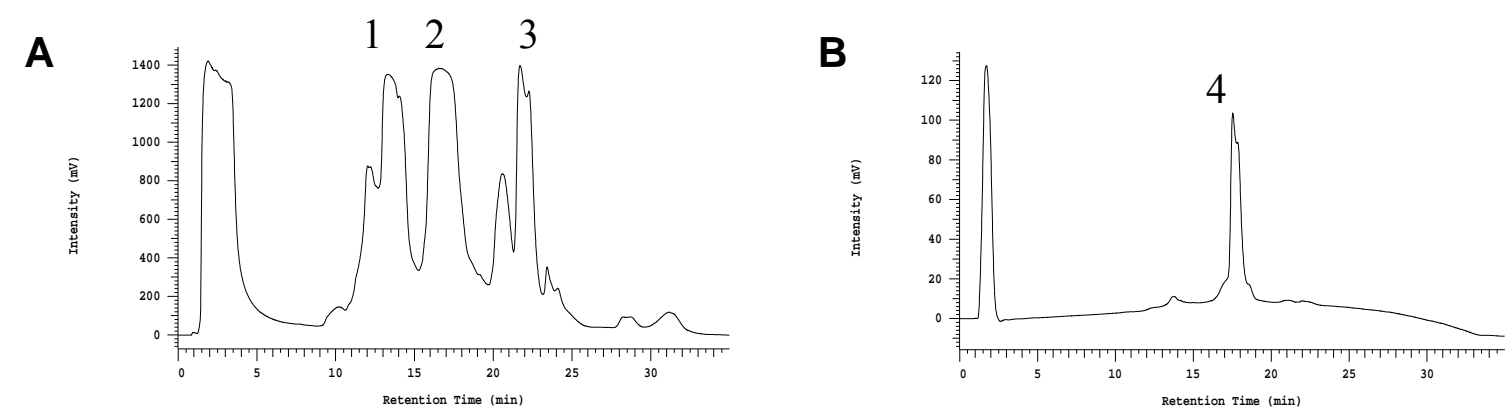

Figure 23. (A) RP-HPLC purification of the $\mathrm{S} 231 \mathrm{C} \mathrm{mPrP}(23-231)$ - 20. $\mathrm{S} 231 \mathrm{C} \mathrm{mPrP}(23-231)$ eluted in fraction 1, S231C mPrP(23-231) - $\mathbf{2 0}$ eluted in fraction 2 and $\mathbf{2 0}$ eluted in fraction 3. (B) Re-purification of fraction 2, under the same conditions as in (A), fraction 4 was collected.

Michael addition of the Cys-extended mPrP to fluorescein-labelled anchor $\mathbf{2 0}$ was achieved in $20 \mathrm{mM}$ Tris, $10 \mathrm{mM}$ TCEP, $\mathrm{pH}$ 7.0. Anchor 20 was added to the protein in 10-fold molar excess in ten portions over $5 \mathrm{~h}$. The $\mathrm{mPrP}$-anchor 20 conjugate precipitated together with denatured $\mathrm{mPrP}$, and the precipitate was dissolved in formic acid and introduced to RP-HPLC for purification (Figure 23). The pure conjugate was dissolved in $20 \mathrm{mM} \mathrm{NaOAc}$, pH 5.5 containing $0.5 \mathrm{mM} \beta$-cyclodextrin for the formation of the inclusion complex. The purified inclusion complex of the mPrP-anchor 20 conjugate was subject to SDS-PAGE, and the fluorescence detection revealed that the $\mathrm{mPrP}$-anchor $\mathbf{2 0}$ preparation was free of surplus fluorescent anchor (Figure 24). CD spectroscopy revealed that the higher order structure of the conjugate was slightly different from the purified S231C mPrP[23-231]. While the spectrum of the folded S231C mPrP(23-231) exhibited distinct $\alpha$-helical character with

A

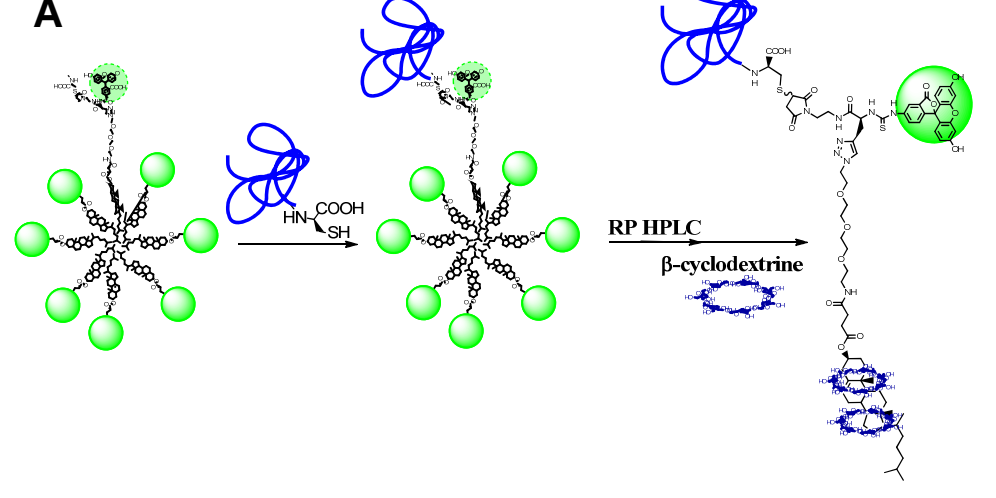

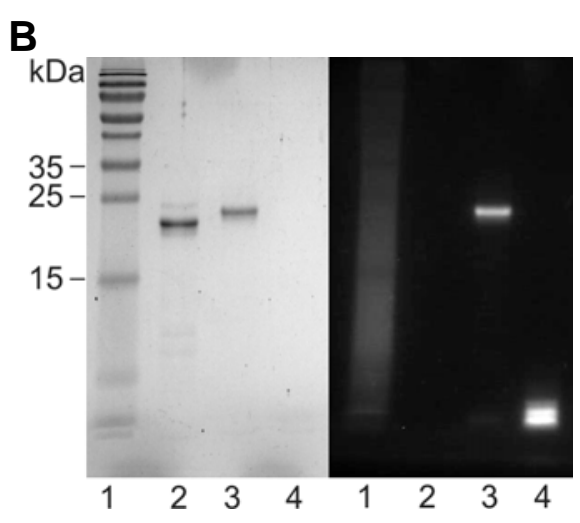

Figure 24. A) Preparation of mPrP-20. B) SDS-PAGE (15\%): lane 1, molecular weight marker; lane 2, S231C $\mathrm{mPrP}[23-231$ ]; lane 3, inclusion complex of mPrP-anchor $\mathbf{2 0}$ conjugate; lane 4, anchor $\mathbf{2 0}$. 


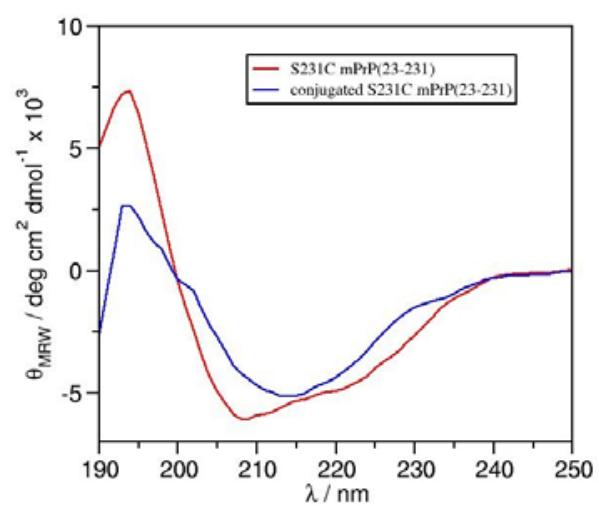

\begin{tabular}{lcccc}
\hline & Helix & $\beta$-Sheet & Turns & Random \\
\hline S231C mPrP(23-231) & 0.13 & 0.33 & 0.22 & 0.32 \\
& & & & \\
S231C mPrP(23-231)-anchor & 0.08 & 0.37 & 0.23 & 0.30 \\
$\mathbf{2 0}$ conjugate with $\beta$-CD & & & & \\
\hline
\end{tabular}

Figure 25. ECD spectra of folded $\mathrm{S} 231 \mathrm{C} \mathrm{mPrP}(23-231)$ (red) and $\mathrm{S} 231 \mathrm{C} \mathrm{mPrP}(23-231)$-anchor 20 conjugate in the presence of $\beta$-cyclodextrin (blue). Fractions of secondary structure elements identified by the deconvolution of the ECD spectra.

minima at 208 and $222 \mathrm{~nm}$, and a maximum around $195 \mathrm{~nm}$, the spectrum obtained for the full length $\mathrm{mPrP}$-anchor $\mathbf{2 0}$ conjugate is more of a $\beta$-sheet character with a wide minimum around $215 \mathrm{~nm}$ (Figure 25). However, spectral deconvolution indicates $4 \%$ higher $\beta$-sheet content for the $\mathrm{mPrP}$ cholesterol derivative. This slight structural difference may be caused by the preparation conditions (Ni affinity chromatography vs RP-HPLC) and not necessarily by the covalent lipidation. The relatively large difference between the ECD spectra of the parent and the conjugated proteins may be explained by the fact that helical structures provide more intense ECD signals than $\beta$ - strands, therefore a minor change in helical contribution may have such dramatic effects. The fluorescent lipo-PrP preparation was immediately used to treat SH-SY5Y human neuroblastoma cells, in $1 \mu \mathrm{M}$ and $3 \mu \mathrm{M}$ concentration and the membrane association of the green fluorescent cholesteryl $\mathrm{mPrP}$ derivative was observed (Figure 26). Because PrP is a highly aggregation prone protein, the Cy5-labelled cholesterol
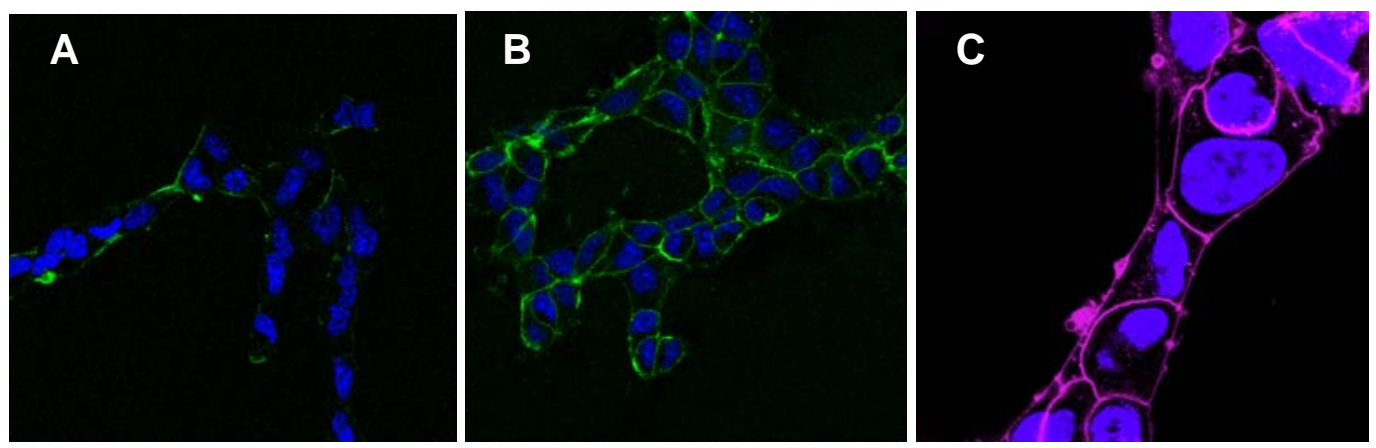

Figure 26. Confocal laser scanning microscopy of SH-SY5Y cells after 30 min incubation with A) $1 \mu \mathrm{M}$ and B) $3 \mu \mathrm{M} \mathrm{S} 231 \mathrm{C} \mathrm{mPrP}(23-231)$-anchor 20, C) $10 \mathrm{nM} \mathrm{S} 231 \mathrm{C} \mathrm{mPrP}(23-231)$-anchor 21. 
anchor 21 was also conjugated to the full length $\mathrm{mPrP}$. Its brighter fluorescent headgroup makes the application of this cholesteryl $\mathrm{mPrP}$ conjugate possible at lower concentrations that decreased the possibility of the protein aggregation.

\subsection{Quantitation of the cell membrane delivery of cholesterol anchors}

In order to determine the concentration of the cell membrane introduced cholesterol anchor, a tritium-labelled cholesterol anchor analogue containing a radioactive reporter in the extracellularly exposed headgroup was designed. ${ }^{190}$ The quantitation of the membrane incorporated protein anchor requires the measurement of the radioactivity of cell membrane preparations therefore the position of the radioactive label is crucial. Although [1,2$\left.{ }^{3} \mathrm{H}\right]$ cholesterol complexed with $\beta$-cyclodextrin was used for the fast enrichment of cell membranes with labelled cholesterol ${ }^{175}$ and it was also used in studying the cyclodextrinmediated cholesterol transfer between different lipid layers, ${ }^{191}$ it is not an optimal choice for our purpose. If the headgroup of the cholesterol anchor is partially removed via the enzymatic hydrolysis of the cholesteryl ester, then the cholesterol moiety will remain in the cell
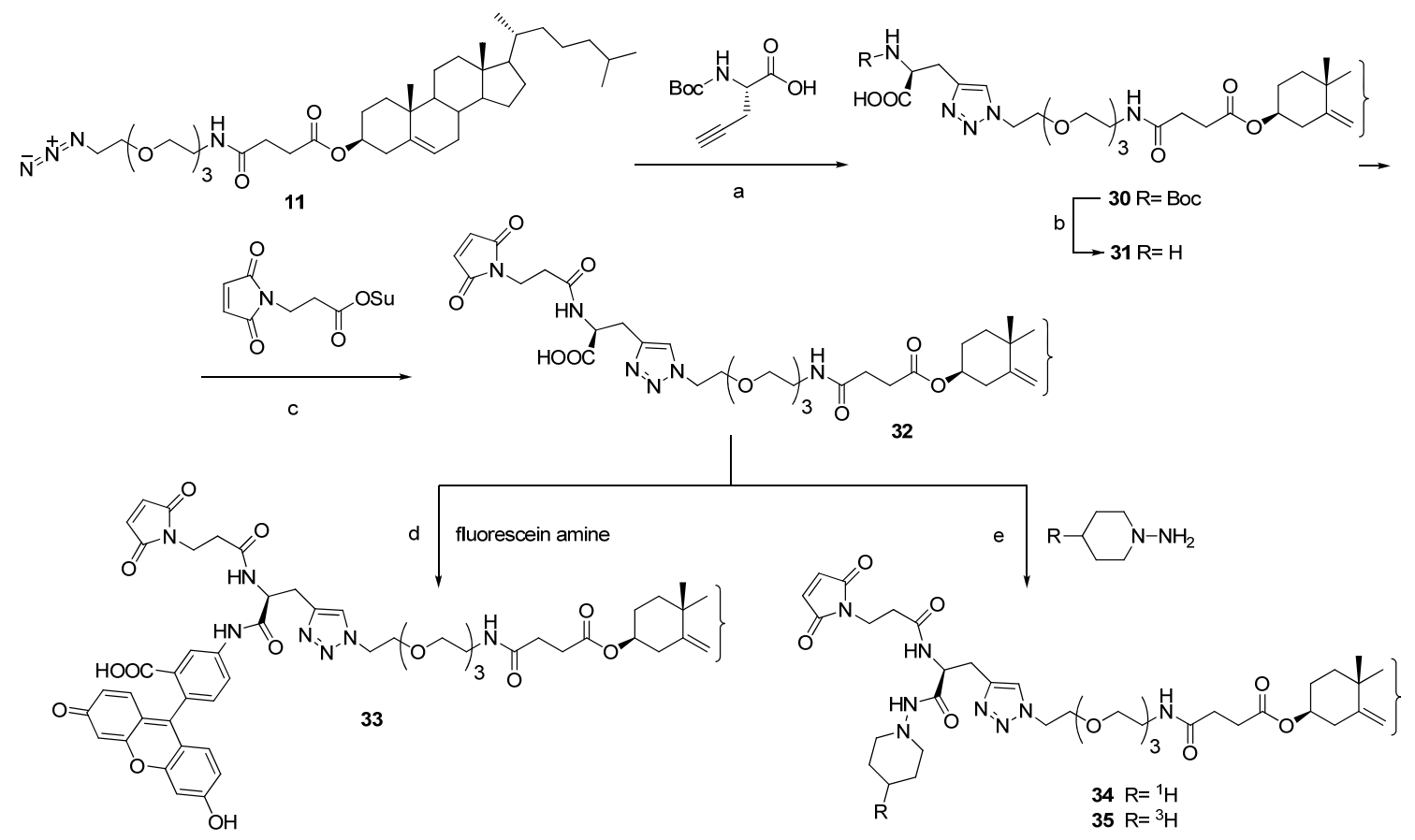

Scheme 3. Preparation of the H-3 labelled cholesterol anchor: a) $\mathrm{NaAsc}, \mathrm{CuSO}_{4} \cdot 5 \mathrm{H}_{2} \mathrm{O}, \mathrm{DMF}-\mathrm{CH}_{2} \mathrm{Cl}_{2}-\mathrm{H}_{2} \mathrm{O}$ (1:4:4), RT, 8h; b) TFA- $\mathrm{CH}_{2} \mathrm{Cl}_{2}$ (1:1), RT, 30 min; c) 2 eq DIEA, MeOH, RT, 3h; d) HATU, DIEA, THF, RT, 16h; e) HOBt, DIC, DMF, RT, 16h. 
membrane. Accordingly, the process cannot be detected in the case of a cholesterol-labelled anchor, because the membrane radioactivity is not affected by the presence or lack of the headgroup. In contrast, if the tritium label is in the headgroup of the anchor molecule, the esterase activity will result in decreased radioactivity of the membrane preparation, and thus, the enzymatic release of the headgroup can be detected in the cell culture medium.

In order to introduce the radioactive label into the cholesterol anchor headgroup, a convergent synthetic strategy was applied (Scheme 3). The tritium label was incorporated into a small molecule that was coupled to an anchor fragment bearing both the cholesterol residue and the bulk of the headgroup. The advantage of this approach is that tritium incorporation either into the cholesterol moiety or into other parts of the headgroup is excluded.

The cholesterol amphiphile 32 was an appropriate intermediate, because it contains an orthogonal function for the protein conjugation, and the carboxylic acid function of the headgroup is available for the introduction of a radiolabelled or a fluorescent tag. The intermediate 32 was prepared from $N^{\alpha}$ - $t$ Boc-protected Pra and 11 via a dipolar cycloaddition in the presence of $\mathrm{CuSO}_{4}$ and sodium ascorbate. The $N^{\alpha}-t$ Boc-protecting group was removed by TFA in DCM and the amine $\mathbf{3 1}$ was liberated in situ with DIEA during the next step. Then 31 was used for the preparation of two constitutionally related, tritium or fluorescein-labelled anchors (35 or 33).

First the thiol reactive maleimide group was coupled to the amine 31, because this way the co-existence of a Michael acceptor and a primary amine in an intermediate compound is excluded that otherwise could lead to self-addition under the basic conditions of the introduction of the labelling tag. It was found that the amino function of $\mathbf{3 1}$ reacts faster with an $N$-hydroxysuccinimide ester than with a maleimide, and accordingly the $N$-acylation of $\mathbf{3 1}$ with 3-maleimidopropionic acid $N$-hydroxysuccinimide ester in DMF resulted in 32. This maleimide serves as a possible protein conjugation function for biological applications. In order to avoid the addition of nucleophiles to the maleimide of $\mathbf{3 2}$ an aniline and an alkylhydrazine - both are less basic than primary amines - were used to introduce the fluorescein and the tritium label, respectively.

In a preliminary study it turned out, that the aniline moiety of 5-aminofluorescein did not react with the Michael acceptor of ( $N$-(2-maleimidoethyl)-2-aminopent-4-ynamide) under the 
coupling conditions planned to apply for the preparation of fluorescein-labelled ancohr $\mathbf{3 3}$. Therefore the fluorescent anchor $\mathbf{3 3}$ was obtained by coupling of the carboxyl group of $\mathbf{3 2}$ with 5-aminofluorescein in the presence of the coupling agent HATU. The NMR structure investigation revealed that 5- aminofluorescein was conjugated to the carboxylic function of 32.

The tritium label was introduced via an aliphatic compound instead of aniline to increase the radiolytic stability of the labelled anchor molecule. $N$-Aminopiperidine was chosen for that purpose, because it is less basic than cyclohexylamine, and after $N$-acylation it results in stable hydrazides. Coupling of tritium labelled $N$-aminopiperidine to the carboxylic acid function of $\mathbf{3 2}$ results in an anchor molecule possessing a headgroup homologous to that of 33, and this way the nonspecific tritium incorporation into the cholesterol moiety or into the maleimido headgroup is not feasible. Before preparing the tritium-labelled anchor by $\mathrm{N}$ acylation of $\left[{ }^{3} \mathrm{H}\right] N$-aminopiperidine with $\mathbf{3 2}$, the unlabelled isotopologue $\mathbf{3 4}$ was prepared in order to optimize the reaction conditions and carry out NMR measurements.

Before the preparation of the tritium-labelled $\mathrm{N}$-aminopiperidine, 4-bromopiperidine was considered as a precursor in a deuterium labelling experiment (Scheme 4). The 4bromopiperidine base was liberated from the hydrobromide salt and it was reduced with deuterium gas in the presence of $\mathrm{Pd} / \mathrm{C}(10 \% \mathrm{Pd})$ catalyst. The resulting $\left[{ }^{2} \mathrm{H}\right]$ piperidine hydrochloride (36) was analyzed by TLC and ESI-MS. The separation of 4-bromopiperidine and piperidine was achieved on silica gel $60 \mathrm{~F}_{254}$ glass plates in $n-\mathrm{BuOH}-\mathrm{AcOH}-\mathrm{H}_{2} \mathrm{O}$ 2:1:1, as their $\mathrm{R}_{\mathrm{f}}$ values were found to be 0.48 and 0.38 , respectively. The TLC analysis of the crude $\left[{ }^{2} \mathrm{H}\right]$ piperidine hydrochloride revealed that the conversion of 4-bromopiperidine was complete. Furthermore, the deuterium incorporation level was estimated by an ESI-MS analysis. It was found that 0.9 deuterium atoms/piperidine molecules were incorporated on

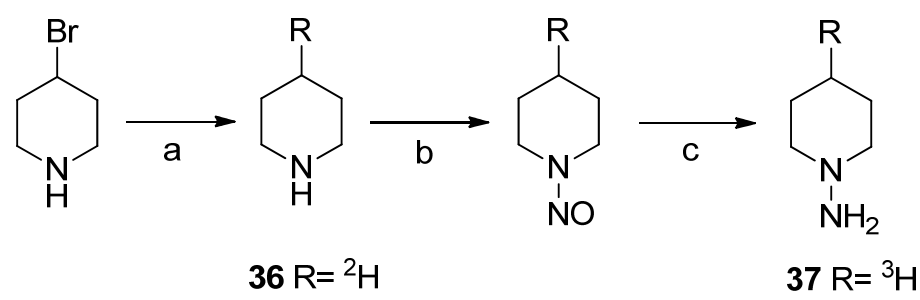

Scheme 4. Preparation of $\left[{ }^{3} \mathrm{H}\right] N$-aminopiperidine: a) $\mathrm{Pd} / \mathrm{C}(10 \% \mathrm{Pd}),{ }^{2} \mathrm{H}_{2(\mathrm{~g})}$ (36) or ${ }^{3} \mathrm{H}_{2(\mathrm{~g})}$ (37), EtOAc, RT, 3h; b) $\mathrm{KNO}_{2}, 1 \mathrm{M} \mathrm{HCl}, 0{ }^{\circ} \mathrm{C}, 2 \mathrm{~h}$; c) $\mathrm{LiAlH}_{4}$, THF, Ar atm., $60{ }^{\circ} \mathrm{C}, 3.5 \mathrm{~h}$. 


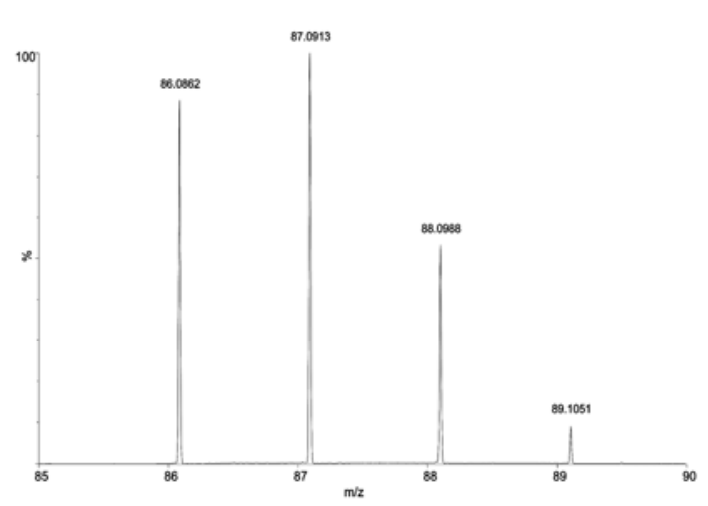

\begin{tabular}{cccc}
\hline Species & $\mathrm{m} / \mathrm{z}$ & intensity $^{\mathrm{a}}$ & $\begin{array}{c}\text { intensity }^{\mathrm{b}} \\
(\%)\end{array}$ \\
\hline $\left.\mathrm{M}\left(d_{0}\right)+\mathrm{H}\right]^{+}$ & 86 & $1.63 \times 10^{5}(88.59 \%)$ & 88.59 \\
$\left.\mathrm{M}\left(d_{1}\right)+\mathrm{H}\right]^{+}$ & 87 & $1.84 \times 10^{5}(100 \%)$ & 94.60 \\
$\left.\mathrm{M}\left(d_{2}\right)+\mathrm{H}\right]^{+}$ & 88 & $9.80 \times 10^{4}(53.26 \%)$ & 47.49 \\
$\left.\mathrm{M}\left(d_{3}\right)+\mathrm{H}\right]^{+}$ & 89 & $1.70 \times 10^{4}(9.24 \%)$ & 6.34 \\
\hline
\end{tabular}

Figure 27. ESI mass spectrum of $\left[{ }^{2} \mathrm{H}\right]$ piperidine and the abundance of the isotopologues. ${ }^{\text {a }}$ measured intensity, ${ }^{b}$ relative intensity corrected with the natural abundance of ${ }^{2} \mathrm{H}$ and ${ }^{13} \mathrm{C}$.

average, but isotopologous species containing two or three deuterium atoms were also identified (Figure 27). These results suggested that this precursor is satisfactory for achieving an approximate molar activity of $1 \mathrm{TBq} / \mathrm{mmol}$.

In the next step $\left[{ }^{3} \mathrm{H}\right] \mathrm{N}$-aminopiperidine was prepared from 4-bromopiperidine (Scheme 4). Reduction of the brominated piperidine with tritium gas in the presence of $\mathrm{Pd} / \mathrm{C}(10 \% \mathrm{Pd})$ catalyst resulted in tritium-labelled piperidine. It was nitrosated and the resulting $\left[{ }^{3} \mathrm{H}\right] N-$ nitrosopiperidine was reduced with $\mathrm{LiAlH}_{4}$, and $\mathbf{3 7}$ was isolated as a hydrochloride salt. The carboxylic acid $\mathbf{3 2}$ was activated with HOBt in the presence of DIC, and the resulting active ester was used in situ for the $N$-acylation of $\mathbf{3 7}$ to give the tritium-labelled anchor $\mathbf{3 5}$. HPLC analysis revealed that a significant amount of tritium-labelled $N$-aminopiperidine was coupled to 32. The purification of the crude cholesterol derivative was achieved by RP-HPLC resulting in $17.4 \mathrm{MBq}$ of pure 35 with an isolated radiochemical yield of 17\%. The sterical hindrance of the carboxylic acid function of $\mathbf{3 2}$ and the more diluted reaction mixture as compared to that of $\mathbf{3 3}$ and $\mathbf{3 4}$ resulted in the low yield of $\mathbf{3 5}$. Quantitative analysis of the concentration and radioactivity of the labelled anchor 35 was performed by RP-HPLC via UV and radioactivity detection using a calibration curve made by $\mathbf{3 4}$. The specific activity of the tritiated cholesterol anchor 35 was found to be $1.37 \mathrm{TBq} / \mathrm{mmol}$ that is higher than the theoretical value. Beyond tritium substitution of $\mathrm{Br}$ in 4-bromopiperidine, catalytic ${ }^{1} \mathrm{H} /{ }^{3} \mathrm{H}$ exchange reactions also took place presumably at the positions 2 and 6 of the piperidine ring. When 2-3 $\mathrm{h}$ of reaction time is applied for catalytic dehalotritiation, the catalytic exchange 
becomes significant and increases the specific activity. The ESI-MS analysis of the deuterium-labelled piperidine also indicated catalytic exchange reactions. It is important to note that the convergent synthetic strategy ensures that all the tritium atoms are localized in the piperidine ring of the headgroup, because after the tritium gas reduction of 4bromopiperidine further transformations do not affect the tritium distribution.

The control compound $\mathbf{3 3}$ was used to assess the membrane association properties of the tritium-labelled cholesterol anchor. The solubility of $\mathbf{3 3}$ was investigated in an aqueous medium before the imaging application. It was important to mimic the protein anchoring conditions, where the cholesterol anchor exists in $\beta$-cyclodextrin inclusion complex. Accordingly, 33 was not transformed into the DIEA salt, and it was found that the amphiphile 33 partially dissolved in a serum free medium as micellar associates and the remaining portion formed precipitates. The resulting heterogeneous mixture was incubated with 10 eq $\beta$ cyclodextrin and this way $0.5 \mathrm{mM}$ aqueous solution of $\mathbf{3 3}$ was prepared. Then SH-SY5Y cells were treated with $1 \mu \mathrm{M}$ of the inclusion complex of $\mathbf{3 3}$ for $30 \mathrm{~min}$. After delivering to live SH-SY5Y cells, an intensive membrane staining was observed, i.e. 33 incorporated into the cell membrane similarly to fluorescein-labelled anchors 20, 23 or 26 (Figure 28). It indicates that a slight modification in the $\alpha$-amino acid function of the headgroup is tolerated with the retention of the membrane association properties.

The tritium-labelled anchor $\mathbf{3 5}$ could also be solubilized in cell culture medium with this
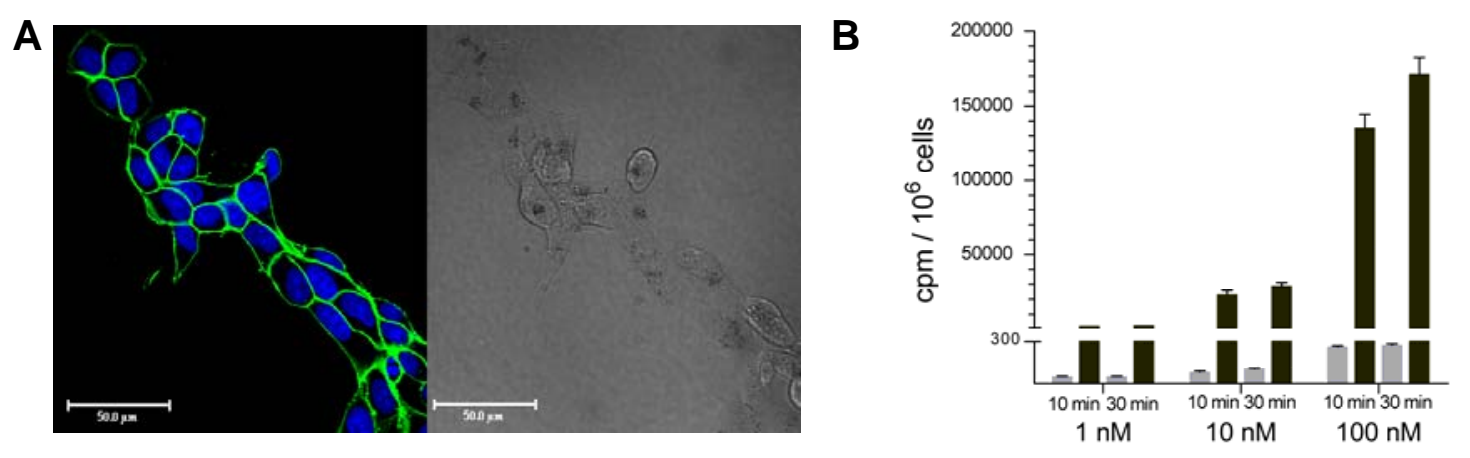

Figure 28. A) Confocal laser scanning (left) and differential interference contrast (right) microscopy of SHSY5Y cells after 30 min incubation with $1 \mu \mathrm{M} 33$ followed by a treatment with DRAQ5 for 5 min at $37^{\circ} \mathrm{C}$. On the image fluorescein is green and nuclei are blue. (B) Incorporation of the $\left[{ }^{3} \mathrm{H}\right]$ cholesterol anchor $\mathbf{3 5}$ to the membrane of SH-SY5Y cells. Cells were incubated with different concentration of $\mathbf{3 7}$ (grey bars) or $\mathbf{3 5}$ (black bars) in the presence of $10 \mu \mathrm{M} \beta$-cyclodextrin followed by liquid scintillation counting of the washed and trypsinized cells. The error bars represent SEM values of three parallel measurements. 
method, and it was applied for studying the cell membrane incorporation of 35. SH-SY5Y cells were incubated with $1-100 \mathrm{nM}$ of $\mathbf{3 5}$ or 37 at $37^{\circ} \mathrm{C}$ for 10 and $30 \mathrm{~min}$, and then cells were washed and trypsinized. The membrane incorporated radioactivity was determined by liquid scintillation counting of the filtered cells. It was found that $\mathbf{3 7}$ was not incorporated into the cell membranes, as the radioactivity of these cell populations was slightly above the background (Figure 28). However, when cells were treated with 35, concentration- and timedependent incorporation of the radioactive cholesterol anchor was observed. The radioactivity of the cell cultures was ca. $20 \%$ higher after 30 min incubation than after 10 min incubation indicating fast plasma membrane incorporation of 35. In order to calculate the membrane concentration of the $\left[{ }^{3} \mathrm{H}\right]$ cholesterol anchor, the concentration of cells was determined by a Bürker chamber and then the radioactivity per cell value was calculated. Using the specific activity of 35, it was found that $2 \times 10^{6}$ cholesterol anchor molecules were incorporated per cell in average when cells were treated with $100 \mathrm{nM} 35$ for $30 \mathrm{~min}$.

\subsection{Protein anchoring to the plasma membrane with cell surface click reaction}

The semisynthesis of lipoproteins has inherent difficulties because the lipid part can initiate protein aggregation. For example the $\beta$-sheet content of the PrP-20 conjugate was $4 \%$ higher as compared with the PrP as observed by CD spectroscopy. Furthermore, the purification of a protein-lipid conjugate can also be difficult. Therefore, an additional method was investigated for the $C$-terminal protein cholesterylation. In this two-step strategy, the $C$-terminus of the protein is modified with an alkyne followed by a CuAAC reaction with a membraneincorporated azido-cholesterol. Beyond the high reaction rate, bioorthogonality, and chemoselectivity the advantage of the CuAAC reaction for our purpose includes the hydrolytic and enzymatic stability of the azides, alkynes and the triazole product forming in the headgroup of the cholesterol anchor in live cell cultures. ${ }^{126-131}$ In order to demonstrate the procedure, the cell surface conjugation of the red fluorescent protein mCherry was performed. The fluorescence of this model protein is sensitive for structural changes, thus, it is indicative about the retention of the native protein structure after the lipidation and it can be detected by fluorescence microscopy in the target cell culture. Furthermore, a fluorescein-labelled Pra derivative was applied as an alkyne tag for the $C$-terminal modification of mCherry. This way a dual fluorescent protein-conjugate was obtained that is advantageous to demonstrate the 

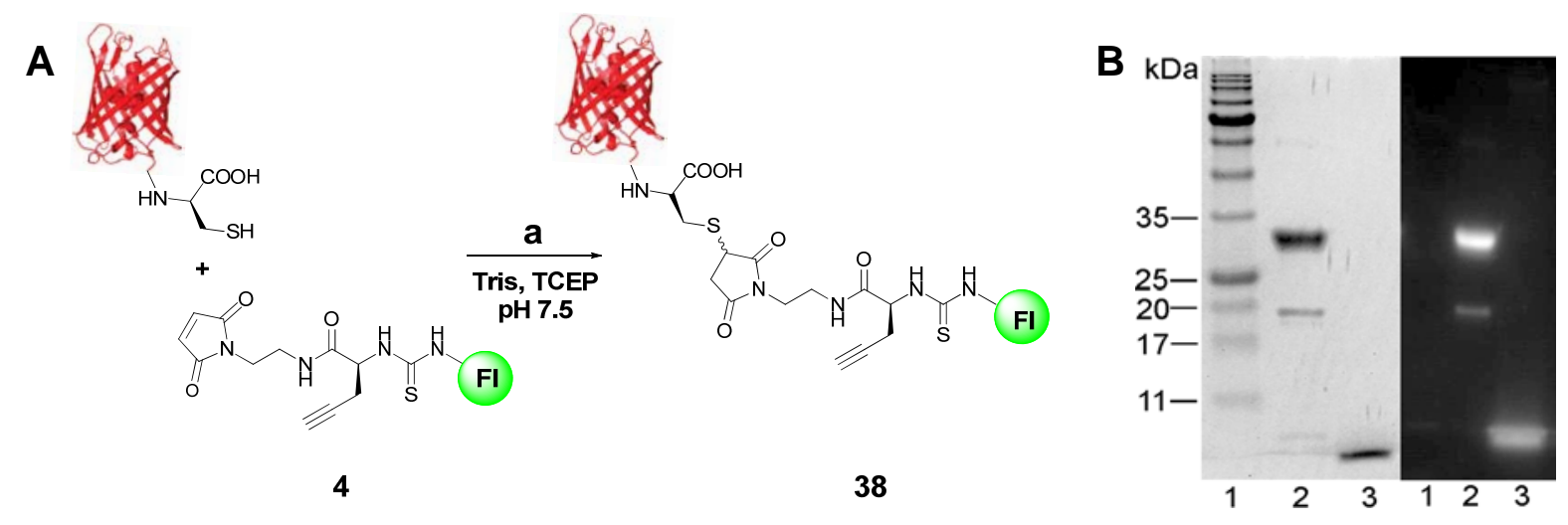

Figure 29. A) Introduction of the fluorescent alkyne 4 to the $C$-terminus of mCherry-Cys; a) 5 equ $4,20 \mathrm{mM}$ Tris, 10 mM TCEP, pH7.5, RT, 1h. B) SDS-PAGE: lane 1, molecular weight marker; lane 2, 38; lane 3, 4.

presence of both the protein and the linker moiety on the cell surface. Furthermore, the unreacted azido-cholesterol does not contribute to the fluorescent signal that is directly assigned to the anchored protein.

Tagging of the model protein mCherry was achieved via the Michael addition of mCherryCys and the fluorescein-labelled maleimido alkyne 4. The conjugation was performed with a protein to maleimide ratio of 1:5, and the total amount of 4 was added in 5 portions over $1 \mathrm{~h}$. The Michael addition was found to be fast and this way the quantitative conversion of mCherry-Cys was achieved. The mCherry-4 conjugate was separated from the linker excess by size exclusion chromatography. When the purified conjugate was analyzed by SDS-PAGE, it was found that it did not contain surplus fluorescent maleimido alkyne 4 (Figure 29). Under denaturing conditions, the acylimine group of the mCherry fluorophore is hydrolized ${ }^{185,186}$ that results in the appearance of additional bands with a $\mathrm{M}_{\mathrm{w}}$ of 7.8 and $19.8 \mathrm{kDa}$. The bands corresponding to the full length mCherry-Cys and to the $C$-terminal mCherry-Cys fragment were found to be fluorescent under UV light that reveals the covalent attachment of the fluorescein-labelled alkyne 4 to the $C$-terminus of mCherry-Cys. Excitation and emission spectra of the mCherry-alkyne conjugate were recorded and the presence of both fluorophores was observed (Figure 30).

In order to perform a $\mathrm{CuAAC}$ on the surface of live cells, the azido-cholesterol was first introduced into the plasma membrane of cultured SH-SY5Y human neuroblastoma cells. $\beta$ cyclodextrin was used as a delivery vector, and the corresponding inclusion complex was prepared by incubating $30 \mu \mathrm{M}$ of azido-cholesterol 11 and $75 \mu \mathrm{M}$ of $\beta$-cyclodextrin overnight 

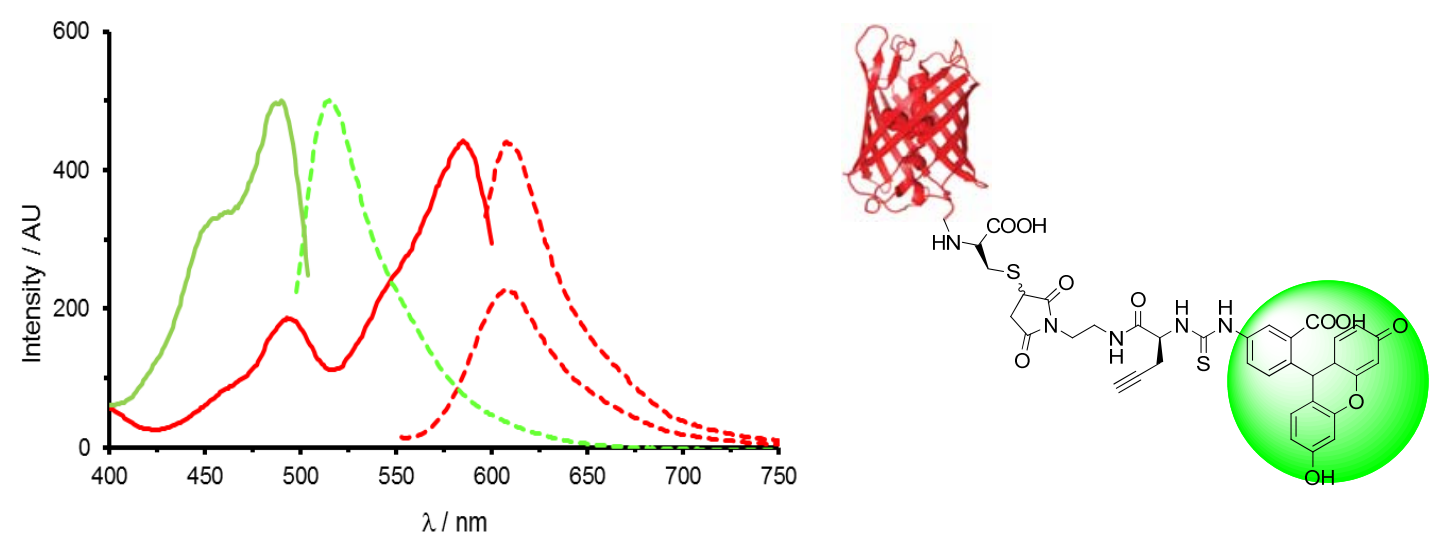

Figure 30. Excitation $\left(-\lambda_{\mathrm{em}}=518 \mathrm{~nm} ;-\lambda_{\mathrm{em}}=610 \mathrm{~nm}\right)$ and emission (--- $\lambda_{\mathrm{ex}}=488 \mathrm{~nm}$; --- $\lambda_{\mathrm{ex}}=543 \mathrm{~nm}$; --$\lambda_{\text {ex }}=587 \mathrm{~nm}$ ) spectra of $15 \mu \mathrm{M} 38$ in $\mathrm{H}_{2} \mathrm{O}$ at $25^{\circ} \mathrm{C}$.

in DMEM cell culture medium. Then cells were treated with a solution of the resulting azidolipid complex in serum-free medium for $30 \mathrm{~min}$. It is important to note, that the normal cellular cholesterol level is not affected at a $\beta$-cyclodextrin concentration of $75 \mu \mathrm{M}$, because cholesterol extraction from the cell membrane requires much higher $\beta$-cyclodextrin concentration. $^{179}$

Parallel to the azido-cholesterol loading the copper catalyst was prepared by reducing $\mathrm{CuSO}_{4}(50 \mu \mathrm{M})$ with NaAsc $(500 \mu \mathrm{M})$ in the presence of the accelerator ligand His $(100 \mu \mathrm{M})$ over $15 \mathrm{~min}$ followed by the addition of the carbonyl-capturing reagent aminoguanidine (500 $\mu \mathrm{M})$. Finally the alkynes $\mathbf{4}$ or $\mathbf{3 8}$ were added (Figure 31). Cells were then washed and treated with the resulting alkyne solutions. The ligand accelerated $\mathrm{CuAAC}$ reactions performed on live cell surface were monitored by fluorescence microscopic imaging of the cells (Figure 32). In control experiments cells were not pretreated with azido-cholesterol, but incubated with 4 or with 38 in the presence of the same catalyst and additives. These experiments resulted in no detectable fluorescent cell labelling even when 4 or 38 was applied at $100 \mu \mathrm{M}$ concentration, and thus, evidenced that neither $\mathbf{4}$ nor $\mathbf{3 8}$ has non-specific adsorption on the surface of SH-SY5Y cells. When cells pretreated with the $\beta$-cyclodextrin inclusion complex of azido-cholesterol were incubated with $\mathbf{4}$, intensive green membrane fluorescence was observed indicating the successful cell surface $\mathrm{CuAAC}$ between the cholesterol azide and 4 . Similarly, when the azido-cholesterol loaded cells were incubated with the dual fluorescent conjugate 38, intensive red and green fluorescence was detected on the cell surface. 


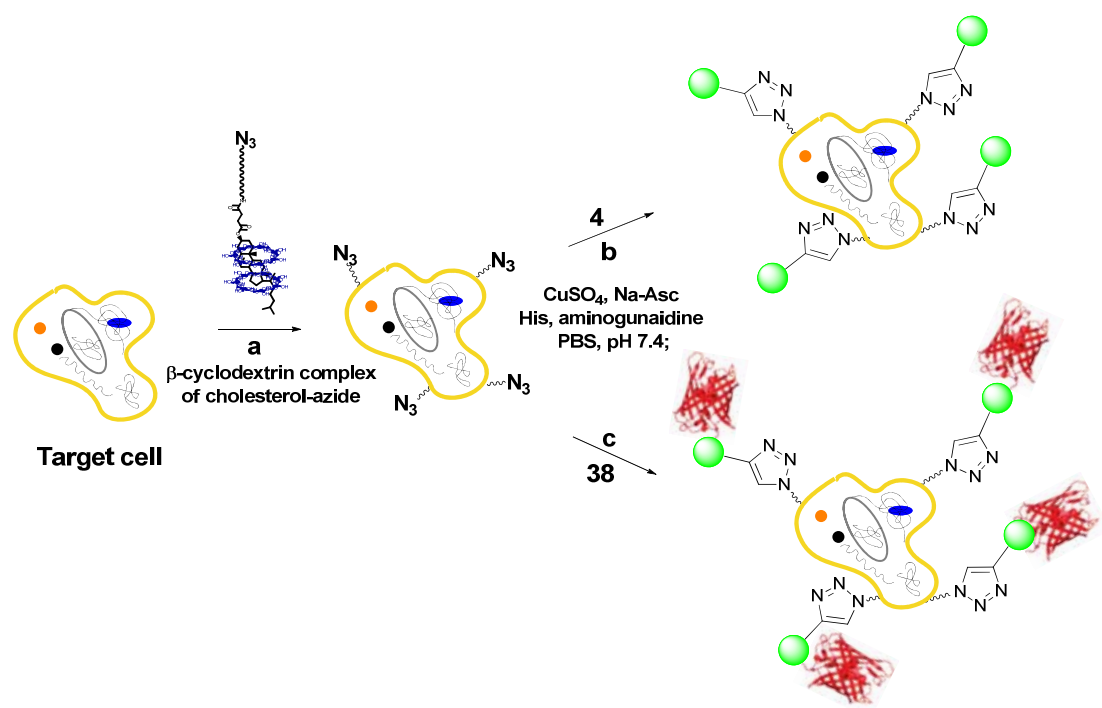

Figure 31. Schematic representation of the cell surface CuAAC. SH-SY5Y cells were azido-cholesterol loaded with a (a) $30 \mu \mathrm{M}$ 11- $\beta$-cyclodextrin inclusion complex-treatment in serum free medium, RT, $30 \mathrm{~min}$, followed by incubation with (b) $30 \mu \mathrm{M} \mathrm{4}$, or (c) $60 \mu \mathrm{M} 38$ in the presence of $50 \mu \mathrm{M} \mathrm{CuSO}_{4}, 500 \mu \mathrm{M} \mathrm{NaAsc}, 100 \mu \mathrm{M}$ His, $500 \mu \mathrm{M}$ aminogunaidine, PBS (pH7.4), 30 min.

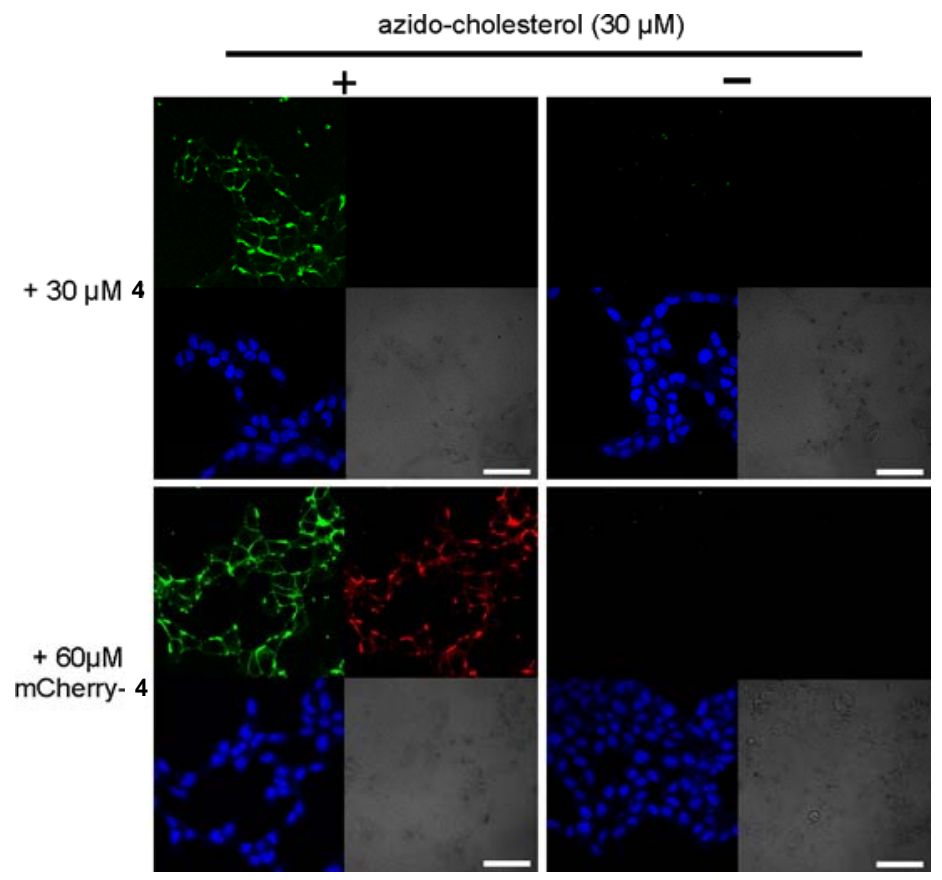

Figure 32. Confocal laser scanning and differential interference contrast (right bottom) microscopy images of SH-SY5Y cells. Azido-cholesterol pretreated cells were incubated with 4 or with $\mathbf{3 8}$ in PBS pH 7.4 in the presence of $50 \mu \mathrm{M} \mathrm{CuSO}_{4}, 500 \mu \mathrm{M} \mathrm{NaAsc}, 100 \mu \mathrm{M}$ His and $500 \mu \mathrm{M}$ aminoguanidine for $30 \mathrm{~min}$. In control experiments SH-SY5Y cells were not pretreated with azido-cholesterol before their incubation with $\mathbf{4}$ or with $\mathbf{3 8}$ under the same conditions. Cells were washed with PBS after the treatments and then incubated in fresh medium during the imaging. On the images fluorescein is green, mCherry is red and nuclei are blue, scale bars: $50 \mu \mathrm{m}$. 
Accordingly, the mCherry protein $C$-terminally derivatized with the fluorescent alkyne 4 was covalently attached to azido-cholesterol. Furthermore, the cholesterol moiety of the resulting cholesteryl mCherry lipoprotein was able to anchor the attached protein to the plasma membrane. The red fluorescence of the anchored mCherry protein also indicated that the cell surface cholesteryl lipoprotein formation did not denature the protein. Finally, the in vitro cytotoxicity of $\mathbf{4}$ and $\mathbf{3 8}$ was investigated in an MTT assay, and it was found that they exerted no cytotoxic effects under the conditions of the applied cell surface CuAAC reaction.

\section{Summary}

The main goal of this work was to develop simplified GPI mimetic lipids and to establish a method for their protein conjugation and for the exogenous introduction of the semisynthetic lipoproteins to the plasma membrane of live cells. The resulting lipidated proteins are useful tools to investigate membrane anchored proteins, which have important role in the maintenance of the normal life functions as well as in some diseases.

In order to achieve our goals, fluorescent cholesterol derivatives were designed and synthesized. The application of cholesterol as the membrane anchoring hydrophobic moiety of the GPI substitutes anticipates the direction of the protein conjugate to the cholesterol-rich lipid rafts, that is the accumulation platform of GPI-APs. In a convergent synthetic strategy propargyl glycine (Pra) was used as an orthogonal trifunctional linker to build up the headgroup of the cholesterol anchors, and separately, amphiphilic cholesterol derivatives were prepared from cholesteryl hemisuccinate and amino-oligo(ethylene glycol) azides. In order to obtain relevant GPI substitutes, the length of the polyether linker was chosen to be similar to that of the glycan core of the GPIs, because this hydrophilic moiety is responsible to expose the attached protein to the extracellular space. A fluorescent reporter and a Michael acceptor were introduced via the transformation of the amino and the carboxyl groups of Pra. The Michael acceptor was exploited for the conjugation with C-terminally Cys-extended proteins, while direct fluorescence microscopic studies of the membrane-associated cholesteryl lipoprotein conjugates required the small molecule fluorophores. Finally, the fluorescent anchors were assembled in an azide-alkyne cycloaddition.

The physicochemical properties of the cholesterol anchors were optimized by the 
introduction of three different fluorescent reporters (fluorescein, BODIPY and Cy5) with different polarities and spectral features. The usefulness of the anchors was estimated by fluorescence microscopic investigation of their capability to stain the plasma membrane of SH-SY5Y cells. The solubility of the cholesterol anchors in aqueous buffers was crucial both for the effective protein conjugation and for the exogenous introduction of the resulting cholesteryl lipoproteins into live cell membranes. It was found that the hydrophilic character of the fluorophore deeply affected the water solubility of the anchors, while increasing the length of the polar oligoether spacer had minor effect. The BODIPY-labelled cholesterol anchors exhibited the least solubility in polar solvents however homogeneous membrane staining was achieved when it was applied in a $\beta$-cyclodextrin inclusion complex. In the case of the fluorescein-labelled anchors homogeneous cell membrane staining was observed without the application of $\beta$-cyclodextrin when the phenol of the fluorescein moiety was converted into diisopropylammonium phenolate salt. However, the $\mathrm{pH}$ dependent fluorescence and the low photostability of fluorescein inspired us to consider the incorporation of sulfonated Cy5 which is highly polar and exceptionally bright. It was found that the Cy5-labelled cholesterol anchor resulted in an intensive homogeneous membrane staining at lower concentration than the fluorescein-labelled derivative.

Two different Michael acceptors, a maleimide and a vinylsulfone were investigated for the protein conjugation. Their reactivity and selectivity differs, that is important when proteins requiring different buffer conditions for solubilization are to be lipidated. The Michael additions were optimized by using a Cys-containing model peptide, and it was found that the maleimide was more reactive at lower $\mathrm{pH}$, while the vinylsulfone was more selective at higher $\mathrm{pH}$ toward the Cys thiol Michael donor.

Before the application of the anchors for protein cell membrane delivery, the hydrolytic stability of the headgroup was also investigated. The crucial cholesteryl ester was found to be stable against hydrolysis at physiological $\mathrm{pH}$. Furthermore, the membrane fluorescence remained constant during long-term incubation of the cell membrane incorporated fluorescent anchors suggesting that the headgroups of the anchors were not subjected to enzymatic hydrolysis.

The protein conjugation of the fluorescent anchors was investigated via Michael addition to the C-terminally Cys extended, recombinant mCherry-Cys protein. mCherry is a red 
fluorescent protein and its conjugation with a green fluorophore containing cholesterol anchor results in a dual fluorescent lipoprotein conjugate. When it is delivered into the cell membrane, the appearance of both red and green fluorescence on the plasma membrane are indicative of the successful membrane anchoring of the protein without significant change in the protein structure. The mCherry-Cys - cholesterol anchor addition resulted in a mixed micellar associate of the protein-anchor conjugate, because the amphiphilic cholesterol anchor dissolved in aqueous buffers in micellar form. A two-step purification method was then optimized to obtain cholesteryl-mCherry free of surplus anchor that included the application of $\beta$-cyclodextrin to disrupt the micellar associates. In the resulting $\beta$-cyclodextrin inclusion complex of cholesteryl mCherry, the lipid part of the conjugate remained soluble in cell culture media and the protein was not denatured. The purity of the dual fluorescent cholesteryl mCherry was evidenced by SDS-PAGE, and the preserved protein structure was revealed by CD spectroscopy. The confocal microscopy images, especially the colocalization of the green and red fluorescence confirmed that the mCherry protein was anchored to the plasma membrane of live cells via the green fluorescent cholesterol anchor.

The most investigated GPI anchored protein, prion protein (PrP) was chosen to be modified using the synthetic cholesterol anchors and to investigate if cholesteryl $\operatorname{PrP}$ derivatives are appropriate for cell membrane delivery. Therefore, the recombinant full length mouse PrP was conjugated to cholesterol anchors and after an optimized semisynthesis and purification, the introduction of the cholesteryl-mPrP into the plasma membrane of live neuroblastoma cells was achieved.

In order to quantitate the cell membrane delivered cholesteryl lipoproteins, a tritium labelled cholesterol anchor was prepared. Similarly to the fluorescent labelling, the radioactive reporter was introduced into the headgroup of the anchor. When SH-SY5Y cells were incubated with the $\left[{ }^{3} \mathrm{H}\right]$ cholesterol anchor, a concentration and time dependent membrane incorporation was observed.

In order to eliminate the cholesteryl lipoprotein purification steps from our strategy and to minimize the risk of the protein denaturation, an alternative convergent semisynthetic method was investigated. This method is a cell surface application of the CuAAC reaction including the conjugation of a maleimido fluorescent Pra linker to the protein C-terminus followed by a cycloaddition through the alkyne to an azido cholesterol pre-incorporated into the cell 
membrane. This way the target fluorescent cholesteryl lipoprotein was formed in situ on the surface of live cells. Similarly to the $\beta$-cyclodextrin-mediated membrane delivery, surplus detergents or unreacted fluorescent lipids were not introduced into the plasma membrane, and thus, the fluorescent signal is unambiguously associated with the cell surface-prepared cholesteryl lipoprotein. By using this method the red fluorescent protein, mCherry was successfully anchored to the plasma membrane of live cells without change of its fluorescent properties. The application of His and aminoguanidine as accelerator ligands protected live cells from the cytotoxic effects of the CuAAC catalyst components, and under these conditions the mCherry protein was not significantly denatured.

Altogether, in this thesis complete protein cell membrane anchoring strategies were developed for the structural and functional investigation of the cell membrane anchored $\operatorname{PrP}$ and other GPI-APs. 


\section{References}

1. M. S. Almén, K. J. Nordström, R. Fredriksson and H. B. Schiöth, BMC Biol, 2009, 7, 50 .

2. J. D. Morrisett, R. L. Jackson and A. M. Gotto, Annu Rev Biochem, 1975, 44, 183-207.

3. J. E. Smotrys and M. E. Linder, Annu Rev Biochem, 2004, 73, 559-587.

4. K. Huang and A. El-Husseini, Curr Opin Neurobiol, 2005, 15, 527-535.

5. P. J. Casey, Science, 1995, 268, 221-225.

6. M. A. Impagnatiello, S. Weitzer, G. Gannon, A. Compagni, M. Cotten and G. Christofori, J Cell Biol, 2001, 152, 1087-1098.

7. J. B. McCabe and L. G. Berthiaume, Mol Biol Cell, 1999, 10, 3771-3786.

8. A. 1.-D. el-Husseini and D. S. Bredt, Nat Rev Neurosci, 2002, 3, 791-802.

9. A. Krogh, B. Larsson, G. von Heijne and E. L. Sonnhammer, J Mol Biol, 2001, 305, 567-580.

10. G. von Heijne, Nat Rev Mol Cell Biol, 2006, 7, 909-918.

11. G. Karp, Cell and Molecular Biology: Concepts and Experiments, John Wiley and Sons, 2010.

12. J. E. Johnson and R. B. Cornell, Mol Membr Biol, 1999, 16, 217-235.

13. S. R. Goodman, Medical cell biology, 2008, Academic Press

14. D. S. Cafiso, Structure and interactions of $C 2$ domains at membrane surfaces, Wiley and Sons, 2005.

15. M. D. Resh, Nat Chem Biol, 2006, 2, 584-590.

16. H. C. Hang, J. P. Wilson and G. Charron, Acc Chem Res, 2011, 44, 699-708.

17. J. I. Gordon, R. J. Duronio, D. A. Rudnick, S. P. Adams and G. W. Gokel, J Biol Chem, 1991, 266, 8647-8650.

18. D. A. Towler, J. I. Gordon, S. P. Adams and L. Glaser, Annu Rev Biochem, 1988, 57, 69-99.

19. H. W. Fu and P. J. Casey, Recent Prog Horm Res, 1999, 54, 315-342; discussion 342313.

20. M. G. Low, Biochim Biophys Acta, 1989, 988, 427-454.

21. M. G. Low and A. R. Saltiel, Science, 1988, 239, 268-275.

22. P. T. Englund, Annu Rev Biochem, 1993, 62, 121-138.

23. M. G. Paulick and C. R. Bertozzi, Biochemistry, 2008, 47, 6991-7000.

24. M. A. Ferguson, J Cell Sci, 1999, 112 ( Pt 17), 2799-2809.

25. A. Tiede, I. Bastisch, J. Schubert, P. Orlean and R. E. Schmidt, Biol Chem, 1999, 380, 503-523.

26. O. Nosjean, A. Briolay and B. Roux, Biochim Biophys Acta, 1997, 1331, 153-186.

27. V. Savage and R. Brodsky, Hematology, 2006, 12, 371-376.

28. S. B. Prusiner, Proc Natl Acad Sci U S A, 1998, 95, 13363-13383.

29. P. Zhao, A. V. Nairn, S. Hester, K. W. Moremen, R. M. O'Regan, G. Oprea, L. Wells, M. Pierce and K. L. Abbott, J Biol Chem, 2012, 287, 25230-25240.

30. M. Nozaki, K. Ohishi, N. Yamada, T. Kinoshita, A. Nagy and J. Takeda, Lab Invest, 1999, 79, 293-299.

31. T. Kinoshita and M. Fujita, in The Enzymes, eds. A. Menon, T. Kinoshita, P. Orlean and E. Tamanoi, Academic Press, New York, 2009, vol. 26, pp. 1-30.

32. S. Chatterjee and S. Mayor, Cell Mol Life Sci, 2001, 58, 1969-1987. 
33. M. A. Ferguson, S. W. Homans, R. A. Dwek and T. W. Rademacher, Science, 1988, 239, 753-759.

34. S. W. Homans, M. A. Ferguson, R. A. Dwek, T. W. Rademacher, R. Anand and A. F. Williams, Nature, 1988, 333, 269-272.

35. H. Ikezawa, Biol Pharm Bull, 2002, 25, 409-417.

36. M. A. Deeg, D. R. Humphrey, S. H. Yang, T. R. Ferguson, V. N. Reinhold and T. L. Rosenberry, J Biol Chem, 1992, 267, 18573-18580.

37. I. A. Brewis, M. A. Ferguson, A. Mehlert, A. J. Turner and N. M. Hooper, J Biol Chem, 1995, 270, 22946-22956.

38. Y. Nakano, K. Noda, T. Endo, A. Kobata and M. Tomita, Arch Biochem Biophys, 1994, 311, 117-126.

39. R. Mukasa, M. Umeda, T. Endo, A. Kobata and K. Inoue, Arch Biochem Biophys, 1995, 318, 182-190.

40. T. Fontaine, T. Magnin, A. Melhert, D. Lamont, J. P. Latge and M. A. Ferguson, Glycobiology, 2003, 13, 169-177.

41. D. Oxley and A. Bacic, Proc Natl Acad Sci USA, 1999, 96, 14246-14251.

42. J. I. Macrae, A. Acosta-Serrano, N. A. Morrice, A. Mehlert and M. A. Ferguson, J Biol Chem, 2005, 280, 12201-12211.

43. M. J. McConville and M. A. Ferguson, Biochem J, 1993, 294 ( Pt 2), 305-324.

44. M. G. Low, FASEB J, 1989, 3, 1600-1608.

45. S. Mayor and H. Riezman, Nat Rev Mol Cell Biol, 2004, 5, 110-120.

46. C. Eggeling, C. Ringemann, R. Medda, G. Schwarzmann, K. Sandhoff, S. Polyakova, V. N. Belov, B. Hein, C. von Middendorff, A. Schönle and S. W. Hell, Nature, 2009, 457, 1159-1162.

47. K. Simons and M. J. Gerl, Nat Rev Mol Cell Biol, 2010, 11, 688-699.

48. D. Lingwood and K. Simons, Science, 2010, 327, 46-50.

49. L. Rajendran and K. Simons, J Cell Sci, 2005, 118, 1099-1102.

50. P. Sharma, R. Varma, R. C. Sarasij, Ira, K. Gousset, G. Krishnamoorthy, M. Rao and S. Mayor, Cell, 2004, 116, 577-589.

51. K. Simons and E. Ikonen, Nature, 1997, 387, 569-572.

52. K. Simons and D. Toomre, Nat Rev Mol Cell Biol, 2000, 1, 31-39.

53. S. Munro, Cell, 2003, 115, 377-388.

54. M. T. Lehto and F. J. Sharom, Biochemistry, 2002, 41, 8368-8376.

55. P. J. Robinson, Adv Exp Med Biol, 1997, 419, 365-370.

56. D. R. Jones and I. Varela-Nieto, Int J Biochem Cell Biol, 1998, 30, 313-326.

57. H. Fölsch, Curr Opin Cell Biol, 2008, 20, 208-213.

58. S. Schuck and K. Simons, J Cell Biol, 2006, 172, 963-965.

59. M. Conese, A. Nykjaer, C. M. Petersen, O. Cremona, R. Pardi, P. A. Andreasen, J. Gliemann, E. I. Christensen and F. Blasi, J Cell Biol, 1995, 131, 1609-1622.

60. C. J. Parkyn, E. G. Vermeulen, R. C. Mootoosamy, C. Sunyach, C. Jacobsen, C. Oxvig, S. Moestrup, Q. Liu, G. Bu, A. Jen and R. J. Morris, J Cell Sci, 2008, 121, 773 783.

61. D. R. Taylor and N. M. Hooper, Mol Membr Biol, 2006, 23, 89-99.

62. M. E. Medof, T. Kinoshita and V. Nussenzweig, J Exp Med, 1984, 160, 1558-1578.

63. C. W. van den Berg, T. Cinek, M. B. Hallett, V. Horejsi and B. P. Morgan, J Cell Biol, 1995, 131, 669-677.

64. M. E. Medof, S. Nagarajan and M. L. Tykocinski, FASEB J, 1996, 10, 574-586. 
65. D. R. Premkumar, Y. Fukuoka, D. Sevlever, E. Brunschwig, T. L. Rosenberry, M. L. Tykocinski and M. E. Medof, J Cell Biochem, 2001, 82, 234-245.

66. P. E. Milhiet, M. C. Giocondi, O. Baghdadi, F. Ronzon, B. Roux and C. Le Grimellec, EMBO Rep, 2002, 3, 485-490.

67. M. R. Rifkin and F. R. Landsberger, Proc Natl Acad Sci U S A, 1990, 87, 801-805.

68. D. E. Dunn, J. Yu, S. Nagarajan, M. Devetten, F. F. Weichold, M. E. Medof, N. S. Young and J. M. Liu, Proc Natl Acad Sci U S A, 1996, 93, 7938-7943.

69. C. Metzner, M. M. Mostegl, W. H. Günzburg, B. Salmons and J. A. Dangerfield, FASEB J, 2008, 22, 2734-2739.

70. C. Metzner, F. Kochan and J. A. Dangerfield, Mol Biotechnol, 2013, 53, 9-18.

71. G. Civenni, S. T. Test, U. Brodbeck and P. Bütikofer, Blood, 1998, 91, 1784-1792.

72. T. Liu, R. Li, T. Pan, D. Liu, R. B. Petersen, B. S. Wong, P. Gambetti and M. S. Sy, J Biol Chem, 2002, 277, 47671-47678.

73. E. M. Sloand, L. Mainwaring, K. Keyvanfar, J. Chen, J. Maciejewski, H. G. Klein and N. S. Young, Blood, 2004, 104, 3782-3788.

74. C. Metzner, B. Salmons, W. H. Günzburg and J. A. Dangerfield, Virology, 2008, 382, 125-131.

75. C. Bate and A. Williams, J Biol Chem, 2011, 286, 8752-8758.

76. R. Djafarzadeh, C. Conrad, S. Notohamiprodjo, S. Hipp, H. Niess, C. J. Bruns and P. J. Nelson, Wound Repair Regen, 2014, 22, 70-76.

77. N. Stahl, D. R. Borchelt, K. Hsiao and S. B. Prusiner, Cell, 1987, 51, 229-240.

78. J. Collinge, Annu Rev Neurosci, 2001, 24, 519-550.

79. B. Chesebro, M. Trifilo, R. Race, K. Meade-White, C. Teng, R. LaCasse, L. Raymond, C. Favara, G. Baron, S. Priola, B. Caughey, E. Masliah and M. Oldstone, Science, 2005, 308, 1435-1439.

80. B. Caughey and P. T. Lansbury, Annu Rev Neurosci, 2003, 26, 267-298.

81. M. B. Pepys, Philos Trans R Soc Lond B Biol Sci, 2001, 356, 203-210; discussion 210201.

82. J. P. Cleary, D. M. Walsh, J. J. Hofmeister, G. M. Shankar, M. A. Kuskowski, D. J. Selkoe and K. H. Ashe, Nat Neurosci, 2005, 8, 79-84.

83. B. Chesebro, R. Race, K. Wehrly, J. Nishio, M. Bloom, D. Lechner, S. Bergstrom, K. Robbins, L. Mayer and J. M. Keith, Nature, 1985, 315, 331-333.

84. H. Büeler, A. Aguzzi, A. Sailer, R. A. Greiner, P. Autenried, M. Aguet and C. Weissmann, Cell, 1993, 73, 1339-1347.

85. R. Zahn, A. Liu, T. Lührs, R. Riek, C. von Schroetter, F. López García, M. Billeter, L. Calzolai, G. Wider and K. Wüthrich, Proc Natl Acad Sci U S A, 2000, 97, 145-150.

86. K. M. Pan, M. Baldwin, J. Nguyen, M. Gasset, A. Serban, D. Groth, I. Mehlhorn, Z. Huang, R. J. Fletterick and F. E. Cohen, Proc Natl Acad Sci U S A, 1993, 90, 1096210966.

87. N. Stahl and S. B. Prusiner, FASEB J, 1991, 5, 2799-2807.

88. A. Aguzzi, Science, 2005, 308, 1420-1421.

89. A. Taraboulos, M. Scott, A. Semenov, D. Avrahami, L. Laszlo, S. B. Prusiner and D. Avraham, J Cell Biol, 1995, 129, 121-132.

90. K. Kaneko, M. Vey, M. Scott, S. Pilkuhn, F. E. Cohen and S. B. Prusiner, Proc Natl Acad Sci U S A, 1997, 94, 2333-2338.

91. G. S. Baron, K. Wehrly, D. W. Dorward, B. Chesebro and B. Caughey, EMBO J, 2002, 21, 1031-1040. 
92. G. S. Baron and B. Caughey, J Biol Chem, 2003, 278, 14883-14892.

93. H. Eberl, P. Tittmann and R. Glockshuber, J Biol Chem, 2004, 279, 25058-25065.

94. M. R. Hicks, A. C. Gill, I. K. Bath, A. K. Rullay, I. D. Sylvester, D. H. Crout and T. J. Pinheiro, FEBS J, 2006, 273, 1285-1299.

95. M. Marella, S. Lehmann, J. Grassi and J. Chabry, J Biol Chem, 2002, 277, 2545725464.

96. C. Bate, M. Salmona, L. Diomede and A. Williams, J Biol Chem, 2004, 279, 14983 14990.

97. S. A. Priola and K. L. McNally, Prion, 2009, 3, 134-138.

98. A. Aguzzi and F. L. Heppner, Cell Death Differ, 2000, 7, 889-902.

99. S. A. Priola and I. Vorberg, Lancet, 2004, 363, 2013-2014.

100. L. Breydo, Y. Sun, N. Makarava, C. I. Lee, V. Novitskaia, O. Bocharova, J. P. Kao and I. V. Baskakov, Biochemistry, 2007, 46, 852-861.

101. D. Olschewski, R. Seidel, M. Miesbauer, A. S. Rambold, D. Oesterhelt, K. F. Winklhofer, J. Tatzelt, M. Engelhard and C. F. Becker, Chem Biol, 2007, 14, 9941006.

102. J. R. Thomas, R. A. Dwek and T. W. Rademacher, Biochemistry, 1990, 29, 54135422.

103. C. F. Becker, X. Liu, D. Olschewski, R. Castelli, R. Seidel and P. H. Seeberger, Angew Chem Int Ed Engl, 2008, 47, 8215-8219.

104. Y. H. Tsai, S. Götze, N. Azzouz, H. S. Hahm, P. H. Seeberger and D. Varon Silva, Angew Chem Int Ed Engl, 2011, 50, 9961-9964.

105. H. L. Ball, D. S. King, F. E. Cohen, S. B. Prusiner and M. A. Baldwin, J Pept Res, 2001, 58, 357-374.

106. H. J. Musiol, S. Dong, M. Kaiser, R. Bausinger, A. Zumbusch, U. Bertsch and L. Moroder, Chembiochem, 2005, 6, 625-628.

107. M. J. Grogan, Y. Kaizuka, R. M. Conrad, J. T. Groves and C. R. Bertozzi, J Am Chem Soc, 2005, 127, 14383-14387.

108. M. G. Paulick, A. R. Wise, M. B. Forstner, J. T. Groves and C. R. Bertozzi, J Am Chem Soc, 2007, 129, 11543-11550.

109. K. Teruya, K. Nishizawa and K. Doh-ura, Protein J, 2010, 29, 493-500.

110. M. G. Paulick, M. B. Forstner, J. T. Groves and C. R. Bertozzi, Proc Natl Acad Sci U $S A, 2007,104,20332-20337$.

111. B. Schäfer, E. Orbán, A. Borics, K. Huszár, A. Nyeste, E. Welker and C. Tömböly, Bioconjug Chem, 2013, 24, 1684-1697.

112. J. A. Porter, K. E. Young and P. A. Beachy, Science, 1996, 274, 255-259.

113. R. K. Mann and P. A. Beachy, Annu Rev Biochem, 2004, 73, 891-923.

114. A. Rietveld, S. Neutz, K. Simons and S. Eaton, J Biol Chem, 1999, 274, 12049-12054.

115. J. Taipale, J. K. Chen, M. K. Cooper, B. Wang, R. K. Mann, L. Milenkovic, M. P. Scott and P. A. Beachy, Nature, 2000, 406, 1005-1009.

116. C. Peters, A. Wolf, M. Wagner, J. Kuhlmann and H. Waldmann, Proc Natl Acad Sci U $S$ A, 2004, 101, 8531-8536.

117. S. L. Hussey, E. He and B. R. Peterson, J Am Chem Soc, 2001, 123, 12712-12713.

118. S. L. Hussey and B. R. Peterson, J Am Chem Soc, 2002, 124, 6265-6273.

119. S. E. Martin and B. R. Peterson, Bioconjug Chem, 2003, 14, 67-74.

120. S. Boonyarattanakalin, S. E. Martin, S. A. Dykstra and B. R. Peterson, J Am Chem Soc, 2004, 126, 16379-16386. 
121. S. Boonyarattanakalin, S. E. Martin, Q. Sun and B. R. Peterson, J Am Chem Soc, 2006, 128, 11463-11470.

122. S. Tomas and L. Milanesi, J Am Chem Soc, 2009, 131, 6618-6623.

123. S. Tomas and L. Milanesi, Nat Chem, 2010, 2, 1077-1083.

124. C. W. Tornøe, C. Christensen and M. Meldal, J Org Chem, 2002, 67, 3057-3064.

125. V. V. Rostovtsev, L. G. Green, V. V. Fokin and K. B. Sharpless, Angew Chem Int Ed Engl, 2002, 41, 2596-2599.

126. E. M. Sletten and C. R. Bertozzi, Angew Chem Int Ed Engl, 2009, 48, 6974-6998.

127. V. Hong, N. F. Steinmetz, M. Manchester and M. G. Finn, Bioconjug Chem, 2010, 21, 1912-1916.

128. C. Uttamapinant, A. Tangpeerachaikul, S. Grecian, S. Clarke, U. Singh, P. Slade, K.

R. Gee and A. Y. Ting, Angew Chem Int Ed Engl, 2012, 51, 5852-5856.

129. V. Hong, S. I. Presolski, C. Ma and M. G. Finn, Angew Chem Int Ed Engl, 2009, 48, 9879-9883.

130. S. I. Presolski, V. P. Hong and M. G. Finn, Curr Protoc Chem Biol, 2011, 3, 153-162.

131. E. Lallana, R. Riguera and E. Fernandez-Megia, Angew Chem Int Ed Engl, 2011, 50, 8794-8804.

132. N. J. Agard, J. A. Prescher and C. R. Bertozzi, J Am Chem Soc, 2004, 126, 1504615047.

133. Q. Zeng, T. Li, B. Cash, S. Li, F. Xie and Q. Wang, Chem Commun (Camb), 2007, 1453-1455.

134. S. Schoffelen, M. H. Lambermon, M. B. van Eldijk and J. C. van Hest, Bioconjug Chem, 2008, 19, 1127-1131.

135. M. R. Levengood, C. C. Kerwood, C. Chatterjee and W. A. van der Donk, Chembiochem, 2009, 10, 911-919.

136. R. H. Nagaraj, D. R. Sell, M. Prabhakaram, B. J. Ortwerth and V. M. Monnier, Proc Natl Acad Sci U S A, 1991, 88, 10257-10261.

137. H. C. Kolb, M. G. Finn and K. B. Sharpless, Angew Chem Int Ed Engl, 2001, 40, 2004-2021.

138. S. C. Fry, Biochem J, 1998, 332 ( Pt 2), 507-515.

139. A. E. Speers, G. C. Adam and B. F. Cravatt, J Am Chem Soc, 2003, 125, 4686-4687.

140. P. S. Ghosh and A. D. Hamilton, J Am Chem Soc, 2012, 134, 13208-13211.

141. R. Bonnet, P. Murat, N. Spinelli and E. Defrancq, Chem Commun (Camb), 2012, 48, 5992-5994.

142. H. Ban, M. Nagano, J. Gavrilyuk, W. Hakamata, T. Inokuma and C. F. Barbas, Bioconjug Chem, 2013, 24, 520-532.

143. H. T. Le, J. G. Jang, J. Y. Park, C. W. Lim and T. W. Kim, Anal Biochem, 2013, 435, 68-73.

144. H. Rao, A. A. Sawant, A. A. Tanpure and S. G. Srivatsan, Chem Commun (Camb), 2012, 48, 498-500.

145. Q. Shen, S. Tang, W. Li, Z. Nie, Z. Liu, Y. Huang and S. Yao, Chem Commun (Camb), 2012, 48, 281-283.

146. W. Wang, S. Hong, A. Tran, H. Jiang, R. Triano, Y. Liu, X. Chen and P. Wu, Chem Asian J, 2011, 6, 2796-2802.

147. D. Soriano Del Amo, W. Wang, H. Jiang, C. Besanceney, A. C. Yan, M. Levy, Y. Liu, F. L. Marlow and P. Wu, J Am Chem Soc, 2010, 132, 16893-16899.

148. E. R. Stadtman and B. S. Berlett, Drug Metab Rev, 1998, 30, 225-243. 
149. A. Kumar, K. Li and C. Cai, Chem Commun (Camb), 2011, 47, 3186-3188.

150. S. Sen Gupta, J. Kuzelka, P. Singh, W. G. Lewis, M. Manchester and M. G. Finn, Bioconjug Chem, 2005, 16, 1572-1579.

151. C. Besanceney-Webler, H. Jiang, T. Zheng, L. Feng, D. Soriano del Amo, W. Wang, L. M. Klivansky, F. L. Marlow, Y. Liu and P. Wu, Angew Chem Int Ed Engl, 2011, 50, 8051-8056.

152. S. I. Presolski, V. Hong, S. H. Cho and M. G. Finn, J Am Chem Soc, 2010, 132, 14570-14576.

153. V. Bevilacqua, M. King, M. Chaumontet, M. Nothisen, S. Gabillet, D. Buisson, C. Puente, A. Wagner and F. Taran, Angew Chem Int Ed Engl, 2014, 53, 5872-5876.

154. D. C. Kennedy, C. S. McKay, M. C. Legault, D. C. Danielson, J. A. Blake, A. F. Pegoraro, A. Stolow, Z. Mester and J. P. Pezacki, J Am Chem Soc, 2011, 133, $17993-$ 18001.

155. J. C. Jewett, E. M. Sletten and C. R. Bertozzi, J Am Chem Soc, 2010, 132, 3688-3690.

156. J. A. Codelli, J. M. Baskin, N. J. Agard and C. R. Bertozzi, J Am Chem Soc, 2008, 130, 11486-11493.

157. N. J. Agard, J. M. Baskin, J. A. Prescher, A. Lo and C. R. Bertozzi, ACS Chem Biol, 2006, 1, 644-648.

158. J. M. Baskin, J. A. Prescher, S. T. Laughlin, N. J. Agard, P. V. Chang, I. A. Miller, A. Lo, J. A. Codelli and C. R. Bertozzi, Proc Natl Acad Sci U S A, 2007, 104, 1679316797.

159. E. M. Sletten and C. R. Bertozzi, Org Lett, 2008, 10, 3097-3099.

160. P. V. Chang, J. A. Prescher, E. M. Sletten, J. M. Baskin, I. A. Miller, N. J. Agard, A. Lo and C. R. Bertozzi, Proc Natl Acad Sci U S A, 2010, 107, 1821-1826.

161. Z. Hao, S. Hong, X. Chen and P. R. Chen, Acc Chem Res, 2011, 44, 742-751.

162. J. M. Baskin, K. W. Dehnert, S. T. Laughlin, S. L. Amacher and C. R. Bertozzi, Proc Natl Acad Sci US A, 2010, 107, 10360-10365.

163. P. V. Chang, D. H. Dube, E. M. Sletten and C. R. Bertozzi, J Am Chem Soc, 2010, 132, 9516-9518.

164. S. T. Laughlin, J. M. Baskin, S. L. Amacher and C. R. Bertozzi, Science, 2008, 320, 664-667.

165. J. H. Viles, F. E. Cohen, S. B. Prusiner, D. B. Goodin, P. E. Wright and H. J. Dyson, Proc Natl Acad Sci U S A, 1999, 96, 2042-2047.

166. N. K. Devaraj, R. Weissleder and S. A. Hilderbrand, Bioconjug Chem, 2008, 19, $2297-$ 2299.

167. A. D. de Araújo, J. M. Palomo, J. Cramer, O. Seitz, K. Alexandrov and H. Waldmann, Chemistry, 2006, 12, 6095-6109.

168. X. L. Sun, L. Yang and E. L. Chaikof, Tetrahedron Lett, 2008, 49, 2510-2513.

169. V. Steven and D. Graham, Org Biomol Chem, 2008, 6, 3781-3787.

170. M. Yang, J. Li and P. R. Chen, Chem Soc Rev, 2014, 43, 6511-6526.

171. T. Fäcke and S. Berger, Tetrahedron, 1995, 51, 3521-3524.

172. M. M. Bradford, Anal Biochem, 1976, 72, 248-254.

173. N. Sreerama and R. Woody, Circular Dichroism of Peptides and Proteins, John Wiley and Sons, 2000.

174. P. E. Dawson, T. W. Muir, I. Clark-Lewis and S. B. Kent, Science, 1994, 266, 776779. 
175. A. E. Christian, M. P. Haynes, M. C. Phillips and G. H. Rothblat, J Lipid Res, 1997, 38, 2264-2272.

176. A. Tsamaloukas, H. Szadkowska, P. J. Slotte and H. Heerklotz, Biophys J, 2005, 89, 1109-1119.

177. P. Wallimann, T. Marti, A. Fürer and F. Diederich, Chem Rev, 1997, 97, 1567-1608.

178. J. Nishijo, S. Moriyama and S. Shiota, Chem Pharm Bull (Tokyo), 2003, 51, 1253 1257.

179. E. P. Kilsdonk, P. G. Yancey, G. W. Stoudt, F. W. Bangerter, W. J. Johnson, M. C. Phillips and G. H. Rothblat, J Biol Chem, 1995, 270, 17250-17256.

180. S. L. Niu and B. J. Litman, Biophys J, 2002, 83, 3408-3415.

181. M. M. Martin and L. Lindqvist, Journal of Luminescence, 1975, 10, 381-390.

182. S. Chatani, D. P. Nair and C. N. Bowman, Polymer Chemistry, 2013, 4.

183. F. J. Lopez-Jaramillo, F. Hernandez-Mateo and F. Santoyo-Gonzalez, in Integrative Proteomics, ed. D. H.-C. Leung, 2012.

184. K. Simons and E. Ikonen, Science, 2000, 290, 1721-1726.

185. M. A. Wall, M. Socolich and R. Ranganathan, Nat Struct Biol, 2000, 7, 1133-1138.

186. R. M. Wachter, J. L. Watkins and H. Kim, Biochemistry, 2010, 49, 7417-7427.

187. W. Kabsch and C. Sander, Biopolymers, 1983, 22, 2577-2637.

188. D. Frishman and P. Argos, Proteins, 1995, 23, 566-579.

189. H. A. Scheidt, P. Muller, A. Herrmann and D. Huster, J Biol Chem, 2003, 278, 4556345569.

190. B. Schäfer, E. Orbán, Z. Kele and C. Tömböly, J Labelled Comp Radiopharm, 2015, 58, 7-13.

191. R. Leventis and J. R. Silvius, Biophys J, 2001, 81, 2257-2267. 


\section{Acknowledgements}

I am grateful to my supervisor, Dr. Csaba Tömböly for giving me an opportunity to acquire all the practical and theoretical skills that were required to perform this work, for his guidance and valuable suggestions.

I am so grateful Dr. Erika Orbán for confocal microscopy studies and for helping me in scientific writing. I thank Mariann Majer for the protein expressions and purifications, and Antal Nyeste and Krisztina Huszár for the plasmids DNAs.

Many thanks to the technician, Éva Papp Tóthné, for her help in the laboratory work. Dr. Attila Borics is ancknowledge for the molecular dynamic simulations and ECD spectroscopy measurements.

I am grateful to Dr. Zsuzsanna Darula, Dr. Éva Hunyadi-Gulyás, Dr. Éva Klement, Dr. Hajnalka Dürgö and Dr. Zoltán Kele for the mass spectrometry analysis of my compounds.

Thanks to Gabriella Fiser and Dorka Németh for their work on this project and I am also grateful to Dr. GézaTóth, Dr. Judit Farkas, Dr. Attila Keresztes for their valuable advices and to Jánosné Bencze and Angéla Ajtai technical assistance.

The financial support provided by the University of Szeged for me to take part in the Ph.D. program is also gratefully acknowledged.

Finally, my special thanks are due to my wife and family for their patience and for all of their support. 
8. Appendices: Off-prints of thesis related publications 
Schäfer B., Orbán E., Borics A., Huszár K., Nyeste A., Welker E. and Tömböly Cs. (2013) Preparation of Semisynthetic Lipoproteins with Fluorescent Cholesterol Anchor and Their Introduction to the Cell Membrane with Minimal Disruption of the Membrane. Bioconjugate Chemistry 24, 1684-1697. 


\title{
Preparation of Semisynthetic Lipoproteins with Fluorescent Cholesterol Anchor and Their Introduction to the Cell Membrane with Minimal Disruption of the Membrane
}

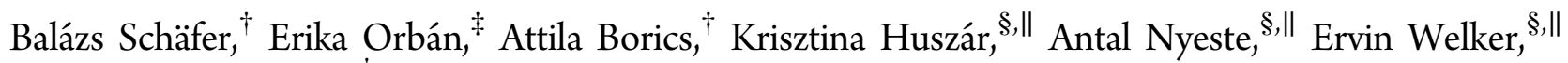 \\ and Csaba Tömböly* ${ }^{\dagger}$
}

\begin{abstract}
${ }^{\dagger}$ Laboratory of Chemical Biology and ${ }^{\S}$ Laboratory of Conformational Diseases, Institute of Biochemistry, Biological Research Centre of the Hungarian Academy of Sciences, Temesvári krt. 62., 6726 Szeged, Hungary

${ }^{\ddagger}$ Research Group of Peptide Chemistry, Hungarian Academy of Sciences, Pázmány Péter sétány 1/a, 1117 Budapest, Hungary

"Institute of Molecular Pharmacology, Research Centre of Natural Sciences, Hungarian Academy of Sciences, Diószegi út $64 ., 1113$ Budapest, Hungary
\end{abstract}

\section{Supporting Information}

ABSTRACT: The exogenous introduction of fluorescent lipoproteins into cell membranes is a method for visualizing the cellular traffic of membrane associated proteins, and also for altering the cell surface in a controlled manner. In order to achieve the cell membrane anchoring of proteins and their subsequent fluorescence based detection, a cholesterol derivative was designed. The headgroup of the novel cholesterol anchor contains a fluorescent reporter and a thiol reactive maleimide for protein conjugation. Protein conjugation was demonstrated by the addition of a green fluorescent maleimido anchor to the C-terminus of a Cys extended red fluorescent protein, mCherry. The resulting dual fluorescent cholesteryl lipoprotein was successfully separated from the

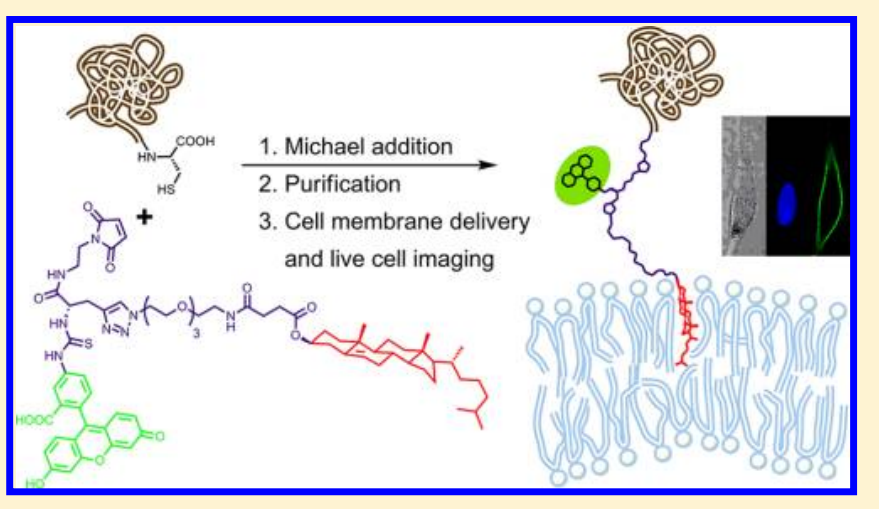
micellar associates of the surplus fluorescent lipid anchor without denaturing the protein, and the lipoprotein containing only the covalently linked, stoichiometric fluorescent lipid was efficiently delivered to the plasma membrane of live cells. It was demonstrated that the membrane fluorescence could be directly assigned to the protein-anchor conjugate, because no excess of fluorescent lipid species were present during the imaging experiment and the protein and anchor fluorescence colocalized in the cell membrane. Molecular dynamics simulations and subsequent trajectory analysis suggest also the spontaneous and stable membrane association of the cholesterol anchor. Thus, the method could be beneficially applied for studying membrane associated proteins and for preparing mimetics of glycosylphosphatidylinositol (GPI)-anchored proteins to target cholesterol-rich membrane microdomains.

\section{INTRODUCTION}

Lipidation plays an important role in the localization and function of proteins. Four common modifications of proteins with lipid moieties are myristoylation, palmitoylation, prenylation, and the attachment of glycosylphosphatidylinositol (GPI) anchors. $^{1-6}$ The amidation of the protein C-terminus with a GPI glycolipid results in proteins tethered to the extracellular leaflet of the cell membrane. ${ }^{7-9}$ This modification is widespread throughout eukaryotes, and more than 150 human GPIanchored proteins (GPI-APs) are known with various functions: enzymes, receptors, complement regulation proteins, antigens, or adhesion molecules. ${ }^{10}$ Beyond the normal physiological functions, GPI-APs are associated with a range of diseases including paroxysmal nocturnal hemoglobinuria, prion diseases, carcinogenesis, and sleeping sickness. ${ }^{11-14}$ The important functional role of the GPI-APs is further evidenced by the embryonic lethality of the GPI-deficient mice. ${ }^{15}$ The
GPI glycolipids have the conserved $\operatorname{Man}(\alpha 1-2) \operatorname{Man}(\alpha 1-$ 6) Man $(\alpha 1-4) \mathrm{GlcN}(\alpha 1-6) m y o$ Ino glycan core and variations arise in the substitution pattern and in the lipid composition. ${ }^{10,16}$ The lipid part of the mammalian GPIs is phosphatidylinositol with stearyl chains; therefore, the GPIAPs are able to temporarily associate with sphingolipid- and cholesterol-rich membrane microdomains, i.e., lipid rafts. ${ }^{7,16-21}$ This clustering is mainly due to the favorable hydrophobic interactions between the saturated acyl chains of the GPI anchor and the lipid constituents of the rafts. ${ }^{77}$ It was evidenced that the lipid raft association of the GPI-APs could be abrogated by cholesterol depletion of the cell membrane and by replacing the GPI moiety with a transmembrane anchor. ${ }^{22}$

Received: April 24, 2013

Revised: September 4, 2013

Published: September 10, 2013 
The accumulation of the GPI-APs in lipid rafts may serve as platforms for diverse cellular functions (e.g., signal transduction) by promoting protein-protein interactions. ${ }^{23,24}$ Beyond the membrane anchoring, other biological functions of the GPIs associated with the carbohydrate moiety are rather unknown, partly because the complexity of the GPIs restricts the preparation of GPI-AP derivatives for structural and functional studies. However, a few studies have been published on the semisynthesis of proteins with simplified anchors, and on their subsequent delivery to membrane structures, ${ }^{25-34}$ and it was shown that the removal of the carbohydrate moiety or its truncation does not interfere with the anchoring function of the GPI. $^{35}$

An important feature of the GPI-APs is that they spontaneously reintegrate into model lipid membranes, or live cell membranes with the retention of the biological function. ${ }^{36-44}$ This property of the GPI-APs may be exploited for structural and functional studies, because semisynthetic lipoproteins containing GPI anchor mimetic lipids can also be introduced into cell membranes by exogenous addition. Since cholesterol prefers the interaction with sphingolipids in the cell membrane, it has the potential to target the attached protein to lipid rafts. ${ }^{20,21}$ This type of lipid anchor is found in the matured $\mathrm{Hh}$ and Shh proteins of the hedgehog family as a C-terminal cholesteryl ester. ${ }^{45-48}$ Furthermore, in the case of a semisynthetic peptidyl cholesterol-Ras protein conjugate, cholesterol was reported to anchor the conjugated protein to the cell membrane. ${ }^{49}$ Other cholesterol derivatives, such as $3 \beta$ cholesterylamine and $3 \beta$-cholesterylcarbamate, were also reported as membrane anchors of artificial membrane receptors. ${ }^{50-56}$

Here, we report on the development of a fluorescent cholesterol anchor as a GPI mimetic, and on its insertion into the plasma membrane of live cells. Fluorescent labeling is generally required when the cellular traffic of a membrane protein is to be monitored, and that is usually achieved by fusion of a fluorescent reporter protein to the target protein. However, the size of the reporter protein is frequently comparable to that of the target protein, and it can perturb the biophysical and biochemical characteristics of the target protein. In order to avoid this drawback, our approach utilizes a small molecule fluorophore for facilitating the imaging of membrane anchored proteins. The fluorescent reporter is introduced into the headgroup of the membrane anchor; therefore, its interference with the lipid chains in the cell membrane is unlikely. Furthermore, it might have minimal effect on protein-protein interactions between the membrane anchored protein and other cell surface proteins. This anchor was used for the semisynthesis of a cholesteryl lipoprotein to demonstrate the usefulness of this protein lipidation approach. Before imaging applications, the separation of the semisynthetic fluorescent lipoprotein from the micellar associates of the amphiphilic fluorescent lipids without denaturing the native fold of the protein is a crucial step. When it is achieved, the fluorescence of the cholesterol anchor can be unambiguously assigned to the attached protein, and thus, the protein can be visualized after cell membrane delivery of the semisynthetic construct. On the whole, our method can be utilized for imaging the cellular traffic of lipoproteins and also for investigating protein-protein interactions on the cell surface.

\section{EXPERIMENTAL SECTION}

Synthesis of the Cholesterol Probe. Cholesteryl 1(Triphenylmethylamino)-15-oxo-4,7,10-trioxa-14-azaoctadecan-18-oate (1). Cholesteryl hemisuccinate $(150 \mathrm{mg}, 0.31$ $\mathrm{mmol})$ and TBTU (100 mg, $0.31 \mathrm{mmol})$ were dissolved in 10 $\mathrm{mL}$ of $\mathrm{CHCl}_{3} / \mathrm{CH}_{2} \mathrm{Cl}_{2}(4: 1)$, and DIEA $(68 \mu \mathrm{L}, 0.40 \mathrm{mmol})$ was added. After $5 \mathrm{~min}$ activation 1-(triphenylmethylamino)13-amino-4,7,10-trioxa-tridecane (143 $\mathrm{mg}, 0.31 \mathrm{mmol}$ ) was added to the solution. The mixture was stirred for $8 \mathrm{~h}$ at RT, then it was evaporated in vacuo. The crude product was purified by column chromatography $\left(\mathrm{CHCl}_{3} / \mathrm{MeOH}\right.$ (99:1)) to give $274.6 \mathrm{mg}(95 \%)$ of 1 as a white solid. $\mathrm{R}_{\mathrm{f}} 0.5\left(\mathrm{CHCl}_{3} /\right.$ $\mathrm{MeOH}=99: 1) ; \mathrm{k}^{\prime}=4.63\left(\mathrm{t}_{\mathrm{R}}=20.05 \mathrm{~min}\right.$; Alltech Alltima HP C18 column $(250 \times 4.6 \mathrm{~mm}, 5 \mu \mathrm{m})$, isocratic elution with $\mathrm{ACN} / \mathrm{MeOH} 15: 85$, flow rate: $1 \mathrm{~mL} / \mathrm{min}, \lambda=215 \mathrm{~nm}) ;[\alpha]_{\mathrm{D}}{ }^{20}$ $=-10.0\left(c=1.1, \mathrm{CHCl}_{3}\right) ;{ }^{1} \mathrm{H}$ NMR $\left(500 \mathrm{MHz}, \mathrm{CDCl}_{3}\right) \delta 7.47$ $(\mathrm{d}, 6 \mathrm{H}, J=7.5 \mathrm{~Hz}$, Trt- $o-\mathrm{H}), 7.26(\mathrm{t}, 6 \mathrm{H}, J=7.5 \mathrm{~Hz}$, Trt- $m-\mathrm{H})$, $7.17(\mathrm{t}, 3 \mathrm{H}, J=7.2 \mathrm{~Hz}$, Trt- $p-\mathrm{H}), 6.31(\mathrm{t}, 1 \mathrm{H}, J=5.0 \mathrm{~Hz}$, amide $\mathrm{NH}), 5.36(\mathrm{~d}, 1 \mathrm{H}, J=3.0 \mathrm{~Hz}, 6-\mathrm{H}), 4.60(\mathrm{~m}, 1 \mathrm{H}, 3 \alpha-\mathrm{H}), 3.57$ (m, 12H, 34-H, 35-H, 36-H, 37-H, 38-H, 39-H), 3.35 (q, 2H, J $=5.8 \mathrm{~Hz}, 32-\mathrm{H}),[2.61(\mathrm{t}, 2 \mathrm{H}, J=6.9 \mathrm{~Hz}), 2.42(\mathrm{t}, 2 \mathrm{H}, J=6.9$ $\mathrm{Hz})](29-\mathrm{H}, 30-\mathrm{H}), 2.31$ (d, 2H, J = 7.8 Hz, 4-H), $2.22(\mathrm{t}, 2 \mathrm{H}, J$ $=5.5 \mathrm{~Hz}, 41-\mathrm{H}), 2.01(\mathrm{~m}, 1 \mathrm{H}, 12 \beta-\mathrm{H}), 1.98(\mathrm{~m}, 1 \mathrm{H}, 7 \beta-\mathrm{H})$, $1.84(\mathrm{~m}, 3 \mathrm{H},(1 \beta-\mathrm{H}, 2 \alpha-\mathrm{H}, 16 \alpha-\mathrm{H})), 1.76(\mathrm{~m}, 4 \mathrm{H}, 33-\mathrm{H}, 40-$ $\mathrm{H}),[1.64-1.04(\mathrm{~m}, 18 \mathrm{H}): 2 \beta-\mathrm{H}, 12 \alpha-\mathrm{H}, 15 \alpha / \beta-\mathrm{H}, 1.55(7 \alpha-$ $\mathrm{H}), 1.52(25-\mathrm{H}), 1.46(11 \alpha / \beta-\mathrm{H}), 1.42(8 \beta-\mathrm{H}), 1.35(23-\mathrm{H})$, $1.33(20-\mathrm{H}, 22-\mathrm{H}), 1.23(16 \beta-\mathrm{H}), 1.18\left(23-\mathrm{H}^{\prime}\right),(1.14,1.09)$ $\left.(1 \alpha-\mathrm{H}, 17 \alpha-\mathrm{H}), \quad 1.12\left(24-\mathrm{H}_{2}\right)\right],[1.04-0.90(\mathrm{~m}, 3 \mathrm{H}): 0.96$ $\left.\left(14 \alpha-\mathrm{H}, 22-\mathrm{H}^{\prime}\right), 0.92(9 \alpha-\mathrm{H})\right], 1.01(\mathrm{~s}, 3 \mathrm{H}, 19-\mathrm{H}), 0.92(\mathrm{~d}, 3 \mathrm{H}$, $J=6.3 \mathrm{~Hz}, 21-\mathrm{H}),[0.88(\mathrm{~d}, 3 \mathrm{H}, J=1.5 \mathrm{~Hz}), 0.86(\mathrm{~d}, 3 \mathrm{H}, J=$ $1.5 \mathrm{~Hz})](26-\mathrm{H}, 27-\mathrm{H}), 0.68(\mathrm{~s}, 3 \mathrm{H}, 18-\mathrm{H}) ;{ }^{13} \mathrm{C}$ NMR $(125$ $\left.\mathrm{MHz}, \mathrm{CDCl}_{3}\right) \delta 172.5$ (ester CO), 171.4 (amide CO), 146.4 $(\mathrm{Ph} \mathrm{C}), 139.7(\mathrm{C}-5), 128.8(\mathrm{Ph} o-\mathrm{CH}), 127.9(\mathrm{Ph} m-\mathrm{CH})$, $126.3(\mathrm{Ph} p-\mathrm{CH}), 122.7$ (C-6), $74.3(\mathrm{C}-3), 71.0\left(\underline{\mathrm{CPh}}_{3}\right),[70.7$ (2C), 70.4, 70.2 (3C)] (C-34, C-35, C-36, C-37, C-38, C-39), (56.8, 56.3) (C-14, C-17), 50.2 (C-9), 42.4 (C-13), 41.1 (C41), 39.9 (C-12), 39.6 (C-24), 38.2 (2C, C-4, C-32), 37.1 (C1), 36.7 (C-10), 36.3 (C-22), 35.9 (C-20), 32.1 (C-7), 32.0 (C8), (31.2, 30.1) (C-29, C-30), 30.7 (C-40), 29.0 (C-16), 28.4 (C-33), 28.1 (C-25), 27.9 (C-2), 24.4 (C-15), 24.0 (C-23), (22.9, 22.7) (C-26, C-27), 21.2 (C-11), 19.4 (C-19), 18.9 (C21), 12.0 (C-18); MS(MALDI) calcd for $\mathrm{C}_{60} \mathrm{H}_{86} \mathrm{~N}_{2} \mathrm{O}_{6} 930.65$, found $931.67[\mathrm{M}+\mathrm{H}]^{+}, 689.52[(\mathrm{M}-\mathrm{Trt})+2 \mathrm{H}]^{+}$; ATR FT-IR $3310,3082,3055,3028,2933,2866,1728,1641,1547,1489$, 1447, 1171, 1107, 1029, 1001, 772, 745, 706, 644, $623 \mathrm{~cm}^{-1}$.

Cholesteryl 1-Amino-15-oxo-4,7,10-trioxa-14-azaoctadecan-18-oate (2). The tritylamine 1 (145 mg, $0.16 \mathrm{mmol}$ ) was dissolved in $5 \mathrm{~mL}$ of $\mathrm{CH}_{2} \mathrm{Cl}_{2}$ containing $10 \%(\mathrm{v} / \mathrm{v})$ TFA and $5 \%(\mathrm{v} / \mathrm{v})$ triisopropylsilane, and it was stirred for $10 \mathrm{~min}$. The solution was evaporated in vacuo and the cleavage was repeated four times. The product was purified by column chromatography $(\mathrm{AcOH} / \mathrm{MeOH}(2: 98))$ to give $120.7 \mathrm{mg}$ (94\%) of pure 2 as a pale yellow solid. $\mathrm{R}_{\mathrm{f}} 0.52(\mathrm{AcOH} / \mathrm{MeOH}$ $=2: 98) ; \mathrm{k}^{\prime}=3.71\left(\mathrm{t}_{\mathrm{R}}=16.77 \mathrm{~min}\right.$, Alltech Alltima HP C18 column $(250 \times 4.6 \mathrm{~mm}, 5 \mu \mathrm{m})$, isocratic elution with ACN/ $\mathrm{MeOH}$ 15:85, flow rate: $1 \mathrm{~mL} / \mathrm{min}, \lambda=215 \mathrm{~nm})$; MS(MALDI) calcd for $\mathrm{C}_{41} \mathrm{H}_{72} \mathrm{~N}_{2} \mathrm{O}_{6} 688.54$, found 689.54 [M $+\mathrm{H}]^{+}$.

Cholesterol Probe (3). The amine $2(91 \mathrm{mg}, 0.11 \mathrm{mmol})$ was dissolved in $5 \mathrm{~mL}$ of DMF and then DIEA $(19 \mu \mathrm{L}, 0.11$ $\mathrm{mmol}$ ) was added. The solution of fluorescein-5-isothiocyanate $(51 \mathrm{mg}, 0.13 \mathrm{mmol})$ and DIEA $(57 \mu \mathrm{L}, 0.33 \mathrm{mmol})$ in $1.5 \mathrm{~mL}$ 
DMF was added in three portions over $6 \mathrm{~h}$ at RT. Then, it was evaporated in vacuo and the crude product was purified by column chromatography $\left(\mathrm{CHCl}_{3} /\right.$ acetone/AcOH 60:39:1) followed by $\left(\mathrm{CHCl}_{3} / \mathrm{MeOH} / \mathrm{AcOH} 94: 5: 1\right)$ to give $55.6 \mathrm{mg}$ (47\%) of pure 3 as an orange solid. $\mathrm{R}_{\mathrm{f}} 0.54\left(\mathrm{CHCl}_{3}\right.$ /acetone/ $\mathrm{AcOH}=60: 39: 1), 0.36\left(\mathrm{CHCl}_{3} / \mathrm{MeOH} / \mathrm{AcOH}=94: 5: 1\right) ; \mathrm{k}^{\prime}=$ $1.25\left(\mathrm{t}_{\mathrm{R}}=7.95 \mathrm{~min}\right.$; Alltech Alltima HP C18 column $(250 \times$ $4.6 \mathrm{~mm}, 5 \mu \mathrm{m})$, isocratic elution with $\mathrm{ACN} / \mathrm{MeOH} 15: 85$, flow rate: $1 \mathrm{~mL} / \mathrm{min}, \lambda=215 \mathrm{~nm}) ;[\alpha]_{\mathrm{D}}{ }^{20}=-9.4\left(c=0.32, \mathrm{CHCl}_{3}\right)$; ${ }^{1} \mathrm{H}$ NMR (500 MHz, $\left.\left(\mathrm{CD}_{3}\right)_{2} \mathrm{SO}\right) \delta 10.17$ (brs, Ar-OH), 9.95 (brs, 1H, CS-N $\underline{H}-A r), 8.23$ (s, 1H, 4'-H), 8.10 (brs, 1H, CS$\left.\mathrm{N} \underline{\mathrm{H}}-\mathrm{CH}_{2}\right), 7.79(\mathrm{t}, 1 \mathrm{H}, J=5.3 \mathrm{~Hz}, \mathrm{CO}-\mathrm{NH}), 7.73$ (d, $1 \mathrm{H}, J=$ $\left.5.3 \mathrm{~Hz}, 6^{\prime}-\mathrm{H}\right), 7.14\left(\mathrm{~d}, 1 \mathrm{H}, J=8.2 \mathrm{~Hz}, 7^{\prime}-\mathrm{H}\right), 6.65$ (d, $2 \mathrm{H}, J=$ $\left.1.4 \mathrm{~Hz}, 4^{\prime \prime}-\mathrm{H}\right), 6.59$ (d, 2H, J = 8.6 Hz, 1"-H), 6.54 (dd, $2 \mathrm{H}, J=$ $\left.8.7 \mathrm{~Hz}, 1.6 \mathrm{~Hz}, 2^{\prime \prime}-\mathrm{H}\right), 5.30(\mathrm{~s}, 1 \mathrm{H}, 6-\mathrm{H}), 4.42(\mathrm{~m}, 1 \mathrm{H}, 3-\mathrm{H})$, $3.50(\mathrm{~m}, 10 \mathrm{H}, 35-\mathrm{H}, 36-\mathrm{H}, 37-\mathrm{H}, 38-\mathrm{H}, 41-\mathrm{H}), 3.36(\mathrm{~m}, 4 \mathrm{H}$, 34-H, 39-H), 3.06 (q, 2H, $J=6.4 \mathrm{~Hz}, 32-\mathrm{H}), 2.44(\mathrm{t}, 2 \mathrm{H}, J=$ $6.7 \mathrm{~Hz}, 30-\mathrm{H}), 2.30(\mathrm{t}, 2 \mathrm{H}, J=6.7 \mathrm{~Hz}, 29-\mathrm{H}), 2.22(\mathrm{~d}, 2 \mathrm{H}, J=$ $7.5 \mathrm{~Hz}, 4-\mathrm{H}$ ), $1.90(\mathrm{~m}, 2 \mathrm{H}, 7 \beta-\mathrm{H}, 12 \beta-\mathrm{H}$ ), 1.80 (quin, $2 \mathrm{H}, J=$ $6.5 \mathrm{~Hz}, 40-\mathrm{H}$ ), $1.75(\mathrm{~m}, 3 \mathrm{H}, 1 \beta-\mathrm{H}, 2 \alpha-\mathrm{H}, 16 \alpha-\mathrm{H}$ ), 1.59 (quin, $2 \mathrm{H}, J=6.5 \mathrm{~Hz}, 33-\mathrm{H})$, [1.55-0.89 (m, 21H): $1.50(2 \beta-\mathrm{H}, 15 \alpha-$ $\mathrm{H}), 1.48(7 \alpha-\mathrm{H}), 1.46(25-\mathrm{H}), 1.45(11-\alpha / \beta-\mathrm{H}), 1.36(8 \beta-\mathrm{H})$, $1.30(22-\mathrm{H}, 23-\mathrm{H}), 1.29(20-\mathrm{H}), 1.20(16 \beta-\mathrm{H}), 1.10\left(23-\mathrm{H}^{\prime}\right)$, $1.09\left(12 \alpha-\mathrm{H}, 15 \beta-\mathrm{H}, 24-\mathrm{H}_{2}\right),(1.05,0.95)(14 \alpha-\mathrm{H}, 17 \alpha-\mathrm{H})$, $\left.1.01(1 \alpha-\mathrm{H}), 0.95\left(22-\mathrm{H}^{\prime}\right), 0.89(9 \alpha-\mathrm{H})\right], 0.94(\mathrm{~s}, 3 \mathrm{H}, 19-\mathrm{H})$, $0.86(\mathrm{~d}, 3 \mathrm{H}, J=6.2 \mathrm{~Hz}, 21-\mathrm{H}),[0.82(\mathrm{~d}, 3 \mathrm{H}, J=1.6 \mathrm{~Hz}), 0.81$ $(\mathrm{d}, 3 \mathrm{H}, J=1.6 \mathrm{~Hz})](26-\mathrm{H}, 27-\mathrm{H}), 0.62(\mathrm{~s}, 3 \mathrm{H}, 18-\mathrm{H}) ;{ }^{13} \mathrm{C}$ NMR (125 MHz, $\left.\left(\mathrm{CD}_{3}\right)_{2} \mathrm{SO}\right) \delta 180.5$ (CS), 171.7 (ester CO), 170.6 (amide CO), 168.5 (lactone CO), $(159.7,152.0)\left(\mathrm{C}-3^{\prime \prime}\right.$, C-4"a), (146.8, 141.4) (C-5', C-8'), 139.5 (C-5), 129.2 (C-6'), 129.0 (C-1" $), 126.7\left(\mathrm{C}-3^{\prime}\right), 124.0\left(\mathrm{C}-7^{\prime}\right), 122.1$ (C-6), 116.4 (C-4'), 112.7 (C-2"), 109.9 (C-1"a), 102.3 (C-4"), 83.5 (C9"), 73.2 (C-3), [69.8 (2C), 69.6 (2C)] (C-35, C-36, C-37, C$38),(68.2,68.1)$ (C-34, C-39), (56.2, 55.7) (C-14, C-17), 49.5 (C-9), 41.9 (C-13), 41.4 (C-41), 39.2 (C-12), 39.0 (C-24), 37.7 (C-4), 36.5 (C-1), 36.1 (C-10), 35.9 (C-32), 35.7 (C-22), 35.3 (C-20), 31.4 (C-8), 31.3 (C-7), 30.0 (C-29), 29.4 (2C, C30, C-33), 28.6 (C-40), 27.8 (C-16), 27.4 (C-25), 27.3 (C-2), 23.9 (C-15), 23.3 (C-23), (22.7, 22.4) (C-26, C-27), 20.6 (C11), 19.0 (C-19), 18.6 (C-21), 11.7 (C-18); MS(MALDI) calcd for $\mathrm{C}_{62} \mathrm{H}_{83} \mathrm{~N}_{3} \mathrm{O}_{11} \mathrm{~S}$ 1077.57, found $1078.58[\mathrm{M}+\mathrm{H}]^{+}$; ATR FTIR $3600-2400$ br, 3300, 3092, 2934, 2866, 1730, 1611, 1587, $1539,1504,1464,1447,1375,1331,1254,1213,1171,1109$, $1078,1024,993,849,824,787,671 \mathrm{~cm}^{-1}$.

Investigation of the in Vitro Hydrolytic Stability of the Cholesteryl Ester in Probe 3. The cholesterol probe 3 (150 $\mu \mathrm{M})$ was dissolved in PBS buffer containing 5\% (v/v) HFIP. Samples were taken over a period of $24 \mathrm{~h}$ and were analyzed by RP-HPLC on an Alltech Alltima HP C18 column $(250 \times 4.6$ $\mathrm{mm}, 5 \mu \mathrm{m})$ with isocratic elution $(\mathrm{ACN} / \mathrm{MeOH} 15: 85)$ at a flow rate of $1 \mathrm{~mL} / \mathrm{min}, \lambda=216 \mathrm{~nm}$. The probe 3 peak area values of the samples were compared to that of the starting solution.

Synthesis of the Cholesterol Anchor. (S)-N-(2-Maleimidoethyl)-2-(tert-butoxycarbonylamino)pent-4-ynamide (4). $\mathrm{N}$-(2-(tert-butoxycarbonylamino)-ethyl)-maleimide (100 mg, $0.41 \mathrm{mmol}$ ) was dissolved in $10 \mathrm{~mL}$ of TFA/ $\mathrm{CH}_{2} \mathrm{Cl}_{2} \quad 1: 1$ and the solution was stirred for $30 \mathrm{~min}$, then it was evaporated in vacuo. The resulting $\mathrm{N}$-(2-aminoethyl)maleimide trifluoroacetate was used without further purification. Boc-Pra-OH (81.3 $\mathrm{mg}, 0.38 \mathrm{mmol})$ and $\mathrm{HOBt}(58.2 \mathrm{mg}, 0.38 \mathrm{mmol})$ were dissolved in THF $(6 \mathrm{~mL})$ and DIC $(58.8 \mu \mathrm{L}, 0.38 \mathrm{mmol})$ was added. After $5 \mathrm{~min}$ stirring $\mathrm{N}$-(2-aminoethyl)maleimide trifluoroacetate $(96.6 \mathrm{mg}, 0.38 \mathrm{mmol})$ and DIEA $(65 \mu \mathrm{L}$, $0.38 \mathrm{mmol})$ in THF $(1 \mathrm{~mL})$ were added, and the reaction mixture was stirred for $8 \mathrm{~h}$ at RT. It was diluted with $20 \mathrm{~mL}$ of EtOAc and then extracted with $0.5 \mathrm{M} \mathrm{HCl}(3 \times 20 \mathrm{~mL})$. The combined organic layer was dried over $\mathrm{Na}_{2} \mathrm{SO}_{4}$ and evaporated in vacuo. The crude product was purified by column chromatography $\left(\mathrm{CHCl}_{3}\right.$ /acetone $\left.4: 1\right)$ to give $114.5 \mathrm{mg}$ (90\%) of pure 4 as a white solid. $\mathrm{R}_{\mathrm{f}} 0.4\left(\mathrm{CHCl}_{3}\right.$ /acetone $4: 1) ; \mathrm{k}^{\prime}=3.86\left(\mathrm{t}_{\mathrm{R}}=17.0 \mathrm{~min}\right.$; Alltech Alltima HP C18 column $(250 \times 4.6 \mathrm{~mm}, 5 \mu \mathrm{m})$, linear gradient of $5 \rightarrow 95 \% \mathrm{~B}$ in A over 30 min (eluent A: $0.1 \%(v / v)$ TFA in $\mathrm{H}_{2} \mathrm{O}$, eluent B: $0.08 \%(\mathrm{v} /$ v) TFA in ACN), flow rate: $1 \mathrm{~mL} / \mathrm{min}, \lambda=216 \mathrm{~nm}) ;[\alpha]_{\mathrm{D}}{ }^{20}=$ $-2.6\left(c=1, \mathrm{CHCl}_{3}\right) ;{ }^{1} \mathrm{H} \mathrm{NMR}\left(500 \mathrm{MHz},\left(\mathrm{CD}_{3}\right)_{2} \mathrm{SO}\right) \delta 8.06$ $(\mathrm{t}, 1 \mathrm{H}, J=5.2 \mathrm{~Hz}$, amide $\mathrm{NH}), 6.98(\mathrm{~s}, 2 \mathrm{H}$, maleimide $\mathrm{CH})$, $6.81(\mathrm{~d}, 1 \mathrm{H}, J=8.5 \mathrm{~Hz}$, carbamate $\mathrm{NH}), 3.95(\mathrm{dt}, 1 \mathrm{H}, J=8.5$, $4.5 \mathrm{~Hz}, \alpha-\mathrm{H}), 3.43(\mathrm{t}, 2 \mathrm{H}, J=5.7 \mathrm{~Hz}, 1-\mathrm{H}), 3.30(\mathrm{~m}, 1 \mathrm{H}, 2-\mathrm{H})$, $3.10\left(\mathrm{~m}, 1 \mathrm{H}, 2-\mathrm{H}^{\prime}\right), 2.77(\mathrm{~s}, 1 \mathrm{H}, \delta-\mathrm{H}), 2.44(\mathrm{ddd}, 1 \mathrm{H}, J=16.7$, 4.5, $2.5 \mathrm{~Hz}, \beta-\mathrm{H}$ ), 2.32 (ddd, $1 \mathrm{H}, J=16.7,9.1,1.6 \mathrm{~Hz}, \beta-\mathrm{H}^{\prime}$ ), 1.36 (s, 9H, Boc- $\left.\mathrm{CH}_{3}\right) ;{ }^{13} \mathrm{C}$ NMR $\left(125 \mathrm{MHz},\left(\mathrm{CD}_{3}\right)_{2} \mathrm{SO}\right) \delta$ 171.0 (maleimide CO), 170.5 (Pra CO), 155.1 (carbamate CO), 134.5 (maleimide $\mathrm{CH}), 81.0(\mathrm{C}-\gamma), 78.2\left(\underline{\mathrm{C}}\left(\mathrm{CH}_{3}\right)_{3}\right), 72.6$ $(\mathrm{C}-\delta), 53.2(\mathrm{C}-\alpha),[37.0,36.9](\mathrm{C}-1, \mathrm{C}-2), 28.2\left(\mathrm{CH}_{3}\right), 21.8$ (C- $\beta$ ); MS(ESI) calcd for $\mathrm{C}_{16} \mathrm{H}_{21} \mathrm{~N}_{3} \mathrm{O}_{5} 335.15$, found 335.90 $[\mathrm{M}+\mathrm{H}]^{+}$, FT-IR (KBr) 3341, 3323, 3273, 3098, 2968, 2926, 2874, 2855, 2116, 1703, 1688, 1661, 1616, 1574, 1560, 1531, $1464,1418,1387,1362,1325,1273,1252,1171,1130,1105$, $1053,961,866,826,804,686$ (br) $\mathrm{cm}^{-1}$.

(S)-N-(2-Maleimidoethyl)-2-aminopent-4-ynamide (5). $N^{\alpha}$ $t$-Butyloxycarbonyl-propargyl-glycine- $N$-(2-maleimidoethyl)amide (4) $(20.0 \mathrm{mg}, 60 \mu \mathrm{mol})$ was dissolved in $2 \mathrm{~mL}$ of TFA/ $\mathrm{CH}_{2} \mathrm{Cl}_{2}$ 1:1 and it was stirred for $30 \mathrm{~min}$. The solution was evaporated in vacuo to give $20.1 \mathrm{mg}(96 \%)$ of pure 5 as a pale yellow solid. $\mathrm{R}_{\mathrm{f}} 0.4\left(\mathrm{CHCl}_{3} / \mathrm{MeOH} 95: 5\right)$; HPLC: $\mathrm{k}^{\prime}=1.23\left(\mathrm{t}_{\mathrm{R}}\right.$ $=7.8 \mathrm{~min}$; Alltech Alltima HP C18 column $(250 \times 4.6 \mathrm{~mm}, 5$ $\mu \mathrm{m}$ ), linear gradient of $5 \rightarrow 95 \% \mathrm{~B}$ in A over 30 min (eluent A: $0.1 \%(\mathrm{v} / \mathrm{v})$ TFA in $\mathrm{H}_{2} \mathrm{O}$, eluent B: $0.08 \%$ (v/v) TFA in ACN), flow rate: $1 \mathrm{~mL} / \mathrm{min}, \lambda=216 \mathrm{~nm})$; MS(ESI) calcd for $\mathrm{C}_{11} \mathrm{H}_{13} \mathrm{~N}_{3} \mathrm{O}_{3}$ 235.10, found $236.20[\mathrm{M}+\mathrm{H}]^{+}$.

(S) - 2-(3-(5-Fluoresceinyl-thioureido) - N-(2maleimidoethyl)pent-4-ynamide (6). Propargyl-glycine- $\mathrm{N}$-(2maleimidoethyl)amide (5) $(20.1 \mathrm{mg}, 57.6 \mu \mathrm{mol})$ was dissolved in THF $(0.5 \mathrm{~mL})$ and then fluorescein-5-isothiocyanate (23.4 $\mathrm{mg}, 60 \mu \mathrm{mol})$ and DIEA $(10.3 \mu \mathrm{L}, 60 \mu \mathrm{mol})$ were added to the solution; then, it was stirred for $13 \mathrm{~h}$. After evaporation in vacuo the crude product was purified by HPLC (Vydac $218 \mathrm{TP} 1010$ column $(250 \times 10 \mathrm{~mm}, 10 \mu \mathrm{m})$, linear gradient of $5 \rightarrow 95 \% \mathrm{~B}$ in A over $30 \mathrm{~min}$ (eluent A: $0.1 \%(\mathrm{v} / \mathrm{v})$ TFA in $\mathrm{H}_{2} \mathrm{O}$, eluent B: $0.08 \%(\mathrm{v} / \mathrm{v})$ TFA in $\mathrm{ACN}$ ), flow rate: $4 \mathrm{~mL} /$ $\min , \lambda=216 \mathrm{~nm})$ to give $25.8 \mathrm{mg}(69 \%)$ of pure 6 as an orange solid. $\mathrm{R}_{\mathrm{f}} 0.4\left(\mathrm{CHCl}_{3} / \mathrm{MeOH} 95: 5\right)$; HPLC: $\mathrm{k}^{\prime}=4.31\left(\mathrm{t}_{\mathrm{R}}=18.6\right.$ min; Alltech Alltima HP C18 column $(250 \times 4.6 \mathrm{~mm}, 5 \mu \mathrm{m})$, linear gradient of $5 \rightarrow 95 \% \mathrm{~B}$ in A over $30 \mathrm{~min}$ (eluent A: $0.1 \%$ (v/v) TFA in $\mathrm{H}_{2} \mathrm{O}$, eluent B: $0.08 \%$ (v/v) TFA in ACN), flow rate: $1 \mathrm{~mL} / \mathrm{min}, \lambda=216 \mathrm{~nm}) ;[\alpha]_{\mathrm{D}}{ }^{20}=-3.9(c=0.7, \mathrm{MeOH})$; ${ }^{1} \mathrm{H}$ NMR $\left(500 \mathrm{MHz},\left(\mathrm{CD}_{3}\right)_{2} \mathrm{SO}\right) \delta 10.41$ (brs, 1H, CS-N $\underline{\mathrm{H}}-$ Ar), 10.10 (brs, Ar-OH), 8.44 (s, 1H, 4'-H), 8.37 (t, 1H, $J=5.8$ $\mathrm{Hz}, \mathrm{CONH}), 8.14$ (d, $1 \mathrm{H}, J=7.4 \mathrm{~Hz}, \mathrm{CS}-\mathrm{NH}-\mathrm{C} \alpha), 7.77$ (dd, $\left.1 \mathrm{H}, J=8.3,1.6 \mathrm{~Hz}, 6^{\prime}-\mathrm{H}\right), 7.18\left(\mathrm{~d}, 1 \mathrm{H}, J=8.3 \mathrm{~Hz}, 7^{\prime}-\mathrm{H}\right), 7.00$ (s, $2 \mathrm{H}$, maleimide $\mathrm{CH}), 6.66\left(\mathrm{~d}, 2 \mathrm{H}, J=1.9 \mathrm{~Hz}, 4^{\prime \prime}-\mathrm{H}\right), 6.59$ (d, $\left.2 \mathrm{H}, J=8.2 \mathrm{~Hz}, 1^{\prime \prime}-\mathrm{H}\right), 6.55\left(\mathrm{dd}, 2 \mathrm{H}, J=8.7,2.0 \mathrm{~Hz}, 2^{\prime \prime}-\mathrm{H}\right)$, $4.88(\mathrm{q}, 1 \mathrm{H}, J=5.6 \mathrm{~Hz}, \alpha-\mathrm{H}), 3.48(\mathrm{~m}, 2 \mathrm{H}, 1-\mathrm{H}), 3.33(\mathrm{~m}, 1 \mathrm{H}$, 2-H), $3.27\left(\mathrm{~m}, 1 \mathrm{H}, 2-\mathrm{H}^{\prime}\right), 2.85(\mathrm{t}, 1 \mathrm{H}, J=2.4 \mathrm{~Hz}, \delta-\mathrm{H}), 2.80$ (ddd, $1 \mathrm{H}, J=17.0,5.2,2.4 \mathrm{~Hz}, \beta-\mathrm{H}), 2.62$ (ddd, $1 \mathrm{H}, J=17.0$, 
5.1, $2.3 \mathrm{~Hz}, \beta$ - $\left.\mathrm{H}^{\prime}\right) ;{ }^{13} \mathrm{C} \mathrm{NMR}\left(125 \mathrm{MHz},\left(\mathrm{CD}_{3}\right)_{2} \mathrm{SO}\right) \delta 179.8$ (CS), 171.1 (maleimide CO), $169.5(\mathrm{CONH}), 168.6$ (lactone CO), (159.5, 151.9) (C-3", C-4"a), (147.3, 141.3) (C-5', C-8'), 134.6 (maleimide $\mathrm{CH}$ ), 129.2 (C-6'), 129.1 (C-1" $), 126.5$ (C$\left.5^{\prime}\right), 124.1$ (C-7'), 116.2 (C-4'), 112.6 (C-2"), 109.7 (C-1"a), $102.3\left(\mathrm{C}-4^{\prime \prime}\right), 79.9(\mathrm{C}-\delta), 73.7(\mathrm{C}-\gamma), 55.3(\mathrm{C}-\alpha), 37.0$ (2C, C1, C-2), 22.1 (C- $\beta$ ); MS(ESI) calcd for $\mathrm{C}_{32} \mathrm{H}_{24} \mathrm{~N}_{4} \mathrm{O}_{8} \mathrm{~S}$ 624.13, found $625.00[\mathrm{M}+\mathrm{H}]^{+}$; FT-IR (KBr) $3433 \mathrm{br}, 3267$ (br), 3065, 2995, 2884, 2822, 2683, 2560, 1744, 1680, 1639, 1612, 1589, $1578,1510,1460,1425,1317,1287,1206,1182,1136,1113$, $783,739 \mathrm{~cm}^{-1}$.

Cholesteryl 1-Azido-13-oxo-3,6,9-trioxa-12-azahexadecan-16-oate (7). Cholesteryl hemisuccinate (200 mg, 0.41 $\mathrm{mmol})$ and TBTU (171 mg, $0.53 \mathrm{mmol}$ ) were dissolved in 6 $\mathrm{mL}$ of $\mathrm{CHCl}_{3} / \mathrm{CH}_{2} \mathrm{Cl}_{2}(4: 1)$, and DIEA $(91.3 \mu \mathrm{L}, 0.53 \mathrm{mmol})$ was added. It was stirred for $5 \mathrm{~min}$, then 1-amino-11-azido3,6,9-trioxaundecane $(89.5 \mathrm{mg}, 0.41 \mathrm{mmol})$ was added to the solution. The mixture was stirred for $8 \mathrm{~h}$ at RT, then it was evaporated in vacuo. The crude product was purified by column chromatography with $\mathrm{CHCl}_{3} / \mathrm{MeOH}(97: 3)$ to give $253.5 \mathrm{mg}$ (90\%) of 7 as a white solid. $\mathrm{R}_{\mathrm{f}} 0.40\left(\mathrm{CHCl}_{3} / \mathrm{MeOH}=97: 3\right)$; $\mathrm{k}^{\prime}(\mathrm{HPLC})=2.33\left(\mathrm{t}_{\mathrm{R}}=14.5 \mathrm{~min}\right.$; Alltech Alltima HP C18 column $(250 \times 4.6 \mathrm{~mm}, 5 \mu \mathrm{m})$, isocratic elution with ACN/ $\mathrm{MeOH}(15: 85)$, flow rate: $1 \mathrm{~mL} / \mathrm{min}, \lambda=216 \mathrm{~nm}) ;[\alpha]_{\mathrm{D}}{ }^{20}=$ $-26.0\left(c=1.7, \mathrm{CHCl}_{3}\right) ;{ }^{1} \mathrm{H} \mathrm{NMR}\left(500 \mathrm{MHz}, \mathrm{CDCl}_{3}\right) \delta 6.20$ (brs, $1 \mathrm{H}, \mathrm{NH}), 5.36(\mathrm{~d}, 1 \mathrm{H}, J=3.3 \mathrm{~Hz}, 6-\mathrm{H}), 4.61(\mathrm{~m}, 1 \mathrm{H}, 3 \alpha-$ $\mathrm{H}), 3.68(\mathrm{~m}, 8 \mathrm{H}, 34-\mathrm{H}, 35-\mathrm{H}, 36-\mathrm{H}, 37-\mathrm{H}), 3.63(\mathrm{~m}, 2 \mathrm{H}, 38-$ $\mathrm{H}), 3.55(\mathrm{t}, 2 \mathrm{H}, J=4.9 \mathrm{~Hz}, 33-\mathrm{H}), 3.45(\mathrm{q}, 2 \mathrm{H}, J=4.6 \mathrm{~Hz}, 32-$ $\mathrm{H}), 3.40(\mathrm{t}, 2 \mathrm{H}, J=4.7 \mathrm{~Hz}, 39-\mathrm{H}),[2.64(\mathrm{t}, 2 \mathrm{H}, J=6.8 \mathrm{~Hz})$, $2.48(\mathrm{t}, 2 \mathrm{H}, J=6.8 \mathrm{~Hz})](29-\mathrm{H}, 30-\mathrm{H}), 2.31(\mathrm{~d}, 2 \mathrm{H}, J=7.7 \mathrm{~Hz}$, 4-H), $2.03(\mathrm{~m}, 1 \mathrm{H}, 12 \beta-\mathrm{H}), 1.96(\mathrm{~m}, 1 \mathrm{H}, 7 \beta-\mathrm{H}), 1.89(\mathrm{~m}, 1 \mathrm{H}$, $2 \alpha-\mathrm{H}), 1.87(\mathrm{~m}, 1 \mathrm{H}, 1 \beta-\mathrm{H}), 1.83(\mathrm{~m}, 1 \mathrm{H}, 16 \alpha-\mathrm{H}),[1.62-1.04$ (m, $18 \mathrm{H}): 1.56(2 \beta-\mathrm{H}, 15 \alpha-\mathrm{H}), 1.53(7 \alpha-\mathrm{H}), 1.52(25-\mathrm{H}), 1.47$ (11 $\alpha / \beta-\mathrm{H}), 1.44(8 \beta-\mathrm{H}), 1.36(23-\mathrm{H}), 1.34(20-\mathrm{H}, 22-\mathrm{H}), 1.20$ $(16 \beta-\mathrm{H}), 1.17\left(23-\mathrm{H}^{\prime}\right), 1.15(12 \alpha-\mathrm{H}), 1.12(1 \alpha-\mathrm{H}), 1.11(24-$ $\left.\left.\mathrm{H}_{2}\right), 1.09(17 \alpha-\mathrm{H}), 1.06(15 \beta-\mathrm{H})\right], 1.01(\mathrm{~s}, 3 \mathrm{H}, 19-\mathrm{H})$, [1.03$\left.0.90(\mathrm{~m}, 3 \mathrm{H}): 0.99\left(14 \alpha-\mathrm{H}, 22-\mathrm{H}^{\prime}\right), 0.94(9 \alpha-\mathrm{H})\right], 0.91(\mathrm{~d}, 3 \mathrm{H}$, $J=6.7 \mathrm{~Hz}, 21-\mathrm{H}),[0.86(\mathrm{~d}, 3 \mathrm{H}, J=1.9 \mathrm{~Hz}), 0.85(\mathrm{~d}, 3 \mathrm{H}, J=$ $1.9 \mathrm{~Hz})](26-\mathrm{H}, 27-\mathrm{H}), 0.67(\mathrm{~s}, 3 \mathrm{H}, 18-\mathrm{H}) ;{ }^{13} \mathrm{C}$ NMR $(125$ $\left.\mathrm{MHz}, \mathrm{CDCl}_{3}\right) \delta 172.2$ (ester CO), 171.4 (amide CO), 139.6 (C-5), 122.6 (C-6), 74.3 (C-3), [70.7, 70.6, 70.5, 70.3, 70.0, 69.8] (C-33, C-34, C-35, C-36, C-37, C-38), 56.7 (C-14), 56.1 (C-17), 50.7 (C-39), 50.0 (C-9), 42.3 (C-13), 39.7 (C-12), 39.5 (C-24), 39.3 (C-32), 38.1 (C-4), 37.0 (C-1), 36.6 (C-10), 36.2 (C-22), 35.8 (C-20), 31.9 (C-7), 31.8 (C-8), [31.0, 29.9] (C-29, C-30), 28.2 (C-16), 28.0 (C-25), 27.7 (C-2), 24.3 (C15), 23.8 (C-23), [22.8, 22.6] (C-26, C-27), 21.0 (C-11), 19.3 (C-19), 18.7 (C-21), 11.8 (C-18); MS(MALDI) calcd for $\mathrm{C}_{39} \mathrm{H}_{66} \mathrm{~N}_{4} \mathrm{O}_{6} 686.50$, found $687.62[\mathrm{M}+\mathrm{H}]^{+}, 659.57[(\mathrm{M}-$ $\left.\left.\mathrm{N}_{2}\right)+\mathrm{H}\right]^{+}$; ATR FT-IR 3314, 2951, 2930, 2866, 2104, 1730, $1647,1547,1466,1441,1375,1366,1327,1304,1283,1254$, $1171,1124,1028,999,627,530 \mathrm{~cm}^{-1}$.

Cholesterol Anchor (8). The alkyne 6 (42 mg, $67.2 \mu \mathrm{mol})$ and the azide $7(46 \mathrm{mg}, 67.2 \mu \mathrm{mol})$ were dissolved in $t \mathrm{BuOH}$ $(0.9 \mathrm{~mL})$. The solution of $\mathrm{L}(+)$-ascorbic acid sodium salt $(7.9$ $\mathrm{mg}, 39.9 \mu \mathrm{mol})$ and $\mathrm{CuSO}_{4} \cdot 5 \mathrm{H}_{2} \mathrm{O}(5.0 \mathrm{mg}, 20.1 \mu \mathrm{mol})$ in 0.9 $\mathrm{mL}$ of water were added and the reaction mixture was stirred for $48 \mathrm{~h}$ at RT. Then it was evaporated in vacuo and the crude product was purified by column chromatography $\left(\mathrm{CHCl}_{3} /\right.$ $\mathrm{MeOH} / \mathrm{AcOH} 90: 9: 1)$ to give $58 \mathrm{mg}(66 \%)$ of pure 8 as an orange solid. $\mathrm{R}_{\mathrm{f}} 0.4\left(\mathrm{CHCl}_{3} / \mathrm{MeOH} / \mathrm{AcOH}\right.$ 90:9:1); $\mathrm{k}^{\prime}=5.20$ $\left(t_{\mathrm{R}}=12.4 \mathrm{~min} ; \mathrm{Vydac} 214 \mathrm{TP} 5410 \mathrm{C} 4\right.$ column $(100 \times 4.6 \mathrm{~mm}$, $5 \mu \mathrm{m}$ ), linear gradient of $50 \rightarrow 95 \% \mathrm{~B}$ in A over $25 \mathrm{~min}$ (eluent
A: $0.1 \%(v / v)$ TFA in $\mathrm{H}_{2} \mathrm{O}$, eluent B: $0.08 \%(\mathrm{v} / \mathrm{v})$ TFA in $\mathrm{ACN})$, flow rate: $1 \mathrm{~mL} / \mathrm{min}, \lambda=216 \mathrm{~nm}) ;[\alpha]_{\mathrm{D}}{ }^{20}=-32.9(c=$ $\left.0.65, \mathrm{CHCl}_{3}\right) ;{ }^{1} \mathrm{H}$ NMR $\left(500 \mathrm{MHz},\left(\mathrm{CD}_{3}\right)_{2} \mathrm{SO}\right) \delta 10.31(\mathrm{~s}, 1 \mathrm{H}$, CS-NH-Ar), 10.19 (brs, Ar-OH), 8.39 (s, 1H, 4"-H), 8.32 (t, $1 \mathrm{H}, J=5.6 \mathrm{~Hz}, \alpha-\mathrm{CONH}), 8.10(\mathrm{~d}, 1 \mathrm{H}, J=5.3 \mathrm{~Hz}, \mathrm{CS}-\mathrm{NH}-$ $\mathrm{C} \alpha), 7.87(\mathrm{t}, 1 \mathrm{H}, J=5.3 \mathrm{~Hz}, 32-\mathrm{NH}), 7.79(\mathrm{~s}, 1 \mathrm{H}$, triazole $\mathrm{CH}), 7.74\left(\mathrm{~d}, 1 \mathrm{H}, J=8.2 \mathrm{~Hz}, 6^{\prime \prime}-\mathrm{H}\right), 7.15(\mathrm{~d}, 1 \mathrm{H}, J=8.2 \mathrm{~Hz}$, $\left.7^{\prime \prime}-\mathrm{H}\right), 7.00$ (s, 2H, maleimide $\mathrm{CH}$ ), 6.64 (s, 2H, 4"'-H), 6.59 $\left(\mathrm{dd}, 2 \mathrm{H}, J=8.6,2.6 \mathrm{~Hz}, 1^{\prime \prime \prime}-\mathrm{H}\right), 6.53(\mathrm{dd}, 2 \mathrm{H}, J=8.6,1.6 \mathrm{~Hz}$, $\left.2^{\prime \prime \prime}-\mathrm{H}\right), 5.30(\mathrm{~d}, 1 \mathrm{H}, J=3.2 \mathrm{~Hz}, 6-\mathrm{H}), 5.04(\mathrm{q}, 1 \mathrm{H}, J=5.9 \mathrm{~Hz}$, $\alpha-\mathrm{H}), 4.47(\mathrm{t}, 2 \mathrm{H}, J=5.0 \mathrm{~Hz}, 39-\mathrm{H}), 4.41(\mathrm{~m}, 1 \mathrm{H}, 3-\mathrm{H}), 3.76$ $(\mathrm{t}, 2 \mathrm{H}, J=5.0 \mathrm{~Hz}, 38-\mathrm{H}), 3.47\left(\mathrm{~m}, 2 \mathrm{H}, 1^{\prime}-\mathrm{H}\right), 3.44$ (brs, $8 \mathrm{H}$, 34-H, 35-H, 36-H, 37-H), 3.35 (t, 2H, J = 5.9 Hz, 33-H), 3.28 $\left(\mathrm{m}, 1 \mathrm{H}, 2^{\prime}-\mathrm{H}\right), 3.22\left(\mathrm{dd}, 1 \mathrm{H}, \mathrm{J}=14.0,6.3 \mathrm{~Hz}, 2^{\prime}-\mathrm{H}^{\prime}\right), 3.16(\mathrm{q}$, $2 \mathrm{H}, J=5.7 \mathrm{~Hz}, 32-\mathrm{H}), 3.15(\mathrm{~m}, 1 \mathrm{H}, \beta-\mathrm{H}), 3.03(\mathrm{dd}, 1 \mathrm{H}, J=$ $\left.14.9,7.1 \mathrm{~Hz}, \beta-\mathrm{H}^{\prime}\right),[2.43(\mathrm{t}, 2 \mathrm{H}, J=6.6 \mathrm{~Hz}), 2.31(\mathrm{t}, 2 \mathrm{H}, J=$ $6.7 \mathrm{~Hz})](29-\mathrm{H}, 30-\mathrm{H}), 2.22(\mathrm{~d}, 2 \mathrm{H}, J=7.6 \mathrm{~Hz}, 4-\mathrm{H}), 1.93(\mathrm{~m}$, $1 \mathrm{H}, 12 \beta-\mathrm{H}), 1.87(\mathrm{~m}, 1 \mathrm{H}, 7 \beta-\mathrm{H}), 1.75(\mathrm{~m}, 3 \mathrm{H}, 1 \beta-\mathrm{H}, 2 \alpha-\mathrm{H}$, $16 \alpha-\mathrm{H}),[1.56-0.89(\mathrm{~m}, 21 \mathrm{H}): 1.50(2 \beta-\mathrm{H}, 15 \alpha-\mathrm{H}), 1.47(7 \alpha-$ $\mathrm{H}), 1.46(25-\mathrm{H}), 1.45(11-\alpha / \beta-\mathrm{H}), 1.36(8 \beta-\mathrm{H}), 1.30(20-\mathrm{H}$, $22-\mathrm{H}, 23-\mathrm{H}), 1.19(16 \beta-\mathrm{H}), 1.12\left(23-\mathrm{H}^{\prime}\right), 1.09(12 \alpha-\mathrm{H}, 15 \beta-\mathrm{H}$, $\left.24-\mathrm{H}_{2}\right), 1.05(17 \alpha-\mathrm{H}), 0.96(14 \alpha-\mathrm{H}), 1.00(1 \alpha-\mathrm{H}), 0.97$ (22$\left.\left.\mathrm{H}^{\prime}\right), 0.88(9 \alpha-\mathrm{H})\right], 0.94(\mathrm{~s}, 3 \mathrm{H}, 19-\mathrm{H}), 0.87(\mathrm{~d}, 3 \mathrm{H}, J=6.4 \mathrm{~Hz}$ $21-\mathrm{H}),[0.83(\mathrm{~d}, 3 \mathrm{H}, J=2.0 \mathrm{~Hz}), 0.82(\mathrm{~d}, 3 \mathrm{H}, J=2.0 \mathrm{~Hz})](26-$ $\mathrm{H}, 27-\mathrm{H}), 0.62(\mathrm{~s}, 3 \mathrm{H}, 18-\mathrm{H}) ;{ }^{13} \mathrm{C}$ NMR (125 MHz, $\left.\left(\mathrm{CD}_{3}\right)_{2} \mathrm{SO}\right) \delta 180.0(\mathrm{CS}), 171.7$ (ester $\left.\mathrm{CO}\right), 171.1$ (maleimide CO), 170.8 (30-CO), 170.4 ( $\alpha$-CO), 168.6 (lactone CO), (159.8, 152.1) (C-3"', C-4"'a), (147.2, 141.2) (C-5", C-8"), 142.2 (triazole $\mathrm{C}_{\mathrm{q}}$ ), 139.6 (C-5), 134.6 (maleimide $\mathrm{CH}$ ), 129.3 (C-6"), 129.1 (C-1"'), 126.8 (C-3"), 124.2 (C-7"), 123.3 (triazole $\mathrm{CH}), 122.1$ (C-6), $116.4\left(\mathrm{C}-4^{\prime \prime}\right), 112.7$ (C-2"') 109.8 (C-1"'a), 102.3 (C-4"'), 83.3 (C-9'"), 73.2 (C-3), [69.72, 69.69, 69.64, 69.58, 69.1, 68.9] (C-33, C-34, C-35, C-36, C-37, C-38), 56.7 (C- $\alpha$ ), 56.1 (C-14), 55.6 (C-17), 49.5 (C-9), 49.3 (C-39), 41.9 (C-13), 39.0 (2C, C-12, C-24), 38.6 (C-32), 37.7 (C-4), 37.0 (2C, C-1', C-2'), 36.5 (C-1), 36.1 (C-10), 35.7 (C-22), 35.2 (C-20), 31.4 (C-8), 31.3 (C-7), [29.9, 29.3] (C-29, C-30), 28.3 (C- $\beta$ ), 27.8 (C-16), 27.4 (C-25), 27.3 (C-2), 23.9 (C-15), 23.2 (C-23), [22.7, 22.4] (C-26, C-27), 20.6 (C-11), 19.0 (C19), 18.6 (C-21), 11.7 (C-18); MS(MALDI) calcd for $\mathrm{C}_{71} \mathrm{H}_{90} \mathrm{~N}_{8} \mathrm{O}_{14} \mathrm{~S}$ 1310.63, found $1311.63[\mathrm{M}+\mathrm{H}]^{+}$; ATR FT-IR 3600-2400 br, 3275, 3066, 2936, 2904, 2868, 1709, 1659, $1639,1587,1502,1464,1406,1381,1329,1254,1207,1175$, $1107,1028,993,914,850,826,696,671 \mathrm{~cm}^{-1}$.

Expression and Purification of mCherry Extended with a C-terminal Cys (mCherry-Cys). Cys extended mCherry with a $\mathrm{His}_{6}$ tag (Figure S6) was cloned into a modified pRSET vector (Invitrogen). Transformed cells of $E$. coli BL21(DE3) were grown at $37{ }^{\circ} \mathrm{C}$ in $1 \mathrm{~L}$ of $\mathrm{LB}$ medium containing $100 \mu \mathrm{g} / \mathrm{mL}$ ampicillin. When $\mathrm{OD}_{600}=0.6$ was achieved, the protein expression was induced by isopropyl-1thio- $\beta$-D-galactopyranoside in a final concentration of $0.5 \mathrm{mM}$. Cells were grown for further $4 \mathrm{~h}$ at $37{ }^{\circ} \mathrm{C}$, and then harvested by centrifugation at $5000 \mathrm{rpm}$ for $15 \mathrm{~min}$ at $4{ }^{\circ} \mathrm{C}$. The pellet was resuspended in $40 \mathrm{~mL}$ of $50 \mathrm{mM} \mathrm{Na} \mathrm{HPO}_{4}, 300 \mathrm{mM}$ $\mathrm{NaCl}, 10 \mathrm{mM}$ imidazole, $\mathrm{pH} 8.0$ containing a protease inhibitor cocktail of Sigma, and cells were disrupted by sonication at 4 ${ }^{\circ} \mathrm{C}$. The lysate was centrifuged at $15000 \mathrm{rpm}$ for $30 \mathrm{~min}$ and the supernatant was applied to a Ni-NTA column equilibrated with the same buffer. The column was washed with 5 column volumes of $50 \mathrm{mM} \mathrm{Na} \mathrm{HPO}_{4}, 300 \mathrm{mM} \mathrm{NaCl}, 20 \mathrm{mM}$ imidazole, $\mathrm{pH} 8.0$, and then the mCherry was eluted with 50 $\mathrm{mM} \mathrm{Na} \mathrm{HPO}_{4}, 300 \mathrm{mM} \mathrm{NaCl}, 250 \mathrm{mM}$ imidazole, $\mathrm{pH}$ 8.0. 
Fractions containing the target protein were desalted on Sephadex G-25 columns with Milli-Q water and stored at -20 ${ }^{\circ} \mathrm{C}$ as a frozen solution.

\section{Conjugation of the Cholesterol Anchor to mCherry-}

Cys. The protein conjugation of the cholesterol anchor was investigated by the addition of different molar excess of $\mathbf{8}$ to the solution of mCherry $(1 \mathrm{mg} / \mathrm{mL}, 36 \mu \mathrm{M})$ in $20 \mathrm{mM}$ Tris, 10 $\mathrm{mM}$ TCEP, $\mathrm{pH} 7.5$, and it was incubated at $20{ }^{\circ} \mathrm{C}$ for $1 \mathrm{~h}$. Then, $100 \mu \mathrm{L}$ of the reaction mixture was introduced to a Superdex 75 column and eluted with $50 \mathrm{mM} \mathrm{Na} 2 \mathrm{HPO}_{4}, 150$ $\mathrm{mM} \mathrm{NaCl}, \mathrm{pH} 7.0$ (Figure S4). On preparative scale, a protein:anchor ratio of 1:10 was applied, and the total amount of 8 was added in 10 portions over $5 \mathrm{~h}$. The mixed micelles composed of the cholesteryl lipoprotein and the cholesterol anchor was purified by size-exclusion chromatography on Superdex 75, and then the mixed micellar associates were incubated with 10 equiv $\beta$-cyclodextrin at $20{ }^{\circ} \mathrm{C}$ for $24 \mathrm{~h}$. The inclusion complex of $\mathbf{8}$ and that of the protein-anchor conjugate was separated with size-exclusion chromatography.

ECD Spectroscopy. ECD spectra of mCherry-Cys and the mCherry-anchor conjugate in the $190-250 \mathrm{~nm}$ region were recorded on a Jasco (Tokyo, Japan) J815 spectropolarimeter, equipped with a Peltier temperature controller, at $25{ }^{\circ} \mathrm{C}$ and $100 \mathrm{~nm} / \mathrm{s}$ scan speed using a $1 \mathrm{~mm}$ path length quartz cell. Protein concentration of the samples was in the $2.5-6.5 \mu \mathrm{M}$ range as measured by the Bradford method. ${ }^{57}$ Spectra presented here are accumulations of 10 scans and the corresponding solvent spectra recorded under the same conditions were subtracted. The contribution of each secondary structural element of the protein was determined by deconvolution of the spectra using the CDSSTR method. ${ }^{58}$

Cell Culture. For in vitro biological studies, SH-SY5Y (ATCC: CRL-2266) human neuroblastoma cells were used. They were cultured in DMEM (Sigma Ltd., St. Louis, MO, USA) medium containing 10\% FCS, L-glutamine (2 mM), gentamycin $(160 \mu \mathrm{g} / \mathrm{mL}), 1 \mathrm{mM}$ pyruvate, and nonessential amino acids (Sigma Ltd., St. Louis, MO, USA). The cultures of cells were maintained at $37^{\circ} \mathrm{C}$ in a humidified atmosphere with $5 \% \mathrm{CO}_{2}$.

In Vitro Cytotoxic Effect of the Cholesterol Anchor and the mCherry-Anchor Conjugate. The in vitro cytotoxic effect of $\mathbf{8}$ and the mCherry-anchor $\mathbf{8}$ conjugate was evaluated by the MTT-assay. ${ }^{59}$ For the experiment, $5 \times 10^{3}$ cells per well were plated on 96-well plates. After $24 \mathrm{~h}$ incubation at $37{ }^{\circ} \mathrm{C}$, cells were treated with 8 or with mCherry-anchor 8 dissolved in serum-free medium $(0.26 \mathrm{nM}$ $-100 \mu \mathrm{M}$ and $0.26 \mathrm{nM}-10 \mu \mathrm{M}$, respectively) for $60 \mathrm{~min}$. The control cells were treated with serum-free medium for 60 min. MTT solution was added to the cells at a final concentration of $367 \mu \mathrm{g} / \mathrm{mL}$; after $3.5 \mathrm{~h}$ incubation they were centrifuged for $5 \mathrm{~min}$ at $863 \times g$ and the supernatant was removed. The formazan crystals were dissolved in DMSO and the absorbance $(A)$ of the samples was measured at $\lambda=540$ and $620 \mathrm{~nm}$ using an ELISA Reader (Labsystems MS reader, Finland). $A_{620}$ was subtracted from $A_{540}$ and the percent of cytotoxicity was calculated using the following equation:

$$
\text { Cytotoxicity }(\%)=\left[1-\left(A_{\text {treated }} / A_{\text {control }}\right)\right] \times 100
$$

where $A_{\text {treated }}$ and $A_{\text {control }}$ correspond to the absorbance of the treated and control cells, respectively.

Live Cell Imaging with Confocal Laser Scanning Microscopy. 20000 cells per well were plated on an 8-well Lab-Tek II Chambered coverglass. After $48 \mathrm{~h}$ incubation at 37
${ }^{\circ} \mathrm{C}$, cells were treated with 3,8 , or mCherry-anchor 8 dissolved in serum-free medium for $30 \mathrm{~min}$. The concentration of the cholesterol probe and the cholesterol anchor was $1 \mu \mathrm{M}$, while the mCherry-anchor 8 conjugate was applied at $10 \mu \mathrm{M}$ concentration. Cells treated with serum-free medium for 30 min were used as a negative control. After treatment and incubation, cells were washed with serum-free medium and the nuclei of the cells were stained for 5 min using the nuclear dye DRAQ5. Sequential excitation was applied for fluorescein, mCherry, and DRAQ5. Fluorescein was excited with an Ar ion laser $(488 \mathrm{~nm})$ and emitted photons were collected through a BA 505-525 nm filter; mCherry was excited with a $\mathrm{He}-\mathrm{Ne}$ laser at $543 \mathrm{~nm}$ and emitted photons were collected through a BA 595-615 nm filter; DRAQ5 was excited with a $\mathrm{He}-\mathrm{Ne}$ laser at $633 \mathrm{~nm}$ and emitted photons were collected through a BA $660 \mathrm{~nm}$ filter. The colocalization of mCherry and fluorescein signals was quantitated on 15 confocal microscopy images with more than 600 cells. In our case the intensities of the two fluorescent signals were different (Figure 7, emission spectra); therefore, Manders colocalization coefficients were calculated, which are not as affected by differences in intensities between the channels as the Pearson coefficient. After deconvolution and background subtraction, Manders coefficients were calculated using the JACoP plugin of ImageJ software. ${ }^{60}$ Manders coefficient varies between 0 and 1 , where $M=0$ represents the lack of colocalization, while complete colocalization is denoted by $M=1 .^{61,62}$ Manders colocalization coefficient has two components: $M 1$ and $M 2 . M 1$ is defined as the ratio of the 'summed intensities of pixels from the green image for which the intensity in the red channel is above zero' to the 'total intensity in the green channel' and M2 is defined conversely for the red channel. ${ }^{63}$

\section{RESULTS AND DISCUSSION}

Synthesis of the Cholesterol Probe and the Cholesterol Anchor. Our semisynthetic strategy for the preparation of cholesteryl lipoproteins is based on the Michael addition of a C-terminally Cys extended recombinant protein to a maleimide functionalized anchor. Cholesterol was chosen as the lipid moiety of the anchor, because it presumably directs the membrane anchored protein to cholesterol-rich membrane microdomains where GPI-APs are also accumulated. The headgroup of the anchor molecule was designed to be similar in length to the glycan part of the GPIs, and to be able to expose the attached protein to the extracellular space with a distance of ca. $20 \AA$ from the surface of the membrane bilayer (Figure S1). A di(ethylene glycol) spacer between the cholesterol hemisuccinate moiety and the trifunctional linker glycine derivative provides hydrogen bond acceptor ether oxygens that improve the hydrophilic character of the headgoup. Furthermore, the conformational flexibility of this type of spacer is expected to be highly similar to that of the GPI glycan core. It is of interest to note that an endocytosis-inhibiting effect has been reported for cholesteryl ethers with long $\mathrm{PEG}_{50}$ and $\mathrm{PEG}_{200}$ chains. ${ }^{64}$ The cholesterol moiety is attached via an ester bond to the headgroup of the anchor. The hydrolytic stability of this cholesteryl ester is crucial for the imaging applications where the membrane anchored protein is to be visualized by the fluorescence of the headgroup of the anchor. In order to investigate the hydrolytic stability and the membrane association properties of the designed cholesterol anchor, the model compound 3 was synthesized and subjected to preliminary experiments. The cholesterol probe 3 was prepared 
Scheme 1. Synthesis of the Fluorescent Cholesterol Probe ${ }^{a}$

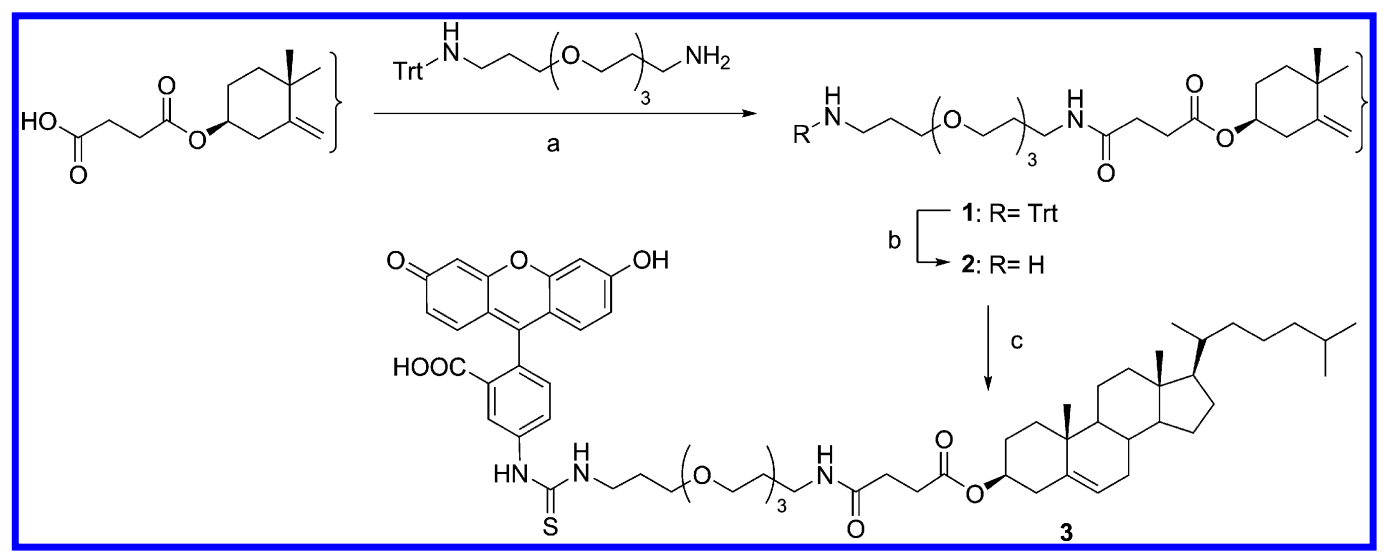

a (a) 1 equiv TBTU, 1.3 equiv DIEA, $\mathrm{CHCl}_{3} / \mathrm{CH}_{2} \mathrm{Cl}_{2}$ (4:1), RT, 8 h, 95\%; (b) TFA, TIS, $\mathrm{CH}_{2} \mathrm{Cl}_{2}, \mathrm{RT}, 5 \times 10$ min, $94 \%$; (c) 1.2 equiv FITC, 1 equiv DIEA, DMF, RT, 6 h, $47 \%$.

from cholesteryl hemisuccinate. It was activated with TBTU in the presence of DIEA, and used for the $N$-acylation of the monotrityl protected 1,13-diamino-4,7,10-trioxa-tridecane (Scheme 1). The application of HOBt and DIC resulted in lower yield, and using a dichloromethane/chloroform mixture was also required to achieve a yield of $95 \%$ in this acylation step. The trityl group was chosen for protecting the terminal amine, because it is cleaved by mild acids under a condition where the cholesteryl ester is stable. The acidolytic removal of the trityl group of $\mathbf{1}$ was performed in the presence of triethylsilane that prevented the realkylation of the amine 2 during the deprotection. Finally, the addition of the amine $\mathbf{2}$ to fluorescein isothiocyanate resulted in the cholesterol probe 3.

The hydrolytic stability of the cholesteryl ester in $\mathbf{3}$ was explored by incubating the probe in PBS at ambient temperature, and HPLC analyses were performed at regular time points. It was found that the HPLC peak area of the probe remained constant over a period of $24 \mathrm{~h}$ (Figure 1), meaning

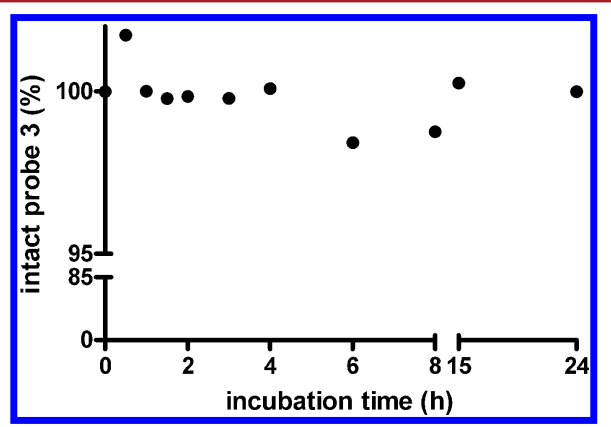

Figure 1. Hydrolytic stability of the cholesterol probe 3 . The peak area of $\mathbf{3}$ in the incubated sample is indicated as a fraction of the peak area of 3 in the starting solution. Representative chromatograms are shown in Table S2.

that the cholesteryl ester was not hydrolyzed. The chemical stability of the cholesteryl ester is a prerequisite to imaging applications, but the cholesteryl ester also needs to be resistant against cellular esterases. In a subsequent experiment $\mathrm{SH}-\mathrm{SY} 5 \mathrm{Y}$ cells were treated with $1 \mu \mathrm{M}$ of 3 , and an intensive membrane staining was observed (Figure 2). These experiments suggested that this cholesteryl ester was stable at physiological $\mathrm{pH}$, and that the hydrophilic headgroup did not prohibit the membrane insertion of the cholesterol amphiphile.

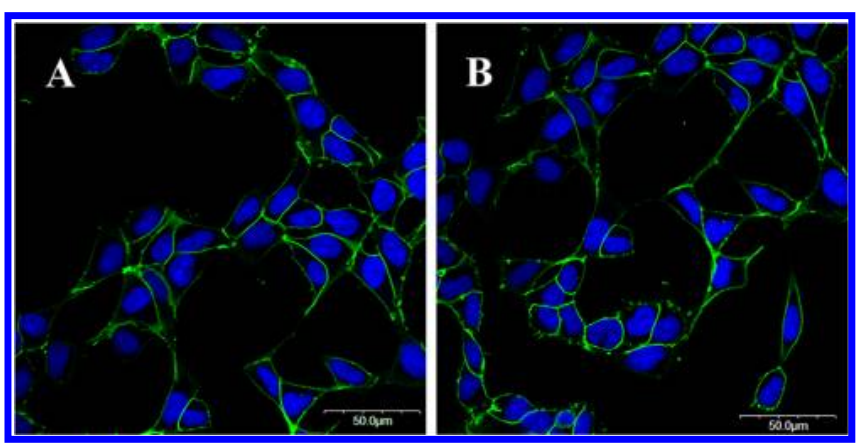

Figure 2. Association of the cholesterol probe 3 (A) and the cholesterol anchor 8 (B) with SH-SY5Y cell membranes. Cells were treated with the compounds at a concentration of $1 \mu \mathrm{M}$ for $30 \mathrm{~min}$, and nuclear staining was carried out with the nuclear dye DRAQ5 for 5 $\min$. On the image, fluorescein is green and nuclei are blue.

The synthesis of the GPI mimetic cholesterol anchor was conducted in a convergent way (Scheme 2). The synthetic strategy is based on the $[3+2]$ cycloaddition of a pegylated azidocholesterol and an alkyne derivative; the latter contains both a thiol reactive maleimide and a fluorescent reporter. The azide-alkyne cycloaddition is fairly fast and chemoselective, and it tolerates the presence of numerous functional groups and a wide range of solvents. Therefore, the demonstrated synthetic strategy can be generally applied for the introduction of diverse fluorescent reporters and protein capture functional groups via the alkyne component, i.e., the headgroup of the cholesterol anchor can be fine-tuned to the experimental setup. The size and the hydrophilic character of the headgroup can be further varied by the introduction of oligo(ethylene glycols) with different length into the azidocholesterol component. The alkyne component was synthesized from propargylglycine (Pra), because the Michael acceptor maleimide and the fluorescent reporter can be orthogonally coupled to the carboxylic and amino groups of Pra without interfering with the alkyne function. The protected maleimido Pra derivative 4 was prepared by the $N$-acylation of $N$-(2-aminoethyl)maleimide with Boc-Pra-OH in the presence of HOBt, DIC, and DIEA. The acidolytic removal of the $N^{\alpha}$-Boc amino protecting group of 4 resulted in the amine 5 , and the fluorescent alkyne 6 was obtained by the addition of fluorescein isothiocyanate. The alkyne $\mathbf{6}$ was formed in high yield when $\mathbf{5}$ was liberated in situ from the TFA salt during the isothiocyanate addition. The azide 
Scheme 2. Synthetic Route to the Green Fluorescent Cholesterol anchor $8^{a}$

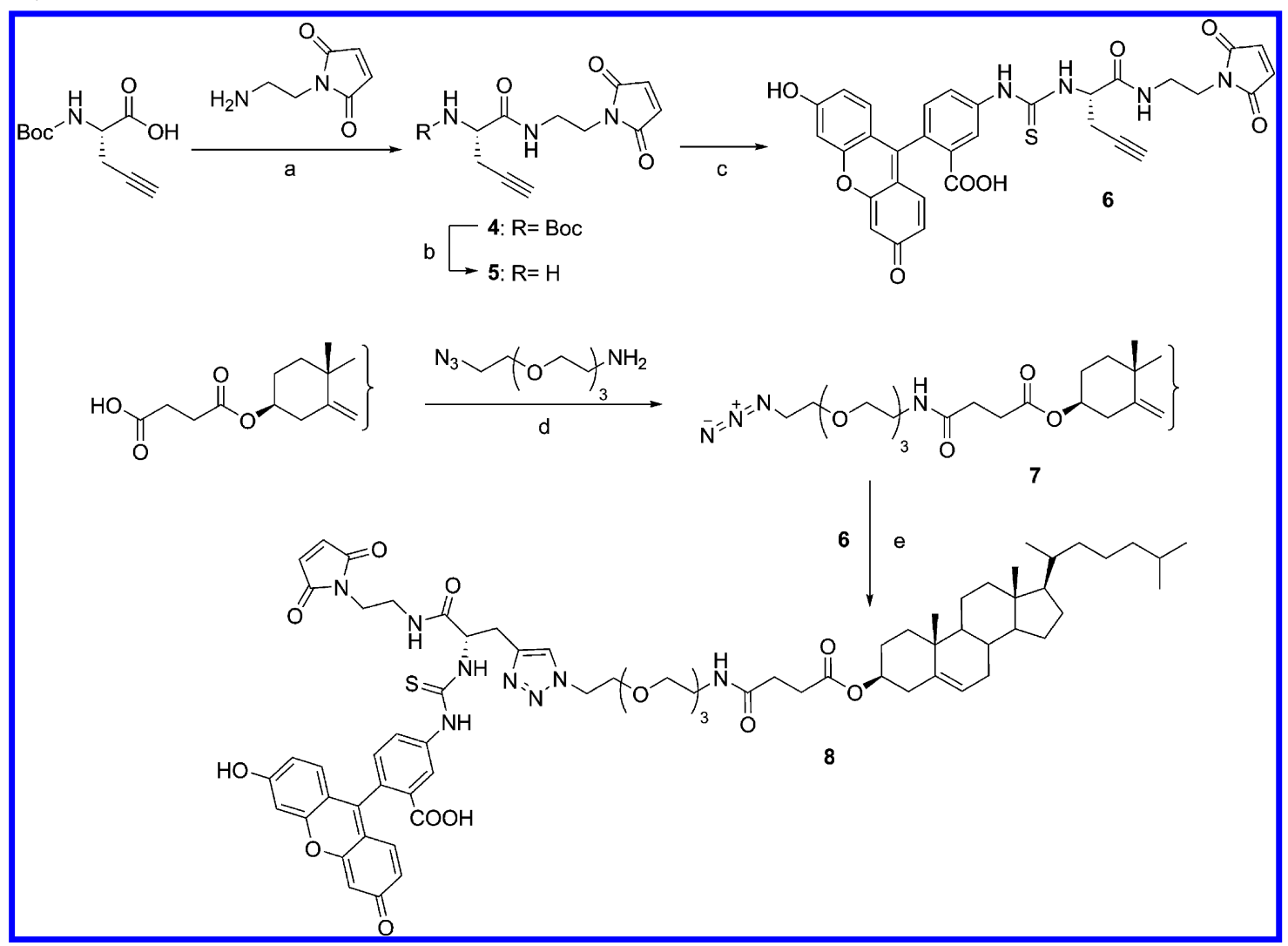

a (a) 1 equiv HOBt, 1 equiv DIC, 1 equiv DIEA, THF, RT, 8 h, 90\%; (b) TFA/ $\mathrm{CH}_{2} \mathrm{Cl}_{2}(1: 1), \mathrm{RT}, 30$ min, $96 \%$; (c) 1.05 equiv FITC, 1.05 equiv DIEA, THF, RT, 13 h, 69\%; (d) 1.3 equiv TBTU, 1.3 equiv DIEA, $\mathrm{CHCl}_{3} / \mathrm{CH}_{2} \mathrm{Cl}_{2}$ (4:1), RT, 8 h, $90 \%$; (e) 0.6 equiv $\mathrm{NaAsc} 0.3$ equiv CuSO . $5 \mathrm{H}_{2} \mathrm{O}, t \mathrm{BuOH} / \mathrm{H}_{2} \mathrm{O}(1: 1)$, RT, $48 \mathrm{~h}, 66 \%$.

component 7 was prepared by the $\mathrm{N}$-acylation of 1-amino-11azido-3,6,9-trioxaundecane with cholesteryl hemisuccinate in the presence of TBTU and DIEA. In the final step the alkyne 6 was linked to the azidolipid 7 by 1,3-dipolar cycloaddition in the presence of $\mathrm{CuSO}_{4}$ and sodium ascorbate in $t \mathrm{BuOH} / \mathrm{H}_{2} \mathrm{O}$ (1:1). The solubility of the resulting cholesterol anchor 8 was investigated in aqueous medium before the protein conjugation and the imaging application. The solution of $\mathbf{8}$ in serum free medium was incubated at ambient temperature for $16 \mathrm{~h}$, and precipitation was not observed. Then SH-SY5Y cells were treated with $1 \mu \mathrm{M}$ of $\mathbf{8}$, and an intensive membrane staining was obtained (Figure 2). Significant loss of the membrane fluorescence was not observed even 1-3 h after the treatment with $\mathbf{8}$, suggesting that the enzymatic cleavage of the headgroup is negligible under our experimental conditions. Beyond an efficient cell membrane association, the lack of cytotoxicity is also an important issue in live cell applications. Therefore the in vitro cytotoxic effect of the anchor was also investigated in a subsequent MTT-assay. It was found that the fluorescent cholesterol anchor did not exhibit apparent cytotoxicity after 1 $\mathrm{h}$ treatment in the concentration range of $0.26 \mathrm{nM}-100 \mu \mathrm{M}$.

Molecular Dynamics Simulations. The atomic details of the association of the cholesterol anchor $\mathbf{8}$ with DOPC membrane was investigated by MD simulations. This membrane model is a simplified representation of the cell membrane that contains a vast variety of lipids and ca. $30 \%$ proteins. However, it represents an electrostatic environment similar to that of the biological membranes, and it is suitable for studying the association mechanism and the atomic orientation of the inserted anchor molecule. First, the simulation system was validated by comparing experimental and calculated characteristic data of the model DOPC bilayer. Good agreement was found between the experimental ${ }^{65-67}$ and the calculated values of area per lipid headgroup, bilayer thickness, lateral diffusion coefficient, and deuterium order parameters (Table S3, Figure S2), which confirmed that the applied MD simulation conditions preserved the integrity of the model DOPC bilayer. Two initial setups were created for the production $\mathrm{MD}$ : $\mathbf{8}$ was initially embedded in the DOPC membrane or $\mathbf{8}$ was initially in the aqueous phase. In the first case, 8 stayed embedded during a 200 ns simulation without visible lateral diffusion. This observation is in agreement with that the time scale of lateral diffusion was reported to be in the range of microseconds. ${ }^{68}$ The angle between the membrane plane normal and the vector connecting the $3 \beta$-oxygen and $\mathrm{C}$ 20 atoms of the cholesterol moiety was found to vary between $0^{\circ}$ and $75^{\circ}$, and the distance between C- $\alpha$ and $3 \beta$-oxygen varied between $8 \AA$ and $19 \AA$ indicating vigorous axial diffusion and wobbling of the cholesterol moiety of the anchor (Figure 3 ). In spite of these fast and constant, nanosecond time scale movements, the anchor molecule acquired a relatively stable conformation and arrangement. The conformational change of 8 took place after approximately $20 \mathrm{~ns}$ of simulation time and resulted in a special twice-bent shape, which remained relatively stable until the end of the simulation (Figure 4). In this arrangement the di(ethylene glycol) linker lies parallel to the membrane plane, the polar groups of this moiety are in close contact with the lipid headgroups, the cholesterol scaffold is 


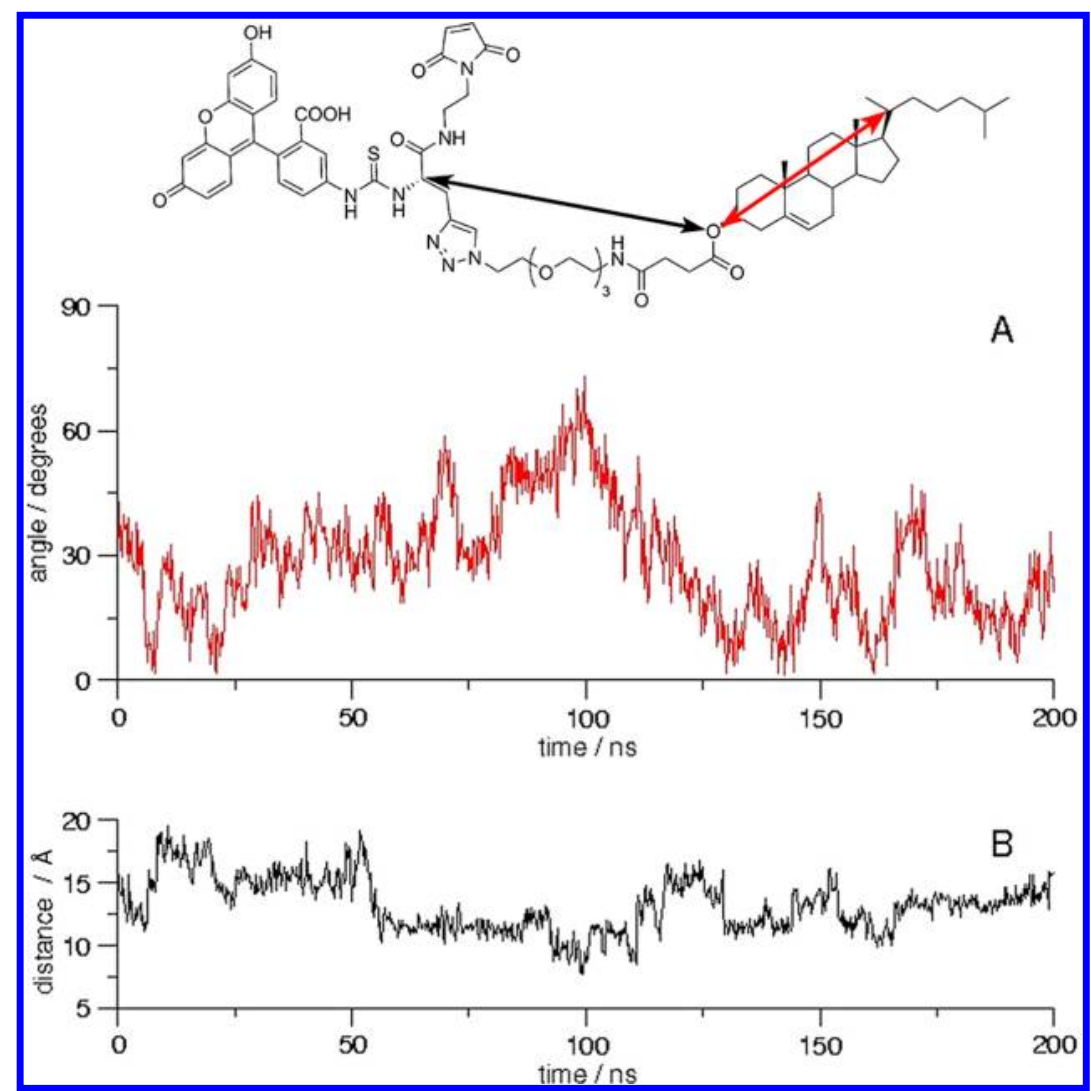

Figure 3. Fluctuation of (A) the angle between the membrane plane normal and the vector connecting the $3 \beta$-oxygen and $\mathrm{C}$ - 20 atoms of the cholesterol moiety (red arrow), and (B) the distance between C- $\alpha$ and $3 \beta$-oxygen of anchor 8 (black arrow) during MD simulations.

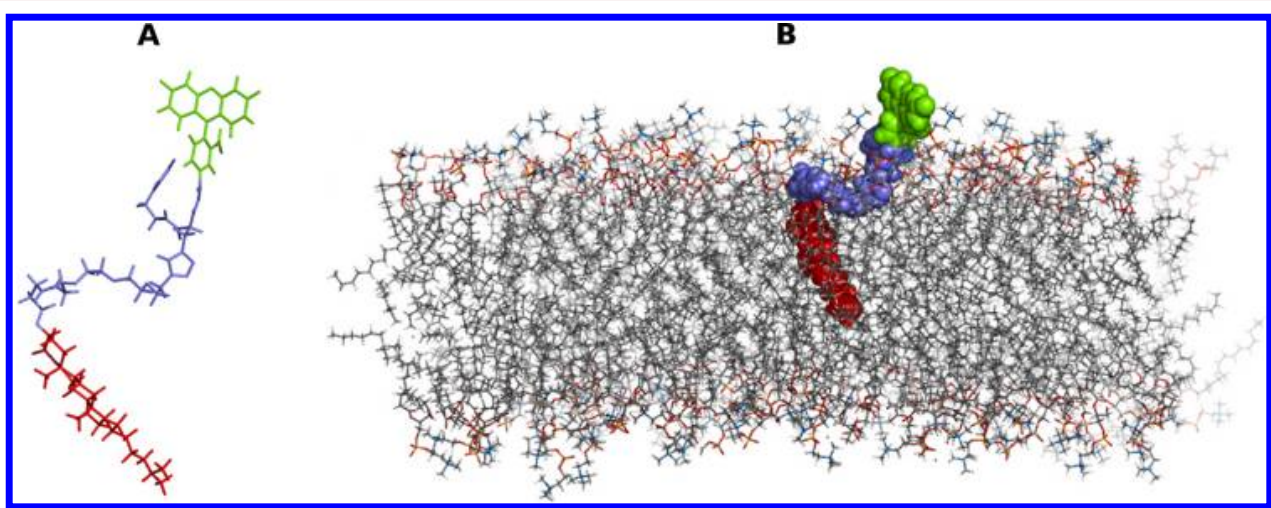

Figure 4. Structure of the cholesterol anchor $\mathbf{8}$ embedded in DOPC model membrane; water and lipid molecules (A) or just water molecules (B) are omitted for clarity.

immersed in the lipophilic region of the bilayer, and both the maleimido and the fluorescent reporter moieties of the headgroup float in the aqueous phase or form interactions with the DOPC headgroups.

In the second simulation $\mathbf{8}$ was initially placed in the aqueous phase, and association of the anchor molecule with the membrane surface was observed (Figure S3). While floating in the aqueous phase, 8 adopted a doubled up bent structure, in which the aromatic rings of fluorescein are packed against the cholesterol scaffold to minimize the solvent accessible hydrophobic surface. Membrane association was initiated by polar interactions between the exposed di(ethylene glycol) linker of 8 and the lipid headgroups, observed shortly after 100 ns of simulation time. This initial association then led to the break-up of the intramolecular hydrophobic interactions of $\mathbf{8}$ and subsequently to the gradual immersion of the cholesterol moiety into the DOPC leaflet. Although this anchormembrane complex remained stable for the rest of the simulation time, formation of the twice-bent conformation of 8 identified in the first MD simulation was not observed here. It suggests that the spontaneous membrane association and complete membrane embedding of $\mathbf{8}$ would take longer than 200 ns. It has to be mentioned that simulations presented here were performed for an isolated cholesterol anchor molecule, while 8 forms either micelles or $\beta$-cyclodextrin inclusion complexes under the experimental conditions. Therefore, the molecular mechanism of membrane embedding may be different from that described above. Nevertheless, the results of the MD simulations are consistent with the experimental observations of the stable and spontaneous membrane 
association of 8. Furthermore, atomic level information was provided about the arrangement of the membrane-anchor complex suggesting that, similarly to the GPI auxiliary, $\mathbf{8}$ could expose the attached protein toward the aqueous phase while firmly attaching it to the membrane surface.

Protein Conjugation of the Cholesterol Anchor. The red fluorescent protein mCherry lacking any native Cys residues was chosen to optimize the protein-cholesterol anchor conjugation, and to demonstrate that the designed fluorescent cholesterol derivative can anchor proteins to the cell membrane. The C-terminal Cys extension of mCherry resulted in a protein that possessed a single Michael donor thiol group assuring the chemoselective addition of the anchor 8 to the protein C-terminus. A further advantage of this two-color fluorescent lipoprotein conjugate (mCherry - red, fluorescein - green) is that its integrity, i.e., the equimolarity of the protein and the anchor, can easily be assessed by SDS-PAGE and by measuring the intensity of the fluorescence emissions.

mCherry was overexpressed in E. coli with a $\mathrm{His}_{6}$ tag preceding the C-terminal Cys residue, and it was purified from the soluble fraction of the E. coli lysate by $\mathrm{Ni}$-affinity chromatography. The conjugation of the cholesterol anchor 8 to mCherry-Cys was performed in $20 \mathrm{mM}$ Tris, $10 \mathrm{mM}$ TCEP at $\mathrm{pH}$ 7.5. Under these conditions the $\beta$-barrel structure of the protein remains intact, and the amphiphilic cholesterol anchor forms highly stable micellar associates with an approximate critical micellar concentration of $10-100 \mathrm{nM}$ as estimated from data on similar amphiphiles. ${ }^{55}$ It was found that the total conversion of mCherry required 25-fold excess of anchor 8 in 1 $\mathrm{h}$ (Figure 5). This ratio suggests that the micelles of 8 compose

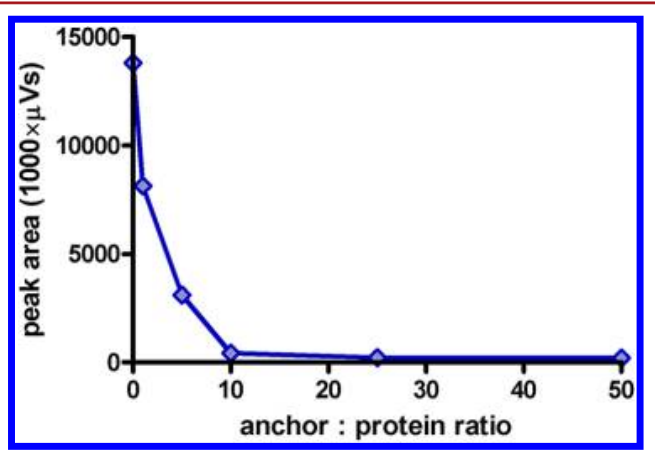

Figure 5. Conjugation of the cholesterol anchor 8 with mCherry-Cys. The concentration of the unreacted mCherry in the reaction mixture after $1 \mathrm{~h}$ is indicated $(\diamond)$.

of ca. 25 cholesterol amphiphiles, and also that a micelle reacts with a single protein molecule. On preparative scale a protein to anchor ratio of 1:10 was applied, and the total amount of 8 was added in 10 portions over $5 \mathrm{~h}$. After the Michael addition, the mixed micelles of the cholesteryl mCherry conjugate and the anchor 8 amphiphiles were separated from both the unreacted protein and the anchor $\mathbf{8}$ micelles by gel chromatography. According to the elution time, the micellar associates of this cholesteryl mCherry preparation exhibited a virtual molecular weight significantly higher than that of the mCherry (Figure S5). The gel chromatographic fraction containing the mCherry-anchor $\mathbf{8}$ conjugate was subjected to SDS-PAGE, and an intensive fluorescence was detected in the dye front indicating the presence of mixed micelles. These mixed micellar associates keep the cholesteryl lipoprotein dissolved in an aqueous medium. Nevertheless, it is essential to remove the surplus fluorescent cholesterol; otherwise, the plasma membrane or the cholesterol homeostasis ${ }^{69}$ could be perturbed during live cell imaging applications. Furthermore, if the mixed micelles of the conjugate are used for the introduction of the lipoprotein into the cell membrane, the unambiguous imaging of the membrane anchored protein will be impossible via the fluorescence of the cholesterol anchor.

Purification of the Cholesteryl Lipoprotein. Different methods were explored for the separation of the cholesteryl lipoprotein from the surplus fluorescent cholesterol anchor with an emphasis on the retention of the native fold of the protein. Dialysis is commonly used to remove small molecules or lipid excess from protein samples; however, the stability of the mixed micelles of $\mathbf{8}$ and cholesteryl mCherry limits the performance of this technique. Extraction of the surplus cholesterol anchor with polar solvents is another option, but the application of chloroform denatured the protein. Refolding of such a denatured cholesteryl lipoprotein was not feasible, because the cholesterol residue permanently participates in hydrophobic interactions, and thus, restricts the protein folding. On the other hand, the application of detergents results in mixed detergent micelles of the cholesteryl lipoprotein which are free of surplus fluorescent cholesterol anchors. The introduction of the cholesteryl lipoprotein into the cell membrane via such detergent micelles makes the imaging of the membrane associated protein feasible, but the detergent molecules have a membrane perturbing effect that is to be avoided. When the mixed micelles of mCherry-anchor $\mathbf{8}$ were purified by reversed phase HPLC, the mixed micelles were disrupted at an acetonitrile concentration of $50 \%$ and the cholesteryl mCherry was eluted as a pure semisynthetic product. However, the resulting lipoprotein lost the red fluorescent properties indicating the distortion of the $\beta$-barrel structure of mCherry. Afterward, the refolding of this denatured cholesteryl mCherry failed similarly to that of the chloroform extracted cholesteryl mCherry. The application of an anchor capture resin was also intended for the separation of the lipoprotein and the anchor excess by filtering off the resin bound anchor. A cysteinyl CLEAR-amide resin was prepared for that purpose, because it has beneficial water swelling properties. But the heterogeneous Michael addition was found to be very slow, and the mixed micelles remained intact. Finally, another approach was tried, where the cholesterol moiety of the protein-anchor conjugate was sequestered by a reversible complexation with $\beta$-cyclodextrin. It is based on the fact that $\beta$ cyclodextrin forms a stable inclusion complex with cholester$\mathrm{ol}^{70}$ In the presence of low concentration of $\beta$-cyclodextrin, cholesterol can be incorporated into the plasma membrane within a few minutes, ${ }^{71}$ because the exchange rate of cholesterol between $\beta$-cyclodextrin and membranes is high. Furthermore, $\beta$-cyclodextrin does not accelerate the extraction of phospholipids from the cell membrane when the concentration of $\beta$ cyclodextrin is below $20 \mathrm{mM}^{72}$ When the mixed micelles composed of the cholesteryl mCherry and anchor 8 were incubated with 10 equiv $\beta$-cyclodextrin, the micellar associates were disrupted without any sign of denaturing the protein (Figure 6). The hydrophobic cavity of the $\beta$-cyclodextrin binds the cholesterol moiety of the conjugate and that of the surplus anchor molecules forming host-guest complexes. The molecular weight of the inclusion complex of the proteinanchor 8 conjugate is significantly higher than that of the cholesterol anchor, and thus, their separation was achieved by size-exclusion chromatography. The purified inclusion complex 


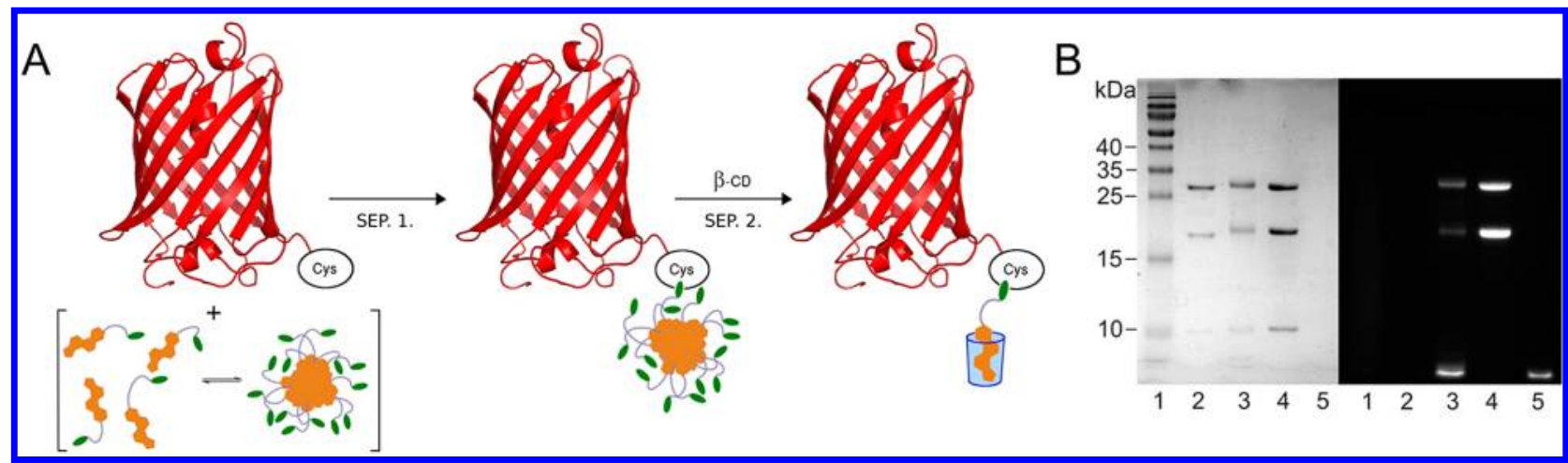

Figure 6. (A) Preparation of the lipid excess-free cholesteryl mCherry. The schematic green heads represent the green fluorophore of the cholesterol anchor 8 ; $\beta$-cyclodextrin is symbolized with a blue truncated cone; SEP.1. and SEP.2. indicate gel chromatographic separations. (B) Coomassie bluestained (left) and fluorescence detected (right) 15\% SDS-PAGE gel: lane 1, molecular weight marker; lane 2, mCherry (see Scheme S1 for the hydrolysis of the red fluorophore resulting in the multiple band pattern); lane 3, mixed micelles of cholesteryl mCherry (the cholesteryl derivatives of the full length mCherry and the C-terminal mCherry fragment, and the surplus 8 are fluorescent); lane $4, \beta$-cyclodextrin inclusion complex of cholesteryl mCherry (in order to emphasize the lack of surplus anchor 8, a larger amount of lipoprotein was introduced than in lane 3); lane 5, cholesterol anchor 8. Quantitation of the fluorescent signals on lanes 3 and 4 was carried out and the ratio of the protein associated fluorescence to the fluorescence of the residual cholesterol anchor is given in Table S4.

of the lipoprotein was subjected to SDS-PAGE analysis followed by fluorescence detection. The intensity of the fluorescent bands of the samples containing the mixed micelles of cholesteryl mCherry and the $\beta$-cyclodextrin inclusion complex of cholesteryl mCherry was measured, and the ratio of the protein associated fluorescence to the cholesterol anchor fluorescence was determined using the gel analyzing tool of ImageJ software. ${ }^{60}$ The ratio of the intensity of the $27.6 \mathrm{kDa}$ band to the front was found to be 1:2.57 and 1:0.003 before and after the purification via the $\beta$-cyclodextrin inclusion complex, respectively (Table S4). Thus, the fluorescence detection revealed that the mCherry-anchor 8 preparation was free of surplus fluorescent anchor.

Characterization of the Cholesteryl Lipoprotein. The fluorescence spectra of the pure lipoprotein exhibited the characteristics of both fluorophores with shoulders on the emission spectrum of fluorescein and on the excitation spectrum of mCherry (Figure 7). The emission spectrum of the red fluorophore was also recorded at an excitation wavelength of $543 \mathrm{~nm}$, because it was applied during the confocal laser scanning microscopic experiments. The red fluorescence of the $\beta$-cyclodextrin inclusion complex of cholesteryl mCherry was indicative of the retention of the native protein fold, but it was further evidenced by ECD spectroscopy. Figure 8 shows the ECD spectra of mCherryCys and those of the mCherry-anchor 8 conjugate. The fractions of the secondary structural elements of the proteins were calculated by deconvoluting these ECD spectra (Table 1). An almost identical distribution of the helix, $\beta$-sheet, turn, and random structures was found for the conjugate and the parent mCherry-Cys. It indicates that the attachment of the cholesterol anchor does not cause significant change in the protein structure, and that the $\beta$-barrel fold of mCherry is intact both in the mixed micellar form and in the $\beta$-cyclodextrin inclusion complex. The distribution of the secondary structural elements was also calculated from the X-ray diffraction structure of mCherry for comparison. The crystal structure was analyzed with both the DSSP ${ }^{73}$ and STRIDE ${ }^{74}$ secondary structure recognition algorithms, which yielded very similar results. However, in the solution structures of mCherry-Cys and the mCherry-anchor 8 conjugate, slightly higher fractions

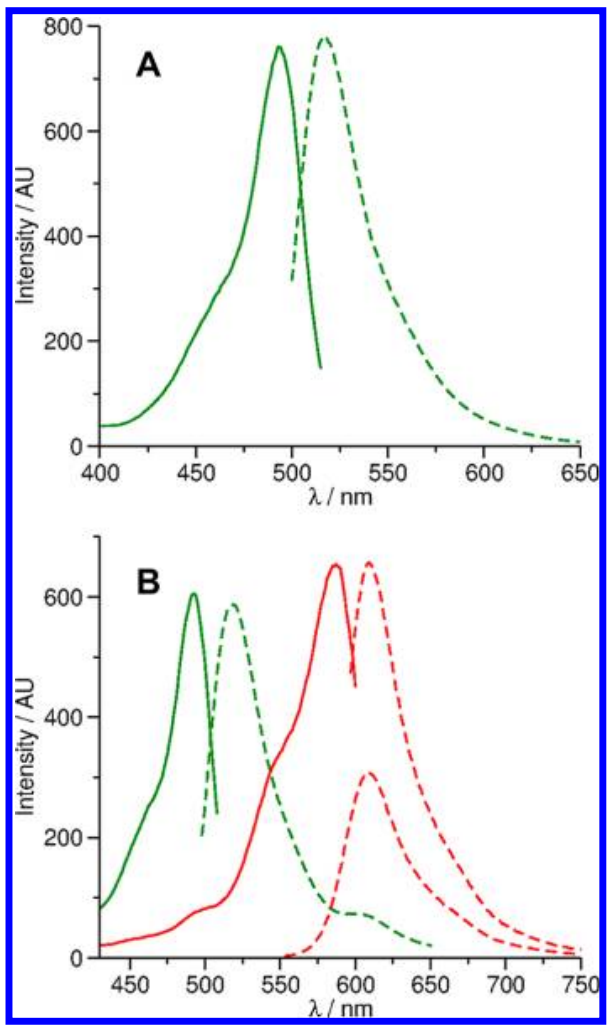

Figure 7. (A) Excitation (-) and emission (- - -) spectra of the cholesterol anchor $8\left(50 \mu \mathrm{M}\right.$ in $\left.\mathrm{H}_{2} \mathrm{O}\right)$ at $25^{\circ} \mathrm{C} ; \lambda_{\text {em }}=525 \mathrm{~nm}$ and $\lambda_{\text {ex }}$ $=488 \mathrm{~nm}$. (B) Excitation (green -, $\lambda_{\mathrm{em}}=518 \mathrm{~nm}$; red -, $\lambda_{\mathrm{em}}=610$ $\mathrm{nm}$ ) and emission (green - - -, $\lambda_{\mathrm{ex}}=488 \mathrm{~nm}$; red - - , $\lambda_{\mathrm{ex}}=543$ and 587 $\mathrm{nm})$ spectra of cholesteryl mCherry $\left(20 \mu \mathrm{M}\right.$ in $\left.\mathrm{H}_{2} \mathrm{O}\right)$ at $25{ }^{\circ} \mathrm{C}$.

of random structures and lower fractions of $\beta$-strands were found. It could be attributed to the flexible $\mathrm{N}$ - and C-terminal regions of mCherry that are missing from the X-ray crystal structure.

Imaging of the Cholesteryl Lipoprotein with Confocal Laser Scanning Microscopy. It was shown that our approach offers an effective way to prepare fluorescent cholesteryl lipoproteins without denaturing the protein fold. The integrity of the resulting fluorescent cholesteryl lipoprotein provides the 


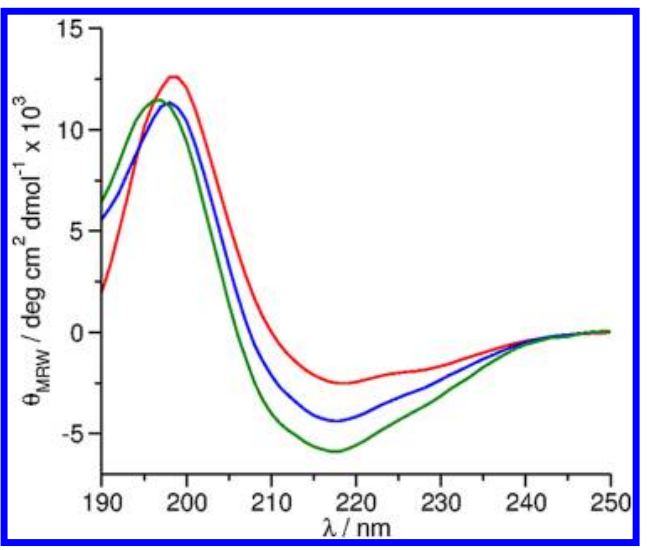

Figure 8. ECD spectra of mCherry-Cys (red), mixed micelles of cholesteryl mCherry (blue), and the $\beta$-cyclodextrin inclusion complex of cholesteryl mCherry (green).

Table 1. Fractions of Secondary Structure Elements in mCherry

\begin{tabular}{lcccc}
\multicolumn{1}{c}{ protein } & helix & $\begin{array}{c}\beta \text { - } \\
\text { sheet }\end{array}$ & turns & random \\
mCherry $^{a}$ & 0.06 & 0.57 & 0.16 & 0.14 \\
mCherry $^{b}$ & 0.05 & 0.58 & 0.27 & 0.11 \\
mCherry-Cys $^{c}$ & 0.09 & 0.40 & 0.24 & 0.27 \\
mCherry-anchor 8 conjugate $^{c}$ & 0.05 & 0.43 & 0.24 & 0.28 \\
mCherry-anchor 8 conjugate with $\beta$ - $^{c}$ & 0.07 & 0.41 & 0.25 & 0.26
\end{tabular}

${ }^{a}$ Results obtained from PDB 2 H5Q by DSSP algorithm. ${ }^{b}$ Results obtained from PDB $2 \mathrm{H} 5 \mathrm{Q}$ by STRIDE algorithm. ${ }^{c}$ Results obtained from experimental ECD spectra by deconvolution.

advantage of avoiding the coadministration of surplus, nonconjugated fluorescent lipids and detergents, and thus, the membrane perturbation by external lipid excess or detergents can be excluded in live cell imaging applications. Importantly, the fluorescence signal of the anchor molecule can be unambiguously assigned to the conjugated protein. In order to introduce the semisynthetic lipoprotein into the plasma membrane of live cells, the mCherry-anchor 8 conjugate was added to a mammalian cell culture along with controls (anchor $\mathbf{8}$ or mCherry-Cys alone) and monitored by confocal laser scanning microscopy. Images of SH-SY5Y cells incubated with the $\beta$-cyclodextrin inclusion complex of the semisynthetic mCherry-anchor $\mathbf{8}$ conjugate show green and red fluorescence on the cell membrane (Figure 9). This suggests that the protein is successfully anchored to the cell membrane after exogenous addition, and also that the protein structure is not affected by the membrane association. Red fluorescence was not observed when cells were treated with mCherry-Cys, confirming that the cholesteryl lipoprotein was firmly associated to the cell membrane via the cholesterol anchor. The membrane association of the conjugate also results in the liberation of $\beta$ cyclodextrin from the inclusion complex. However, the presence of $10-20 \mu \mathrm{M} \beta$-cyclodextrin in the cell culture medium has no effect on the normal cellular cholesterol level, because the cholesterol extraction from the cell membrane requires higher $\beta$-cyclodextrin concentration in the $\mathrm{mM}$ range. $^{75}$ It is important to note that, due to the structure of the anchor and the moderate hydrophobicity of fluorescein, the fluorescent reporter is expected to be situated extracellularly. It is in agreement with the results of the MD simulations on the anchor 8 , where only the cholesterol residue immersed into the outer leaflet of the membrane bilayer. This spatial arrangement of the conjugate helps to maintain lipid-lipid interactions specific for cholesterol, and proposes lateral diffusion properties similar to that of cholesterol. These membrane biophysical properties would be altered if the sterane skeleton was modified with a fluorescent molecule. ${ }^{76}$ The colocalization of the fluorophores also evidenced that the cholesteryl ester and consequently the whole conjugate was stable under the circumstances of the live cell imaging. In order to quantitate the colocalization of the mCherry and fluorescein fluorophores, the Manders colocalization coefficients were calculated. The original $M 1$ and $M 2$ values were found to be $0.993 \pm 0.020$ and $0.999 \pm 0.001$, respectively. These data represent high colocalization, which is unambiguously visualized in Figure 9B. It is also visible on the differential interference contrast picture that the conjugate exhibited no apparent toxic effects on the SH-SY5Y cells. This finding is in agreement with the results

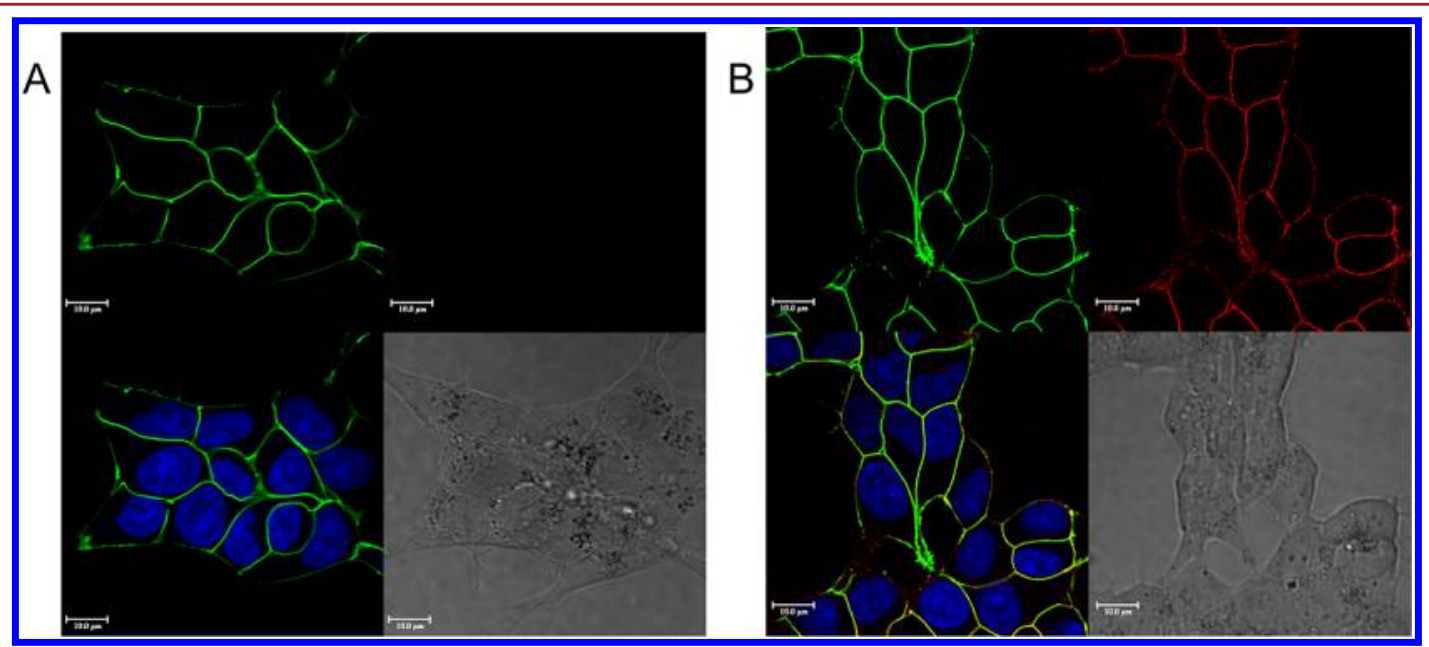

Figure 9. Confocal laser scanning and differential interference contrast (right bottom) microscopy of SH-SY5Y cells after 30 min incubation (A) with $1 \mu \mathrm{M}$ cholesterol anchor 8 , and (B) with $\beta$-cyclodextrin inclusion complex of $1 \mu \mathrm{M}$ cholesteryl mCherry at $37^{\circ} \mathrm{C}$. On the images fluorescein is green, $\mathrm{mCherry}$ is red, and nuclei are blue. On the overlaid image (A and B, left bottom) yellow represents the colocalization of the fluorescein and mCherry signals. 
of the MTT assays, where the mCherry-anchor 8 conjugate was found to be nontoxic at a concentration of $10 \mu \mathrm{M}$.

\section{CONCLUSIONS}

A general approach for the modification of proteins with fluorescent cholesterol derivatives is suggested, where the resulting semisynthetic proteins enable the direct imaging of membrane associated cholesteryl proteins after exogenous introduction into live cells. The appropriate cholesterol anchor is prepared with a convergent synthetic strategy that allows flexibility in the molecular design of the headgroup, i.e., the Michael acceptor, the length of the PEG spacer, and the fluorescent reporter molecule all can be fine-tuned to the preferences of the particular application, to the target protein, and to the instrumentation. The stable membrane association of the cholesterol anchor was confirmed experimentally, and an extracellular orientation of the headgroup is in agreement with the molecular dynamics simulations performed with anchor $\mathbf{8}$. As a proof of concept, the method was demonstrated on the red fluorescent protein mCherry that was conjugated with a green fluorescent anchor. Due to the presence and position of the green fluorescent reporter, the purity and the homogeneity of the cholesteryl lipoprotein could be unambiguously analyzed. Furthermore, the retention of the red fluorescence of mCherry was indicative of the preservation of the native protein fold after cholesterol conjugation, and after delivery into membranes of live cells. In imaging applications, the model protein mCherry can be substituted with other target proteins having a Cterminal Cys residue. The main advantage of our method is that the use of the $\beta$-cyclodextrin inclusion complex of the protein conjugate allows the treatment of live cells with fluorescent cholesteryl lipoproteins without the use of membrane perturbing detergents. Furthermore, no surplus fluorescent lipids over the stoichiometric cholesterol moiety of the semisynthetic lipoprotein are introduced into the cell membrane. As a consequence, direct imaging of a membrane anchored protein became feasible with a small molecule fluorophore, and thus, the strategy offers a beneficial alternative to GFP fusions for studying membrane associated proteins. Our conjugation method might also be applied in fluorescence microscopic investigation of the cellular traffic of GPI-APs and in cell surface engineering, because the exogenous insertion of pure cholesteryl lipoproteins into cell membranes causes a lower degree of stress to the recipient cells as compared to the liposome fusion or micelle fusion methods.

\section{ASSOCIATED CONTENT}

\section{S Supporting Information}

Comparison of a GPI anchor and the designed cholesterol anchor; synthetic procedures, numbering of compounds for NMR assignation; representative RP-HPLC chromatograms; details of the MD simulations; MD simulation snapshots of the membrane association of $\mathbf{8}$; plasmid construction for mCherryCys. This material is available free of charge via the Internet at http://pubs.acs.org.

\section{AUTHOR INFORMATION}

\section{Corresponding Author}

*E-mail: tomboly@brc.hu. Phone: +36-62-599-646. Fax: +3662-433-506.

\section{Present Address}

Erika Orbán, Institute of Biophysical Chemistry, Goethe University Frankfurt, Max-von-Laue str. 9, 60438 Frankfurt, Germany.

\section{Notes}

The authors declare no competing financial interest.

\section{ACKNOWLEDGMENTS}

Financial support from the Hungarian Scientific Research Fund (K77783 (Cs.T.) and K82090 (E.W.)), from the Hungarian National Development Agency (TÁMOP 4.2.2.A-11/1/ KONV-2012-0052 (Cs.T.) and TÁMOP 4.2.4.A/2-11-1-20120001 (A.B.), and the János Bolyai Research Scholarship of the Hungarian Academy of Sciences (Cs.T.), and access granted to the high performance computing centre of the National Information Infrastructure Development Institute (A.B.) are acknowledged. We also thank D. Tourwé for critical reading of the manuscript and helpful discussions.

\section{REFERENCES}

(1) Hang, H. C., Wilson, J. P., and Charron, G. (2011) Bioorthogonal chemical reporters for analyzing protein lipidation and lipid trafficking. Acc. Chem. Res. 44, 699-708.

(2) Gordon, J. I., Duronio, R. J., Rudnick, D. A., Adams, S. P., and Gokel, G. W. (1991) Protein N-myristoylation. J. Biol. Chem. 266, $8647-8650$.

(3) Smotrys, J. E., and Linder, M. E. (2004) Palmitoylation of intracellular signaling proteins: regulation and function. Annu. Rev. Biochem. 73, 559-587.

(4) Towler, D. A., Gordon, J. I., Adams, S. P., and Glaser, L. (1988) The biology and enzymology of eukaryotic protein acylation. Annu. Rev. Biochem. 57, 69-99.

(5) Fu, H. W., and Casey, P. J. (1999) Enzymology and biology of CaaX protein prenylation. Recent Prog. Horm. Res. 54, 315-342.

(6) Low, M. G. (1989) The glycosyl-phosphatidylinositol anchor of membrane-proteins. Biochim. Biophys. Acta 988, 427-454.

(7) Low, M. G., and Saltiel, A. R. (1988) Structural and functional roles of glycosyl-phosphatidylinositol in membranes. Science 239, 268275.

(8) Englund, P. T. (1993) The structure and biosynthesis of glycosyl phosphatidylinositol protein anchors. Annu. Rev. Biochem. 62, 121138.

(9) Paulick, M. G., and Bertozzi, C. R. (2008) The glycosylphosphatidylinositol anchor: a complex membrane-anchoring structure for proteins. Biochemistry 47, 6991-7000.

(10) Kinoshita, T. and Fujita, M. (2009) Overview of GPI biosynthesis. The Enzymes. Vol. 26: Glycosylphosphatidylinositol (GPI) anchoring of proteins (Menon, A. K., Kinoshita, T., Orlean, P., Tamanoi, F., Eds.) pp 1-30, Academic Press, New York.

(11) Savage, V. J., and Brodsky, R. A. (2006) New insights into paroxysmal nocturnal hemoglobinuria. Hematology 12, 371-376.

(12) Prusiner, S. B. (1998) Prions. Proc. Natl. Acad. Sci. U. S. A. 95, 13363-13383.

(13) Zhao, P., Nairn, A. V., Hester, S., Moremen, K. W., O’Regan, R. M., Oprea, G., Wells, L., Pierce, M., and Abbott, K. L. (2012) Proteomic identification of glycosylphosphatidylinositol anchordependent membrane proteins elevated in breast carcinoma. J. Biol. Chem. 287, 25230-25240.

(14) Ferguson, M. A. (1999) The structure, biosynthesis and functions of glycosylphosphatidylinositol anchors, and the contributions of trypanosome research. J. Cell Sci. 112, 2799-2809.

(15) Nozaki, M., Ohishi, K., Yamada, N., Kinoshita, T., Nagy, A., and Takeda, J. (1999) Developmental abnormalities of glycosylphosphatidylinositol-anchor-deficient embryos revealed by Cre/IoxP system. Lab. Invest. 79, 293-299.

(16) Chatterjee, S., and Mayor, S. (2001) The GPI-anchor and protein sorting. Cell. Mol. Life Sci. 58, 1969-1987. 
(17) Low, M. G. (1989) Glycosyl-phosphatidylinositol: a versatile anchor for cell surface proteins. FASEB J. 3, 1600-1608.

(18) Mayor, S., and Riezman, H. (2004) Sorting GPI-anchored proteins. Nat. Rev. Mol. Cell Biol. 5, 110-120.

(19) Eggeling, C., Ringemann, C., Medda, R., Schwarzmann, G., Sandhoff, K., Polyakova, S., Belov, V. N., Hein, B., von Middendorff, C., Schonle, A., and Hell, S. W. (2009) Direct observation of the nanoscale dynamics of membrane lipids in a living cell. Nature 457, $1159-1162$.

(20) Simons, K., and Gerl, M. J. (2010) Revitalizing membrane rafts: new tools and insights. Nat. Rev. Mol. Cell Biol. 11, 688-699.

(21) Lingwood, D., and Simons, K. (2010) Lipid rafts as a membrane-organizing principle. Science 327, 46-50.

(22) Sharma, P., Varma, R., Sarasij, R. C., Ira, Gousset, K., Krishnamoorthy, G., Rao, M., and Mayor, S. (2004) Nanoscale organization of multiple GPI-anchored proteins in living cell membranes. Cell 116, 577-589.

(23) Simons, K., and Ikonen, E. (1997) Functional rafts in cell membranes. Nature 387, 569-572.

(24) Simons, K., and Toomre, D. (2000) Lipid rafts and signal transduction. Nat. Rev. Mol. Cell Biol. 1, 31-39.

(25) Ball, H. L., King, D. S., Cohen, F. E., Prusiner, S. B., and Baldwin, M. A. (2001) Engineering the prion protein using chemical synthesis. J. Pept. Res. 58, 357-374.

(26) Eberl, H., Tittmann, P., and Glockshuber, R. (2004) Characterization of recombinant, membrane-attached full-length prion protein. J. Biol. Chem. 279, 25058-25065.

(27) Musiol, H. J., Dong, S., Kaiser, M., Bausinger, R., Zumbusch, A., Bertsch, U., and Moroder, L. (2005) Toward semisynthetic lipoproteins by convergent strategies based on click and ligation chemistry. ChemBioChem 6, 625-628.

(28) Grogan, M. J., Kaizuka, Y., Conrad, R. M., Groves, J. T., and Bertozzi, C. R. (2005) Synthesis of lipidated green fluorescent protein and its incorporation in supported lipid bilayers. J. Am. Chem. Soc. 127, $14383-14387$.

(29) Paulick, M. G., Wise, A. R., Forstner, M. B., Groves, J. T., and Bertozzi, C. R. (2007) Synthetic analogues of glycosylphosphatidylinositol-anchored proteins and their behavior in supported lipid bilayers. J. Am. Chem. Soc. 129, 11543-11550.

(30) Hicks, M. R., Gill, A. C., Bath, I. K., Rullay, A. K., Sylvester, I. D., Crout, D. H., and Pinheiro, T. J. (2006) Synthesis and structural characterization of a mimetic membrane-anchored prion protein. FEBS J. 273, 1285-1299.

(31) Breydo, L., Sun, Y., Makarava, N., Lee, C. I., Novitskaia, V., Bocharova, O., Kao, J. P., and Baskakov, I. V. (2007) Nonpolar substitution at the $\mathrm{C}$-terminus of the prion protein, a mimic of the glycosylphosphatidylinositol anchor, partially impairs amyloid fibril formation. Biochemistry 46, 852-861.

(32) Olschewski, D., Seidel, R., Miesbauer, M., Rambold, A. S., Oesterhelt, D., Winklhofer, K. F., Tatzelt, J., Engelhard, M., and Becker, C. F. (2007) Semisynthetic murine prion protein equipped with a GPI anchor mimic incorporates into cellular membranes. Chem. Biol. 14, 994-1006.

(33) Becker, C. F., Liu, X., Olschewski, D., Castelli, R., Seidel, R., and Seeberger, P. H. (2008) Semisynthesis of a glycosylphosphatidylinositol-anchored prion protein. Angew. Chem., Int. Ed. 47, 8215-8219.

(34) Teruya, K., Nishizawa, K., and Doh-ura, K. (2010) Semisynthesis of a protein with cholesterol at the C-terminal, targeted to the cell membrane of live cells. Protein J. 29, 493-500.

(35) Paulick, M. G., Forstner, M. B., Groves, J. T., and Bertozzi, C. R. (2007) A chemical approach to unraveling the biological function of the glycosylphosphatidylinositol anchor. Proc. Natl. Acad. Sci. U. S. A. 104, 20332-20337.

(36) Medof, M. E., Kinoshita, T., and Nussenzweig, V. (1984) Inhibition of complement activation on the surface of cells after incorporation of decay-accelerating factor (DAF) into their membranes. J. Exp. Med. 160, 1558-1578.

(37) van den Berg, C. W., Cinek, T., Hallett, M. B., Horejsi, V., and Morgan, B. P. (1995) Exogenous glycosyl phosphatidylinositol- anchored CD59 associates with kinases in membrane clusters on U937 cells and becomes $\mathrm{Ca}(2+)$-signaling competent. J. Cell Biol. 131, 669-677.

(38) Medof, M. E., Nagarajan, S., and Tykocinski, M. L. (1996) Cellsurface engineering with GPI-anchored proteins. FASEB J. 10, 574586.

(39) Premkumar, D. R., Fukuoka, Y., Sevlever, D., Brunschwig, E., Rosenberry, T. L., Tykocinski, M. L., and Medof, M. E. (2001) Properties of exogenously added GPI-anchored proteins following their incorporation into cells. J. Cell Biochem. 82, 234-245.

(40) Milhiet, P. E., Giocondi, M. C., Baghdadi, O., Ronzon, F., Roux, B., and Le Grimellec, C. (2002) Spontaneous insertion and partitioning of alkaline phosphatase into model lipid rafts. EMBO Rep. 3, 485-490.

(41) Rifkin, M. R., and Landsberger, F. R. (1990) Trypanosome variant surface glycoprotein transfer to target membranes: a model for the pathogenesis of trypanosomiasis. Proc. Natl. Acad. Sci. U. S. A. 87, 801-805.

(42) Dunn, D. E., Yu, J., Nagarajan, S., Devetten, M., Weichold, F. F., Medof, M. E., Young, N. S., and Liu, J. M. (1996) A knock-out model of paroxysmal nocturnal hemoglobinuria: Pig-a(-) hematopoiesis is reconstituted following intercellular transfer of GPI-anchored proteins. Proc. Natl. Acad. Sci. U. S. A. 93, 7938-7943.

(43) Metzner, C., Mostegl, M. M., Gunzburg, W. H., Salmons, B., and Dangerfield, J. A. (2008) Association of glycosylphosphatidylinositolanchored protein with retroviral particles. FASEB J. 22, 2734-2739.

(44) Metzner, C., Kochan, F., and Dangerfield, J. A. (2013) Fluorescence molecular painting of enveloped viruses. Mol. Biotechnol. 53, 9-18.

(45) Porter, J. A., Young, K. E., and Beachy, P. A. (1996) Cholesterol modification of hedgehog signaling proteins in animal development. Science 274, 255-259.

(46) Mann, R. K., and Beachy, P. A. (2004) Novel lipid modifications of secreted protein signals. Annu. Rev. Biochem. 73, 891-923.

(47) Rietveld, A., Neutz, S., Simons, K., and Eaton, S. (1999) Association of sterol- and glycosylphosphatidylinositol-linked proteins with Drosophila raft lipid microdomains. J. Biol. Chem. 274, 1204912054 .

(48) Taipale, J., Chen, J. K., Cooper, M. K., Wang, B., Mann, R. K., Milenkovic, L., Scott, M. P., and Beachy, P. A. (2000) Effects of oncogenic mutations in Smoothened and Patched can be reversed by cyclopamine. Nature 406, 1005-1009.

(49) Peters, C., Wolf, A., Wagner, M., Kuhlmann, J., and Waldmann, H. (2004) The cholesterol membrane anchor of the Hedgehog protein confers stable membrane association to lipid-modified proteins. Proc. Natl. Acad. Sci. U. S. A. 101, 8531-8536.

(50) Hussey, S. L., He, E., and Peterson, B. R. (2001) A synthetic membrane-anchored antigen efficiently promotes uptake of antifluorescein antibodies and associated protein a by mammalian cells. J. Am. Chem. Soc. 123, 12712-12713.

(51) Hussey, S. L., and Peterson, B. R. (2002) Efficient delivery of streptavidin to mammalian cells: clathrin-mediated endocytosis regulated by a synthetic ligand. J. Am. Chem. Soc. 124, 6265-6273.

(52) Martin, S. E., and Peterson, B. R. (2003) Non-natural cell surface receptors: synthetic peptides capped with N-cholesterylglycine efficiently deliver proteins into Mammalian cells. Bioconjugate Chem. 14, 67-74.

(53) Boonyarattanakalin, S., Martin, S. E., Dykstra, S. A., and Peterson, B. R. (2004) Synthetic mimics of small mammalian cell surface receptors. J. Am. Chem. Soc. 126, 16379-16386.

(54) Boonyarattanakalin, S., Martin, S. E., Sun, Q., and Peterson, B. R. (2006) A synthetic mimic of human Fc receptors: defined chemical modification of cell surfaces enables efficient endocytic uptake of human immunoglobulin-G. J. Am. Chem. Soc. 128, 11463-11470.

(55) Tomas, S., and Milanesi, L. (2009) Hydrophobically selfassembled nanoparticles as molecular receptors in water. J. Am. Chem. Soc. 131, 6618-6623. 
(56) Tomas, S., and Milanesi, L. (2010) Mutual modulation between membrane-embedded receptor clustering and ligand binding in lipid membranes. Nat. Chem. 2, 1077-1083.

(57) Bradford, M. M. (1976) A rapid and sensitive method for the quantitation of microgram quantities of protein utilizing the principle of protein-dye binding. Anal. Biochem. 72, 248-254.

(58) Sreerama, N. and Woody, R. W. (2000) Circular dichroism of peptides and proteins. Circular Dichroism, 2nd ed. (Berova, N., Nakanishi, K. and Woody, R. W., Eds.) pp 601-620, John Wiley \& Sons, Inc., New York.

(59) Slater, T. F., Sawyer, B., and Straeuli, U. (1963) Studies on succinate-tetrazolium reductase systems. III. Points of coupling of four different tetrazolium salts. Biochim. Biophys. Acta 77, 383-393.

(60) http://rsbweb.nih.gov/ij/plugins/track/jacop.html.

(61) Hibbs, A. R., MacDonald, G., and Garsha, K. (2006) Practical confocal microscopy. In Handbook of biological confocal microscopy (Pawley, J. B., Ed.) pp 667-670, Chapter 36, Springer, New York.

(62) Adler, J., and Parmryd, I. (2010) Quantifying colocalization by correlation: the Pearson correlation coefficient is superior to the Mander's overlap coefficient. Cytometry A 77, 733-742.

(63) Bolte, S., and Cordelieres, F. P. (2006) A guided tour into subcellular colocalization analysis in light microscopy. J. Microsc. 224, 213-232.

(64) Sato, S. B., Ishii, K., Makino, A., Iwabuchi, K., Yamaji-Hasegawa, A., Senoh, Y., Nagaoka, I., Sakuraba, H., and Kobayashi, T. (2004) Distribution and transport of cholesterol-rich membrane domains monitored by a membrane-impermeant fluorescent polyethylene glycol-derivatized cholesterol. J. Biol. Chem. 279, 23790-23796.

(65) Liu, Y. F., and Nagle, J. F. (2004) Diffuse scattering provides material parameters and electron density profiles of biomembranes. Phys. Rev. E 69, 040901.

(66) Filippov, A., Oradd, G., and Lindblom, G. (2003) Influence of cholesterol and water content on phospholipid lateral diffusion in bilayers. Langmuir 19, 6397-6400.

(67) Warschawski, D. E., and Devaux, P. F. (2005) Order parameters of unsaturated phospholipids in membranes and the effect of cholesterol: a H-1-C-13 solid-state NMR study at natural abundance. Eur. Biophys. J. 34, 987-996.

(68) Vermeer, L. S., de Groot, B. L., Reat, V., Milon, A., and Czaplicki, J. (2007) Acyl chain order parameter profiles in phospholipid bilayers: computation from molecular dynamics simulations and comparison with $2 \mathrm{H}$ NMR experiments. Eur. Biophys. J. 36, 919-931.

(69) Simons, K., and Ikonen, E. (2000) How cells handle cholesterol. Science 290, 1721-1726.

(70) Ravichandran, R., and Divakar, S. (1998) Inclusion of ring A of cholesterol inside the beta-cyclodextrin cavity: Evidence from oxidation reactions and structural studies. J. Inclusion Phenom. Mol. Recognit. Chem. 30, 253-270.

(71) Tsamaloukas, A., Szadkowska, H., Slotte, P. J., and Heerklotz, H. (2005) Interactions of cholesterol with lipid membranes and cyclodextrin characterized by calorimetry. Biophys. J. 89, 1109-1119.

(72) Niu, S. L., and Litman, B. J. (2002) Determination of membrane cholesterol partition coefficient using a lipid vesicle-cyclodextrin binary system: effect of phospholipid acyl chain unsaturation and headgroup composition. Biophys. J. 83, 3408-3415.

(73) Kabsch, W., and Sander, C. (1983) Dictionary of protein secondary structure: pattern recognition of hydrogen-bonded and geometrical features. Biopolymers 22, 2577-2637.

(74) Frishman, D., and Argos, P. (1995) Knowledge-based protein secondary structure assignment. Proteins 23, 566-579.

(75) Kilsdonk, E. P., Yancey, P. G., Stoudt, G. W., Bangerter, F. W., Johnson, W. J., Phillips, M. C., and Rothblat, G. H. (1995) Cellular cholesterol efflux mediated by cyclodextrins. J. Biol. Chem. 270, $17250-17256$.

(76) Scheidt, H. A., Muller, P., Herrmann, A., and Huster, D. (2003) The potential of fluorescent and spin-labeled steroid analogs to mimic natural cholesterol. J. Biol. Chem. 278, 45563-45569. 
Schäfer B., Orbán E., Kele Z., Tömböly Cs. (2015): Tritium labeling of a cholesterol amphiphile designed for cell membrane anchoring of proteins. Journal of Labelled Compounds and Radiopharmaceuticals 58, 7-13. 


\title{
Tritium labelling of a cholesterol amphiphile designed for cell membrane anchoring of proteins
}

\author{
Balázs Schäfer, ${ }^{a}$ Erika Orbán, ${ }^{b \dagger}$ Zoltán Kele, ${ }^{c}$ and Csaba Tömböly ${ }^{a *}$
}

Cell membrane association of proteins can be achieved by the addition of lipid moieties to the polypeptide chain, and such lipid-modified proteins have important biological functions. A class of cell surface proteins contains a complex glycosylphosphatidylinositol (GPI) glycolipid at the C-terminus, and they are accumulated in cholesterol-rich membrane microdomains, that is, lipid rafts. Semisynthetic lipoproteins prepared from recombinant proteins and designed lipids are valuable probes and model systems of the membrane-associated proteins. Because GPI-anchored proteins can be reinserted into the cell membrane with the retention of the biological function, they are appropriate candidates for preparing models

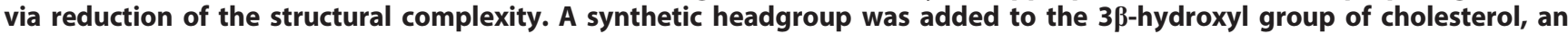
essential lipid component of rafts, and the resulting cholesterol derivative was used as a simplified GPI mimetic. In order to quantitate the membrane integrated GPI mimetic after the exogenous addition to live cells, a tritium labelled cholesterol anchor was prepared. The radioactive label was introduced into the headgroup, and the radiolabelled GPI mimetic anchor was obtained with a specific activity of $1.37 \mathrm{TBq} / \mathrm{mmol}$. The headgroup labelled cholesterol derivative was applied to demonstrate the sensitive detection of the cell membrane association of the anchor under in vivo conditions.

Keywords: tritium; cholesterol; membrane anchor; lipoprotein

\section{Introduction}

A unique class of cell membrane-associated proteins contains a C-terminal glycosylphosphatidylinositol (GPI) moiety, and these lipoproteins associate with the outer leaflet of the membrane bilayer via the lipid chains of the GPI molecule. GPI-anchored proteins are functionally diverse including enzymes, cell adhesion molecules, receptors, complement regulatory proteins, immunoproteins and further proteins (e.g. prion protein) with unknown functions. ${ }^{1}$ It was shown that their biological functions were retained after exogenous addition to membranes ${ }^{2-5}$; therefore, semisynthetic lipoproteins containing diverse reporters in the headgroup of the lipid moiety can be valuable probes for investigating GPI-anchored proteins. $^{6-13}$ The GPI moiety directs the attached protein towards the extracellular space and locates the attached protein in special membrane microdomains, that is, lipid rafts. Because cholesterol maintains the dynamic lipid-lipoprotein associates of GPI-anchored proteins, sphingolipids and cholesterol, ${ }^{14,15}$ it is hypothesized that cholesteryl lipoproteins may also be accumulated in lipid rafts. ${ }^{16}$ Based on the finding that cholesteryl poly(ethylene glycol) ethers accumulate in cholesterol-rich membranes and their cytotoxicity is low, ${ }^{17}$ we have recently prepared a cholesterol derivative containing both a maleimide and a fluorescent reporter in the headgroup for protein conjugation and imaging, respectively. It was shown that after protein conjugation, the semisynthetic cholesteryl lipoprotein could be purified via a $\beta$-cyclodextrin inclusion complex that made the cholesterol moiety soluble in polar solvents. Then, the lipid excess- and detergent-free lipoprotein could be introduced into the cell membrane of live cells with minimal disruption of the membrane, and the fluorescence of the headgroup could be unambiguously assigned to the attached protein. ${ }^{18}$ In order to further study the membraneassociated cholesteryl lipoproteins, it is important to quantitate the lipoprotein incorporated into the cell membrane. It can be achieved by determining the radioactivity of cell membrane preparations or intact cells treated with a tritium labelled analogue of the anchor molecule. Herein, we report our results on the preparation and biological application of a tritium labelled cholesterol derivative designed for that purpose.

\footnotetext{
a Laboratory of Chemical Biology, Institute of Biochemistry, Biological Research Centre of the Hungarian Academy of Sciences, Temesvári krt. 62., 6726 Szeged, Hungary
}

${ }^{b}$ Research Group of Peptide Chemistry, Hungarian Academy of Sciences, Pázmány Péter sétány 1/a, 1117 Budapest, Hungary

${ }^{c}$ Department of Medicinal Chemistry, Szeged University, Dóm tér 8., 6720 Szeged, Hungary

*Correspondence to: Csaba Tömböly, Laboratory of Chemical Biology, Institute of Biochemistry, Biological Research Centre of the Hungarian Academy of Sciences, Temesvári krt. 62., 6726 Szeged, Hungary.

E-mail: tomboly@brc.hu

${ }^{+}$Current address: Institute of Biophysical Chemistry, Goethe University Frankfurt, Max-von-Laue str. 960438 Frankfurt, Germany 


\section{Experimental}

The purity of all reagents and solvents was analytical or the highest commercially available grade. Protected propargylglycine (Pra) and 5 -amiofluorescein were purchased from Bachem Feinchemicalen AG (Bubendorf, Switzerland), and coupling reagents and substituted di (ethylene glycols) were obtained from Calbiochem-Novabiochem AG (Läufelfingen, Switzerland). Other chemicals were from Sigma Ltd. (St. Louis, MO, USA). Tritium labelling was carried out in a self-designed vacuum manifold, ${ }^{19,20}$ and radioactivity was measured with a Packard Tri-Carb 2100 TR liquid scintillation analyser using Hionic-Fluor scintillation cocktail of PerkinElmer (Waltham, MA, USA). Analytical thin layer chromatography (TLC) was performed on $5 \times 10 \mathrm{~cm}$ glass plates precoated with silica gel $60 \mathrm{~F}_{254}$ (Merck, Darmstadt, Germany), spots were visualized with UV light, ninhydrin or phosphomolybdic acid, and radioactivity was detected with a Berthold LB511 linear TLC analyser. Flash chromatography was carried out on silica gel 60 (Sigma Ltd., St. Louis, MO, USA) using the indicated solvents. Analytical and semipreparative HPLC separations were performed with a Merck-Hitachi LaChrom system under the indicated conditions. Radio-HPLC was performed on a Jasco HPLC system equipped with a Packard Radiomatic 505 TR Flow Scintillation Analyser. NMR spectra were recorded on a Bruker Spectra DRX $500 \mathrm{MHz}$ spectrometer in the indicated solvent, and chemical shifts $(\delta)$ are reported in ppm after calibration to the solvent signals. Molecular weights of the compounds were determined by MS analysis on a Finnigan TSQ 7000 spectrometer equipped with an ESI source or on a Bruker reflex III MALDI-TOF spectrometer. In the case of MALDI-MS, 2,5-dihydroxybenzoic acid matrix was applied. Mass spectrometric measurements of $\left.{ }^{2} \mathrm{H}\right]$ piperidine were performed on a Micromass Q-TOF Premier mass spectrometer (Waters MSTechnologies, Manchester, UK) equipped with a nanoelectrospray ion source. The instrument was scanned in the mass range of $85-90$. Peak intensities were calculated for $[\mathrm{M}+\mathrm{H}]^{+}, \quad\left[\mathrm{M}\left({ }^{2} \mathrm{H}_{1}\right)+\mathrm{H}\right]^{+},\left[\mathrm{M}\left({ }^{2} \mathrm{H}_{2}\right)+\mathrm{H}\right]^{+}$and $\left[\mathrm{M}\left({ }^{2} \mathrm{H}_{3}\right)+\mathrm{H}\right]^{+}$ molecule ions by the Masslynx software. The measured peak intensities of mono-, di- and tri-deuterated ions were corrected by the calculated intensities of overlapping $\left[\mathrm{M}\left({ }^{13} \mathrm{C}\right)+\mathrm{H}\right]^{+},\left[\mathrm{M}\left({ }^{2} \mathrm{H}_{1},{ }^{13} \mathrm{C}\right)+\mathrm{H}\right]^{+}$and $[\mathrm{M}$ $\left.\left({ }^{2} \mathrm{H}_{2},{ }^{13} \mathrm{C}\right)+\mathrm{H}\right]^{+}$peaks, respectively. The effects of $\left[\mathrm{M}\left({ }^{13} \mathrm{C}_{2}\right)+\mathrm{H}\right]^{+}$and $[\mathrm{M}$ $\left.\left({ }^{2} \mathrm{H}_{1},{ }^{13} \mathrm{C}_{2}\right)+\mathrm{H}\right]^{+}$and ${ }^{15} \mathrm{~N}$ containing ions were neglected. Live cells treated with the fluorescent anchor were visualized with an Olympus IX81 confocal laser scanning microscope, and images were prepared by the FluoView 500 software.

\section{$\left[{ }^{2} \mathrm{H}\right]$ piperidine (1)}

An amount of $5 \mathrm{mg}$ of 4-bromopiperidine hydrobromide $(20 \mu \mathrm{mol})$ was dissolved in $400 \mu \mathrm{L}$ of $10 \mathrm{M} \mathrm{NaOH}$, and it was extracted with $1 \mathrm{~mL}$ of EtOAc. The organic phase was washed with brine, dried over $\mathrm{Na}_{2} \mathrm{SO}_{4}$ and evaporated at atmospheric pressure. The resulting amine was dissolved in $500 \mu \mathrm{L}$ of EtOAc, and it was reduced under 0.4 bar deuterium gas in the presence of $11 \mathrm{mg}$ of $\mathrm{Pd} / \mathrm{C}(10 \% \mathrm{Pd})$ catalyst. After $3 \mathrm{~h}$, the catalyst was filtered off, and the EtOAc solution was extracted with $1 \mathrm{M}$ $\left.\mathrm{HCl} .{ }^{2} \mathrm{H}\right]$ piperidine hydrochloride (1) was obtained after repeated evaporations from the acidic aqueous solution $(2 \mathrm{mg}, 82 \%) . R_{\mathrm{f}} 0.38(n-$ $\mathrm{BuOH}-\mathrm{AcOH}-\mathrm{H}_{2} \mathrm{O}$ 2:1:1); ESI-MS calcd for $\mathrm{C}_{5} \mathrm{H}_{10} \mathrm{DN} 86.10$, found 87.09 $[\mathrm{M}+\mathrm{H}]^{+}$.

\section{[ ${ }^{3}$ H]piperidine}

Tritium labelling was performed with $2.1 \mathrm{mg}$ of 4-bromopiperidine base $(12.9 \mu \mathrm{mol})$ dissolved in $1 \mathrm{~mL}$ of EtOAc in the presence of $5 \mathrm{mg}$ of $\mathrm{Pd} / \mathrm{C}$ $(10 \% \mathrm{Pd})$ catalyst. The reaction mixture was degassed prior to tritium reduction by a freeze-thaw cycle, and then it was stirred under 0.4 bar of tritium gas for $3 \mathrm{~h}$, followed by the filtration of the catalyst. The EtOAc solution was extracted with $1 \mathrm{M} \mathrm{HCl}$, and labile tritium was removed by repeated evaporations from $1 \mathrm{M} \mathrm{HCl}$ solution. Finally, $20.5 \mathrm{GBq}$ of $\left[{ }^{3} \mathrm{H}\right]$ piperidine hydrochloride was isolated as a white solid (s.a. $1.58 \mathrm{TBq} /$ $\mathrm{mmol}$ ), which was immediately used for the next step.

\section{$\left[{ }^{3} \mathrm{H}\right] \mathrm{N}$-nitrosopiperidine}

The solid $\left[{ }^{3} \mathrm{H}\right]$ piperidine hydrochloride $(20.5 \mathrm{GBq})$ was dissolved in $100 \mu \mathrm{L}$ of $1 \mathrm{M} \mathrm{HCl}$, and the solution was cooled into ice. Then, $250 \mathrm{mg}$ of $\mathrm{KNO}_{2}$ was added, and the reaction mixture was stirred at $0^{\circ} \mathrm{C}$ for $2 \mathrm{~h}$ followed by extraction with $\mathrm{Et}_{2} \mathrm{O}$. The ethereal solution was evaporated at atmospheric pressure yielding $17.8 \mathrm{GBq}(87 \%)$ of crude $\left[{ }^{3} \mathrm{H}\right] \mathrm{N}$ nitrosopiperidine. It was dissolved in $100 \mu \mathrm{L}$ THF and immediately used in the next step without further purification. $R_{\mathrm{f}} 0.28$ (petroleum ether-acetone 9:1), 93\% radiochemical purity by radio-TLC.

\section{$\left[{ }^{3} \mathrm{H}\right] \mathrm{N}$-aminopiperidine (2)}

The solution of $17.8 \mathrm{GBq}$ of $\left[^{3} \mathrm{H}\right] \mathrm{N}$-nitrosopiperidine in $100 \mu \mathrm{L}$ of THF was transferred to a reaction vessel equipped with a condenser. A suspension of $4.5 \mathrm{mg}$ of $\mathrm{LiAlH}_{4}$ in $600 \mu \mathrm{L}$ of THF was added, and the reaction mixture was stirred under Ar at $60^{\circ} \mathrm{C}$ for $3.5 \mathrm{~h}$. After cooling, $100 \mu \mathrm{L}$ of $10 \mathrm{M} \mathrm{NaOH}$ was added, and it was stirred for further $20 \mathrm{~min}$. The resulting slurry was extracted with $\mathrm{Et}_{2} \mathrm{O}$, and the ethereal solution was extracted with $3 \mathrm{M}$ $\mathrm{HCl}$. The $\mathrm{HCl}$ solution was evaporated, and labile tritium was removed by repeated evaporations from water: ethanol (1:1), resulting in $8.4 \mathrm{GBq}$ $(47 \%)$ of solid $\left[{ }^{3} \mathrm{H}\right] \mathrm{N}$-aminopiperidine hydrochloride $(0.8 \mathrm{mg})$, which was used for the preparation of $\mathbf{8}$ without further purification. $R_{\mathrm{f}} 0.38$ ( $n$ $\mathrm{BuOH}-\mathrm{AcOH}-\mathrm{H}_{2} \mathrm{O}$ 2:1:1), 73\% radiochemical purity by radio-TLC, s.a. $1.33 \mathrm{TBq} / \mathrm{mmol}$.

\section{Cholesteryl (S)-1-(4-(2-(tert-butoxycarbonylamino)-2- carboxyethyl)-1H-1,2,3-triazol-1-yl)-13-oxo-3,6,9-trioxa-12- azahexadecan-16-oate (3)}

Boc-Pra-OH (60 mg, $281.4 \mu \mathrm{mol}$ ) was dissolved in $1 \mathrm{~mL}$ of dimethylformamide (DMF), and it was added to the solution of cholesteryl 1-azido-13-oxo-3,6,9trioxa-12-azahexadecan-16-oate ${ }^{18}(230 \mathrm{mg}, 335.0 \mu \mathrm{mol})$ in $\mathrm{CH}_{2} \mathrm{Cl}_{2}(4 \mathrm{~mL})$. Then, a solution of $\mathrm{L}(+)$-ascorbic acid sodium salt $(33.4 \mathrm{mg}, 168.8 \mu \mathrm{mol})$ and $\mathrm{CuSO}_{4} .5 \mathrm{H}_{2} \mathrm{O}(21.1 \mathrm{mg}, 84.4 \mu \mathrm{mol})$ in water $(4 \mathrm{~mL})$ was added. The reaction mixture was stirred for $8 \mathrm{~h}$ at room temperature, and then it was evaporated in vacuo. The crude product was purified by column chromatography $\left(\mathrm{CHCl}_{3}-\mathrm{MeOH}-\mathrm{AcOH}\right.$ 90:9:1) to give $230.4 \mathrm{mg}(91 \%)$ of pure 3 as a white solid. $R_{\mathrm{f}} 0.30\left(\mathrm{CHCl}_{3}-\mathrm{MeOH}-\mathrm{AcOH} 90: 9.5: 0.5\right) ; k^{\prime}=8.61\left(t_{\mathrm{R}}=12.5 \mathrm{~min} ; \mathrm{Vydac}\right.$ 214TP5410 C 4 column $(100 \times 4.6 \mathrm{~mm}, 5 \mu \mathrm{m})$, gradient elution with $1.8 \% / \mathrm{min}$ acetonitrile (ACN) $\left(0.08 \%(\mathrm{v} / \mathrm{v})\right.$ trifluoroacetic acid (TFA) in $\mathrm{H}_{2} \mathrm{O}(0.1 \%(\mathrm{v} / \mathrm{v})$ TFA) starting from $50 \% \mathrm{ACN}$, flow rate: $1 \mathrm{~mL} / \mathrm{min}, \lambda=216 \mathrm{~nm}) ;{ }^{1} \mathrm{H}$ NMR $\left(500 \mathrm{MHz}, \mathrm{CDCl}_{3}\right) \delta 7.63(\mathrm{~s}, 1 \mathrm{H}), 6.63(\mathrm{~s}, 1 \mathrm{H}), 5.61(\mathrm{~s}, 1 \mathrm{H}), 5.34(\mathrm{~d}, 1 \mathrm{H}$, $J=3.7 \mathrm{~Hz}), 4.58(\mathrm{~s}, 2 \mathrm{H}), 4.53(\mathrm{~m}, 1 \mathrm{H}), 4.47(\mathrm{~s}, 1 \mathrm{H}), 3.86(\mathrm{~s}, 2 \mathrm{H}), 3.60(\mathrm{~m}, 10 \mathrm{H})$, $3.42(\mathrm{q}, 2 \mathrm{H}, J=4.6 \mathrm{~Hz}), 3.28(\mathrm{~m}, 2 \mathrm{H}), 2.62(\mathrm{t}, 2 \mathrm{H}, J=6.7 \mathrm{~Hz}), 2.47(\mathrm{t}, 2 \mathrm{H}$, $J=6.7 \mathrm{~Hz}), 2.29(\mathrm{~d}, 2 \mathrm{H}, J=7.6 \mathrm{~Hz}), 1.98(\mathrm{~m}, 1 \mathrm{H}), 1.93(\mathrm{~m}, 1 \mathrm{H}), 1.83(\mathrm{~m}, 3 \mathrm{H})$, [1.62-1.00 (m, 18H): $1.57(3 \mathrm{H}), 1.52(1 \mathrm{H}), 1.48(2 \mathrm{H}), 1.40(1 \mathrm{H}), 1.32(1 \mathrm{H}), 1.30$ $(2 \mathrm{H}), 1.20(1 \mathrm{H}), 1.14(1 \mathrm{H}), 1.11(4 \mathrm{H}), 1.09(2 \mathrm{H})], 1.42(\mathrm{~s}, 9 \mathrm{H}), 1.00(\mathrm{~s}, 3 \mathrm{H})$, [0.99-0.86 (m, 3H): $0.94(2 \mathrm{H}), 0.88(1 \mathrm{H})], 0.90(\mathrm{~d}, 3 \mathrm{H}, J=6.4 \mathrm{~Hz}),[0.86(\mathrm{~d}, 3 \mathrm{H}$, $J=1.8 \mathrm{~Hz}), 0.84(\mathrm{~d}, 3 \mathrm{H}, J=1.8 \mathrm{~Hz})], 0.66(\mathrm{~s}, 3 \mathrm{H}) ;{ }^{13} \mathrm{C} \mathrm{NMR}\left(125 \mathrm{MHz}, \mathrm{CDCl}_{3}\right) \delta$ $172.7,172.1,155.7,142.7,139.7,124.1,122.7,80.0,74.5,70.7,70.5,70.3$, $70.1,69.9,69.5,56.8,56.2,53.3,50.5,50.1,42.4,39.8,39.6,39.3,38.2,37.1$, $36.7,36.3,35.9,32.0$ (2C), 31.0, 30.0, 28.5, 28.3, 28.12, 28.07, 27.8, 24.4, 23.9, 22.9, 22.7, 21.1, 19.4, 18.8, 12.0; MS(MALDI) calcd for $\mathrm{C}_{49} \mathrm{H}_{81} \mathrm{~N}_{5} \mathrm{O}_{10} 899.60$ found $900.44[\mathrm{M}+\mathrm{H}]^{+}$.

\section{Cholesteryl (S)-1-(4-(2-amino-2-carboxyethyl)-1H-1,2,3- triazol-1-yl)-13-oxo-3,6,9-trioxa-12-azahexadecan-16-oate} (4)

Compound 3 ( $200 \mathrm{mg}, 222.3 \mu \mathrm{mol}$ ) was dissolved in $2 \mathrm{~mL}$ of TFA $-\mathrm{CH}_{2} \mathrm{Cl}_{2}$ $1: 1$, and it was stirred for $30 \mathrm{~min}$. The solution was evaporated in vacuo to give $197.0 \mathrm{mg}(97 \%)$ of pure 4 trifluoroacetate as a pale yellow solid. $R_{\mathrm{f}}$ $0.12\left(\mathrm{CHCl}_{3}-\mathrm{MeOH}-\mathrm{AcOH} \quad 90: 9.5: 0.5\right) ; \quad k^{\prime}=4.15 \quad\left(t_{\mathrm{R}}=6.7 \mathrm{~min} ; \quad \mathrm{Vydac}\right.$ 214TP5410 C4 column $(100 \times 4.6 \mathrm{~mm}, 5 \mu \mathrm{m})$, gradient elution with $1.8 \% / \mathrm{min}$ ACN $\left(0.08 \%(\mathrm{v} / \mathrm{v})\right.$ TFA) in $\mathrm{H}_{2} \mathrm{O}(0.1 \%(\mathrm{v} / \mathrm{v})$ TFA) starting from $50 \%$ ACN, flow rate: $1 \mathrm{~mL} / \mathrm{min}, \lambda=216 \mathrm{~nm}$ ); MS(MALDI) calcd for $\mathrm{C}_{44} \mathrm{H}_{73} \mathrm{~N}_{5} \mathrm{O}_{8} 799.55$, found $800.48[\mathrm{M}+\mathrm{H}]^{+}$. 


\section{Cholesteryl (S)-1-(4-(2-carboxy-2-(3-(maleimido) propanamido)ethyl)-1H-1,2,3-triazol-1-yl)-13-oxo-3,6,9- trioxa-12-azahexadecan-16-oate (5)}

The amino acid derivative $\mathbf{4}$ (140 mg, $153.2 \mu \mathrm{mol})$ and N-ethyldiisopropylamine (DIEA) $(61 \mu \mathrm{L}, 350.4 \mu \mathrm{mol})$ were dissolved in $\mathrm{MeOH}(4 \mathrm{~mL})$, and 3maleimidopropionic acid $\mathrm{N}$-hydroxysuccinimide ester $(56.0 \mathrm{mg}, 210.4 \mu \mathrm{mol})$ was added. The mixture was stirred for $3 \mathrm{~h}$ at room temperature, and then it was evaporated in vacuo. The crude product was purified by column chromatography $\left(\mathrm{CHCl}_{3}-\mathrm{MeOH}-\mathrm{AcOH} 85: 14: 1\right)$ to give $118 \mathrm{mg}$ (81\%) of pure 5 as a white solid. $R_{\mathrm{f}} 0.43\left(\mathrm{CHCl}_{3}-\mathrm{MeOH}-\mathrm{AcOH} 80: 19: 1\right) ; k^{\prime}=6.53$ $\left(t_{R}=9.8 \mathrm{~min} ; \mathrm{Vydac} 214 \mathrm{TP} 5410 \mathrm{C} 4\right.$ column $(100 \times 4.6 \mathrm{~mm}, 5 \mu \mathrm{m})$, gradient elution with $1.8 \% / \mathrm{min} \mathrm{ACN}\left(0.08 \%(\mathrm{v} / \mathrm{v})\right.$ TFA) in $\mathrm{H}_{2} \mathrm{O}(0.1 \%(\mathrm{v} / \mathrm{v})$ TFA) starting from $50 \%$ ACN, flow rate: $1 \mathrm{~mL} / \mathrm{min}, \lambda=216 \mathrm{~nm}) ;{ }^{1} \mathrm{H} \mathrm{NMR}\left(500 \mathrm{MHz}, \mathrm{CDCl}_{3}\right) \delta$ $7.70(\mathrm{~s}, 1 \mathrm{H}), 7.02(\mathrm{brs}, 1 \mathrm{H}), 6.68(\mathrm{~s}, 2 \mathrm{H}), 6.63(\mathrm{brs}, 1 \mathrm{H}), 5.34(\mathrm{~d}, 1 \mathrm{H}, J=3.7 \mathrm{~Hz})$, 4.77 (brs, 1H), $4.57(\mathrm{~m}, 2 \mathrm{H}), 4.49(\mathrm{~s}, 1 \mathrm{H}), 3.82(\mathrm{~m}, 4 \mathrm{H}), 3.61(\mathrm{~m}, 10 \mathrm{H}), 3.42(\mathrm{q}$, $2 \mathrm{H}, J=4.6 \mathrm{~Hz}), 3.24(\mathrm{~m}, 2 \mathrm{H}), 2.62(\mathrm{t}, 2 \mathrm{H}, J=6.7 \mathrm{~Hz}), 2.58(\mathrm{t}, 2 \mathrm{H}, J=6.3 \mathrm{~Hz})$, $2.47(\mathrm{t}, 2 \mathrm{H}, J=6.7 \mathrm{~Hz}), 2.30(\mathrm{~d}, 2 \mathrm{H}, J=7.6 \mathrm{~Hz}), 2.01(\mathrm{~m}, 1 \mathrm{H}), 1.94(\mathrm{~m}, 1 \mathrm{H})$, $1.83(\mathrm{~m}, 3 \mathrm{H}),[1.62-1.03(\mathrm{~m}, 18 \mathrm{H}): 1.57(3 \mathrm{H}), 1.52(1 \mathrm{H}), 1.48(2 \mathrm{H}), 1.40(1 \mathrm{H})$, $1.32(1 \mathrm{H}), 1.30(2 \mathrm{H}), 1.20(1 \mathrm{H}), 1.14(1 \mathrm{H}), 1.11(4 \mathrm{H}), 1.09(2 \mathrm{H})], 1.00(\mathrm{~s}, 3 \mathrm{H})$, [0.99-0.86 (m, 3H): $0.94(2 \mathrm{H}), 0.88(1 \mathrm{H})], 0.90(\mathrm{~d}, 3 \mathrm{H}, J=6.4 \mathrm{~Hz}),[0.86(\mathrm{~d}, 3 \mathrm{H}$, $J=1.8 \mathrm{~Hz}), 0.84(\mathrm{~d}, 3 \mathrm{H}, J=1.8 \mathrm{~Hz})], 0.66(\mathrm{~s}, 3 \mathrm{H}) ;{ }^{13} \mathrm{C} \mathrm{NMR}\left(125 \mathrm{MHz}, \mathrm{CDCl}_{3}\right) \delta$ $172.80,172.7,172.2,170.7,169.9,142.7,139.8,134.3,124.3,122.8,74.5$, $70.6,70.5,70.3,70.0,69.9,69.4,56.8,56.3,53.5,50.5,50.1,42.4,39.8,39.6$, $39.4,38.2,37.1,36.7,36.3,35.9,34.6,34.3,32.0$ (2C), 31.0, 30.0, 28.4, 28.1 (2C), 27.9, 24.4, 24.0, 23.0, 22.7, 21.2, 19.4, 18.8, 12.0; MS(MALDI) calcd for $\mathrm{C}_{51} \mathrm{H}_{78} \mathrm{~N}_{6} \mathrm{O}_{11} 950.57$, found $951.45[\mathrm{M}+\mathrm{H}]^{+}$.

\section{Fluorescent cholesterol anchor 6}

The maleimide derivative $\mathbf{5}$ (50 mg, $52.6 \mu \mathrm{mol}$ ) and 1-[Bis(dimethylamino) methylene]-1 $\mathrm{H}$-1,2,3-triazolo[4,5-b]pyridinium 3-oxid hexafluorophosphate (HATU) $(20.0 \mathrm{mg}, 52.6 \mu \mathrm{mol})$ were dissolved in THF $(5 \mathrm{~mL})$, and DIEA $(9.1 \mu \mathrm{L}, 52.6 \mu \mathrm{mol})$ was added to the solution. It was stirred for $5 \mathrm{~min}$ followed by the addition of fluorescein amine $(54.8 \mathrm{mg}, 157.8 \mu \mathrm{mol})$ in THF $(2 \mathrm{~mL})$. The reaction mixture was stirred for $16 \mathrm{~h}$ at room temperature, and then it was evaporated in vacuo; the crude product was purified by column chromatography $\left(\mathrm{CHCl}_{3}-\mathrm{MeOH}-\mathrm{AcOH}\right.$ 90:9:1) to give $37.0 \mathrm{mg}$ (55\%) of pure 6 as an orange solid. $R_{\mathrm{f}} 0.41\left(\mathrm{CHCl}_{3}-\mathrm{MeOH}-\mathrm{AcOH} 90: 9: 1\right) ; k^{\prime}$ $=8.53\left(t_{R}=12.4 \mathrm{~min}\right.$; Vydac $214 \mathrm{TP} 5410 \mathrm{C} 4$ column $(100 \times 4.6 \mathrm{~mm}, 5 \mu \mathrm{m})$, gradient elution with $1.8 \% / \mathrm{min} \mathrm{ACN}\left(0.08 \%(\mathrm{v} / \mathrm{v})\right.$ TFA) in $\mathrm{H}_{2} \mathrm{O}(0.1 \%(\mathrm{v} / \mathrm{v})$ TFA) starting from $50 \%$ ACN, flow rate: $1 \mathrm{~mL} / \mathrm{min}, \lambda=216 \mathrm{~nm}) ;{ }^{1} \mathrm{H}$ NMR $\left(500 \mathrm{MHz},\left(\mathrm{CD}_{3}\right)_{2} \mathrm{SO}\right) \delta 10.30(\mathrm{~s}, 1 \mathrm{H}), 10.21$ (brs, 2H), $8.43(\mathrm{~s}, 1 \mathrm{H}), 8.32(\mathrm{~d}$, $1 \mathrm{H}, J=5.7 \mathrm{~Hz}), 7.89(\mathrm{t}, 1 \mathrm{H}, J=5.4 \mathrm{~Hz}), 7.79(\mathrm{~s}, 1 \mathrm{H}), 7.74(\mathrm{~d}, 1 \mathrm{H}, J=8.3 \mathrm{~Hz})$, $7.15(\mathrm{~d}, 1 \mathrm{H}, J=8.3 \mathrm{~Hz}), 6.97(\mathrm{~s}, 2 \mathrm{H}), 6.90(\mathrm{~s}, 2 \mathrm{H}), 6.87(\mathrm{dd}, 2 \mathrm{H}, J=8.6,2.6 \mathrm{~Hz})$, $6.73(\mathrm{dd}, 2 \mathrm{H}, J=8.6,1.6 \mathrm{~Hz}), 5.31(\mathrm{~d}, 1 \mathrm{H}, J=3.2 \mathrm{~Hz}), 5.09(\mathrm{q}, 1 \mathrm{H}, J=5.8 \mathrm{~Hz})$, $4.47(\mathrm{t}, 2 \mathrm{H}, J=5.1 \mathrm{~Hz}), 4.42(\mathrm{~m}, 1 \mathrm{H}), 3.92(\mathrm{~m}, 2 \mathrm{H}), 3.77(\mathrm{t}, 2 \mathrm{H}, J=5.1 \mathrm{~Hz})$, 3.45 (brs, $10 \mathrm{H}), 3.38(\mathrm{q}, 2 \mathrm{H}, J=5.7 \mathrm{~Hz}), 3.12(\mathrm{~m}, 1 \mathrm{H}), 3.05(\mathrm{dd}, 1 \mathrm{H}, J=14.9$, $7.1 \mathrm{~Hz}), 2.71(\mathrm{~m}, 2 \mathrm{H}), 2.43(\mathrm{t}, 2 \mathrm{H}, J=6.7 \mathrm{~Hz}), 2.34(\mathrm{t}, 2 \mathrm{H}, J=6.7 \mathrm{~Hz}), 2.22(\mathrm{~d}$, $2 \mathrm{H}, J=7.6 \mathrm{~Hz}), 1.92(\mathrm{~m}, 1 \mathrm{H}), 1.85(\mathrm{~m}, 1 \mathrm{H}), 1.76(\mathrm{~m}, 3 \mathrm{H}),[1.60-0.92$ $(\mathrm{m}, 21 \mathrm{H}): 1.48(2 \mathrm{H}), 1.52(1 \mathrm{H}), 1.47(1 \mathrm{H}), 1.44(2 \mathrm{H}), 1.39(1 \mathrm{H}), 1.28$ $(3 \mathrm{H}), 1.17(1 \mathrm{H}), 1.13(1 \mathrm{H}), 1.11(4 \mathrm{H}), 1.02(1 \mathrm{H}), 1.00(1 \mathrm{H}), 0.97(1 \mathrm{H})$, $0.96(1 \mathrm{H}), 0.91(1 \mathrm{H})], 0.95(\mathrm{~s}, 3 \mathrm{H}), 0.87(\mathrm{~d}, 3 \mathrm{H}, J=6.4 \mathrm{~Hz}), 0.84(\mathrm{~d}, 3 \mathrm{H}$, $J=2.0 \mathrm{~Hz}), 0.81(\mathrm{~d}, 3 \mathrm{H}, J=2.0 \mathrm{~Hz}), 0.65(\mathrm{~s}, 3 \mathrm{H}, 18-\mathrm{H}) ;{ }^{13} \mathrm{C} \mathrm{NMR}$ $\left(125 \mathrm{MHz},\left(\mathrm{CD}_{3}\right)_{2} \mathrm{SO}\right) \delta 171.5,171.2,171.0,170.6,169.3,168.5,159.2$, $152.7,146.5,142.8,142.1,139.2,134.1,129.6,125.9,125.5,125.3$, $123.1,121.9,116.9,114.0,109.1,101.3,83.8,72.8,69.8,69.7$ (2C), $69.6,69.3,69.2,56.1,55.9,55.4,49.5,49.4,42.1,39.1,39.0,38.8$, $37.7,36.6,36.1,35.7,35.0,34.9,34.5,31.8,31.1,29.7,29.2,27.9$, 27.7, 27.4, 27.2, 23.9, 23.3, 22.6, 22.4, 20.9, 19.0, 18.6, 11.7; MS(MALDI) calcd for $\mathrm{C}_{71} \mathrm{H}_{89} \mathrm{~N}_{7} \mathrm{O}_{15} 1279.64$, found $1280.56[\mathrm{M}+\mathrm{H}]^{+}$.

\section{Cholesterol anchor 7}

The maleimide derivative 5 ( $25 \mathrm{mg}, 26.3 \mu \mathrm{mol}), \mathrm{N}$-hydroxybenzotriazole (HOBt) $(3.6 \mathrm{mg}, 26.3 \mu \mathrm{mol})$ and $\mathrm{N}^{\mathrm{N}} \mathrm{N}^{\prime}$-diisopropylcarbodiimide (DIC) $(4 \mu \mathrm{L}$, $26.3 \mu \mathrm{mol})$ were dissolved in DMF $(2 \mathrm{~mL})$. Then, $\mathrm{N}$-aminopiperidine (3.1 $\mu \mathrm{L}, 29 \mu \mathrm{mol}$ ) was added, and the solution was stirred for $16 \mathrm{~h}$ at room temperature. It was evaporated in vacuo, and the crude product was purified by HPLC on a Discovery Bio Wide Pore $C_{5}$ column to give $16 \mathrm{mg}(59 \%)$ of pure 7 as a white solid. $R_{\mathrm{f}} 0.45\left(\mathrm{CHCl}_{3}-\mathrm{MeOH}-\mathrm{TEA}\right.$ 90:9.9:0.1); $k^{\prime}=4.31 \quad\left(t_{R}=6.9 \mathrm{~min} ; \quad V y d a c \quad 214 \mathrm{TP} 5410 \quad\right.$ C4 column $(100 \times 4.6 \mathrm{~mm}, 5 \mu \mathrm{m})$, gradient elution with $1.5 \% / \mathrm{min}$ ACN $(0.08 \%(\mathrm{v} / \mathrm{v})$ TFA) in $\mathrm{H}_{2} \mathrm{O}(0.1 \%(\mathrm{v} / \mathrm{v})$ TFA) starting from $60 \% \mathrm{ACN}$, flow rate: $1 \mathrm{~mL} / \mathrm{min}, \lambda=216 \mathrm{~nm}) ;{ }^{1} \mathrm{H}$ NMR $\left(500 \mathrm{MHz}, \mathrm{CDCl}_{3}\right) \delta 7.63(\mathrm{~s}, 1 \mathrm{H}), 7.08(\mathrm{~s}$, $1 \mathrm{H}), 6.68(\mathrm{~s}, 2 \mathrm{H}), 6.60(\mathrm{~s}, 1 \mathrm{H}), 6.48(\mathrm{~s}, 1 \mathrm{H}), 5.34(\mathrm{~d}, 1 \mathrm{H}, J=3.7 \mathrm{~Hz}), 4.87$ (brs, 1H), $4.55(\mathrm{~m}, 2 \mathrm{H}), 4.46(\mathrm{~s}, 1 \mathrm{H}), 3.83(\mathrm{~s}, 4 \mathrm{H}), 3.61$ (brs, 10H), 3.42 (q, $2 \mathrm{H}, J=4.6 \mathrm{~Hz}), 3.20(\mathrm{~m}, 2 \mathrm{H}), 2.73(\mathrm{~m}, 4 \mathrm{H}), 2.62(\mathrm{t}, 2 \mathrm{H}, J=6.7 \mathrm{~Hz}), 2.58(\mathrm{t}$, $2 \mathrm{H}, J=6.7 \mathrm{~Hz}), 2.47(\mathrm{t}, 2 \mathrm{H}, J=7.6 \mathrm{~Hz}), 2.29(\mathrm{~d}, 2 \mathrm{H}), 1.99(\mathrm{~m}, 1 \mathrm{H}), 1.96(\mathrm{~m}$, $1 \mathrm{H}), 1.83(\mathrm{~m}, 3 \mathrm{H}), 1.71(\mathrm{~m}, 4 \mathrm{H}),[1.58-1.01(\mathrm{~m}, 20 \mathrm{H}): 1.55(3 \mathrm{H}), 1.50(1 \mathrm{H})$, $1.47(2 \mathrm{H}), 1.43(\mathrm{~m}, 3 \mathrm{H}), 1.32(1 \mathrm{H}), 1.30(2 \mathrm{H}), 1.23(1 \mathrm{H}), 1.14(1 \mathrm{H}), 1.11$ (4H), $1.09(1 \mathrm{H}), 1.05(1 \mathrm{H})], 1.00(\mathrm{~s}, 3 \mathrm{H}),[0.96-0.83(\mathrm{~m}, 3 \mathrm{H}): 0.96(1 \mathrm{H}), 0.92$ $(1 \mathrm{H}), 0.90(1 \mathrm{H})], 0.88(\mathrm{~d}, 3 \mathrm{H}, J=6.4 \mathrm{~Hz}),[0.86(\mathrm{~d}, 3 \mathrm{H}, J=1.8 \mathrm{~Hz}), 0.84(\mathrm{~d}$, $3 \mathrm{H}, J=1.8 \mathrm{~Hz})], 0.66(\mathrm{~s}, 3 \mathrm{H}) ;{ }^{13} \mathrm{C}$ NMR $\left(125 \mathrm{MHz}, \mathrm{CDCl}_{3}\right) \delta 172.7,172.2$, $170.7,169.9,156.8142 .7,139.8,134.3,124.3,122.8,74.5,70.6,70.5,70.3$, $70.0,69.9,69.4,63.4,56.8,56.3,53.6,50.5,50.1,42.4,39.8,39.6,39.4$, $38.2,37.1,36.7,36.3,35.9,34.6,34.3,32.0$ (2C), 31.0, 30.0, 28.4, 28.14, $28.12,27.9,27.2,24.4,24.0,23.5,23.0,22.7,21.2,19.4,18.8,12.0 ; \mathrm{MS}$ (MALDI) calcd for $\mathrm{C}_{56} \mathrm{H}_{88} \mathrm{~N}_{8} \mathrm{O}_{10} 1032.66$, found $1033.58[\mathrm{M}+\mathrm{H}]^{+}$.

\section{$\left[{ }^{3} \mathrm{H}\right]$ cholesterol anchor 8}

The maleimide derivative 5 ( 1 mg, $1 \mu \mathrm{mol})$ was dissolved in DMF (300 $\mu \mathrm{L}$ ) containing HOBt $(0.13 \mathrm{mg}, 1 \mu \mathrm{mol})$, DIC $(0.14 \mu \mathrm{L}, 1 \mu \mathrm{mol})$ and DIEA $(0.09 \mu \mathrm{L}, 0.5 \mu \mathrm{mol})$. Then, $\left[{ }^{3} \mathrm{H}\right] \mathrm{N}$-aminopiperidine $(100 \mathrm{MBq})$ dissolved in $24 \mu \mathrm{L}$ of DMF was added, and the solution was stirred for $16 \mathrm{~h}$ at room temperature. It was evaporated in vacuo; the crude product was dissolved in HFIP, and it was purified by HPLC on a Vydac 214TP5410 column to give $17.4 \mathrm{MBq}$ of pure 8. $k^{\prime}=4.31 \quad\left(t_{\mathrm{R}}=6.9 \mathrm{~min}\right.$; Vydac 214TP5410 C4 column $(100 \times 4.6 \mathrm{~mm}, 5 \mu \mathrm{m})$, gradient elution with $1.5 \% / \mathrm{min}$ ACN $\left(0.08 \%(\mathrm{v} / \mathrm{v})\right.$ TFA) in $\mathrm{H}_{2} \mathrm{O}(0.1 \%(\mathrm{v} / \mathrm{v})$ TFA) starting from $60 \%$ ACN, flow rate: $1 \mathrm{~mL} / \mathrm{min}, \lambda=216 \mathrm{~nm}$ ), s.a. $1.37 \mathrm{TBq} / \mathrm{mmol}$.

\section{Cell culture}

SH-SY5Y (ATCC: CRL-2266) human neuroblastoma cells were used to test the membrane association potency of $\mathbf{6}$ and $\mathbf{8}$. Cells were cultured in DMEM (Sigma Ltd., St. Louis, MO, USA) medium containing 10\% FCS, L-glutamine $(2 \mathrm{mM})$, gentamycin $(160 \mu \mathrm{g} / \mathrm{mL}), 1 \mathrm{mM}$ pyruvate and nonessential amino acids (Sigma Ltd., St. Louis, MO, USA). The cell culture was maintained at $37^{\circ} \mathrm{C}$ in a humidified atmosphere with $5 \% \mathrm{CO}_{2}$.

\section{Live cell imaging with confocal laser scanning microscopy}

Twenty thousand cells per well were plated on an 8-well Lab-Tek II Chambered cover glass. After $48 \mathrm{~h}$ incubation at $37^{\circ} \mathrm{C}$, cells were treated with $1 \mu \mathrm{M}$ of 6 dissolved in serum-free medium containing $10 \mu \mathrm{M} \beta$ cyclodextrin for $30 \mathrm{~min}$. Cells treated with serum-free medium for $30 \mathrm{~min}$ were used as a negative control. After treatment and incubation, cells were washed with serum-free medium, and the nuclei of the cells were stained for $5 \mathrm{~min}$ with DRAQ5. Sequential excitation was applied for fluorescein and DRAQ5. Fluorescein was excited with an Ar ion laser $(488 \mathrm{~nm})$, and emitted photons were collected through a BA 505-525 nm filter; DRAQ5 was excited with a He-Ne laser at $633 \mathrm{~nm}$, and emitted photons were collected through a BA $660 \mathrm{~nm}$ filter.

\section{Membrane incorporation of $\left[{ }^{3} \mathrm{H}\right]$ cholesterol anchor 8}

$10^{6}$ cells per well were plated on a 24-well plate, and after $12 \mathrm{~h}$ incubation at $37^{\circ} \mathrm{C}$, cells were treated with $1-100 \mathrm{nM}$ of $\mathbf{2}$ or $\mathbf{8}$ dissolved in serum-free medium containing $10 \mu \mathrm{M} \beta$-cyclodextrin for 10 and $30 \mathrm{~min}$. Then, cells were washed with serum-free medium and trypsinized. The resulting cell suspensions were filtered on a GF/B filter (Whatman) using a 24-well cell harvester (Brandel) and washed with phosphate-buffered saline (PBS) pH7.4. Filter discs containing the cells were immersed into Ultima Gold XR scintillation cocktail, and they were counted in glass vials with a 
Packard Tri-Carb 2100 TR LSA. Cells treated with serum-free medium for 30 min were used for background counting.

\section{Results and discussion}

Our earlier studies revealed that a maleimide functionalized fluorescent cholesterol derivative is capable of anchoring proteins to the plasma membrane of live cells. ${ }^{18}$ The headgroup of the anchor molecule contains a diethylene glycol residue, which increases the polarity of the molecule and exposes the attached protein towards the extracellular space. When applied in a form of $\beta$-cyclodextrin inclusion complex, the headgroup fluorescence of the cholesterol anchor can be used for the unambiguous visualization of the attached protein after cell membrane delivery. In order to determine the membrane concentration of the cholesterol anchor, a tritium labelled analogue (8) was designed. By using this compound, the quantitation of the membrane incorporated protein anchor can be achieved by measuring the radioactivity of cell membrane preparations or intact cells. For this purpose, a defined position of the radioactive label is crucial. Although $\left[1,2-{ }^{3} \mathrm{H}\right]$ cholesterol complexed with $\beta$-cyclodextrin was reported to use for the fast enrichment of cell membranes with labelled cholesterol, ${ }^{21}$ and it was also used in studying the cyclodextrin-mediated cholesterol transfer between different lipid layers ${ }^{22}$; cholesterol labelling is not appropriate for our purposes. The headgroup of the cholesterol anchor can be enzymatically removed via the hydrolysis of the cholesteryl ester, and as a result the labelled cholesterol, moiety remains in the cell membrane and the unlabelled headgroup is released to the cell culture medium. In this case, the membrane radioactivity is not affected by the presence or lack of the headgroup, and the process cannot be detected, resulting in overestimation of the amount of the membrane-associated cholesterol anchor. In contrast, if the tritium label is incorporated into the headgroup of the anchor molecule, enzymatic removal of the headgroup will result in decreasing radioactivity of the cell membrane preparation and also emerging the labelled headgroup in the cell culture medium.

In order to introduce the radioactive label into the cholesterol anchor headgroup, a convergent synthetic strategy was applied. The tritium label was incorporated into a small molecule that was coupled to an anchor fragment bearing both the cholesterol residue and the bulk of the headgroup. The advantage of this approach is that tritium incorporation either into the cholesterol moiety or into other parts of the headgroup is excluded. The cholesterol amphiphile $\mathbf{4}$ is an appropriate intermediate, because primary amine and carboxylic acid functions in the headgroup are available for the introduction of a radiolabelled or a fluorescent tag, and a protein conjugation function as well. It was prepared from $N^{\alpha}$-tBoc-protected propargylglycine and cholesteryl 1-azido-13-oxo-3,6,9-trioxa-12-azahexadecan-16-oate via a dipolar cycloaddition in the presence of $\mathrm{CuSO}_{4}$ and sodium ascorbate (Scheme 1). The $N^{\alpha}$-tBoc-protecting group was removed by TFA in DCM, and the amine $\mathbf{4}$ was liberated in situ with DIEA during the next step. Then, $\mathbf{4}$ was used for the preparation of two constitutionally related tritium or fluorescein labelled anchors. First, the thiol reactive maleimide group was coupled to the amine $\mathbf{4}$, because this way, the co-existence of a Michael acceptor and a primary amine in an intermediate compound is excluded that otherwise could lead to self-addition under the basic conditions of the introduction of the labelling tag. It was found that the amino function of $\mathbf{4}$ reacts faster with an $\mathrm{N}$-hydroxysuccinimide ester than with a maleimide, and accordingly, the $\mathrm{N}$-acylation of $\mathbf{4}$ with 3-maleimidopropionic acid<smiles>CC(C)CCCC1CCC2C3CC=C4CC(OC(=O)CCC(=O)NC(C)(C)CCC(C)C)CCC4(C)C3CCC12C</smiles>
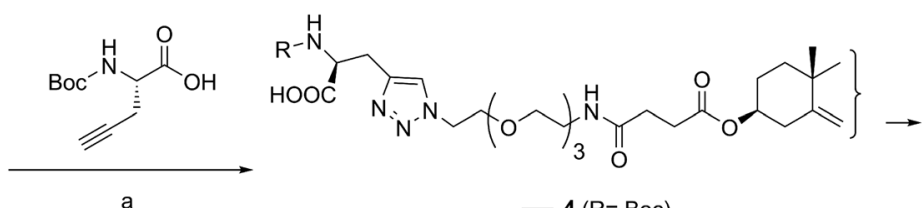<smiles>CCCCC(=O)OCCN1C(=O)C=CC1=O</smiles><smiles>CC(C)CCN1C(=O)C=CC1=O</smiles>

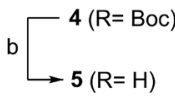

c<smiles>CN=CCC(N)O</smiles><smiles>CCCCCC(C)Cn1cc(C)nn1</smiles><smiles>CC(C)(C)NC(=O)CCC(=O)OC1CCC2(C)CC=C(C1)C2(C)C</smiles><smiles>Cc1cc(NC(=O)[C@H](Cc2cn(CC(C)(C)OCC(C)(C)NC(=O)CCC(=O)O[C@H]3CC[C@@H](C)[C@@]4(C)CCC[C@H]3C4)nn2)NC(=O)CCN2C(=O)C=CC2=O)ccc1-c1c2ccc(=O)cc-2oc2cc(O)ccc12</smiles>

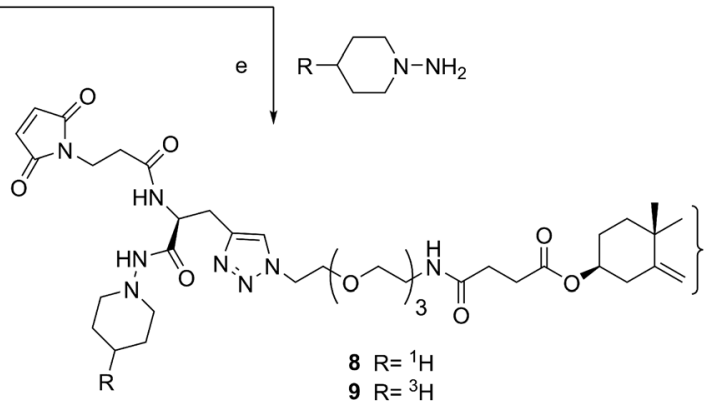

Scheme 1. Preparation of the fluorescein and tritium labelled cholesterol anchors: (a) $\mathrm{NaAsc}, \mathrm{CuSO}_{4} \cdot 5 \mathrm{H}_{2} \mathrm{O}, \mathrm{DMF}-\mathrm{CH}_{2} \mathrm{Cl}_{2}-\mathrm{H}_{2} \mathrm{O}(1: 4: 4), \mathrm{RT}, 8 \mathrm{~h}$; (b) $\mathrm{TFA}-\mathrm{CH}_{2} \mathrm{Cl}_{2}(1: 1), \mathrm{RT}$, 30 min; (c) 2 eq DIEA, MeOH, RT, 3 h; (d) HATU, DIEA, THF, RT, 16 h; (e) HOBt, DIC, DMF, RT, 16 h. 
$\mathrm{N}$-hydroxysuccinimide ester in DMF resulted in $\mathbf{5}$. This maleimide serves as a possible protein conjugation function in biological applications. In order to avoid the addition of nucleophiles to the maleimide of $\mathbf{5}$, an aniline and an alkyl-hydrazine-both are less basic than primary amines-were used to introduce the fluorescein and the tritium label, respectively. In a preliminary study, it turned out that the aniline moiety of 5-aminofluorescein did not react with the Michael acceptor of $\mathrm{N}$-(2-maleimidoethyl)2-aminopent-4-ynamide under the coupling condition applied for the preparation of $\mathbf{6}$. Then, the fluorescent anchor $\mathbf{6}$ was obtained by coupling of the carboxyl group of 5 with 5aminofluorescein in the presence of the coupling agent HATU. The NMR structure investigation revealed that 5aminofluorescein was conjugated to the carboxylic function of $\mathbf{5}$.

Based on earlier observations on isotopomer radioligands, ${ }^{21-23}$ the tritium label was introduced via an aliphatic compound instead of aniline to increase the radiolytic stability of the labelled anchor molecule. $\mathrm{N}$-Aminopiperidine was chosen for that purpose, because it is less basic than cyclohexylamine, ${ }^{24,25}$ and after $\mathrm{N}$-acylation, it results in stable hydrazides. Coupling of tritium labelled $\mathrm{N}$-aminopiperidine to the carboxylic acid function of $\mathbf{5}$ results in an anchor molecule possessing a headgroup homologous to that of $\mathbf{6}$, and this way, the

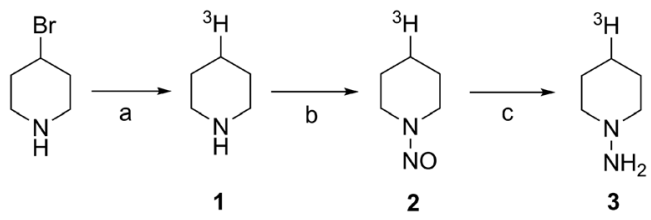

Scheme 2. Preparation of $\left[{ }^{3} \mathrm{H}\right] \mathrm{N}$-aminopiperidine: (a) $\mathrm{Pd} / \mathrm{C}(10 \% \mathrm{Pd}),{ }^{2} \mathrm{H}_{2}$ (1) or ${ }^{3} \mathrm{H}_{2}$ (2), EtOAc, RT, $3 \mathrm{~h}$; (b) $\mathrm{KNO}_{2}, 1 \mathrm{M} \mathrm{HCl}, 0{ }^{\circ} \mathrm{C}, 2 \mathrm{~h}$; (c) $\mathrm{LiAlH}_{4}, \mathrm{THF}, \mathrm{Ar}$ atm, $60{ }^{\circ} \mathrm{C}, 3.5 \mathrm{~h}$.

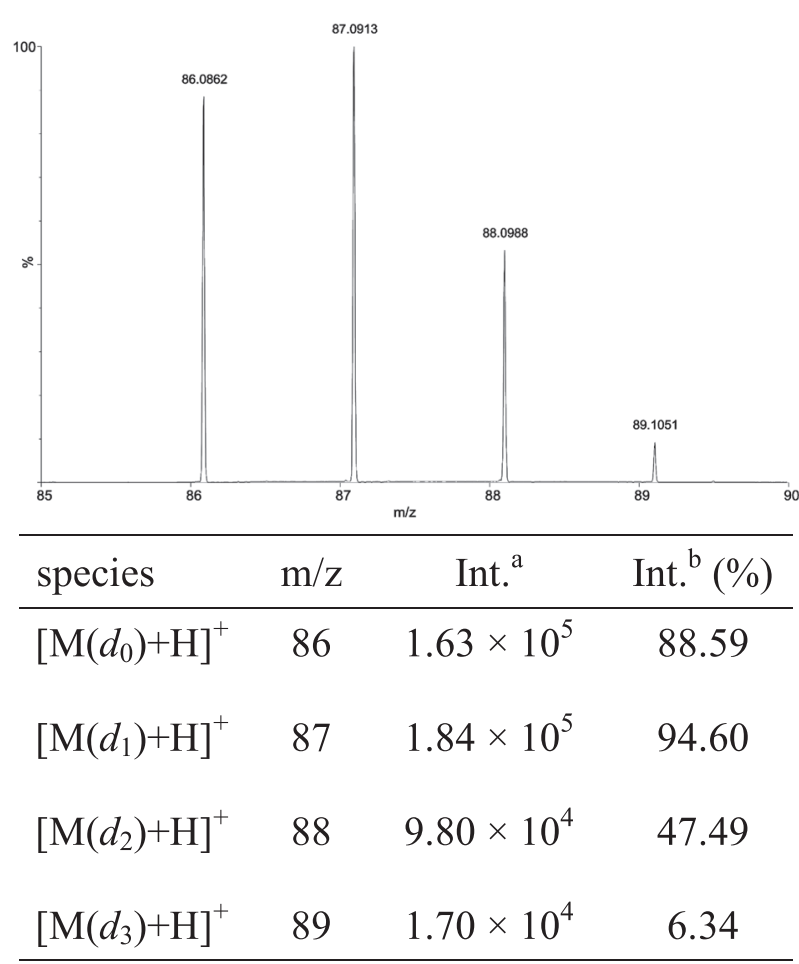

Figure 1. ESI mass spectrum of $\left[{ }^{2} \mathrm{H}\right]$ piperidine and the abundance of the isotopologues; ${ }^{a}$ measured intensity, ${ }^{b}$ relative intensity corrected with the natural abundance of ${ }^{2} \mathrm{H},{ }^{13} \mathrm{C}$. nonspecific tritium incorporation into the cholesterol moiety or into the headgroup is not feasible. Before preparing the tritium labelled anchor by $\mathrm{N}$-acylation of $\left[{ }^{3} \mathrm{H}\right] \mathrm{N}$-aminopiperidine with $\mathbf{5}$, the unlabelled isotopologue $\mathbf{7}$ was prepared in order to optimize the reaction conditions and carry out NMR measurements. For the preparation of the tritium labelled $\mathrm{N}$-aminopiperidine, 4-bromopiperidine was considered as a precursor in a deuterium labelling experiment (Scheme 2). The 4-bromopiperidine base was liberated from the hydrobromide salt, and it was reduced with deuterium gas in the presence of $\mathrm{Pd} / \mathrm{C}(10 \% \mathrm{Pd})$ catalyst. The resulting $\left[{ }^{2} \mathrm{H}\right]$ piperidine hydrochloride was analysed by TLC and ESI-MS. The separation of 4-bromopiperidine and piperidine was achieved on silica gel $60 \mathrm{~F}_{254}$ glass plates in $n-\mathrm{BuOH}-\mathrm{AcOH}-\mathrm{H}_{2} \mathrm{O}$ 2:1:1, as their $R_{\mathrm{f}}$ values were found to be 0.48 and 0.38 , respectively. The TLC analysis of the crude $\left[{ }^{2} \mathrm{H}\right]$ piperidine hydrochloride revealed that the conversion of 4-bromopiperidine was complete. Furthermore, the deuterium incorporation level was estimated by an ESI-MS analysis. It was found that 0.9 deuterium atoms/piperidine molecules were incorporated on average, but isotopologous species containing two or three deuterium atoms were also identified (Figure 1). These results suggested that this precursor is satisfactory for achieving an approximate molar activity of $1 \mathrm{TBq} / \mathrm{mmol}$. In the next step, $\left[{ }^{3} \mathrm{H}\right] \mathrm{N}$-amino-piperidine was prepared from 4-bromopiperidine (Scheme 2). Reduction of the brominated piperidine with tritium gas in the presence of $\mathrm{Pd} / \mathrm{C}(10 \% \mathrm{Pd})$ catalyst resulted in tritium labelled piperidine that was nitrosated. The resulting $\left[{ }^{3} \mathrm{H}\right] \mathrm{N}$-nitrosopiperidine was then reduced with $\mathrm{LiAlH}_{4}$, and $\left[{ }^{3} \mathrm{H}\right] \mathrm{N}$-aminopiperidine was isolated as a hydrochloride salt. The carboxylic acid $\mathbf{5}$ was activated with $\mathrm{HOBt}$ in the presence of $\mathrm{DIC}$, and the resulting active ester was used in situ for the $\mathrm{N}$-acylation of $\left.{ }^{3} \mathrm{H}\right] \mathrm{N}$-aminopiperidine to give the tritium labelled anchor 8 . HPLC analysis revealed that a significant amount of tritium labelled $\mathrm{N}$-aminopiperidine was coupled to $\mathbf{5}$ (Figure 2). The purification of the crude cholesterol derivative was achieved by RP-HPLC, resulting in $17.4 \mathrm{MBq}$ of pure $\mathbf{8}$ with an isolated radiochemical yield of $17 \%$. The sterical hindrance of the carboxylic acid function of $\mathbf{5}$ and the more diluted reaction mixture as compared with that of $\mathbf{6}$ and $\mathbf{7}$ resulted in the low yield of $\mathbf{8}$. Quantitative analysis of the concentration and radioactivity of the labelled anchor $\mathbf{8}$ was performed by RP-HPLC via UV and radioactivity detection using a calibration curve made by 7 . The specific activity of the tritiated cholesterol anchor 8 was found to be $1.37 \mathrm{TBq} / \mathrm{mmol}$ that is higher than the theoretical value. Beyond tritium substitution of $\mathrm{Br}$ in 4-bromopiperidine, catalytic ${ }^{1} \mathrm{H} /{ }^{3} \mathrm{H}$ exchange reactions also took place presumably at positions 2 and 6 of the piperidine ring. When $2-3 \mathrm{~h}$ of reaction time is applied for catalytic dehalotritiation, the catalytic exchange becomes significant and increases the specific activity. ${ }^{23}$ The ESI-MS analysis of the deuterium labelled piperidine also indicated catalytic exchange reactions. It is important to note that the convergent synthetic strategy ensures that all the tritium atoms are localized in the piperidine ring of the headgroup, because after the tritium gas reduction of 4-bromopiperidine, further transformations do not affect the tritium distribution.

The control compound 6, a fluorescent GPI anchor mimetic, was used to assess the membrane association property of the designed $\left[{ }^{3} \mathrm{H}\right]$ anchor. The solubility of $\mathbf{6}$ was investigated in an aqueous medium before the imaging application. It was found that the amphiphile 6 partially dissolved in a serum-free medium as micellar associates and the remaining portion formed 

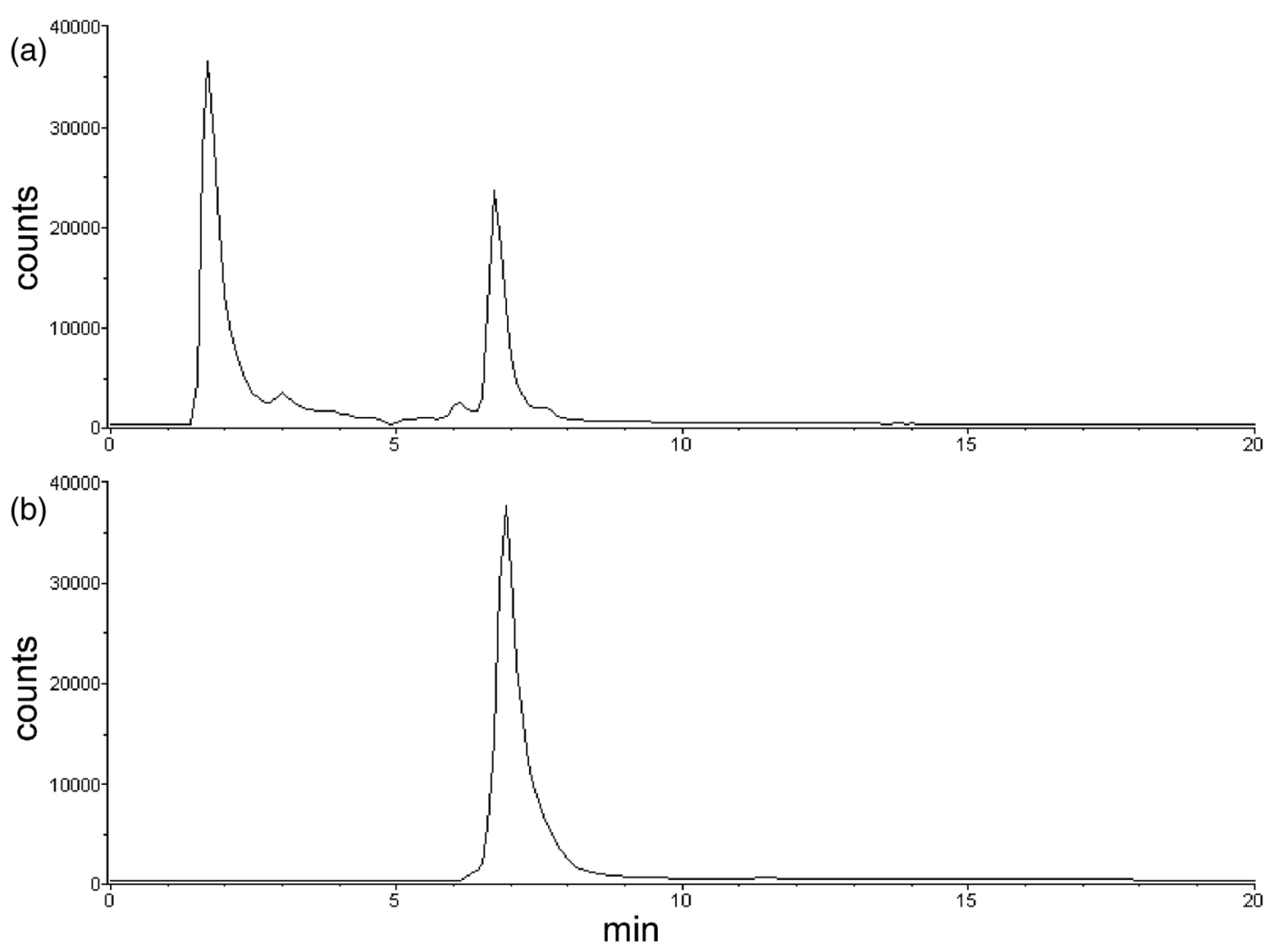

Figure 2. Radio-HPLC chromatogram of (a) the crude and (b) the purified tritium labelled cholesterol anchor $\left.8 .{ }^{3} \mathrm{H}\right] \mathrm{N}$-aminopiperidine was eluted without retention, and 8 was eluted at $t_{\mathrm{R}}=6.90 \mathrm{~min}$.

precipitates. The resulting heterogeneous mixture was incubated with $10 \mathrm{eq} \beta$-cyclodextrin that forms water-soluble inclusion complexes with cholesterol and $3 \beta$-hydroxyl-modified cholesterol derivatives. ${ }^{26}$ This way, $0.5 \mathrm{mM}$ aqueous solution of the cholesterol amphiphile was prepared. Then, SH-SY5Y cells were treated with $1 \mu \mathrm{M}$ of the inclusion complex of $\mathbf{6}$ for $30 \mathrm{~min}$. After delivering to live SH-SY5Y cells, an intensive membrane staining was observed, that is, $\mathbf{6}$ incorporated into the cell membrane similarly to our original anchor ${ }^{18}$ (Figure 3 ). It indicates that a slight modification in the $\alpha$-amino acid function of the headgroup is tolerated with the retention of the membrane association properties. The tritium labelled anchor $\mathbf{8}$ could also be solubilized in cell culture medium with this method, and it was applied for studying the cell membrane incorporation of $\mathbf{8}$. SH-SY5Y cells were incubated with 1-100 nM of $\mathbf{8}$ or $\mathbf{2}$ at $37^{\circ} \mathrm{C}$ for 10 and $30 \mathrm{~min}$, and then cells were washed and trypsinized. The membrane incorporated radioactivity was determined by liquid scintillation counting of the filtered cells. It was found that $\mathbf{2}$ was not incorporated into the cell membranes, as the radioactivity of these cell population was slightly above the background (Figure 4). However, when cells were treated with $\mathbf{8}$, concentration- and time-dependent incorporation of the radioactive cholesterol anchor was observed. The radioactivity of the cell cultures was ca. $20 \%$ higher after $30 \mathrm{~min}$ incubation than after $10 \mathrm{~min}$ incubation, indicating fast plasma membrane incorporation of $\mathbf{8}$.

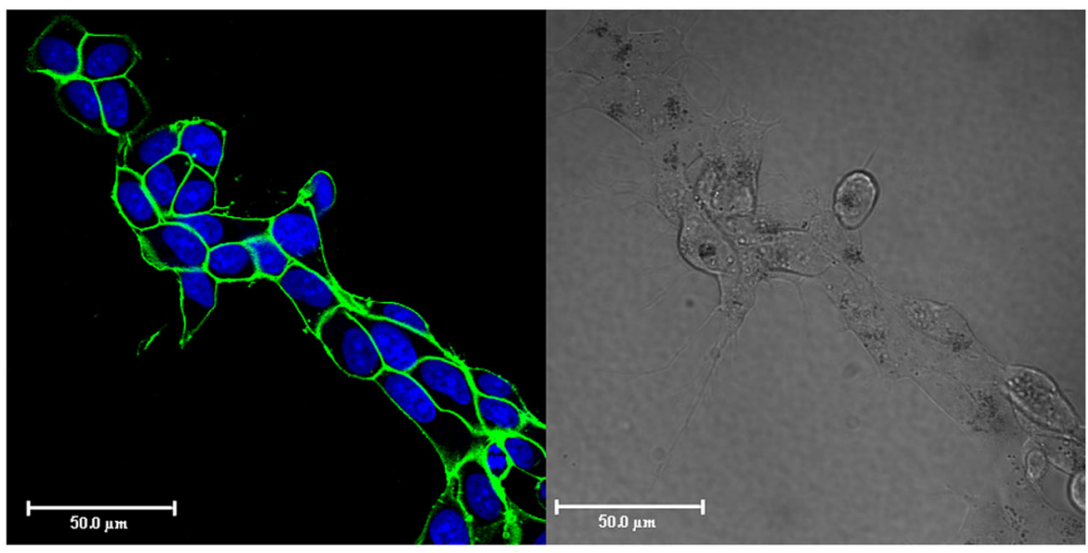

Figure 3. Confocal laser scanning (left) and differential interference contrast (right) microscopy of SH-SY5Y cells after 30 min incubation with $1 \mu \mathrm{M}$ cholesterol anchor 6 followed by a treatment with the nuclear dye DRAQ5 for $5 \mathrm{~min}$ at $37^{\circ} \mathrm{C}$. On the image, fluorescein is green and nuclei are blue. This figure is available in colour online at wileyonlinelibrary.com/journal/jlcr. 


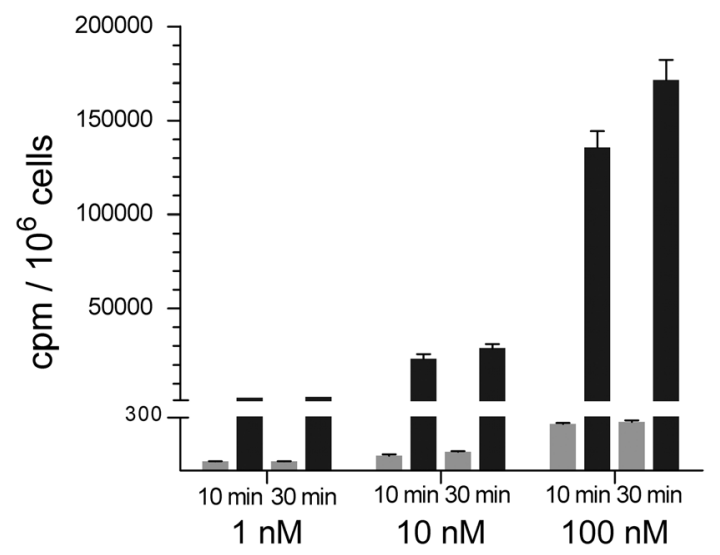

Figure 4. Incorporation of the $\left[{ }^{3} \mathrm{H}\right]$ cholesterol anchor 8 to the membrane of $\mathrm{SH}$ SY5Y cells. Cells were incubated with different concentrations of $\mathbf{2}$ (grey bars) or 8 (black bars) in the presence of $10 \mu \mathrm{M} \beta$-cyclodextrin followed by liquid scintillation counting of the washed and trypsinized cells. The error bars represent SEM values of three parallel measurements.

\section{Conclusions}

Semisynthetic lipoproteins prepared from recombinant proteins and designed lipid derivatives are valuable probes of the membrane-associated lipoproteins. In this article, we reported the synthesis of a novel tritium labelled cholesterol anchor that contains the radioactive label in the headgroup. It was achieved in a convergent synthetic approach by the acylation of $\left[{ }^{3} \mathrm{H}\right] \mathrm{N}$ aminopiperidine with the 1-hydroxybenzotriazole ester of the carboxylic acid derivative $\mathbf{5}$. This structure of the headgroup features the introduction of the tritium label into the same position where a fluorophore was introduced in $\mathbf{6}$. Thus, the fluorescein and tritium labelled anchors are constitutionally related, and the fluorescence microscopic images are relevant to the $\left[{ }^{3} \mathrm{H}\right]$ cholesterol incorporation data. Each synthetic step was optimized by using unlabelled standard compounds and by tracer experiments, and finally, the target cholesterol amphiphile $\mathbf{8}$ was obtained with a radiochemical purity of $98 \%$ and with a chemical purity of $99 \%$. It was demonstrated that the membrane incorporation of the resulting headgroup labelled $\left[{ }^{3} \mathrm{H}\right]$ cholesterol anchor is concentration and time dependent, and that it can be investigated at low concentrations, below the working concentration of fluorescent analogues. It is advantageous because under these conditions, the exogenous introduction of cholesterol derivative $\mathbf{8}$ results in low membrane concentration and thus low level of membrane perturbation, cellular stress.

\section{Acknowledgements}

Financial support from the Hungarian Scientific Research Fund (K77783), the Hungarian National Development Agency (TÁMOP
4.2.2.A-11/1/KONV-2012-0052) and the János Bolyai Research Scholarship of the Hungarian Academy of Sciences (Cs.T.), and technical help of Balázs Csibrány in cell culturing are acknowledged.

\section{Conflict of Interest}

The authors did not report any conflict of interest.

\section{References}

[1] T. Kinoshita, M. Fujita, chapter title: Overview of GPI biosynthesis. In The Enzymes. Volume 26: Glycosylphosphatidylinositol (GPI) Anchoring of Proteins (Eds.: A. K. Menon, T. Kinoshita, P. Orlean, F. Tamanoi), Academic Press: New York, 2009, pp. 1-30.

[2] M. E. Medof, T. Kinoshita, V. Nussenzweig, J. Exp. Med. 1984, 160, 1558.

[3] C. W. van den Berg, T. Cinek, M. B. Hallett, V. Horejsi, B. P. Morgan, J. Cell Biol. 1995, 131, 669.

[4] P. E. Milhiet, M. C. Giocondi, O. Baghdadi, F. Ronzon, B. Roux, C. Le Grimellec, EMBO Rep. 2002, 3, 485.

[5] C. Metzner, M. M. Mostegl, W. H. Gunzburg, B. Salmons, J. A. Dangerfield, FASEB J. 2008, 22, 2734.

[6] M. E. Medof, S. Nagarajan, M. L. Tykocinski, FASEB J. 1996, 10, 574.

[7] B. Bader, K. Kuhn, D. J. Owen, H. Waldmann, A. Wittinghofer, J. Kuhlmann, Nature 2000, 403, 223.

[8] D. R. Premkumar, Y. Fukuoka, D. Sevlever, E. Brunschwig, T. L. Rosenberry, M. L. Tykocinski, M. E. Medof, J. Cell. Biochem. 2001, 82, 234.

[9] F. R. Taylor, D. Wen, E. A. Garber, A. N. Carmillo, D. P. Baker, R. M. Arduini, K. P. Williams, P. H. Weinreb, P. Rayhorn, X. Hronowski, A. Whitty, E. S. Day, A. Boriack-Sjodin, R. I. Shapiro, A. Galdes, R. B. Pepinsky, Biochemistry 2001, 40, 4359.

[10] C. Peters, A. Wolf, M. Wagner, J. Kuhlmann, H. Waldmann, Proc. Natl. Acad. Sci. U. S. A. 2004, 101, 8531.

[11] M. J. Grogan, Y. Kaizuka, R. M. Conrad, J. T. Groves, C. R. Bertozzi, J. Am. Chem. Soc. 2005, 127, 14383.

[12] M. G. Paulick, M. B. Forstner, J. T. Groves, C. R. Bertozzi, Proc. Natl. Acad. Sci. U. S. A. 2007, 104, 20332.

[13] K. Teruya, K. Nishizawa, K. Doh-ura, Protein J. 2010, 29, 493.

[14] K. Simons, M. J. Gerl, Nat. Rev. Mol. Cell Biol. 2010, 11, 688.

[15] D. Lingwood, K. Simons, Science 2010, 327, 46.

[16] S. Agarwal, C. Schroeder, G. Schlechtingen, T. Braxmeier, G. Jennings, H. J. Knolker, Bioorg. Med. Chem. Lett. 2013, 23, 5165.

[17] S. B. Sato, K. Ishii, A. Makino, K. Iwabuchi, A. Yamaji-Hasegawa, Y. Senoh, I. Nagaoka, H. Sakuraba, T. Kobayashi, J. Biol. Chem. 2004, 279, 23790.

[18] B. Schäfer, E. Orbán, A. Borics, K. Huszár, A. Nyeste, E. Welker, Cs. Tömböly, Bioconj. Chem. 2013, 24, 1684.

[19] G. Tóth, S. Lovas, F. Ötvös, In Methods in Molecular Biology: Neuropeptide Protocols (Eds.: G. B. Irvine, C. H. Williams), Humana Press: Totowa, NJ, 1997, pp. 219-230.

[20] Cs. Tömböly, A. Péter, G. Tóth, Peptides 2002, 23, 1573.

[21] A. E. Christian, M. P. Haynes, M. C. Phillips, G. H. Rothblat, J. Lipid Res. 1997, 38, 2264.

[22] R. Leventis, J. R. Silvius, Biophys. J. 2001, 81, 2257.

[23] Cs. Tömböly, R. Dixit, I. Lengyel, A. Borsodi, G. Tóth, J. Label. Compd. Radiopharm. 2001, 44, 355.

[24] R. Hinman, J. Org. Chem. 1958, 23, 1587-1588.

[25] H. K. Hall Jr., J. Am. Chem. Soc. 1957, 79, 5441.

[26] R. Ravichandran, S. Divakar, J. Incl. Phenom. Mol. Recognit. Chem. 1998, 30, 253 